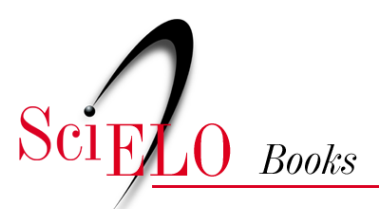

\title{
As causas sociais das iniqüidades em saúde no Brasil
}

\author{
Comissão Nacional sobre Determinantes Sociais da Saúde
}

\section{SciELO Books / SciELO Livros / SciELO Libros}

COMISSÃO NACIONAL SOBRE DETERMINANTES SOCIAIS DA SAÚDE. As causas sociais das iniqüidades em saúde no Brasil [online]. Rio de Janeiro: Editora FIOCRUZ, 2008, 215 p. ISBN: 978-85-7541-591-7. Available from: doi: 10.7476/9788575415917. Also available in ePUB from: http://books.scielo.org/id/bwb4z/epub/comissao-9788575415917.epub.

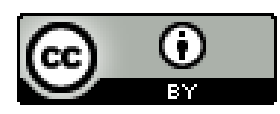

All the contents of this work, except where otherwise noted, is licensed under a Creative Commons Attribution $\underline{4.0 \text { International license. }}$

Todo o conteúdo deste trabalho, exceto quando houver ressalva, é publicado sob a licença Creative Commons Atribição 4.0. 


\section{As Causas Sociais das Iniqüidades em Saúde no Brasil}


Fundação Oswaldo Cruz

Presidente

Paulo Marchiori Buss

Vice-Presidente de Ensino, Informação e Comunicação

Maria do Carmo Leal

\author{
Editora Fiocruz \\ Diretora \\ Maria do Carmo Leal \\ Editor Executivo \\ João Carlos Canossa P. Mendes \\ Editores Científicos \\ Nísia Trindade Lima e Ricardo Ventura Santos \\ Conselho Editorial \\ Carlos E. A. Coimbra Jr. \\ Gerson Oliveira Penna \\ Gilberto Hochman \\ Lígia Vieira da Silva \\ Maria Cecília de Souza Minayo \\ Maria Elizabeth Lopes Moreira \\ Pedro Lagerblad de Oliveira \\ Ricardo Lourenço de Oliveira
}


As Causas Sociais

das Iniqüidades em Saúde no Brasil

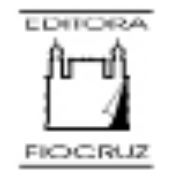


Copyright (c) 2008 dos autores

Todos os direitos desta edição reservados a

FUNDAÇÃO OSWALDO CRUZ / EDITORA

ISBN: 978-85-7541-160-5

Capa, Projeto Gráfico e Editoração Eletrônica

Mara Lemos (Prog.Visual/Icict)

Editoração Eletrônica de Gráficos

Marcello Pelliccione e Ruben Fernandes (Prog.Visual/Icict)

Fotos Capa

Raul Santana, Vinicius Marinho e Peter Ilicciev (Fiocruz Multimagens/Banco de Imagens Digitais)

Montagem fotos (capa)

Raul Santana

Foto Moacyr Scliar

Claudia R. Lopes

Revisão

Fernanda Veneu

Normalização bibliográfica

Clarissa Bravo

Supervisão

Janaina S. Silva

Catalogação na fonte

Centro de Informação Científica e Tecnológica

Biblioteca da Escola Nacional de Saúde Pública Sergio Arouca

C733c Comissão Nacional sobre Determinantes Sociais da Saúde

As Causas Sociais das Iniqüidades em Saúde no Brasil. / Comissão Nacional sobre Determinantes Sociais da Saúde.

- Rio de Janeiro: Editora Fiocruz, 2008.

220 p. il., tab., graf.

1.Desigualdades em Saúde-Brasil. 2.Diagnóstico da Situação em Saúde. 3.Desenvolvimento Econômico. 4.Condições Sociais. 5.Fatores Socioeconômicos. 6.Redes Comunitárias. 7.Estilo de Vida. 8.Saúde Materno-Infantil. 9. Saúde Indígena. I.Título.

CDD - 22.ed. - 362.10981

2008

EDITORA FIOCRUZ

Av. Brasil, $4036-1^{\circ}$ andar - sala 112 - Manguinhos

21040-361 - Rio de Janeiro - RJ

Tels: (21) 3882-9039 e 3882-9041

Fax: (21) 3882-9007

e-mail: editora@fiocruz.br

http://www.fiocruz.br 


\section{INTEGRANTES DA COMISSÃO NACIONAL SOBRE DETERMINANTES SOCIAIS DA SAÚDE}

\section{Adib Jatene}

Médico, professor e pesquisador, ex-diretor do Instituto do Coração da Universidade de São Paulo e do Instituto Dante Pazzanese de Cardiologia, ex-secretário estadual de Saúde de São Paulo, duas vezes ministro da Saúde. Integra a Academia Nacional de Medicina.

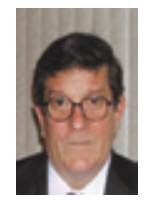

\section{Aloísio Teixeira}

Economista, reitor da Universidade Federal do Rio de Janeiro, doutor em Economia pela Universidade Estadual de Campinas. Desenvolve pesquisa em políticas públicas e sistemas de proteção social.

\section{Cesar Victora}

Professor de Epidemiologia da Universidade Federal de Pelotas, doutor em Saúde Pública pela Escola de Higiene e Medicina Tropical de Londres, consultor da Organização Mundial da Saúde e titular da Academia Brasileira de Ciências.

\section{Dalmo Dallari}

Advogado, professor da Universidade de São Paulo, ex-secretário de Negócios Jurídicos da Prefeitura de São Paulo. Tem diversos artigos e livros publicados nas mais diversas áreas do direito, da ética e da participação popular.

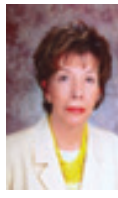

\section{Elza Berquó}

Demógrafa, professora titular aposentada da Universidade de São Paulo, membro titular da Academia Brasileira de Ciências, membro do Conselho Superior do Núcleo de Estudos de População da Universidade de Campinas e coordenadora da Área de População e Sociedade do Centro Brasileiro de Análise e Planejamento.

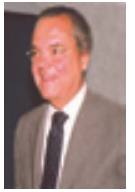

\section{Eduardo Eugênio Gouvêa Vieira}

Engenheiro, presidente do Sistema da Federação das Indústrias do Estado do Rio de Janeiro e do Centro Industrial do Rio de Janeiro. Integra o Conselho de Administração do Banco Nacional de Desenvolvimento Econômico e Social.

\section{Jaguar}

Considerado um dos maiores cartunistas brasileiros, iniciou a carreira na página de humor da revista Manchete. Co-fundador do Pasquim, em 1969, atuou em diversos jornais e revistas brasileiras e atualmente é colunista do jornal carioca O Dia.

\section{Jairnilson Paim}

Médico, professor da Universidade Federal da Bahia, doutor honoris causa, é co-fundador do Centro Brasileiro de Estudos de Saúde e da Associação Brasileira de Pós-Graduação em Saúde Coletiva, da qual foi vice-presidente. 
Lucélia Santos

Atriz de televisão, teatro e cinema, alcançou grande sucesso nacional e internacional ao interpretar a protagonista da novela da Rede Globo, Escrava Isaura, em 1976. Conjugando atividades artísticas e políticas, dirigiu documentário sobre o Timor Leste.

\section{Moacyr Scliar}

Escritor, médico e doutor em Ciências pela Escola Nacional de Saúde Pública Sergio Arouca da Fundação Oswaldo Cruz, trabalhou como sanitarista e leciona saúde pública em Porto Alegre. Tem 67 livros publicados e foi eleito, em 2003, para a Academia Brasileira de Letras.

\section{Paulo Buss}

Médico pediatra, sanitarista, é presidente da Fundação Oswaldo Cruz, pesquisador da Escola Nacional de Saúde Pública Sergio Arouca, integra a Academia Nacional de Medicina e representa o Brasil no Comitê Executivo da Organização Mundial da Saúde. É o presidente da Comissão Nacional sobre Determinantes Sociais da Saúde.

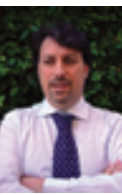

\section{Roberto Smeraldi}

Jornalista e especialista em desenvolvimento sustentável, é diretor da Organização da Sociedade Civil de Interesse Público Amigos da Terra-Amazônia Brasileira. Possui longa experiência na Região Amazônica, presidiu o Comitê Internacional das ONGs para a Eco 92 e faz parte do Conselho da Mesa Redonda Global sobre Biocombustíveis.

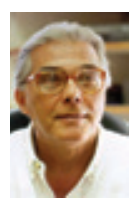

\section{Rubem César Fernandes}

Historiador, fundador e secretário-executivo da organização não-governamental Viva-Rio, é mestre em filosofia pela Universidade de Varsóvia, na Polônia, e doutor pela Universidade de Colúmbia, nos Estados Unidos.

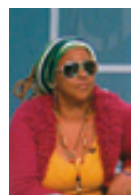

\section{Sandra de Sá}

Cantora e compositora, iniciou sua trajetória de sucesso na música popular brasileira ao participar do Festival MPB-80, aos 25 anos, quando lançou seu primeiro disco. É engajada em projetos sociais de ampliação da cidadania.

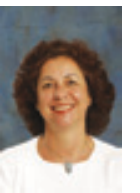

\section{Sônia Fleury}

Psicóloga, pesquisadora da Fundação Getulio Vargas, doutora em Ciência Política pelo Instituto Universitário de Pesquisas do Rio de Janeiro, atua no Programa de Estudos e Pesquisa sobre a Democratização da Esfera Pública.

\section{Zilda Arns}

Médica pediatra, sanitarista, fundadora e coordenadora nacional da Pastoral da Criança, entidade que lida com apoio ao desenvolvimento integral da criança. Foi indicada por três anos seguidos, pelo governo brasileiro, ao Prêmio Nobel da Paz. 


\section{COLABORADORES}

ORGANIZAÇÃO E REDAÇÃO GERAL

Alberto Pellegrini Filho

Médico. Doutor em Ciências pela Universidade Estadual de Campinas (Unicamp). Pesquisador da Fundação Oswaldo Cruz (Fiocruz) e responsável pela Secretaria Técnica da Comissão Nacional sobre Determinantes Sociais da Saúde (CNDSS).

BUSCA E SELEÇÃO DE DADOS, INFORMAÇÕES E INDICADORES

Maria Alice Fernandes Branco

Psicóloga. Doutora em Saúde Coletiva pelo Instituto de Medicina Social da Universidade do Estado do Rio de Janeiro (IMS/Uerj). Pesquisadora da Fiocruz.

REVISÃo BIBLIOGRÁFICA

Ana Paula Esteves Pereira

Nutricionista. Mestre em Saúde Pública pela Ensp/Fiocruz. Colaboradora (bolsista) da Fiocruz.

Evandro da Silva Freire Coutinho

Médico. Doutor em Saúde Pública pela Universidade Federal da Bahia (Ufba). Pesquisador titular da Fiocruz e professor adjunto da Uerj.

\section{Mario Vianna Vettore}

Graduado em Odontologia. Doutor em Saúde Pública pela Ensp/Fiocruz. Pesquisador visitante do Departamento de Epidemiologia e Métodos Quantitativos em Saúde da Escola Nacional de Saúde Pública Sergio Arouca (DEMQS/Ensp/ Fiocruz) e editor adjunto dos Cadernos de Saúde Pública.

Mariza Miranda Theme Filha

Médica. Doutora em Saúde Pública pela Ensp/Fiocruz. Pesquisadora do DEMQS/Ensp/Fiocruz.

Rosa Maria Soares Madeira Domingues

Médica. Mestre em Saúde Pública pela Fiocruz. Pesquisadora do DEMQS/Ensp/Fiocruz.

Sandra Costa Fonseca

Médica. Doutora em Saúde Pública pela Fiocruz. Professora adjunta do Departamento de Epidemiologia e Bioestatística da Universidade Federal Fluminense (UFF).

\section{Seção CONDIÇÕES DE EMPREGO E TRABALHO}

\section{Carlos Minayo Gómez}

Graduado em Ciências. Doutor em Ciências pela Universidade de Salamanca, Espanha. Pesquisador titular do Centro de Estudos da Saúde do Trabalhador e Ecologia Humana (Cesteh/Ensp/Fiocruz).

\section{Elizabeth Costa Dias}

Médica. Doutora em Saúde Coletiva/Saúde Ocupacional pela Unicamp. Professora aposentada do Departamento de Medicina Preventiva e Social da Faculdade Medicina da Universidade Federal de Minas Gerais (DMPS/FM/ UFMG) e pesquisadora convidada do Cesteh/Ensp/Fiocruz.

\section{Jorge Mesquita Huet Machado}

Médico. Doutor em Saúde Pública pela Ensp/Fiocruz. Professor e pesquisador da Fiocruz.

\section{Marco António Gomes Pérez}

Médico. Mestre em Saúde Coletiva pela Unicamp. Coordenador da área técnica de Saúde do Trabalhador do Ministério da Saúde. 


\section{Maria da Graça Luderitz Hoefel}

Médica. Doutora em Sociologia pela Universidade Federal do Rio Grande do Sul (UFRGS). Médica do Hospital das Clínicas de Porto Alegre (HCPA) e assessora técnica do Departamento de Saúde Ambiental e Saúde do Trabalhador do Ministério da Saúde.

\section{Roberval Passos de Oliveira}

Psicólogo. Doutor em Saúde Pública pela Ufba. Professor do Centro de Ciências da Saúde da Universidade Federal do Recôncavo da Bahia (CCS/UFRB). Pesquisador do Instituto de Saúde Coletiva (ISC/Ufba).

\section{Vilma Sousa Santana (coordenadora)}

Médica. Pós-doutora em Epidemiologia Ocupacional pela University of North Carolina, EUA. Professora adjunta do ISC/Ufba.

\section{Seção ALGUNS DETERMINANTES DA MORTALIDADE NA INFÂNCIA NO BRASIL}

\section{Celso Cardoso da Silva Simões}

Bacharel em Estatística. Doutor em Demografia pelo Centro de Desenvolvimento e Planejamento Regional (Cedeplar/UFMG). Pesquisador do Instituto Brasileiro de Geografia e Estatística (IBGE).

\section{Seção REVISÃO DA LITERATURA SOBRE SAÚDE MATERNO-INFANTIL}

\section{Fernando C. Barros}

Médico. Doutor em Epidemiologia pela University of London. Professor da Universidade Católica de Pelotas (UCPel) e pesquisador do Centro de Pesquisas Epidemiológicas da Universidade Federal de Pelotas (UFPel).

\section{Seção SAÚDE INDÍGENA}

Carlos E. A. Coimbra Jr.

Bacharel em Ciências Biológicas. Pós-doutor pela University of Massachusetts EUA. Pesquisador titular da Ensp/ Fiocruz e editor-chefe dos Cadernos de Saúde Pública.

\section{Ricardo Ventura Santos}

Graduado em Ciências Biológicas. Pós-doutor pelo Massachusetts Institute of Technology (MIT) e pela University of Massachusetts, EUA. Professor adjunto do Departamento de Antropologia do Museu Nacional da Universidade Federal do Rio de Janeiro (UFRJ) e pesquisador titular da Ensp/Fiocruz.

\section{Seção AS POLÍTICAS E PROGRAMAS EM CURSO}

\section{Alex Molinaro}

Graduado em Administração de Empresas. Mestre em Saúde Pública pela Ensp/Fiocruz. Assistente técnico em Saúde Pública da Fiocruz.

\section{Eliane Hollanda de Carvalho}

Graduada em Ciências Sociais. Doutorado em Ciências pela Ensp/Fiocruz. Pesquisadora adjunta da Fiocruz.

\section{Gabriela Rieveres Borges de Andrade}

Psicóloga. Doutora em Saúde Pública pela Ensp/Fiocruz. Colaboradora (bolsista) da Fiocruz.

\section{Jeni Vaitsman (coordenadora)}

Socióloga. Doutora em Sociologia pelo Instituto Universitário de Pesquisas do Estado do Rio de Janeiro (Iuperj). Pesquisadora titular da Ensp/Fiocruz.

\section{Maria Elizabeth Salerno Pinho}

Arquiteta. Colaboradora (bolsista) da Fiocruz.

\section{Rômulo Paes de Sousa (coordenador)}

Médico. Doutor em Epidemiologia Ambiental pela London School of Hygiene and Tropical Medicine, University of London. Professor adjunto da Pontifícia Universidade Católica de Minas Gerais (PUC/MG).

\section{Sandra Aparecida Venâncio de Siqueira}

Graduada em Serviço Social. Doutora em Saúde Pública pela Fiocruz. Pesquisadora adjunta da Fiocruz. 


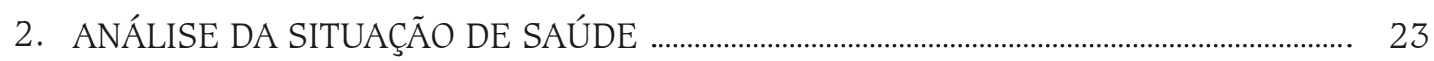

2.1. Situação e tendências da evolução demográfica, social e econômica................. 23

2.2. A estratificação socioeconômica e a saúde ................................................................ 52

2.3. Condições de vida, ambiente e trabalho ............................................................. 58

2.4. Redes sociais, comunitárias e saúde ............................................................................ 84

2.5. Comportamentos, estilos de vida e saúde .................................................................... 87

2.6. Saúde materno-infantil ....................................................................................... 98

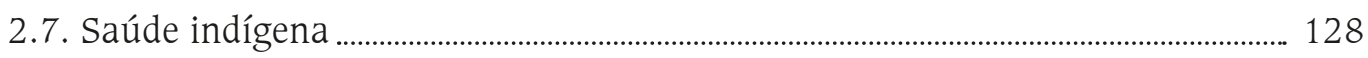

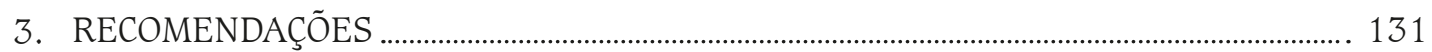

REFERÊNCIAS E BIBLIOGRAFIA COMPLEMENTAR ................................................ 149

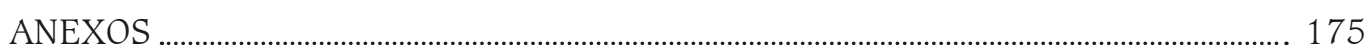

SUMÁRIO EXECUTIVO | EXECUTIVE SUMMARY ..................................................... 193|205 


\section{PREFÁCIO}

É com grande satisfação que vejo publicado este relatório final da Comissão Nacional sobre Determinantes Sociais da Saúde (CNDSS), intitulado As Causas Sociais das Iniqüidades em saúde no Brasil.

Ao longo de seus dois anos de existência desde março de 2006, a CNDSS - integrada por 16 personalidades da vida civil, científica, cultural e empresarial do país e apoiada por uma secretaria técnica instalada na Fiocruz - desenvolveu uma série de atividades que contribuíram para o debate nacional sobre a problemática dos determinantes sociais e das iniqüidades em saúde. Estas atividades estiveram voltadas para a produção de conhecimentos e informações sobre os determinantes sociais da saúde (DSS), para a revisão e análise de políticas e programas de intervenção sobre estes determinantes e para a comunicação aos diversos setores da sociedade sobre a importância dos DSS e as possibilidades de atuação sobre eles.

O presente relatório é produto desse trabalho. Com base em informações e conhecimentos existentes em diversos sistemas de informação ou registrados na literatura nacional e internacional, analisa o impacto dos DSS em seus diversos níveis sobre a situação de saúde, com especial ênfase nas iniqüidades em saúde. Compreende os determinantes vinculados aos comportamentos individuais e às condições de vida e trabalho, bem como os relacionados com a macroestrutura econômica, social e cultural. Suas recomendações, solidamente fundamentadas na análise da situação de saúde e das intervenções em curso, têm por objetivo permitir uma atuação mais sustentável, coordenada e eficiente sobre os determinantes sociais.

Estamos seguros de que o conjunto de dados e reflexões aqui reunidos vai se constituir em uma referência obrigatória para pesquisadores, profissionais da área social, gestores das diversas esferas da administração pública e para todos aqueles interessados em contribuir para a promoção da saúde e da eqüidade por meio da atuação sobre os determinantes sociais, que, como bem mostra este relatório, são produto da ação humana e, portanto, podem e devem ser transformados pela ação humana.

José Gomes Temporão

Ministro de Estado da Saúde 


\section{APRESENTAÇÃo}

O relatório da Comissão Nacional sobre Determinantes Sociais da Saúde (CNDSS) tem três objetivos:

- traçar um panorama geral da situação de saúde do país, com ênfase em dados, informações e conhecimentos sobre as iniqüidades em saúde geradas pelos determinantes sociais;

- propor políticas, programas e intervenções relacionadas aos determinantes sociais a partir da avaliação das políticas e intervenções atualmente em curso e das experiências registradas na literatura nacional e internacional;

- descrever as atividades desenvolvidas pela Comissão para cumprir com seus objetivos.

Os conteúdos estão dispostos nas seguintes seções: introdução, análise da situação de saúde, recomendações (de políticas e programas), referências e bibliografia complementar, anexos e sumário executivo.

A Introdução traz um breve histórico e antecedentes da criação da CNDSS, bem como seus objetivos. Inclui ainda os principais compromissos que orientaram o trabalho da CNDSS desde sua criação - compromissos com a eqüidade, com as evidências e com a ação. Finalmente, apresenta o modelo de Dahlgren e Whitehead (1991) que esquematiza os diversos níveis de determinantes sociais da saúde (DSS) e serviu de base para orientar as atividades da Comissão e a organização dos conteúdos deste relatório.

O corpo do relatório, intitulado Análise da situação de saúde, congrega dados, informações e conhecimentos disponíveis sobre as relações entre os DSS, bem como a situação de saúde dos diversos grupos populacionais, com destaque para as relações entre estes determinantes e as iniqüidades em saúde. Utilizaram-se, como fontes de informação, diversos sistemas de abrangência nacional e a literatura científica produzida por autores nacionais e internacionais nos últimos cinco anos.

Tanto a análise de situação como as recomendações de políticas e programas estão prioritariamente voltadas para a problemática das iniqüidades em saúde nas áreas urbanas. Esta ênfase se justifica não apenas porque a imensa maioria da população brasileira vive em áreas urbanas, como também pela forma extremamente acelerada com que se deu o processo de urbanização, sem contrapartida equivalente de adequação da infra-estrutura, gerando enormes iniqüidades e concentrando, principalmente nas áreas metropolitanas, grandes parcelas da população em precárias condições de vida, de ambiente e de trabalho. 
A análise da situação de saúde compreende as seguintes seções:

- Situação e tendências da evolução demográfica, social e econômica do país: traça um panorama geral de referência para a análise da situação de saúde, descrevendo a evolução destes macrodeterminantes, particularmente nas últimas quatro décadas. Inclui dados sobre crescimento populacional, fecundidade, mortalidade, migrações, urbanização, estrutura do mercado de trabalho, distribuição de renda e educação.

- A estratificação socioeconômica e a saúde: apresenta a situação atual e tendências da situação de saúde no país, destacando as desigualdades de saúde segundo variáveis de estratificação socioeconômica, como renda, escolaridade, gênero e local de moradia.

- Condições de vida, ambiente e trabalho: apresenta as relações entre situação de saúde e condições de vida, ambiente e trabalho, com ênfase nas relações entre saneamento, alimentação, habitação, ambiente de trabalho, poluição, acesso à informação e serviços de saúde e seu impacto nas condições de saúde dos diversos grupos da população.

- Redes sociais, comunitárias e saúde: inclui evidências sobre a organização comunitária e redes de solidariedade e apoio para a melhoria da situação de saúde, destacando particularmente o grau de desenvolvimento dessas redes nos grupos sociais mais desfavorecidos.

- Comportamentos, estilos de vida e saúde: inclui evidências existentes no Brasil sobre condutas de risco como hábito de fumar, alcoolismo, sedentarismo, dieta inadequada, entre outros, segundo os diferentes estratos socioeconômicos da população.

- Saúde materno-infantil e saúde indígena: por sua importância social e por apresentarem necessidades específicas de políticas públicas.

Este relatório não pode, nem pretende ser exaustivo. Há uma série de temas, que estão ausentes ou foram parcialmente desenvolvidos e que, por sua importância, mereceriam maior desenvolvimento posterior. Entre estes temas poderiam ser incluídos: saúde e ambiente nas grandes cidades; seguridade social e saúde; cultura e promoção da saúde; distribuição, acesso e utilização de serviços de saúde em áreas urbanas; violência e saúde; iniciativas comunitárias de promoção e proteção da saúde; desemprego e saúde, entre outros.

Para superação dos problemas relatados, são feitas Recomendações de políticas e programas, tendo por base a experiência internacional e nacional em intervenções sobre os DSS em seus diversos níveis.

Atendendo a um de seus compromissos fundamentais, as recomendações da Comissão devem estar fundamentadas em sólidas evidências. Nesta parte se incluem dois tipos de recomendações. Um primeiro deriva da análise de políticas e programas existentes na esfera federal e que incidem sobre os DSS. Apresenta-se uma análise de conjunto dessas políticas e programas, buscando identificar superposições, paralelismos ou contradições, com as correspondentes recomendações para superação dos problemas encontrados, visando a uma ação intersetorial mais integrada. 
Um segundo grupo de recomendações se refere à institucionalização de determinados processos que são fundamentais para a atuação sustentável sobre os DSS e cujo desenvolvimento deve gerar políticas e programas específicos. Incluem-se recomendações para a institucionalização da ação intersetorial visando à melhoria da qualidade de vida e saúde, da participação social e empoderamento de grupos populacionais mais vulneráveis e da produção sistemática de informações e conhecimentos sobre as relações entre DSS e a saúde e sobre avaliação de intervenções.

A literatura científica nacional e internacional, publicada nos últimos cinco anos, sobre DSS no Brasil, foi amplamente revisada e está reunida em Referências e bibliografia complementar.

Finalmente, o relatório inclui três Anexos, a saber:

- Anexo I - para o cumprimento de seus objetivos, a Comissão definiu cinco linhas de ação e projetos específicos relacionados a cada uma delas. Este anexo descreve as atividades realizadas e apresenta seus principais resultados.

- Anexo II - reproduz o Decreto Presidencial de 13 de março de 2006, que criou a Comissão Nacional sobre Determinantes Sociais da Saúde, e a Portaria Ministerial que nomeou seus integrantes.

- Anexo III - contém o documento "Iniqüidades em Saúde no Brasil: nossa mais grave doença”, que foi apresentado por ocasião do lançamento da CNDSS em 13 de março de 2006, e o discurso proferido pelo Dr. Adib Jatene na cerimônia de entrega do relatório ao Exmo. presidente da República em 1 de agosto de 2008.

Este volume traz encartado um CD, produzido pela equipe do Centro Latino-Americano e do Caribe de Informação em Ciências da Saúde (Bireme/Opas/OMS), com versões na íntegra de textos que constam das referências e bibliografia complementar.

Dália Romero e Patricia Rivero apoiaram na consulta a diversos sistemas de informação de abrangência nacional e Vangela Costa da Silva, na normalização bibliográfica e preparação inicial de tabelas e gráficos. A todos os colaboradores das várias etapas de confecção deste relatório, o nosso muito obrigado. 


\section{INTRODUÇÃO}

\subsection{A Comissão}

Em março de 2005, a Organização Mundial da Saúde (OMS) criou a Comissão sobre Determinantes Sociais da Saúde (Commission on Social Determinants of Health, CSDH), com o objetivo de promover, em âmbito internacional, uma tomada de consciência sobre a importância dos determinantes sociais na situação de saúde de indivíduos e populações e sobre a necessidade do combate às iniqüidades em saúde por eles geradas. Um ano depois, em 13 março de 2006, através de Decreto Presidencial, foi criada no Brasil a Comissão Nacional sobre Determinantes Sociais da Saúde (CNDSS) com um mandato de dois anos.

O fato de o Brasil ser o primeiro país a criar sua própria Comissão, integrando-se precoce e decisivamente ao movimento global em torno dos determinantes sociais da saúde (DSS) desencadeado pela OMS, responde a uma tradição do sanitarismo brasileiro. De fato, desde o início do século passado, os sanitaristas brasileiros vêm se dedicando a aprofundar o conhecimento das relações entre os determinantes socioeconômicos e a situação de saúde e a desenvolver ações concretas, baseadas nesse conhecimento.

Mais recentemente, inspirados por essa tradição, diversos setores da sociedade se articularam em um movimento de reforma sanitária, que contribuiu decisivamente para incluir, na Constituição de 1988, o reconhecimento da saúde como um direito de todo cidadão e um dever do Estado, bem como para criar o Sistema Único de Saúde (SUS), fundado nos princípios de solidariedade e universalidade.

A criação da CNDSS se inscreveu nesse processo de desenvolvimento da reforma sanitária. Integrada por dezesseis expressivas lideranças de nossa vida social, cultural, científica e empresarial, sua constituição diversificada é uma expressão do reconhecimento de que a saúde é um bem público construído com a participação solidária de todos os setores da sociedade brasileira.

Os objetivos da CNDSS, estabelecidos no Decreto Presidencial que a criou, podem ser assim resumidos:

- gerar informações e conhecimentos sobre os determinantes sociais da saúde no Brasil;

- contribuir para a formulação de políticas que promovam a eqüidade em saúde;

- mobilizar diferentes instâncias do governo e da sociedade civil sobre este tema. 


\subsection{Os Compromissos}

Para alcançar seus objetivos, a CNDSS se apóia em três compromissos básicos:

\section{Compromisso com a eqüidade}

Apesar dos importantes avanços dos últimos anos na melhoria do valor médio de seus indicadores de saúde, o Brasil está entre os países com maiores iniqüidades em saúde, ou seja, desigualdades de saúde entre grupos populacionais que além de sistemáticas e relevantes são também evitáveis, injustas e desnecessárias (Whitehead, 1992). Estas iniqüidades em saúde são produto de grandes desigualdades entre os diversos estratos sociais e econômicos da população brasileira. Segundo o Relatório do Programa das Nações Unidas para o Desenvolvimento de 2007, com dados de 2005, o Brasil está situado em $11^{\circ}$ lugar entre os mais desiguais do mundo em termos de distribuição da renda, superado apenas por seis países da África e quatro da América Latina.

Autores como Amartya Sen (Sen, 2000) e John Rawls (Rawls, 1999) enfatizam a importância de eliminar todas as privações de liberdade que limitam as escolhas e as oportunidades das pessoas para exercer sua condição de cidadão. As precárias condições de vida e saúde de amplos setores da população brasileira são privações de liberdade que limitam sua capacidade de optar entre diferentes alternativas, de ter voz frente às instituições do Estado e da sociedade e de ter maior participação na vida social. O compromisso da CNDSS com a eqüidade, visando a assegurar o direito universal à saúde, não é apenas uma decisão racional, mas fundamentalmente um compromisso ético e uma posição política.

\section{Compromisso com a evidência}

A CNDSS procura fundamentar suas análises e recomendações em sólidas evidências científicas, pois são estas que permitem, por um lado, entender como operam os determinantes sociais na geração das iniqüidades em saúde e, por outro, como e onde devem incidir as intervenções para combatê-las e que resultados podem ser esperados em termos de efetividade e eficiência.

Entretanto, há uma série de limitações e desafios para a produção da evidência científica, particularmente no que se refere à avaliação do impacto de intervenções. Nos últimos anos, observa-se um importante aumento de estudos sobre as iniqüidades em saúde na literatura científica nacional e internacional e uma maior preocupação destes estudos em não apenas descrever as relações entre pobreza e saúde ou descrever os gradientes de saúde, de acordo com vários critérios de estratificação socioeconômica, mas também entender os mecanismos de produção das iniqüidades em saúde (Almeida Filho et al., 2003).

Várias abordagens vêm sendo utilizadas para enfrentar esse desafio como as que privilegiam os aspectos materiais da existência dos indivíduos e da infra-estrutura comunitária e as que enfatizam fatores psicossociais na geração de problemas de saúde como a percepção das pessoas sobre sua posição em sociedades desiguais. Há, ainda, os enfoques "ecossociais" ou 
multinível e os que destacam o enfraquecimento da coesão social e dos laços de solidariedade e cooperação em sociedades com grandes disparidades, além de outros (Adler, 2006).

Apesar dessa riqueza e diversidade de enfoques e abordagens disciplinares, há ainda muito que se avançar no conhecimento da dinâmica de relações e mediações entre os determinantes sociais proximais, intermediários e distais e há, principalmente, uma relativa carência de estudos sobre o impacto de intervenções sobre os DSS. Além disso, esse impacto é em grande medida influenciado pelo contexto, ou seja, depende de situações locais específicas, dificultando a transferência de experiências (Buss \& Pellegrini Filho, 2007).

\section{Compromisso com a ação}

O compromisso maior da Comissão - e que dá sentido à sua existência - é o combate às iniqüidades em saúde por meio da atuação sobre os determinantes sociais que as geraram, os quais, sendo produto da ação humana, podem e devem ser modificados pela ação humana. o compromisso com a ação está alicerçado, por um lado, nas evidências científicas, conforme já assinalado, e por outro, numa ampla base de sustentação política, produto da conscientização e mobilização de diversos setores da sociedade.

A adoção do compromisso com a ação enfrenta também uma série de dificuldades e desafios. Um deles se refere à intersetorialidade. A atuação sobre os DSS sejam eles proximais, intermediários ou distais, particularmente sobre estes últimos, extrapola o nível de competência do setor saúde, obrigando à ação conjunta de diversos setores governamentais, cuja lógica de atuação, em geral, está marcada pela fragmentação.

Já foi mencionada também a relativa carência de estudos de avaliação da efetividade de intervenções sobre os DSS e o estreito vínculo das mesmas com situações específicas, o que dificulta a simples transferência de experiências exitosas para diferentes contextos.

Entretanto, mesmo quando há evidências suficientes para orientar determinada ação na área social, estas nunca são prescrições categóricas. Em geral, o que existe é um leque possível de intervenções e opções de políticas que a ciência ajuda a delimitar, mas cuja seleção se faz através de um processo complexo que envolve diversos atores, com diferentes interesses, atuando e negociando politicamente (Pellegrini Filho, 2000). Assim, em lugar de esperar que a racionalidade científica se sobreponha à política, é necessário reconhecer o caráter essencialmente político do processo de tomada de decisões. Isso implica fortalecer a democratização desse processo e apoiar a atuação dos diferentes atores, particularmente daqueles que em geral estão excluídos da tomada de decisões. Implica, também, proporcionarlhes acesso eqüitativo a informações e conhecimentos pertinentes que ajudem a fundamentar a defesa de seus interesses. Deste modo, não há contradição em considerar que as ações voltadas para o combate às iniqüidades devem estar baseadas, por um lado, na evidência científica e, por outro, na mobilização e participação social, pois evidência e participação se complementam e se reforçam mutuamente. 


\subsection{Os Modelos de ReferênCIA}

Os diversos estudos sobre os DSS e as iniqüidades em saúde permitiram a construção de modelos que procuram esquematizar a trama de relações entre os vários níveis de determinantes sociais e a situação de saúde. Entre estes modelos, a CNDSS resolveu adotar o de Dahlgren e Whitehead (1991), que serve de base para orientar a organização de suas atividades e os conteúdos do presente relatório. Apesar da existência de outros modelos mais complexos, que buscam explicar com maiores detalhes as relações e mediações entre os diversos níveis de DSS e a gênese das iniqüidades, ${ }^{1}$ a escolha do modelo de Dahlgren e Whitehead se justifica por sua simplicidade, por sua fácil compreensão para vários tipos de público e pela clara visualização gráfica dos diversos DSS.

O modelo de Dahlgren e Whitehead inclui os DSS dispostos em diferentes camadas, segundo seu nível de abrangência, desde uma camada mais próxima aos determinantes individuais até uma camada distal onde se situam os macrodeterminantes. Como se pode ver na figura a seguir (Figura 1), os indivíduos estão na base do modelo, com suas características individuais de idade, sexo e fatores genéticos que, evidentemente, exercem influência sobre seu potencial e suas condições de saúde.

$\mathrm{Na}$ camada imediatamente externa, aparecem o comportamento e os estilos de vida individuais. Esta camada está situada no limiar entre os fatores individuais e os DSS, já que os comportamentos dependem não apenas de opções feitas pelo livre arbítrio das pessoas, mas também de DSS, como acesso a informações, propaganda, pressão de pares, possibilidades de acesso a alimentos saudáveis e espaços de lazer, entre outros.

A camada seguinte destaca a influência das redes comunitárias e de apoio, cuja maior ou menor riqueza expressa o nível de coesão social que, é de fundamental importância para a saúde da sociedade como um todo. No próximo nível, estão representados os fatores relacionados a condições de vida e de trabalho, disponibilidade de alimentos e acesso a ambientes e serviços essenciais, como saúde e educação, indicando que as pessoas em desvantagem social apresentam diferenciais de exposição e de vulnerabilidade aos riscos à saúde, como conseqüência de condições habitacionais inadequadas, exposição a condições mais perigosas ou estressantes de trabalho e acesso menor aos serviços. Finalmente, no último nível, estão situados os macrodeterminantes que possuem grande influência sobre as demais camadas e estão relacionados às condições econômicas, culturais e ambientais da sociedade, incluindo também determinantes supranacionais como o processo de globalização.

${ }^{1}$ Há uma vasta literatura sobre aspectos conceituais e modelos de referência relacionados aos determinantes sociais e iniqüidades em saúde, que foi revisada pela Comissão sobre Determinantes Sociais da Saúde da OMS e pode ser encontrada em:

$<$ www.who.int/social_determinants/resources/latest_publications/en/index.html $>$. Recomenda-se, em particular, o texto preparado pela secretaria técnica dessa Comissão, denominado "A conceptual framework for action on the social determinants of health", de abril de 2007, encontrado em: <www.who.int/social_determinants/resources/latest_publications/en/index.html> 


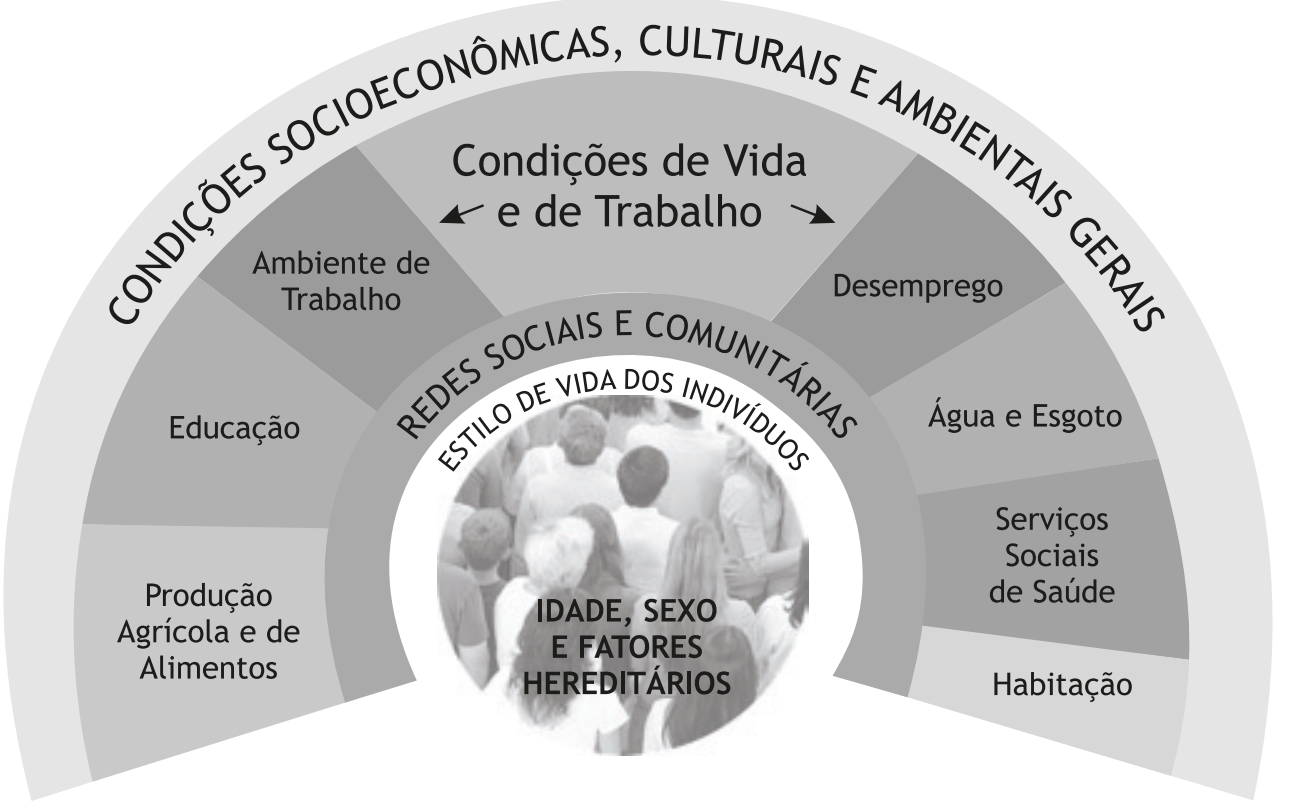




\subsection{Situação e Tendências da Evolução Demográfica, Social e Econômica do País}

O Brasil vem passando por grandes transformações econômicas, sociais e demográficas, particularmente nas quatro últimas décadas, com significativas repercussões nas condições de vida e trabalho da população e conseqüentemente em sua situação de saúde. Esta seção traça um esboço dessas transformações, destacando determinados processos, seus avanços, desafios e diferenciais segundo os diversos grupos sociais.

\section{Urbanização}

Conforme pode ser observado na Tabela 1 e no Gráfico 1, o censo demográfico de 1960 revelava que $55 \%$ da população economicamente ativa (PEA), portanto sua maioria, dedicavam-se à agricultura, ao passo que os restantes $45 \%$ se dedicavam aos setores secundário e terciário. Já na década seguinte, essa proporção se inverteu, com $54 \%$ da população empregada na indústria ou no setor serviços. Segundo o último censo de 2000 , apenas $19 \%$ da população estava empregada no campo, ou seja, uma queda de 55\% para $19 \%$ em quatro décadas. Nesse mesmo período, a população empregada pelo setor serviços passou de $27 \%$ a $60 \%$, ao passo que a dedicada à indústria, depois de uma ascensão de 17 a 29\% entre 1960 e 1980, caiu para $21 \%$, no censo de 2000.

Tabela 1 - Proporção de pessoas de 10 anos ou mais da PEA, por setor econômico. Brasil - 1940 - 2000

\begin{tabular}{c|ccc}
\hline \multirow{2}{*}{ Ano } & \multicolumn{3}{|c}{ PEA por setor de atividade econômica (\%) } \\
\cline { 2 - 4 } & Primário & Secundário & Terciário \\
\hline 1940 & 67 & 13 & 20 \\
1950 & 61 & 17 & 22 \\
1960 & 55 & 17 & 27 \\
1970 & 46 & 22 & 32 \\
1980 & 31 & 29 & 40 \\
1996 & 25 & 20 & 55 \\
2000 & 19 & 21 & 60 \\
\hline
\end{tabular}

Fonte: Censos Demográficos (1940 a 1980 e 2000) e Contagem da População (1996), Instituto Brasileiro de Geografia e Estatística (IBGE). 
Gráfico 1 - Evolução da proporção de pessoas de 10 anos ou mais de idade da PEA, por setor econômico. Brasil - 1940 - 2000

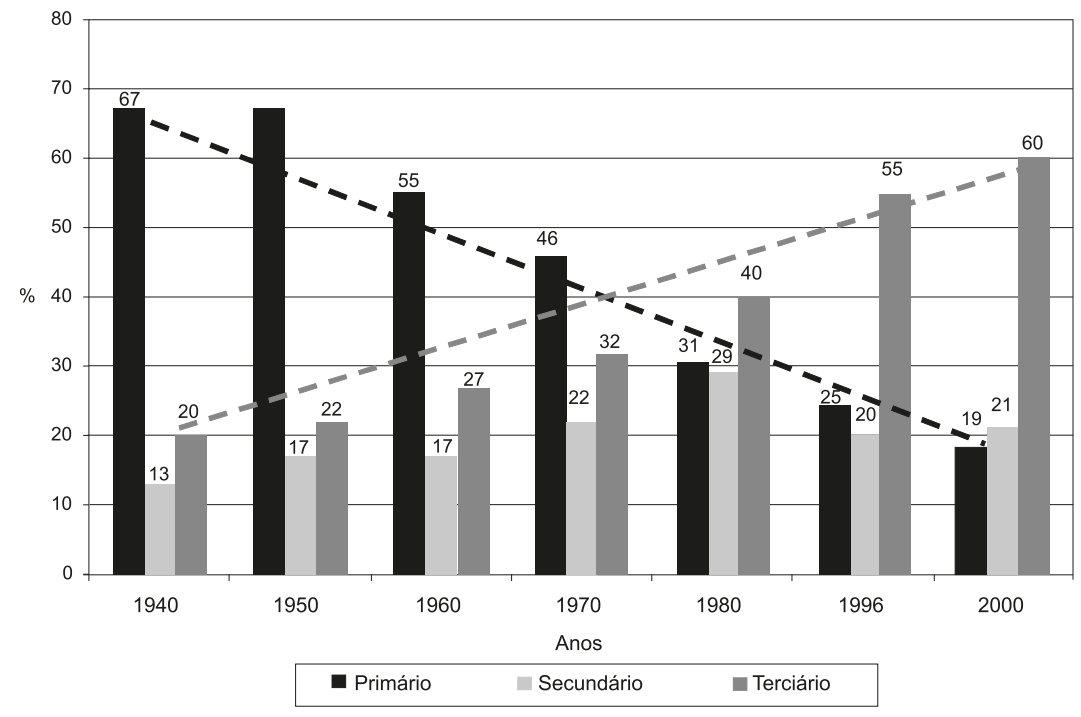

Fonte: Censos Demográficos (1940 a 1980 e 2000) e Contagem da População (1996), Instituto Brasileiro de Geografia e Estatística (IBGE).

Evidentemente, essa redistribuição acelerada da PEA do setor agrícola para os setores industriais e de serviços implicou um processo de urbanização também extraordinariamente acelerado. A Tabela 2 e o Gráfico 2 revelam que, em 1960, a maioria da população (55\%) possuía seu domicílio na zona rural. Na década seguinte, a proporção se inverteu, com $56 \%$ da população residindo na área urbana, proporção que cresce explosivamente desde então para atingir $81 \%$ em 2000. Em números absolutos, a população total do país era de 70.070.457 em 1960, sendo 31.303.034 na área urbana e 38.767.423 na área rural. Em 2000 , a população total cresceu para 169.610 .693 , sendo 137.775 .550 na área urbana e 31.835.143 na área rural, ou seja, no período de apenas quatro décadas a população rural diminuiu em 6.932.280, enquanto a população urbana cresceu em 106.472.516 milhões, um acréscimo de cerca de 2,7 milhões de pessoas por ano nas áreas urbanas, gerando uma enorme demanda por infra-estrutura e serviços.

A oferta dessa infra-estrutura e serviços urbanos não acompanhou a grande demanda, a tal ponto que, por exemplo, em 1980, havia 38,2 milhões de moradores em domicílios urbanos inadequados (neste ano a população total era de 119.002.706 habitantes, sendo 80.921.836 em áreas urbanas). Deve-se destacar que há uma diferença de mais de $75 \%$ nos níveis de mortalidade infantil entre crianças residentes em domicílios inadequados em relação aos adequados (Simões, 1985).

A urbanização acelerada, embora comum a todas as regióes do país, apresenta algumas variações, sendo mais precoce e mais acelerada na Região Sudeste, que em 2000 já contava com $91 \%$ da população vivendo em áreas urbanas. No outro extremo, situa-se a Região Nordeste, onde a população urbana apenas se torna majoritária no censo de 1991, atingindo $69 \%$ no ano 2000. 
Tabela 2 - População residente (\%), por situação do domicílio, segundo as grandes regiões. Brasil - 1940 - 2000

\begin{tabular}{|c|c|c|c|c|c|c|c|c|c|c|c|c|c|c|}
\hline \multirow{3}{*}{$\begin{array}{l}\text { Grandes } \\
\text { regiões }\end{array}$} & \multicolumn{14}{|c|}{ População residente (\%) } \\
\hline & \multicolumn{7}{|c|}{ Urbana } & \multicolumn{7}{|c|}{ Rural } \\
\hline & 1940 & 1950 & 1960 & 1970 & 1980 & 1991 & 2000 & 1940 & 1950 & 1960 & 1970 & 1980 & 1991 & 2000 \\
\hline BRASIL & 31 & 36 & 45 & 56 & 68 & 76 & 81 & 69 & 64 & 55 & 44 & 32 & 24 & 19 \\
\hline Norte & 28 & 31 & 37 & 45 & 52 & 59 & 70 & 72 & 69 & 63 & 55 & 48 & 41 & 30 \\
\hline Nordeste & 23 & 26 & 34 & 42 & 50 & 61 & 69 & 77 & 74 & 66 & 58 & 50 & 39 & 31 \\
\hline Sudeste & 39 & 48 & 57 & 73 & 83 & 88 & 91 & 61 & 52 & 43 & 27 & 17 & 12 & 9 \\
\hline Sul & 28 & 29 & 37 & 44 & 62 & 74 & 81 & 72 & 71 & 63 & 56 & 38 & 26 & 19 \\
\hline Centro-Oeste & 22 & 24 & 34 & 48 & 68 & 81 & 87 & 78 & 76 & 66 & 52 & 32 & 19 & 13 \\
\hline
\end{tabular}

Fonte: Censos demográficos (1940-2000). Instituto Brasileiro de Geografia e Estatística (IBGE).

Gráfico 2 - População residente (\%), por situação do domicílio. Brasil - 1940 - 2000

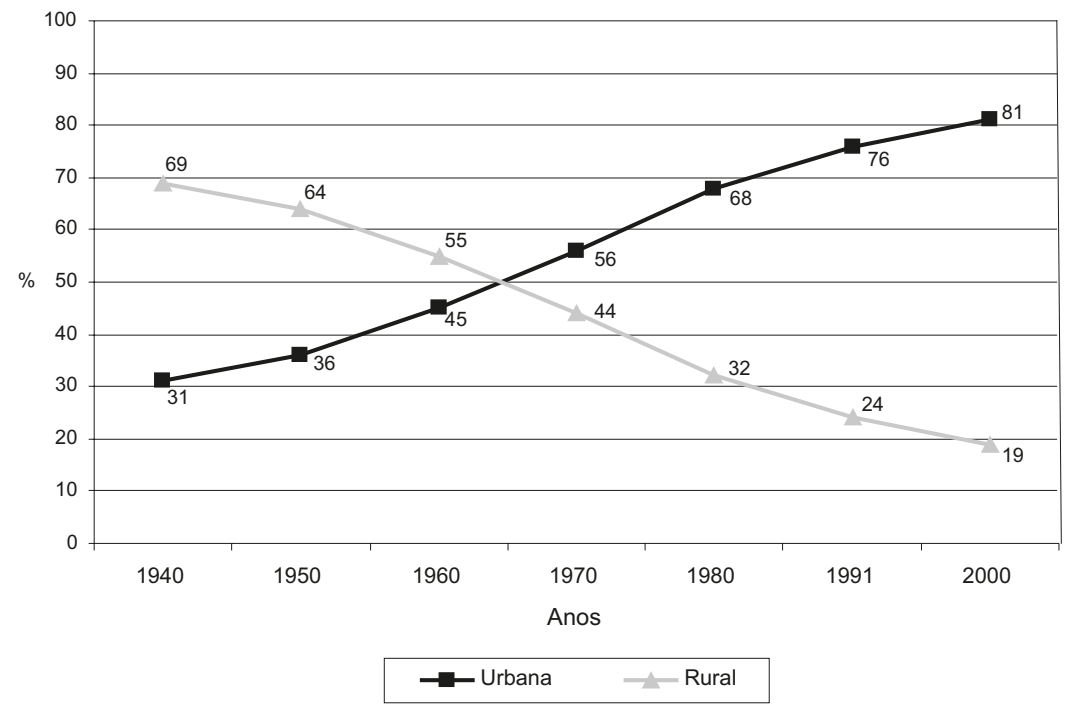

Fonte: Censos demográficos (1940-2000). Instituto Brasileiro de Geografia e Estatística (IBGE).

\section{Transição Demográfica}

Os processos de industrialização e urbanização acelerada foram responsáveis por importantes mudanças nos padrões de fecundidade da população. Segundo dados do censo, a taxa média geométrica de crescimento anual da população passou de 2,89\% no período 1960/1970 para 1,64\% no período 1991/2000. A taxa de fecundidade, que se mantinha estável desde 1940, passou a cair de maneira acelerada a partir de 1960. Como pode ser observado no Gráfico 3, também com dados censitários, a taxa de fecundidade, que era de 6,3 filhos por mulher em idade fértil em 1960, caiu para 2,3 em 2000, devendo situar-se em 2,0 em 2006, segundo projeções do IBGE. 
Gráfico 3 - Taxa de fecundidade. Brasil - 1940 - 2000

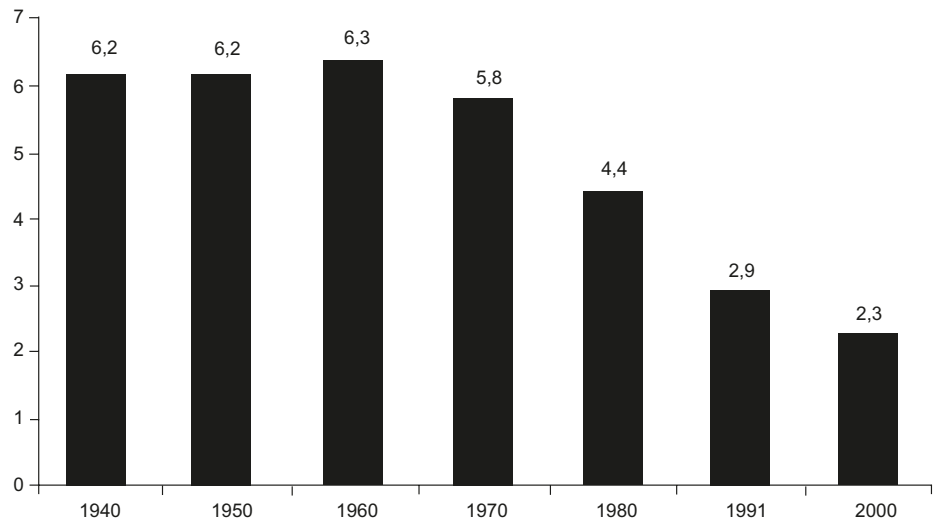

Fonte: Censo demográfico (1940-2000). Instituto Brasileiro de Geografia e Estatística (IBGE)

Essa importante queda da fecundidade ocorrida no Brasil nas últimas décadas é bem mais acelerada do que a observada nos países desenvolvidos. No Gráfico 4, observa-se que a queda da fecundidade experimentada por Itália e França é anterior e bem mais suave que a verificada no Brasil.

Embora a queda acelerada da taxa de fecundidade ocorra em todas as regiões do país, existem importantes diferenças segundo a escolaridade das mulheres. De acordo com dados da Pesquisa Nacional por Amostra de Domicílios (Pnad) de 2006, a taxa de fecundidade total, que em 2005 era de 2,1 filhos por mulher em idade fértil, variava de 4 para mulheres com até três anos de estudo a 1,5 para as que possuíam oito ou mais anos de estudo, como pode ser observado na Tabela 3.

Gráfico 4 - Taxa de fecundidade total. Brasil, França e Itália - 1900 - 2050

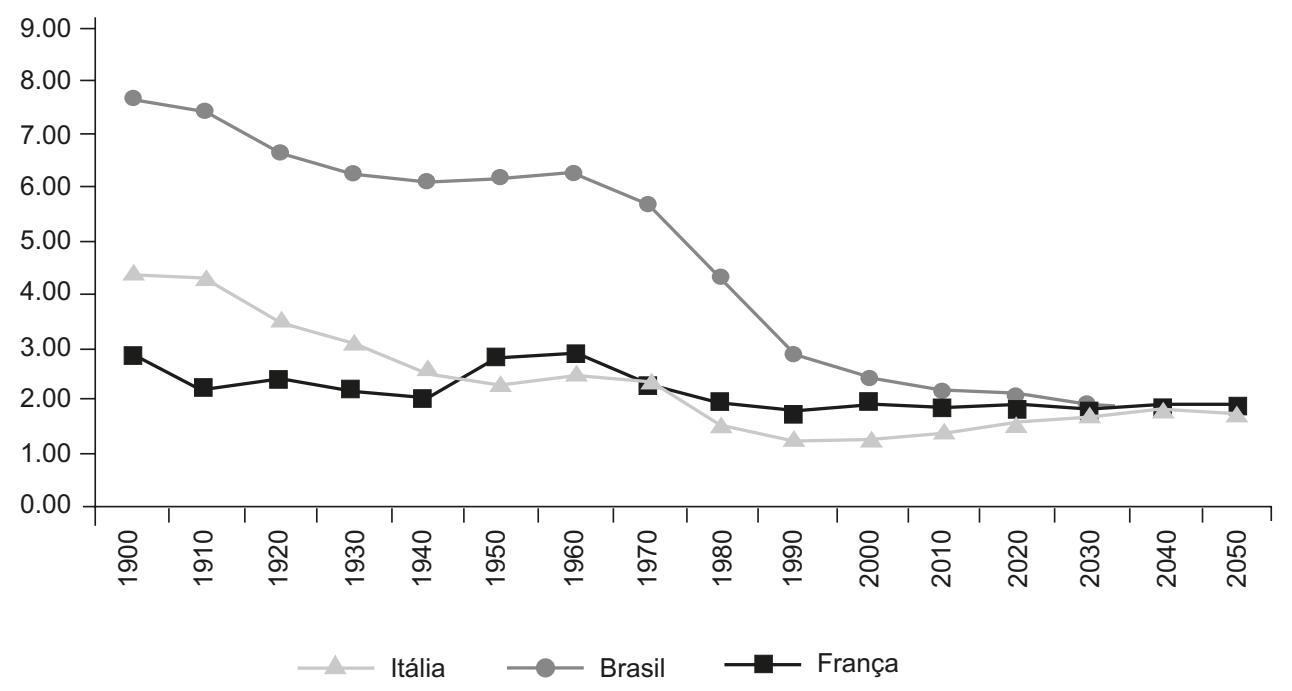

Fonte: ONU, Population Division of the Departament of Economic and Social Affairs of the United Nations Secretariat, World Population Prospects: The 2004 Revision; BACCI, 1999, p.137 e 167; FIBGE, 1990, p.33; IBGE, 2006, p34-36; IBGE, Censo demográfico de 1940, 1950, 1960 e 1970; IBGE/Diretoria de Pesquisas. Coordenação de População e Indicadores Sociais. Gerência de Estudos e Análises da Dinâmica Demográfica, 2004.

In: Brito, F. A Transição Demográfica no Brasil: as possibilidades e os desafios para a economia e a sociedade. Belo Horizonte: Cedeplar/UFMG, 2007. 
Tabela 3 - Taxa de fecundidade total por grupos de anos de estudo das mulheres, segundo as grandes regiões. Brasil -2005

\begin{tabular}{l|cccc}
\hline \multirow{2}{*}{$\begin{array}{l}\text { Grandes } \\
\text { regiões }\end{array}$} & \multicolumn{4}{|c}{$\begin{array}{c}\text { Taxa de fecundidade total, por grupos de anos de } \\
\text { estudo das mulheres }\end{array}$} \\
\cline { 2 - 5 } & TotAL $^{(1)}$ & Até 3 anos & 4 a 7 anos & 8 anos ou mais \\
\hline Brasil & 2,1 & 4,0 & 3,1 & 1,5 \\
Norte & 2,5 & 4,5 & 3,4 & 1,8 \\
Nordeste & 2,3 & 4,1 & 3,0 & 1,5 \\
Sudeste & 1,9 & 3,7 & 3,1 & 1,5 \\
Sul & 2,0 & 3,7 & 3,1 & 1,6 \\
Centro-Oeste & 2,0 & 3,4 & 3,1 & 1,5 \\
\hline
\end{tabular}

(1) Inclusive as mulheres sem declaração de anos de estudo.

Fonte: Pesquisa Nacional por Amostra de Domicílios 2005. Instituto Brasileiro de Geografia e Estatística (IBGE).

Importantes diferenças também são observadas de acordo com a renda. No Gráfico 5, construído a partir de dados de um trabalho de Berquó e Cavenaghi (2006), pode-se observar um nítido gradiente da taxa de fecundidade entre as diversas faixas de rendimento médio domiciliar per capita. A taxa para as mulheres que vivem em domicílios com renda per capita até um quarto do salário mínimo é mais de quatro vezes maior do que as que vivem em domicílios com cinco ou mais salários mínimos per capita.

Gráfico 5 - Taxa de fecundidade total, segundo rendimento médio mensal domiciliar per capita. Brasil 1991, 2000, 2004

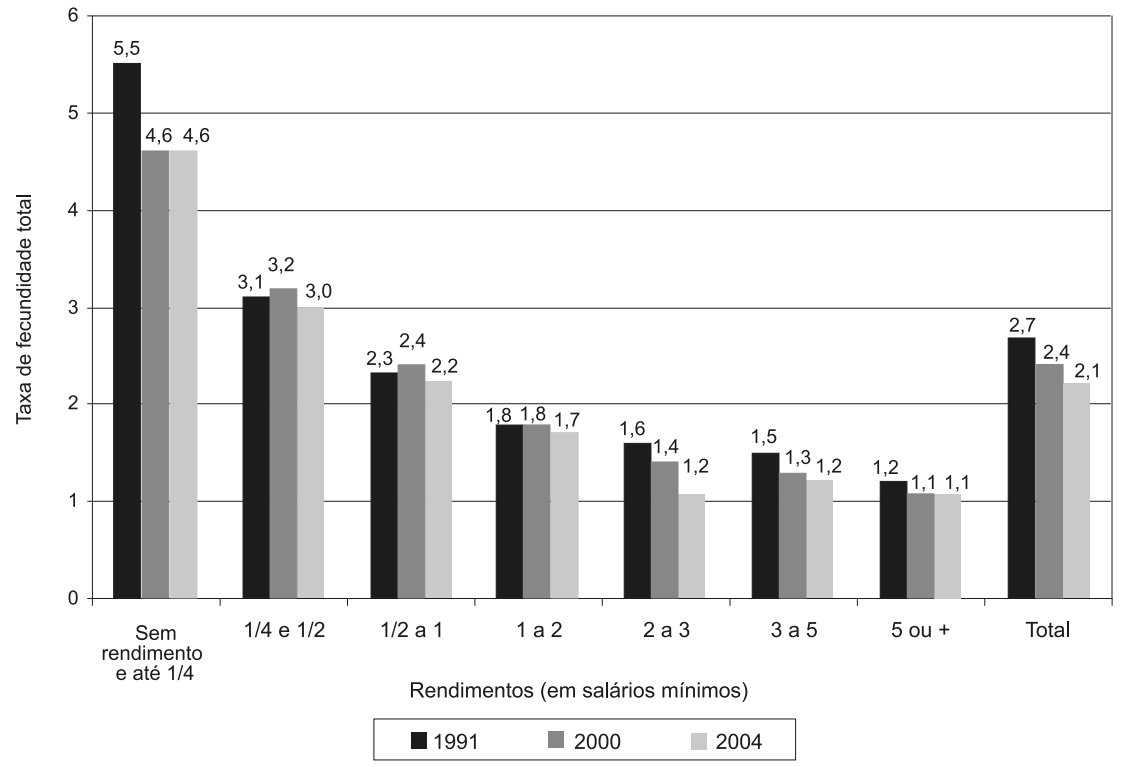

Fonte: Berquó, E.; Cavenaghi, S. Fecundidade em declínio: Breve nota sobre a redução no número médio de filhos por mulher no Brasil. Novos Estudos, Cebrap, 74, p. 11-15, março 2006. 
Importante observar o extraordinário aumento da contribuição das mulheres de 15 a 19 anos de idade na fecundidade total, em grande medida devido à redução da fecundidade das mulheres com idade mais avançada. Segundo dados do censo, no curto período de duas décadas, essa contribuição praticamente duplicou em todas as regiões do país, como pode ser observado no Gráfico 6.

Gráfico 6 - Contribuição da fecundidade das mulheres de 15 a 19 anos de idade na fecundidade total, por grandes regiões. Brasil - 1980 - 2000

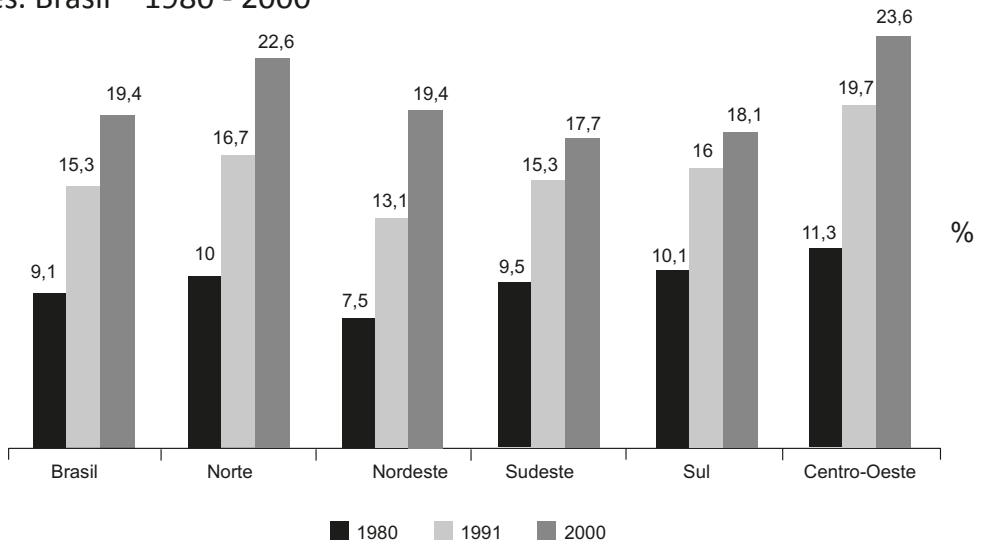

Fonte: Censo Demográfico 2000, Fecundidade e Mortalidade Infantil, Resultados Preliminares da Amostra. IBGE, 2002.

Apesar das baixas taxas atuais de fecundidade, a população brasileira ainda deve crescer de maneira expressiva nas próximas décadas, como resultado da fecundidade passada, como pode ser observado no Gráfico 7. O gráfico também mostra uma importante modificação na estrutura etária, com envelhecimento da população causado pela diminuição da fecundidade e aumento da expectativa de vida. A proporção de jovens de 0 a 14 anos que era de 42,6\% em 1960 passou para 30\% em 2000 e deverá atingir 18\% em 2050, ao passo que a de idosos maiores de 65 anos, que era de 2,7\% em 1960, passou para 5,4\% em 2000 e no ano de 2050 deverá superar a de jovens, alcançando 19\%.

Gráfico 7 - População total, segundo grandes grupos etários. Brasil - 1940 - 2050

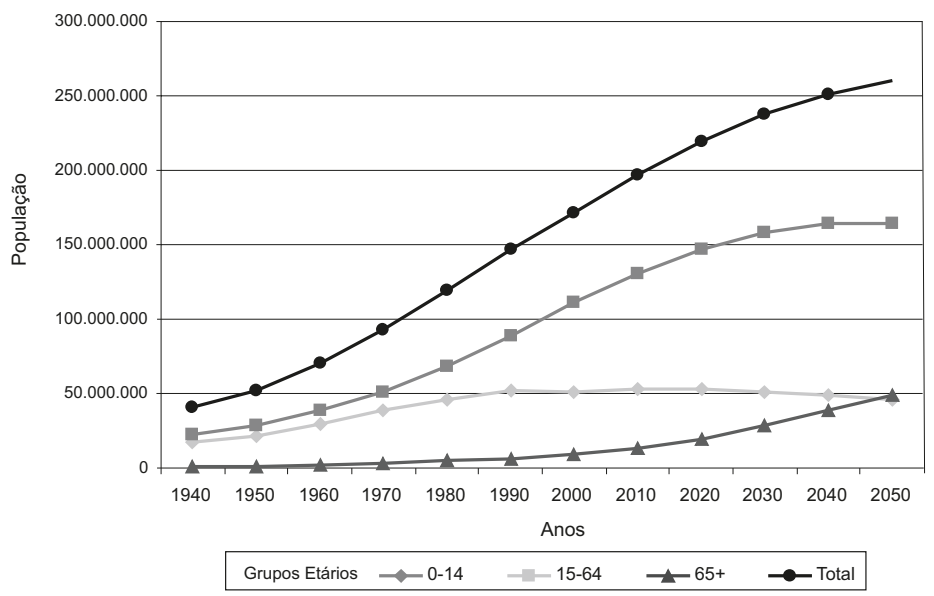

Fonte: IBGE.Censos Demogáficos de 1940, 1950, 1960 e 1980; IBGE/Diretoria de Pesquisas. Coordenação de População e Indicadores Sociais. Gerência de Estudos e Análises da Dinâmica Demoráfica, 2004.

In: Brito, F. A Transição Demográfica no Brasil: as possibilidades e os desafios para a economia e a sociedade. Belo Horizonte: Cedeplar/UFMG, 2007. 
As mudanças na estrutura etária, principalmente da maneira acelerada como vêm ocorrendo no Brasil, com um crescimento rápido do peso relativo dos idosos, têm um impacto importante na economia e na sociedade, obrigando a definição de políticas públicas que possam fazer frente a esse fenômeno sem paralelo na experiência mundial. Conforme salienta Brito (2007), essas políticas devem também levar em conta que, apesar do decréscimo relativo da presença dos jovens, seu número absoluto ainda é muito importante, devendo atingir o maior valor em 2010, para depois começar a decrescer também em termos absolutos.

Outro desafio para as políticas públicas é o fato de que as mudanças na estrutura etária ocorrem de forma desigual entre estados e regiões e entre os diferentes níveis de renda da população. O Gráfico 8 mostra as pirâmides populacionais do censo de 2000 para a população com renda familiar per capita de menos de meio salário mínimo, correspondente a $30 \%$ da população naquele ano, e para a população com mais de dez salários mínimos de renda familiar per capita, cerca de $3 \%$ da população.

Gráfico 8 - Pirâmides etárias dos grupos extremos, por faixa de renda familiar per capita em salários mínimos. Brasil - 2000 (\%)
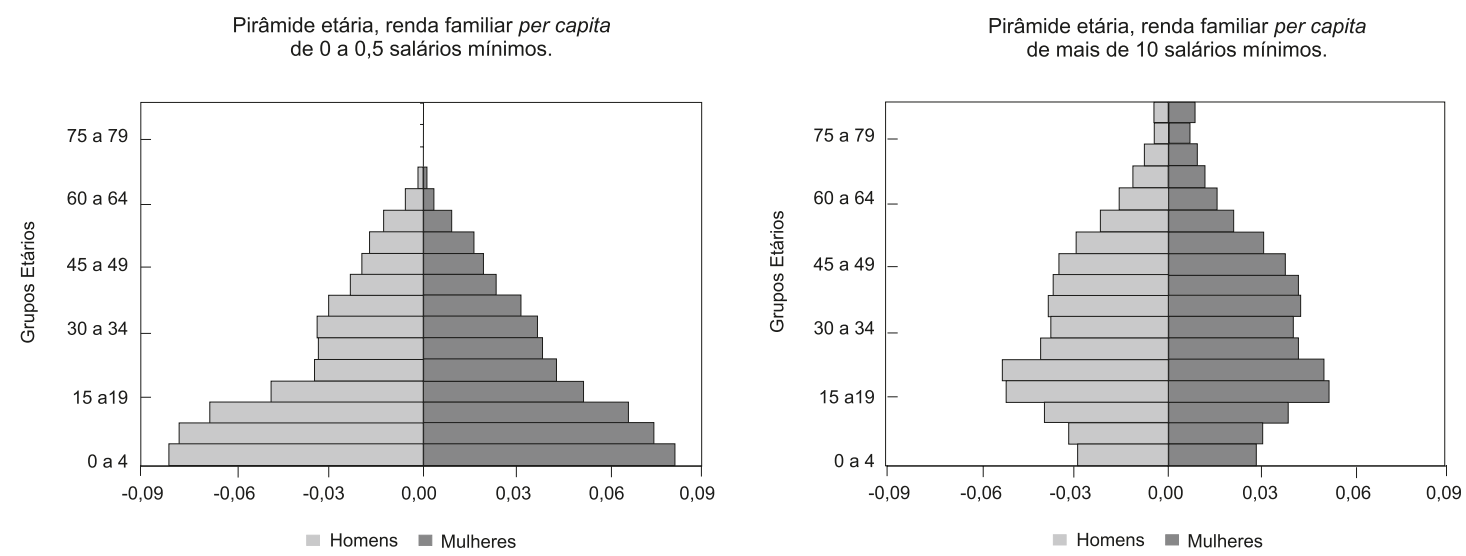

Fonte: IBGE.Censos Demogáficos de 1940, 1950, 1960 e 1980; IBGE/Diretoria de Pesquisas. Coordenação de População e Indicadores Sociais. Gerência de Estudos e Análises da Dinâmica Demoráfica, 2004.

In: Brito, F. A Transição Demográfica no Brasil: as possibilidades e os desafios para a economia e a sociedade. Belo Horizonte: Cedeplar/UFMG, 2007.

Outro elemento importante a ser tomado em conta pelas políticas públicas se refere à evolução da razão de dependência em função das mudanças na estrutura etária. Considerando que tanto a população de 0 a 14 anos como a de mais de 65 anos são dependentes da população em idade ativa de 15 a 64 anos (PIA), define-se a razão de dependência total (RDT) como a proporção da soma de jovens e idosos em relação à PIA. A RDT pode ser desdobrada em razão de dependência de jovens e razão de dependência de idosos, sendo a primeira a proporção dos jovens em relação a PIA e a segunda, a dos idosos. Como mostra a Tabela 4, em 1960, a RDT era de cerca de $83 \%$, ou seja, havia 83 dependentes para cada 100 pessoas na PIA, sendo que desses 83 dependentes, 78 eram jovens e 5 idosos. Entre 1960 e 2000, há uma queda importante da razão de dependência de jovens e um aumento da razão de dependência de idosos. A RDT caiu para 54\% em 2000, correspondendo a cerca de 46 jovens e 8 idosos para cada 100 pessoas da PIA. O índice de idosos, ou seja, a razão de idosos em relação aos jovens, triplicou nesse período, passando de 6,4 para 18,3. As projeções indicam que, a partir 
de 2000, a RDT deve manter-se relativamente estável até 2050, mas com uma importante mudança progressiva em sua composição, praticamente igualando-se nesse ano a razão de dependência de idosos $(29,7)$ e a de jovens $(28,2)$.

Tabela 4 - Razão de dependência total, de jovens e de idosos (\%), índice de idosos e idade mediana. Brasil - 1950 - 2050

\begin{tabular}{l|ccc|c|c}
\hline \multirow{2}{*}{ Período } & \multicolumn{3}{|c|}{ Razão de dependência } & \multirow{2}{*}{$\begin{array}{c}\text { Índice de } \\
\text { Idosos }\end{array}$} & $\begin{array}{c}\text { Idade } \\
\text { mediana }\end{array}$ \\
\cline { 2 - 3 } 1950 & TOTAL & Jovens & Idosos & 5,8 & 19,2 \\
1960 & 79,1 & 74,7 & 4,4 & 6,4 & 18,6 \\
1970 & 83,0 & 78,0 & 5,0 & 7,5 & 18,6 \\
1980 & 82,3 & 76,6 & 5,7 & 10,5 & 20,3 \\
1990 & 73,0 & 66,1 & 6,9 & 12,3 & 22,5 \\
2000 & 65,8 & 58,6 & 7,2 & 18,3 & 25,3 \\
2010 & 54,4 & 46,0 & 8,4 & 24,9 & 28,5 \\
2020 & 50,7 & 40,6 & 10,1 & 36,3 & 31,9 \\
2030 & 48,8 & 35,8 & 13,0 & 57,1 & 34,7 \\
2040 & 50,2 & 31,9 & 18,2 & 79,1 & 37,6 \\
2050 & 53,0 & 29,6 & 23,4 & 105,6 & 40,3 \\
\hline
\end{tabular}

Fonte: IBGE. Censos Demográficos de 1950, 1960 e 1970; IBGE/Diretoria de Pesquisas. Coordenação de População e Indicadores Sociais. Gerência de Estudos e Análises da Dinâmica Demográfica, 2004.

In: Brito, F. A Transição Demográfica no Brasil: as possibilidades e os desafios para a economia e a sociedade. Belo Horizonte: Cedeplar/UFMG, 2007.

Os demógrafos têm chamado a atenção para a necessidade de estabelecer políticas sociais e de emprego que aproveitem as oportunidades demográficas relacionadas com a queda na RDT e sua estabilidade entre 2010 e 2030. Nesse período, para 100 pessoas da PIA, teremos 50 jovens e idosos dependentes, com predomínio dos jovens, ou seja, uma relação de uma pessoa dependente para cada duas potencialmente produtivas. Um vez mais, vale o alerta de que essas políticas devem levar em conta que as oportunidades e desafios demográficos variam segundo as condições econômicas e sociais dos diversos grupos da população. Na Tabela 5 , pode-se observar que as razões de dependência e índice de idosos no ano 2000 são bastante diferentes de acordo com os níveis de renda familiar per capita. No grupo mais pobre, para cada 100 pessoas da PIA havia 82 dependentes, ao passo que no mais rico, para as mesmas 100 pessoas, havia 31 dependentes, 51 a menos. A composição dos dependentes é também bastante diferente, pois ao contrário da razão de dependência de jovens, a de idosos cresce com a renda. Dos 82 dependentes para cada 100 da PIA entre os mais pobres, 76 eram jovens e 6 eram idosos, ao passo que dos 31 dependentes dos grupos de maior renda, 17 eram jovens e 14 idosos, sendo a diferença no índice de idosos entre os dois grupos superior a dez vezes. 
Tabela 5 - Razão de dependência total, de jovens e de idosos e índice de idosos, segundo renda familiar per capita em salários mínimos. Brasil - 2000

\begin{tabular}{c|ccc|c}
\hline \multirow{2}{*}{$\begin{array}{c}\text { Renda familiar } \\
\text { per capita } \\
\text { (em salários mínimos) }\end{array}$} & \multicolumn{3}{|c|}{ Razão de dependência } & \multirow{2}{*}{$\begin{array}{c}\text { Índice de } \\
\text { idosos }\end{array}$} \\
\cline { 2 - 3 } & TOTAL & Jovens & Idosos & \\
\hline 0 a 0,5 & 82,2 & 76,2 & 5,9 & 7,8 \\
0,5 a 1 & 59,9 & 47,6 & 12,4 & 26,0 \\
1 a 2 & 43,1 & 34,3 & 8,8 & 25,8 \\
2 a 3 & 35,5 & 26,3 & 9,2 & 35,0 \\
3 a 5 & 34,1 & 24,5 & 9,7 & 39,5 \\
5 a 10 & 32,3 & 21,8 & 10,5 & 48,0 \\
$10+$ & 30,9 & 16,9 & 14,0 & 83,3 \\
BRASIL & 54,37 & 45,97 & 8,41 & 18,28 \\
\hline
\end{tabular}

Fonte: IBGE. Censos Demográficos de 2000

In: Brito, F. A Transição Demográfica no Brasil: as possibilidades e os desafios para a economia e a sociedade. Belo Horizonte: Cedeplar/UFMG, 2007.

\section{Crescimento Econômico e Distribuição de Renda}

As quatro décadas entre 1960 e 2000 também foram marcadas por importantes transformações econômicas. Segundo o Ipeadata, o PIB per capita passou de 2.060 dólares, em 1960, para 5.250, em 2000, e 5.720 em 2006 (em valores constantes do dólar de 2006), com forte crescimento entre 60 e 80 , cerca de $7,45 \%$ ao ano, e um crescimento menos intenso de cerca de $2,58 \%$ ao ano entre 80 e 2000. A agropecuária, responsável por $25 \%$ do PIB em 1960, teve sua participação reduzida para 8,9 \% em 2004, enquanto que a indústria, que correspondia a $18 \%$ do PIB em 1960, passou a responder por 42\% em 2004. Nesse período, a agropecuária teve um crescimento de $209 \%$ e a indústria cresceu $1.727 \%$.

Entretanto, esse extraordinário aumento da riqueza produzida e a modernização da economia não significaram melhoria na distribuição de renda. Segundo dados do censo, no ano 2000, cerca de $30 \%$ da população tinha uma renda familiar per capita menor que meio salário mínimo e 75\% uma renda familiar per capita menor que dois salários mínimos, situando-se no outro extremo 3\% da população com uma renda familiar per capita superior a 10 salários mínimos.

O Índice de Gini mostra uma piora da distribuição de renda, entre 1960 e 1991, com pequena melhoria em 2000 (Tabela 6). 
Tabela 6 - Índice de Gini, por ano, para renda familiar per capita das pessoas com 10 anos e mais. Brasil - 1960 - 2000

\begin{tabular}{c|c}
\hline Anos & Índice de Gini \\
\hline 1960 & 0,50 \\
1970 & 0,56 \\
1980 & 0,59 \\
1991 & 0,64 \\
2000 & 0,61 \\
\hline
\end{tabular}

Fonte: Ribeiro e Scalon, 2007

A Tabela 7 apresenta dados atualizados que mostram as grandes disparidades ainda existentes em indicadores de emprego e distribuição de renda por região e por cor da pele. Vale notar que, em 2006, cerca de $23 \%$ das famílias na Região Nordeste tinham uma renda per capita inferior a até um quarto do salário mínimo, enquanto esse percentual era de 5,5\% na Região Sul. Da mesma forma, a proporção de pobres na população nordestina, em 2005 , era cerca de três vezes maior que a do Sul.

A Tabela 8, também com dados atualizados de 2006, mostra a proporção de famílias nas diferentes classes de rendimento mensal familiar domiciliar total, segundo situação do domicílio (urbano, rural) e região. Observam-se, em todas as regiões, as grandes diferenças na proporção de famílias por classes de rendimento, de acordo com a situação urbano/rural, em prejuízo destas últimas. Há também grandes diferenças entre as regiões, situando-se o Sul e o Nordeste nos dois extremos. Cerca de 55\% das famílias urbanas no Sul residem em domicílios com renda total acima de três salários mínimos, ao passo que, no Nordeste, esta proporção é praticamente a metade $(26,3 \%)$. 
Tabela 7 - Indicadores econômicos, segundo região. Brasil

\begin{tabular}{|c|c|c|c|c|c|c|}
\hline \multirow{2}{*}{ Indicadores * } & \multicolumn{5}{|c|}{ Região } & \multirow{2}{*}{ BRASIL } \\
\hline & Norte & Nordeste & $\begin{array}{c}\text { Centro- } \\
\text { Oeste }\end{array}$ & Sudeste & Sul & \\
\hline $\begin{array}{l}\text { 1. População total e \% em } \\
\text { relação à população total do } \\
\text { país, } 2007\end{array}$ & $\begin{array}{c}15.342 .522 \\
(8,1 \%)\end{array}$ & $\begin{array}{c}52.193 .889 \\
(27,6 \%)\end{array}$ & $\begin{array}{c}13.516 .198 \\
(7,1 \%)\end{array}$ & $\begin{array}{c}80.641 .160 \\
(42,6 \%)\end{array}$ & $\begin{array}{c}27.641 .418 \\
(14,6 \%)\end{array}$ & $\begin{array}{c}189.335 .187 \\
(100,0 \%)\end{array}$ \\
\hline $\begin{array}{l}\text { 2. PIB per capita (em reais), } \\
2004\end{array}$ & $6.499,35$ & $4.926,86$ & $10.392,95$ & $12.539,04$ & $12.080,40$ & $9.728,83$ \\
\hline $\begin{array}{l}\text { 3. Índice de Gini da } \\
\text { distribuição do rendimento } \\
\text { mensal das pessoas de } 10 \\
\text { anos ou mais de idade com } \\
\text { rendimento, } 2006\end{array}$ & 0,508 & 0,556 & 0,558 & 0,529 & 0,510 & 0,547 \\
\hline $\begin{array}{l}\text { 4. Percentual de famílias por } \\
\text { classes de renda familiar per } \\
\text { capita**, 2006: }\end{array}$ & & & & & & \\
\hline Sem rendimento $* * *$ & 4,1 & 3,2 & 2,4 & 2,2 & 1,6 & 2,5 \\
\hline Até $1 / 4$ salário mínimo & 12,0 & 19,6 & 5,1 & 3,8 & 3,9 & 8,6 \\
\hline Mais de 5 salários mínimos & 2,6 & 2,5 & 6,9 & 7,5 & 6,6 & 5,7 \\
\hline $\begin{array}{l}\text { 5. Proporção (\%) de pobres, } \\
2005\end{array}$ & 46,2 & 56,5 & 27,9 & 21,4 & 19,9 & 33,4 \\
\hline \multicolumn{7}{|l|}{$\begin{array}{l}\text { 6. Proporção (\%) de pobres, } \\
\text { por cor da pele, 2005: }\end{array}$} \\
\hline Branca & 35,9 & 47,5 & 20,5 & 15,3 & 17,0 & 22,1 \\
\hline Preta & 44,8 & 56,2 & 32,0 & 27,7 & 28,0 & 37,8 \\
\hline Parda & 49,8 & 60,8 & 33,6 & 31,0 & 33,7 & 46,0 \\
\hline $\begin{array}{l}\text { 7. Taxa de desemprego ( } 10 \\
\text { anos ou mais de idade), } 2005\end{array}$ & 7,9 & 9,0 & 9,6 & 10,9 & 6,1 & 9,3 \\
\hline \multicolumn{7}{|l|}{$\begin{array}{l}\text { 8. Taxa de desemprego ( } 10 \\
\text { anos ou mais de idade), por } \\
\text { cor da pele, } 2005 \text { : }\end{array}$} \\
\hline Branca & 7,7 & 8,0 & 8,1 & 9,7 & 5,6 & 8,2 \\
\hline Preta & 8,8 & 13,4 & 12,0 & 12,3 & 10,1 & 12,3 \\
\hline Parda & 7,9 & 8,9 & 10,7 & 12,7 & 8,2 & 10,2 \\
\hline
\end{tabular}

* A fonte do indicador número 1 é a Estimativa Populacional do IBGE para o ano de 2007; o indicador 3 é oriundo da PNAD, 2006 - IBGE. Os demais indicadores têm como fonte o IDB 2006 (Indicadores e Dados Básicos), produto da ação integrada do Ministério da Saúde e da Organização Pan-Americana da Saúde (Opas), no âmbito da Rede Interagencial de Informações para a Saúde (Ripsa).

** Exclusive o rendimento das pessoas cuja condição na família era pensionista, empregado doméstico ou parente do empregado doméstico.

*** A categoria "Sem rendimento" inclui as famílias cujos componentes receberam somente benefícios. 
Tabela 8 - Proporção (\%) de famílias residentes em domicílios particulares, por classes de rendimento mensal familiar domiciliar, segundo situação do domicílio e região. Brasil - 2006

\begin{tabular}{|c|c|c|c|c|c|}
\hline \multirow{2}{*}{$\begin{array}{l}\text { Situação do domicílio e classe } \\
\text { de rendimento }{ }^{(1)}\end{array}$} & \multicolumn{5}{|c|}{ Região } \\
\hline & Norte & Nordeste & $\begin{array}{l}\text { Centro- } \\
\text { Oeste }\end{array}$ & Sudeste & Sul \\
\hline \multicolumn{6}{|l|}{ Sem rendimento ${ }^{(2)}$} \\
\hline Urbana & 4,1 & 3,2 & 2,4 & 2,1 & 1,5 \\
\hline Rural & 3,9 & 3,1 & 2,4 & 2,4 & 1,9 \\
\hline \multicolumn{6}{|l|}{ Até 1 salário mínimo } \\
\hline Urbana & 15,9 & 23,9 & 10,9 & 8,3 & 7,7 \\
\hline Rural & 24,1 & 40,7 & 18,3 & 16,8 & 13,5 \\
\hline \multicolumn{6}{|l|}{ Mais de 1 a 3 salários mínimos } \\
\hline Urbana & 45,8 & 45,6 & 40,0 & 35,4 & 35,6 \\
\hline Rural & 52,6 & 46,3 & 54,4 & 52,5 & 47,4 \\
\hline \multicolumn{6}{|l|}{ Mais de 3 a 5 salários mínimos } \\
\hline Urbana & 16,3 & 12,5 & 18,2 & 20,7 & 22,2 \\
\hline Rural & 11,4 & 6,5 & 14,0 & 17,1 & 19,7 \\
\hline \multicolumn{6}{|l|}{ Mais de 5 salários mínimos } \\
\hline Urbana & 17,3 & 13,8 & 27,4 & 30,3 & 32,1 \\
\hline Rural & 6,7 & 2,2 & 9,6 & 9,0 & 16,4 \\
\hline
\end{tabular}

(1) Exclusive os rendimentos dos moradores de 10 anos de idade e dos moradores cuja condição no domicílio era pensionista, empregado doméstico ou parente do empregado.

(2) Inclusive as pessoas que receberam somente em benefícios.

Fonte: elaboração própria, a partir da Pesquisa Nacional por Amostra de Domicílios (Pnad) 2006. Instituto Brasileiro de Geografia e Estatística (IBGE).

Também no caso de idosos existem enormes diferenciais de renda. O Gráfico 9 mostra a distribuição percentual de pessoas com 65 anos ou mais de idade por classes de rendimento médio mensal domiciliar per capita, observando-se, por exemplo, que no Nordeste $68 \%$ dos idosos residem em domicílios com renda familiar per capita menor que um salário mínimo, enquanto no Sul e no Sudeste este percentual está abaixo dos 35\%.

Mesmo com as melhorias recentes na distribuição de renda - relacionadas ao controle da inflação e estabilidade macroeconômica proporcionadas pelo Plano Real, à valorização do salário mínimo e aos programas de transferência de renda intensificados nos últimos anos -, a distribuição de renda no Brasil continua entre as piores do mundo. Com base em um Índice de Gini de 0,57 em 2003, o relatório do Pnud de 2007 situa o Brasil em $11^{\circ}$ lugar entre os países com mais alta concentração de renda (em 2006, o Índice de Gini caiu para 0,54). Conforme pode ser observado no Gráfico 10, há uma melhoria na razão de renda, ou seja, no número de vezes que a renda dos $20 \%$ mais ricos supera a dos $20 \%$ mais pobres, embora em 2005 a renda dos $20 \%$ mais ricos seja ainda cerca de 22 vezes maior do que a renda dos $20 \%$ mais pobres. 
Gráfico 9 - Distribuição percentual de pessoas com 65 anos ou mais de idade, residentes em domicílios particulares, por classes de rendimento médio mensal domiciliar per capita, segundo as grandes regiões. Brasil - 2006

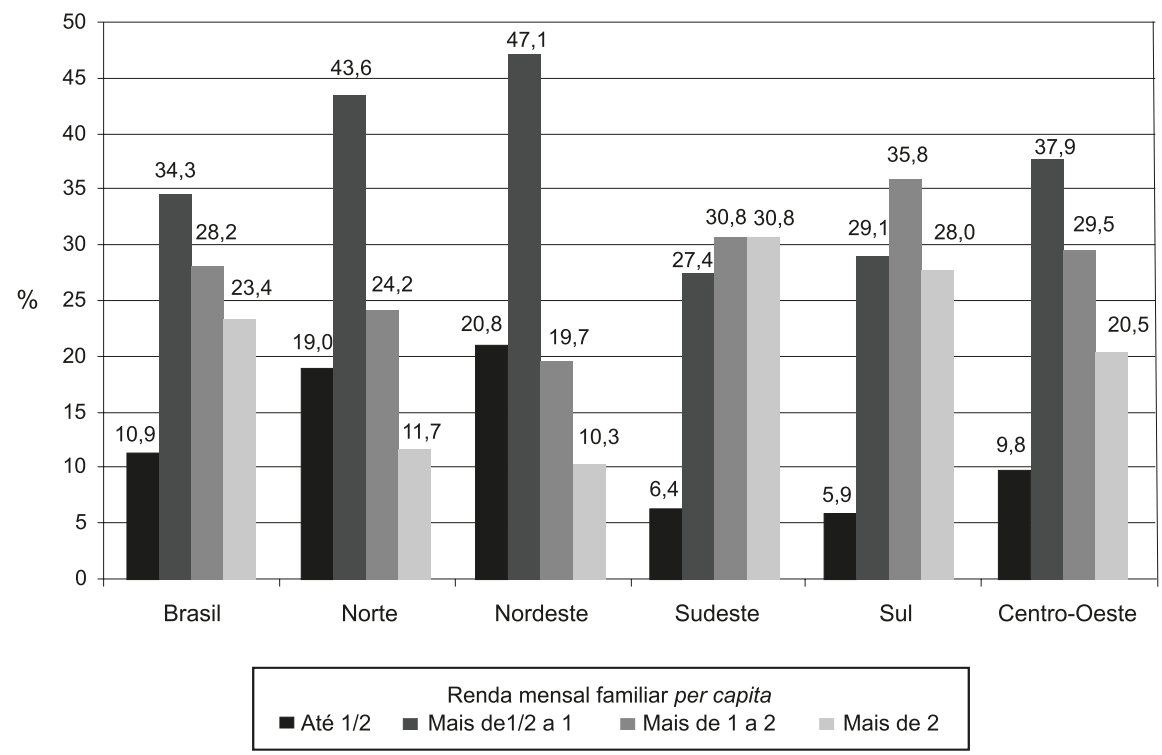

Fonte: Pesquisa Nacional por Amostra de Domicílios 2006. Instituto Brasileiro de Geografia e Estatística (IBGE).

Gráfico 10 - Razão de renda (n. de vezes que a renda dos $20 \%$ mais ricos supera a dos $20 \%$ mais pobres) por ano e região. Brasil - 1993, 1999, 2005

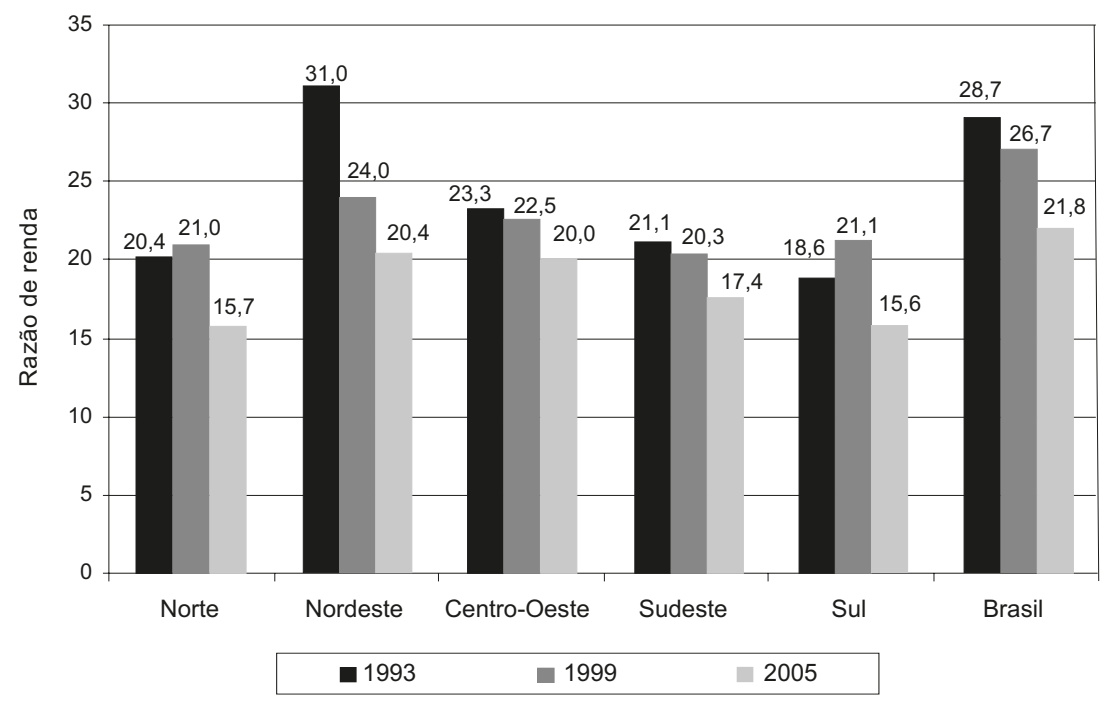

Obs.: Até o ano de 2003, informações não disponíveis para a área rural de RO, AC, AM, RR, PA e AP.

Fonte: IDB 2006 (Indicadores e Dados Básicos), produto da ação integrada do Ministério da Saúde e da Organização Pan-Americana da Saúde (Opas), no âmbito da Rede Interagencial de Informações para a Saúde (Ripsa). 


\section{Desenvolvimento Social: educação e saúde}

$\mathrm{Na}$ esfera do desenvolvimento social, ocorreram também grandes mudanças nas últimas décadas, destacando-se, entre elas, as ocorridas na educação. Conforme observado no Gráfico 11, em 1940, 56\% da população brasileira era analfabeta, percentual que cai para $40 \%$ em 1960 e $13,6 \%$ no ano 2000.

Gráfico 11 - Evolução temporal da taxa de analfabetismo por década. Brasil - 1940 - 2000

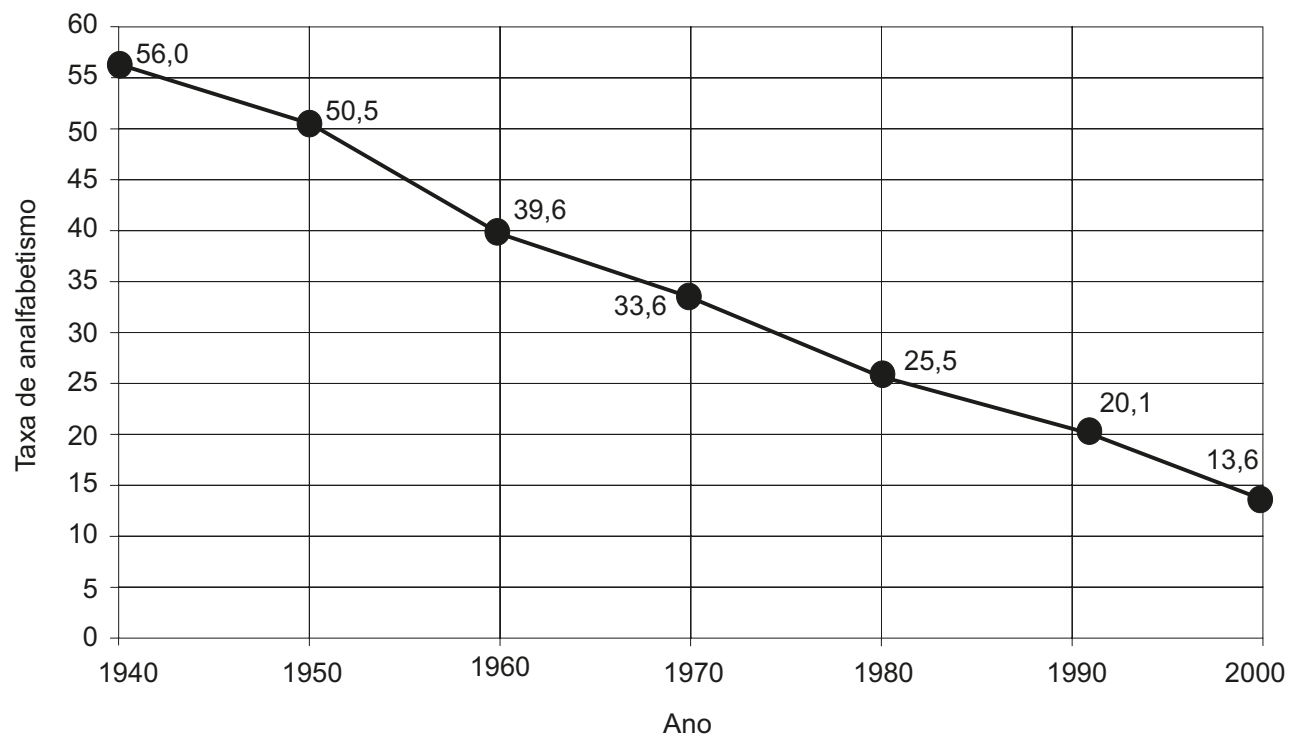

Fonte: IETS - Instituto de Estudos do Trabalho e Sociedade, a partir dos Censos Demográficos.

Segundo a Pnad, em 2006, havia 12,3\% de analfabetos entre as pessoas com 5 ou mais anos de idade, observando-se, entretanto, importantes diferenças regionais, já que este percentual na Região Sul era de $7,6 \%$, enquanto no Nordeste era de $22,10 \%$. Há, também, importantes diferenças de acordo com a renda familiar. Ainda segundo a Pnad 2006, a média de 10,4\% de analfabetos entre as pessoas com 15 ou mais anos de idade variava de $17,9 \%$ para as pessoas com rendimento mensal familiar per capita menor que meio salário mínimo até 1,3\% para as pessoas com mais de dois salários mínimos. Estas diferenças segundo renda estão também presentes no interior das regiões, sendo que, na Região Nordeste, a média de 20,8\% de analfabetos variava de $24,9 \%$ para as pessoas com menos de $1 / 2$ salário mínimo de renda mensal familiar per capita, até 1,9\% para as com mais de dois salários mínimos, enquanto na Região Sul a média de 5,7\% de analfabetos variava de 10,4\% para menos de meio salário até $1,1 \%$ para mais de dois salários. Estes e outros dados se encontram na Tabela 9. 
Tabela 9 - Pessoas de 15 anos ou mais de idade, analfabetas, total e taxa de analfabetismo, por classes de rendimento mensal familiar per capita, segundo as grandes regiões. Brasil -2006

\begin{tabular}{|c|c|c|c|c|c|c|}
\hline \multirow{3}{*}{ Grandes regiões } & \multicolumn{6}{|c|}{ Pessoas de 15 anos ou mais de idade, analfabetas } \\
\hline & \multirow{2}{*}{$\begin{array}{c}\text { TOTAL } \\
\text { (1000 pessoas) }\end{array}$} & \multicolumn{5}{|c|}{$\begin{array}{l}\text { Taxa de analfabetismo, por classes de rendimento familiar } \\
\text { per capita (salários mínimos) (\%) }\end{array}$} \\
\hline & & TOTAL & Até $1 / 2$ & $\begin{array}{l}\text { Mais de } \\
1 / 2 \text { a } 1\end{array}$ & $\begin{array}{l}\text { Mais de } \\
1 \text { a } 2\end{array}$ & Mais de 2 \\
\hline Brasil & 14.391 & 10,4 & 17,9 & 13,7 & 6,5 & 1,3 \\
\hline Norte & 1.142 & 11,3 & 15,1 & 13,1 & 6,8 & 2,4 \\
\hline Nordeste & 7.595 & 20,8 & 24,9 & 23,7 & 13,5 & 1,9 \\
\hline Sudeste & 3.667 & 6,0 & 10,1 & 9,5 & 5,1 & 1,2 \\
\hline Sul & 1.179 & 5,7 & 10,4 & 8,8 & 4,6 & 1,1 \\
\hline Centro-Oeste & 808 & 8,3 & 12,7 & 11,7 & 6,6 & 1,4 \\
\hline
\end{tabular}

Fonte: Pesquisa Nacional por Amostra de Domicílios 2006. Instituto Brasileiro de Geografia e Estatística (IBGE).

A taxa de analfabetismo, que no Nordeste é cerca de quatro vezes maior do que na Região Sul, também varia no interior das regiões de acordo com sexo, cor da pele e local de moradia, como pode ser observado na Tabela 10.

Estas diferenças tendem a se reproduzir, pois de acordo com o relatório do Unicef de 2006 sobre a situação da infância brasileira, os filhos de mulheres brasileiras com até um ano de escolaridade têm uma probabilidade 23 vezes maior de chegarem analfabetos à adolescência se comparados com os filhos de mulheres com 11 anos ou mais de estudo.

De acordo com o Instituto Nacional de Estudos e Pesquisas do Ministério da Educação (Inep/ MEC), a taxa de escolarização líquida, ou seja, o percentual da população de determinada faixa etária matriculada no nível de ensino adequado, cresceu no caso do ensino fundamental para todo o Brasil de 80\% em 1980 para 94,3\% em 2000. Há uma tendência à diminuição das diferenças regionais, já que a Região Nordeste, que apresenta o menor percentual, cresceu de 69,1\% em 1980 para 92,8 em 2000, e a Região Sudeste, com o maior percentual, cresceu de $89,2 \%$ para $96,1 \%$. No caso do ensino médio, embora a taxa de escolarização líquida permaneça bem mais baixa, observa-se também uma tendência de crescimento dessa taxa acompanhada de diminuição das ainda grandes diferenças regionais. Para o Brasil como um todo, o percentual cresceu de 14,3 \% em 1980 para 33,3\% em 2000, sendo que para a Região Nordeste cresceu de 6,5\% a 16,7\% no mesmo período e na Região Sudeste de 20,3\% para 45,6\%. 
Tabela 10 - Taxas de analfabetismo segundo sexo, cor da pele e local de moradia, por região. Brasil - 2005

\begin{tabular}{|c|c|c|c|c|c|c|}
\hline \multirow[b]{2}{*}{ Indicadores * } & \multicolumn{5}{|c|}{ Região } & \multirow[b]{2}{*}{ BRASIL } \\
\hline & Norte & Nordeste & $\begin{array}{l}\text { Centro- } \\
\text { Oeste }\end{array}$ & Sudeste & Sul & \\
\hline $\begin{array}{l}\text { 1. Taxa de analfabetismo } \\
\text { (15 anos ou mais de idade), } 2005\end{array}$ & 11,6 & 21,9 & 8,9 & 6,6 & 5,9 & 11,1 \\
\hline \multicolumn{7}{|l|}{$\begin{array}{l}\text { 2. Taxa de analfabetismo } \\
\text { ( } 15 \text { anos ou mais de idade), } \\
\text { por sexo, 2005: }\end{array}$} \\
\hline Feminino & 10,4 & 20,0 & 9,1 & 7,2 & 6,5 & 10,8 \\
\hline Masculino & 12,8 & 24,0 & 8,7 & 5,8 & 5,2 & 11,3 \\
\hline \multicolumn{7}{|l|}{$\begin{array}{l}\text { 3. Taxa de analfabetismo } \\
\text { ( } 15 \text { anos ou mais de idade), por } \\
\text { cor da pele, 2005: }\end{array}$} \\
\hline Branca & 7,4 & 17,6 & 6,6 & 4,9 & 4,7 & 7,0 \\
\hline Preta & 14,9 & 23,2 & 12,8 & 10,3 & 11,0 & 14,6 \\
\hline Parda & 12,8 & 23,8 & 10,5 & 8,8 & 11,5 & 15,6 \\
\hline \multicolumn{7}{|l|}{$\begin{array}{l}\text { 4. Taxa de analfabetismo } \\
\text { ( } 15 \text { anos ou mais de idade), por } \\
\text { situação, 2005: }\end{array}$} \\
\hline Urbana & 8,9 & 16,4 & 7,9 & 5,7 & 5,1 & 8,4 \\
\hline Rural & 20,0 & 36,4 & 15,4 & 17,2 & 9,8 & 25,0 \\
\hline
\end{tabular}

* Os indicadores têm como fonte o IDB 2006 (Indicadores e Dados Básicos), produto da ação integrada do Ministério da Saúde e da Organização Pan-Americana da Saúde (Opas), no âmbito da Rede Interagencial de Informações para a Saúde (Ripsa).

A Pnad 2006 mostra o extraordinário avanço da escolaridade no nível fundamental com cobertura quase universal entre 7 a 14 anos em todas as regiões, tanto na área urbana como rural. No caso do ensino médio, a taxa de freqüência líquida entre 15 a 17 anos ainda é bastante baixa para o Brasil como um todo, com grandes variações segundo região e segundo situação do domicílio, conforme mostra a Tabela 11.

Há importantes diferenças na média de anos de estudo das pessoas com 25 ou mais anos de idade de acordo com o rendimento mensal familiar per capita. Conforme se observa na Tabela 12 e no Gráfico 12, com dados da Pnad 2006, há um claro gradiente de anos de estudo conforme rendimento familiar no Brasil e nas diversas regiões. Tanto nas regiões com menor como naquelas com maior escolaridade, há uma diferença de cerca de seis anos na média de anos de estudo entre as pessoas situadas nos dois quintis extremos. 
Tabela 11 - Taxa de freqüência líquida a estabelecimento de ensino das pessoas de 7 a 17 anos de idade, por nível de ensino, grupos de idade e situação do domicílio (\%). Brasil - 2006

\begin{tabular}{l|ccc|ccc}
\hline \multirow{2}{*}{$\begin{array}{l}\text { Grandes } \\
\text { regiões }\end{array}$} & \multicolumn{3}{|c|}{ Fundamental } & \multicolumn{3}{c}{ Médio } \\
\cline { 2 - 7 } & \multicolumn{3}{|c}{ 7 a 14 anos } & \multicolumn{3}{c}{ 15 a 17 anos } \\
\cline { 2 - 7 } & TOTAL & Urbana & Rural & TOTAL & Urbana & Rural \\
\hline \multirow{2}{*}{ Brasil } & 94,8 & 95,3 & 93,0 & 47,1 & 51,9 & 26,9 \\
Norte & 93,7 & 94,2 & 92,4 & 34,7 & 40,8 & 17,4 \\
Sudeste & 93,4 & 93,9 & 92,3 & 33,1 & 40,6 & 17,6 \\
Sul & 95,7 & 95,9 & 93,6 & 57,9 & 59,6 & 40,6 \\
Centro-Oeste & 96,1 & 96,4 & 94,7 & 54,9 & 55,8 & 50,4 \\
\hline
\end{tabular}

Fonte: Pesquisa Nacional por Amostra de Domicílios 2006. Instituto Brasileiro de Geografia e Estatística (IBGE).

Tabela 12 - Média de anos de estudo das pessoas de 25 anos ou mais de idade, por quintis de rendimento mensal familiar per capita, segundo as grandes regiões. Brasil - 2006

\begin{tabular}{|c|c|c|c|c|c|c|}
\hline \multirow{2}{*}{$\begin{array}{l}\text { Grandes } \\
\text { Regiões }\end{array}$} & \multirow{2}{*}{ TOTAL } & \multicolumn{5}{|c|}{ Quintis de rendimento mensal familiar per capita } \\
\hline & & 10 & 20 & 30 & 40 & 50 \\
\hline BRASIL & 6,7 & 3,9 & 5,0 & 5,5 & 6,7 & 10,2 \\
\hline Norte & 6,2 & 3,9 & 5,0 & 5,2 & 6,0 & 9,0 \\
\hline Nordeste & 5,2 & 2,9 & 3,8 & 4,4 & 4,9 & 8,1 \\
\hline Sudeste & 7,4 & 5,0 & 5,7 & 6,0 & 7,6 & 10,8 \\
\hline Sul & 7,1 & 4,7 & 5,7 & 5,9 & 7,3 & 10,4 \\
\hline Centro-Oeste & 6,9 & 4,7 & 5,1 & 5,3 & 7,1 & 10,6 \\
\hline
\end{tabular}


Gráfico 12 - Média de anos de estudo das pessoas de 25 anos ou mais de idade, por quintis de rendimento mensal familiar per capita. Brasil - 2006

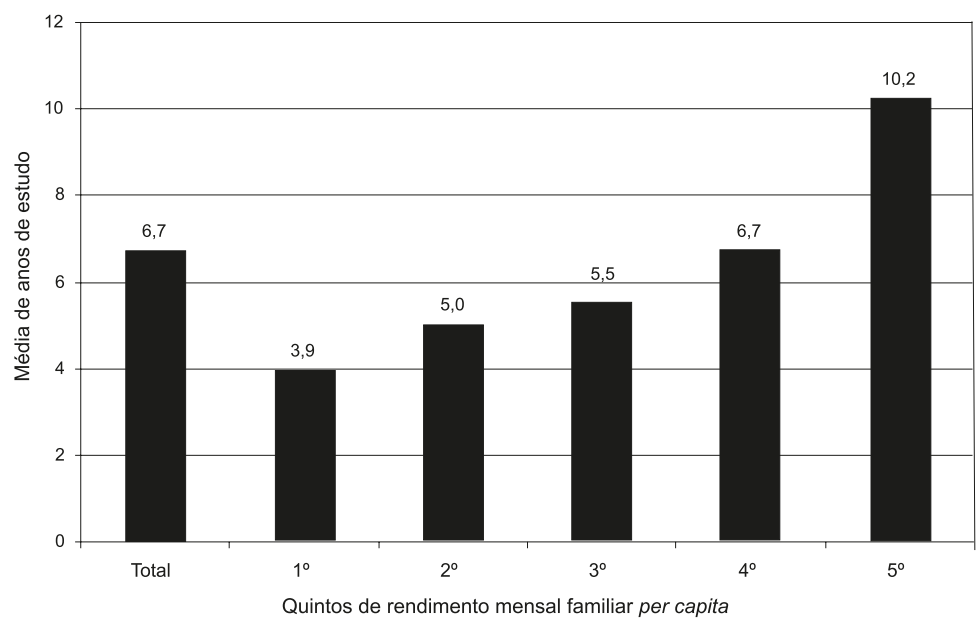

Fonte: Pesquisa Nacional por Amostra de Domicílios 2006. Instituto Brasileiro de Geografia e Estatística (IBGE).

As diferenças em escolaridade também são marcantes de acordo com a cor da pele. Segundo dados da Pnad 2006, a taxa de analfabetismo e analfabetismo funcional de pretos e pardos é cerca do dobro da observada nos brancos. Por sua vez, a proporção de pessoas de cor branca com 25 anos ou mais de idade com 15 ou mais anos de estudo é três vezes maior do que a encontrada entre pretos e pardos, como mostra a Tabela 13.

Tabela 13 - Escolaridade segundo cor da pele. Brasil - 2006

\begin{tabular}{l|c|ccc}
\hline \multicolumn{1}{c|}{ BRASIL } & TotAL & Branca & Preta & Parda \\
\hline Analfabetos (\%) & 10,4 & 6,5 & 14,1 & 14,7 \\
Analfabetos funcionais (\%) & 22,2 & 16,4 & 27,5 & 28,6 \\
$\begin{array}{l}\text { Média de anos de estudo } \\
\text { \% pessoas com 25 ou + anos } \\
\begin{array}{l}\text { de idade com 15 ou + anos } \\
\text { de estudo }\end{array}\end{array}$ & 7,2 & 8,1 & 6,4 & 6,2 \\
\hline
\end{tabular}

Fonte: Pesquisa Nacional por Amostra de Domicílios 2006. Instituto Brasileiro de Geografia e Estatística (IBGE).

A Pnad 2006 também mostra a distribuição dos estudantes da rede pública e privada no ensino médio e superior. Conforme pode ser observado na Tabela 14, no caso do ensino médio público, tanto para o Brasil como um todo como para as diversas regiões predominam os estudantes pertencentes ao $2^{\circ}, 3^{\circ}$, e $4^{\circ}$ quintis de renda, com baixa participação dos quintis extremos de menor e maior renda. O mesmo não ocorre no caso do ensino superior público, onde há um gradiente ascendente segundo o nível de renda, com forte predominância dos estudantes pertencentes ao quintil de renda mais alta. Estes dados indicam que embora o ensino público cumpra um papel compensatório no ensino médio, privilegiando as classes 
menos favorecidas, o mesmo não ocorre no ensino superior, onde as desigualdades sociais são reproduzidas e fortalecidas, pois quanto maior a renda maior o acesso ao ensino superior público em todas as regiões. No caso da rede particular, tanto para o ensino médio como para o ensino superior há um gradiente que acompanha o perfil de renda, com forte predominância do quintil de maior renda.

Tabela 14 - Estudantes da rede pública e da rede particular, por nível de ensino freqüentado, total e respectiva distribuição percentual, por quintis de rendimento mensal familiar per capita, segundo as grandes regiões. Brasil - 2006

\begin{tabular}{|c|c|c|c|c|c|c|c|c|c|c|c|c|}
\hline \multirow{4}{*}{$\begin{array}{c}\text { Grandes } \\
\text { regiões }\end{array}$} & \multicolumn{12}{|c|}{ Estudantes da Rede Pública } \\
\hline & \multicolumn{6}{|c|}{ Ensino médio } & \multicolumn{6}{|c|}{ Ensino superior } \\
\hline & \multirow[t]{2}{*}{$\begin{array}{c}\text { TOTAL } \\
(1000)\end{array}$} & \multicolumn{5}{|c|}{$\begin{array}{l}\text { Distribuição percentual, } \\
\text { por quintis de } \\
\text { rendimento mensal } \\
\text { familiar per capita }(\%)\end{array}$} & \multirow[t]{2}{*}{$\begin{array}{c}\text { TOTAL } \\
\text { (1000) }\end{array}$} & \multicolumn{5}{|c|}{$\begin{array}{l}\text { Distribuição percentual, } \\
\text { por quintis de } \\
\text { rendimento mensal } \\
\text { familiar per capita (\%) }\end{array}$} \\
\hline & & 10 & 20 & 3은 & 40 & 50 & & 10 & 20 & 3 웅 & 40 & 50 \\
\hline BRASIL & 7043 & 18,3 & 25,5 & 25,8 & 20,7 & 9,7 & 1366 & 1,8 & 6,2 & 11,6 & 26,1 & 54,3 \\
\hline Norte & 641 & 13,2 & 20,1 & 26,1 & 23,6 & 17,0 & 151 & 1,8 & 5,7 & 8,8 & 21,8 & 61,9 \\
\hline Nordeste & 2058 & 14,2 & 21,4 & 27,0 & 24,7 & 12,7 & 388 & 0,6 & 3,0 & 8,8 & 19,1 & 68,5 \\
\hline Sudeste & 2882 & 22,8 & 27,5 & 23,2 & 19,4 & 7,1 & 476 & 2,1 & 5,4 & 10,1 & 24,1 & 58,3 \\
\hline Sul & 954 & 17,6 & 26,7 & 24,8 & 20,6 & 10,2 & 219 & 2,7 & 5,4 & 14,2 & 22,8 & 54,8 \\
\hline $\begin{array}{l}\text { Centro- } \\
\text { Oeste }\end{array}$ & 508 & 17,1 & 23,7 & 24,6 & 23,7 & 10,8 & 131 & 2,6 & 7,8 & 13,5 & 28,3 & 47,8 \\
\hline \multirow{4}{*}{$\begin{array}{c}\text { Grandes } \\
\text { regiões }\end{array}$} & \multicolumn{12}{|c|}{ Estudantes da Rede Particular } \\
\hline & \multicolumn{6}{|c|}{ Ensino médio } & \multicolumn{6}{|c|}{ Ensino superior } \\
\hline & $\begin{array}{c}\text { TOTAL } \\
(1000)\end{array}$ & \multicolumn{5}{|c|}{$\begin{array}{c}\text { Distribuição percentual, } \\
\text { por quintis de } \\
\text { rendimento mensal } \\
\text { familiar per capita }(\%)\end{array}$} & $\begin{array}{l}\text { TOTAL } \\
(1000)\end{array}$ & \multicolumn{5}{|c|}{$\begin{array}{c}\text { Distribuição percentual, } \\
\text { por quintis de } \\
\text { rendimento mensal } \\
\text { familiar per capita }(\%)\end{array}$} \\
\hline & & 10 & 20 & 3은 & $4 \stackrel{\circ}{1}$ & 50 & & 10 & $2 \circ$ & 30 & $4 \stackrel{\circ}{2}$ & 50 \\
\hline BRASIL & 1191 & 2,1 & 6,2 & 11,1 & 20,3 & 60,2 & 4198 & 1,0 & 3,2 & 8,8 & 22,8 & 64,2 \\
\hline Norte & 66 & 1,6 & 6,5 & 11,7 & 14,3 & 65,9 & 209 & 0,7 & 2,3 & 6,1 & 17,3 & 73,6 \\
\hline Nordeste & 287 & 1,6 & 3,7 & 9,9 & 22,1 & 62,6 & 657 & 0,5 & 2,0 & 5,7 & 14,8 & 77,1 \\
\hline Sudeste & 559 & 2,5 & 7,0 & 10,3 & 22,0 & 58,2 & 2190 & 1,5 & 4,6 & 11,1 & 27,3 & 55,5 \\
\hline Sul & 175 & 1,4 & 6,1 & 8,7 & 26,2 & 57,6 & 775 & 1,6 & 5,4 & 10,4 & 25,8 & 57,0 \\
\hline $\begin{array}{l}\text { Centro- } \\
\text { Oeste }\end{array}$ & 104 & 2,8 & 4,1 & 7,6 & 18,8 & 66,7 & 366 & 2,3 & 4,1 & 9,6 & 23,2 & 60,7 \\
\hline
\end{tabular}

(*) Os indicadores têm como fonte o IDB 2006 (Indicadores e Dados Básicos), produto da ação integrada do Ministério da Saúde e da Organização Pan-Americana da Saúde (Opas), no âmbito da Rede Interagencial de Informações para a Saúde (Ripsa). 
Nos últimos anos, houve um extraordinário avanço no número de instituições, assim como de egressos no ensino superior. Segundo o MEC/Inep, em 1980, havia um total de 882 instituições de ensino superior (IES), sendo 77,3\% delas privadas, e em 2004 havia 2.013 IES, com aumento da participação privada para 89\%. Em 1980, concluíram o curso superior 226.423 alunos (64,2\% em instituições privadas), cerca de $0,2 \%$ da população total do país, e em 2005 esse número aumentou para 717.858 alunos (72,8\% em instituições privadas), correspondendo a cerca de $0,4 \%$ da população do país.

Quanto à pós-graduação, também houve um crescimento significativo: segundo a Coordenação de Aperfeiçoamento de Pessoal de Nível Superior, do Ministério da Educação (Capes/MEC), em 1987 houve 4.750 titulados em mestrado e doutorado, 932 dos quais em doutorado (19,6\%), número que cresceu para 40.406 titulados em 2006, 9.192 dos quais em doutorado (22,7\%), um aumento do número anual de titulados doutores de praticamente dez vezes no período. Em 2004, foram titulados 8.856 doutores, cerca de $80 \%$ deles na Região Sudeste. Deste total de 8.856 doutores, 8.000 foram titulados em instituições de ensino públicas, federais e estaduais e 856 em instituições privadas. Vale notar que as instituições estaduais foram responsáveis pela titulação de 4.076 doutores entre os 8.000 titulados por instituições públicas, sendo quase sua totalidade titulada por instituições estaduais de São Paulo, responsáveis por 3.841 dos 4.076 titulados. O desenvolvimento do ensino superior e da pós-graduação, principalmente em nível de doutorado, se reflete na produção científica. O número de artigos científicos produzidos por autores brasileiros, na base do Institute for Scientific Information (ISI), que registra a literatura científica de maior impacto a nível internacional, pouco mais que duplicou entre 1981 e 1994, enquanto no período seguinte (1994 a 2006) cresceu quase quatro vezes, conforme se observa no Gráfico 13. Entre 1981 e 2006, o número de artigos de autores brasileiros cresceu 795,5\%, bem acima dos Estados Unidos, Reino Unido e Alemanha, por exemplo, que cresceram, respectivamente, $66,2 \%, 95,1 \%$ e $112,7 \%$.

Esse importante crescimento do número de artigos publicados por autores brasileiros, com impacto internacional, permitiu um significativo aumento do peso relativo da produção científica do país no contexto mundial. Entre 1981 e 1994, a produção científica brasileira oscilava entre 0,5 e 0,9\% da produção mundial e, graças a um crescimento relativo constante a partir de então, atingiu cerca de $2 \%$ da produção mundial em 2006 . No contexto latinoamericano a produção científica de autores brasileiros corresponde hoje a cerca de $50 \%$ de toda a produção da região, conforme se observa no Gráfico 14. 
Gráfico 13 - Brasil: artigos publicados em periódicos científicos indexados no ISI - 1981 - 2006

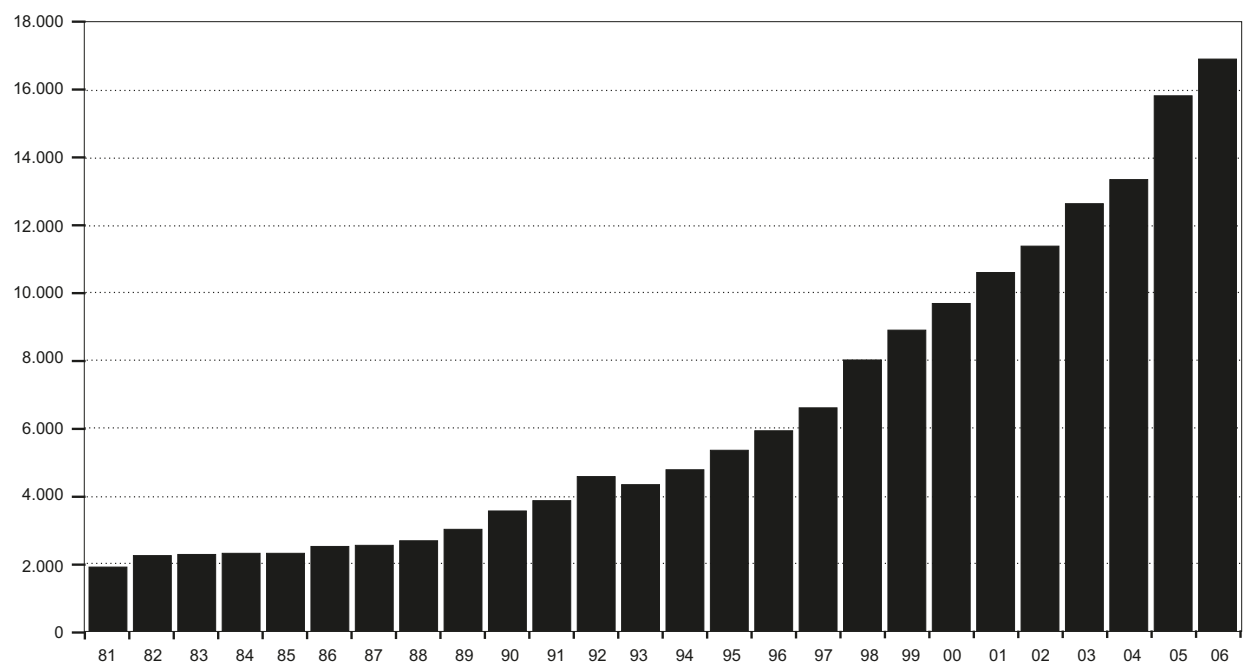

Fonte(s): Institute for Scientific Information (ISI). National Science Indicators. Elaboração: Coordenação-Geral de Indicadores - ASCAV/SEXEC Ministério da Ciência e Tecnologia.

Gráfico 14 - Brasil: percentual de artigos publicados em periódicos científicos indexados no ISI, em relação à América Latina e ao mundo, 1981 - 2006

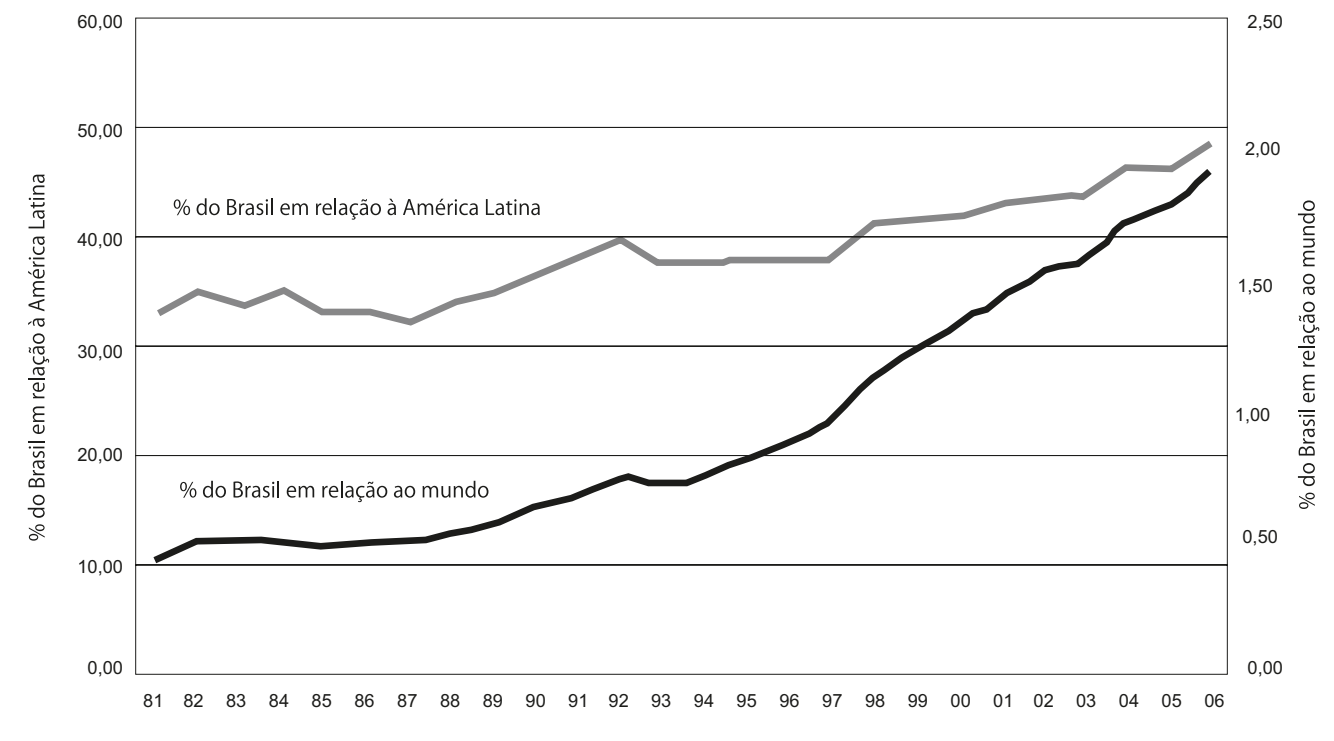

Fonte(s): Institute for Scientific Information (ISI). National Science Indicators. Elaboração: Coordenação-Geral de Indicadores - ASCAV/SEXEC Ministério da Ciência e Tecnologia. 
A exemplo do que ocorre com o ensino de pós-graduação, as atividades científico-tecnológicas estão altamente concentradas. Segundo o Diretório de Grupos de Pesquisa do Conselho Nacional de Desenvolvimento Científico e Tecnológico (CNPq), cerca de 70 a $80 \%$ desses grupos se situam nas regiões Sudeste e Sul, o mesmo ocorrendo para a distribuição de pesquisadores e doutores. Como conseqüência, a produção científica está também bastante concentrada. Os autores das regiões Sudeste e Sul foram responsáveis por cerca de 80\% dos artigos publicados em revistas de circulação nacional e internacional no ano de 2002 . No caso da produção científica em saúde, esta concentração é particularmente prejudicial, já que características epidemiológicas e da organização de serviços específicas de cada região obrigam a existência de uma capacidade instalada de pesquisa local para o estudo destas especificidades.

Além da alta concentração das atividades científico-tecnológicas há uma grande desproporção entre a produção científica expressa pela publicação de artigos e a produção tecnológica expressa pela concessão de patentes, com grande prejuízo desta última, indicando a crônica dificuldade do país para transformar os conhecimentos que produz em inovações e produtos. Além de escassas, as patentes concedidas se limitam praticamente às regióes Sudeste e Sul. Segundo o Instituto Nacional de Propriedade Industrial (Inpi), o número de pedidos de patentes tipo privilégio de invenção feitos por residentes no país foi de apenas 679 no ano 2000, caindo para 389 em 2001, 351 em 2002, 413 em 2003 e 546 em 2004.

Esta debilidade na cadeia pesquisa/inovação/produção, representada pela relativamente baixa concessão de patentes em relação à produção científica, pode ser em parte explicada pela escassa presença de pesquisadores dedicados à pesquisa e desenvolvimento (P\&D) nas empresas. De fato, segundo dados do Ministério da Ciência e Tecnologia (MCT), para 2004, 65,9\% dos pesquisadores envolvidos em P\&D (equivalência de tempo integral) estão vinculados a instituições do ensino superior e apenas $26,3 \%$ a empresas, proporção praticamente inversa à observada em países desenvolvidos.

Quanto ao financiamento das atividades de P\&D, o Brasil mantém uma proporção de gastos em relação ao PIB de pouco mais de $1 \%$. Segundo o IBGE, esta proporção foi de $1,22 \%$ em 2000 e 1,17\% em 2004, bem abaixo dos 3,15\% do Japão, 2,64\% da Coréia, 2,6\% dos Estados Unidos ou 2,5\% da Alemanha, segundo dados da Unesco. Houve um grande avanço nos anos recentes quanto à proporção do gasto total em P\&D proveniente de recursos privados, passando de 23,9\% em 1990 (segundo a Red de Indicadores de Ciencia y Tecnología - RICYT) para 39,71\% em 2000 e 44,55\% em 2004 (MCT). Os gastos públicos correspondentes a 60,29\% em 2000 e 55,45\% em 2004 são em sua maioria (cerca de 70\%) provenientes de recursos federais. Os gastos estaduais correspondem a cerca de $30 \%$ dos gastos públicos, sendo que $70 \%$ dos gastos estaduais correspondem a três estados: São Paulo $(48,9 \%)$, Paraná $(12,4 \%)$ e Rio de Janeiro (8,8\%).

Os importantes avanços e contradições no desenvolvimento econômico-social das últimas décadas são também observados na situação de saúde. Segundo o IBGE, a taxa de mortalidade infantil (TMI) que era de 124 óbitos no primeiro ano de vida para cada mil nascidos vivos em 
1960, caiu para 48,3 em 1990, 35,26 em 2000 e 25,1 em 2006. O declínio médio anual da TMI, que se mantinha em $1 \%$ ao ano (aa) desde 1940 , cresce para 1,5\% aa entre 1965/1975, para $4,5 \%$ aa entre $1975 / 85$ e se mantém em cerca de $2,6 \%$ aa, desde então, com ligeira queda nos últimos anos.

O Gráfico 15 mostra a evolução da TMI de 1960 a 2006 para o Brasil e regiões, mantendo-se a Região Nordeste como a que apresenta as mais altas taxas em todo o período e a Região Sul com as menores taxas.

Gráfico 15 - Evolução da mortalidade infantil. Brasil e regiões - 1960 - 2006

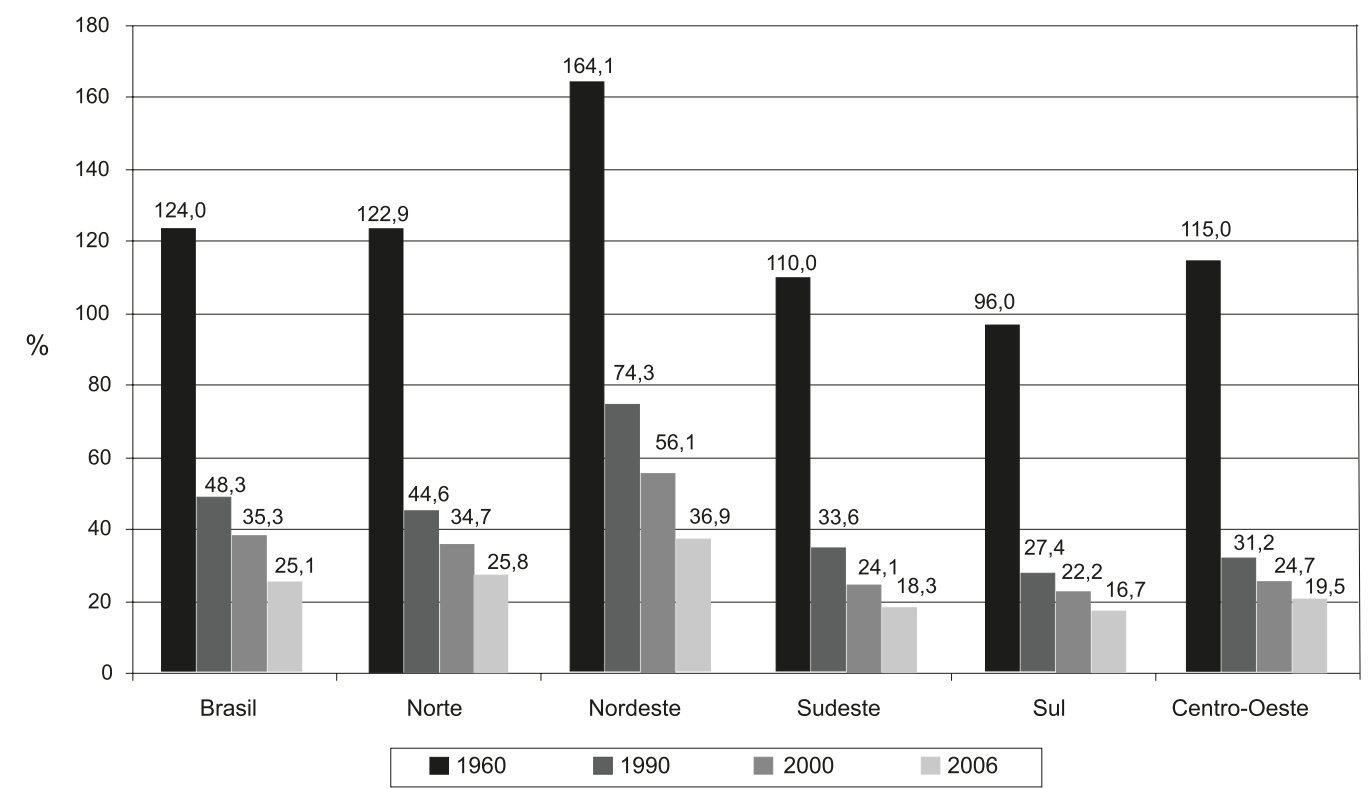

Fonte: IBGE (1999). Evolução e Perspectivas da Mortalidade Infantil no Brasil. Rio de Janeiro e Projeção da População do Brasil por Sexo e Idade para o Período 1980 2050 - Revisão 2004

A proporção de mortes de menores de um ano de idade, sobre o total de óbitos, reduziu-se de 24\%, em 1980, para 5\%, em 2005, variando de 11,3\% na Região Norte a 3,4\% na Região Sul (Gráfico 16). Em 2003, 58\% dos óbitos informados ocorreram na faixa de 60 ou mais anos de idade, com variações de 43\%, na Região Norte, a 62\%, na Região Sul.

Quanto à esperança de vida ao nascer, o Gráfico 17 mostra um ganho de mais de 20 anos, entre 1960 e 2006, para o Brasil como um todo. O valor de 72,4 anos em 2006 é 9 anos inferior ao do Japão, país com a maior expectativa de vida ao nascer em todo o mundo. Embora persistam importantes diferenças regionais, como, por exemplo, a expectativa de vida no Nordeste em 2006 ainda é dois anos menor do que era a do Sul em 1990, há uma tendência à diminuição dessas diferenças. Em 1960, um brasileiro que nascesse no Nordeste tinha uma expectativa de vida 20 anos menor que a de outro brasileiro nascido na Região Sul, diferença que cai para cinco anos em 2006. 
Gráfico 16 - Percentual de óbitos infantis no total de óbitos, * por região. Brasil - 2005

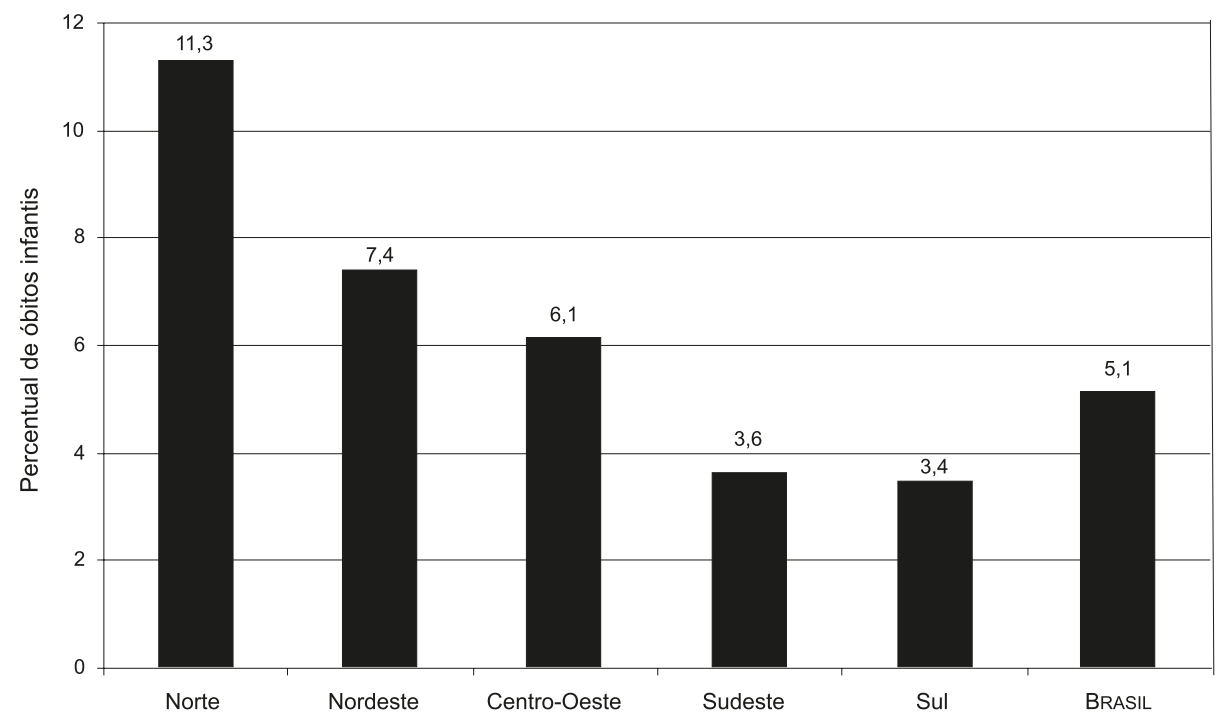

* Coeficiente de mortalidade infantil proporcional.

Fonte: Caderno de Informações em Saúde, Datasus/MS, julho/2007.

Gráfico 17 - Evolução da esperança de vida ao nascer. Brasil e regiões - 1960 - 2006

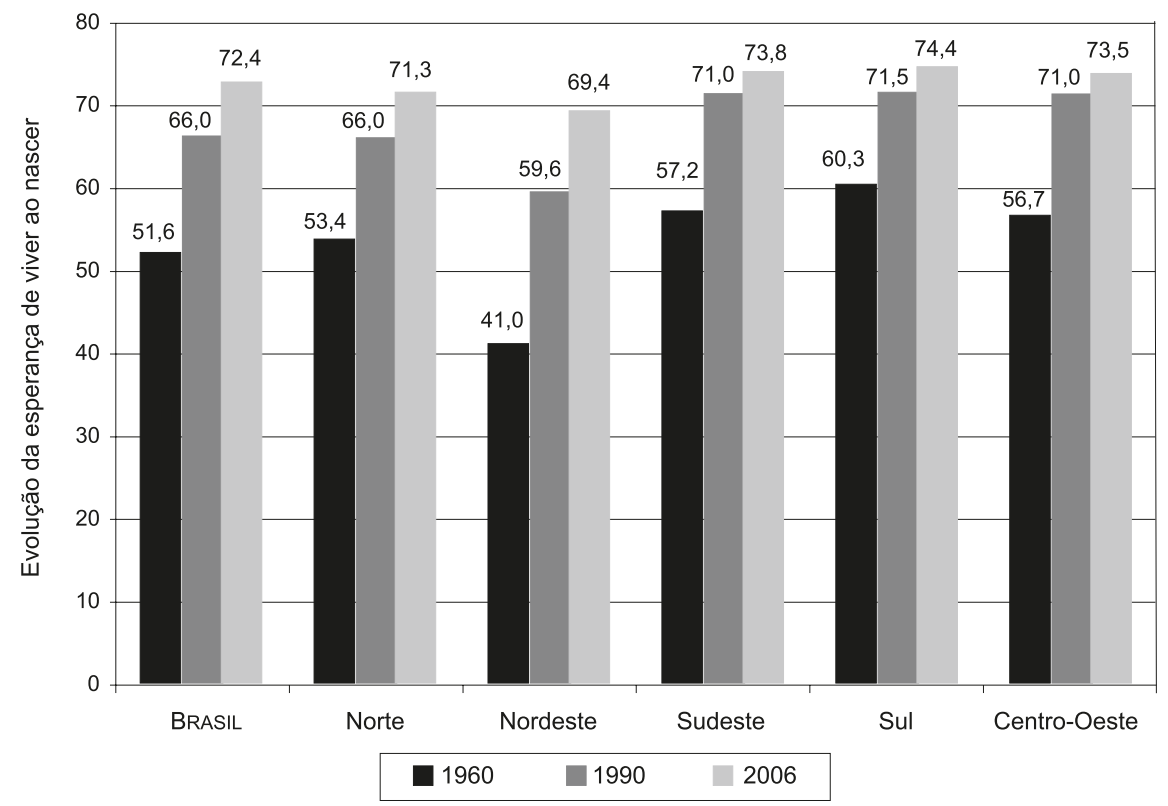

Fonte: 1940/80 - IBGE. DPE/DEPIS e Simões (1996); 1990 - IBGE Estimativas preliminares grandes regiões 1991/2030; 2006- IBGE Projeção pop. Período 1980-2050-revisão 2004. 
Com relação às diferenças entre a mortalidade masculina e a feminina, entre 1960 e 2006, a sobremortalidade masculina cresceu acentuadamente, principalmente na faixa dos 20 aos 24 anos de idade: em 1960, a chance de um homem com 20 anos de idade morrer antes de passar para o grupo etário seguinte (25 a 29 anos) era 1,1 vez maior que a de uma mulher do mesmo grupo etário. Já em 2006, a chance masculina, na mesma comparação com a chance feminina, no mesmo grupo etário (20 a 24 anos), aumentou para 4,1 vezes.

A principal causa do aumento da sobremortalidade masculina são os óbitos por causas externas (ou violentos). Dados do Ministério da Saúde mostram que, no Brasil, em 2005, houve 1.003 .005 óbitos e $12,5 \%$ deles (125.816) foram por causas externas. Entre estes, $83,5 \%$ (105.062) ocorreram na população masculina. Os homicídios são a primeira causa de morte entre as causas externas, sendo responsáveis por 38\% dos óbitos neste grupo de causas, 89\% deles na faixa etária entre 15 a 49 anos. A taxa de mortalidade específica por homicídios encontrada no sexo masculino é cerca de 12 vezes maior do que no feminino, chegando a quinze vezes na faixa etária de 20 a 29 anos. A taxa de homicídios no sexo masculino para pretos e pardos é superior a dos brancos em todas as regiões do país, como mostra o Gráfico 18.

Gráfico 18 - Taxa padronizada de homicídios no sexo masculino, segundo cor da pele e região. Brasil - 2004

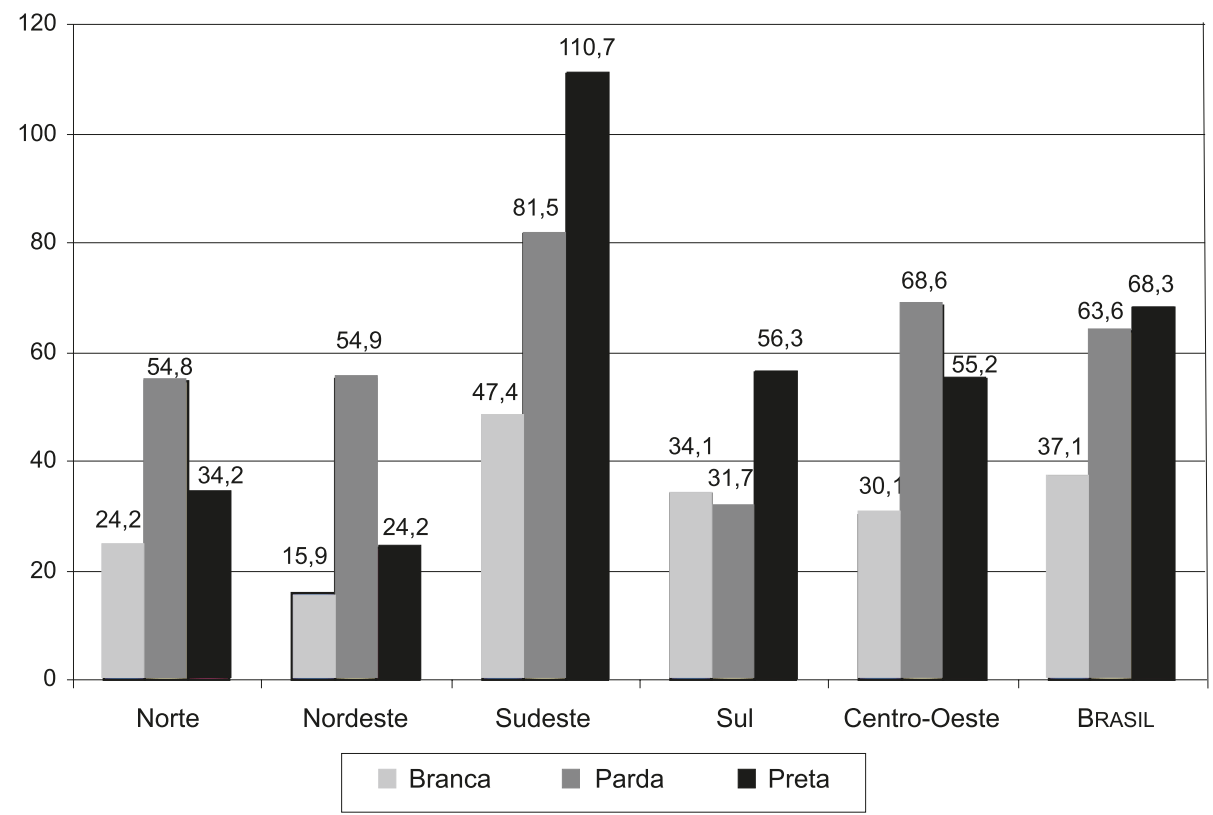

Fonte: Secretaria de Vigilância em Saúde - MS

A Tabela 15 mostra as diferenças na expectativa de vida ao nascer entre sexos para o Brasil e regiões. A diferença de cerca de 7 a 8 anos favorável às mulheres tende a aumentar, pois no período de 1991 a 2000 houve um ganho de 2,59 anos em média para o Brasil como um todo, sendo que para os homens esse ganho foi de 2,26 anos e para as mulheres de 2,84 anos. 
Tabela 15 - Esperança de vida ao nascer, por sexo, segundo as grandes regiões. Brasil - 2006

\begin{tabular}{l|c|c|c}
\hline \multirow{2}{*}{$\begin{array}{l}\text { Grandes } \\
\text { regiões }\end{array}$} & \multicolumn{3}{|c}{ Esperança de vida ao nascer } \\
\cline { 2 - 4 } & TOTAL & Homens & Mulheres \\
\hline BRASIL & 72,4 & 68,7 & 76,2 \\
Norte & 71,3 & 68,5 & 74,3 \\
Nordeste & 69,4 & 65,8 & 73,1 \\
Sudeste & 73,8 & 69,8 & 77,9 \\
Sul & 74,4 & 71,1 & 78,0 \\
Centro-Oeste & 73,5 & 70,1 & 77,0 \\
\hline
\end{tabular}

Fontes: Projeto IBGE/Fundo de População das Nações Unidas - UNFPA/BRASIL (BRA/02/P02), População e Desenvolvimento: Sistematização das Medidas e Indicadores Sociodemográficos, oriundos da Projeção da População por Sexo e Idade, por Método Demográfico, das Grandes Regiões e Unidades da Federação para o Período 1991/2030; IBGE, Diretoria de Pesquisas, Coordenação de População e Indicadores Sociais, Projeção da População do Brasil por Sexo e Idade para o Período 1980-2050 - Revisão 2004.

Os anos 60 também marcam uma inflexão importante nas causas de mortalidade, o que se convencionou chamar de transição epidemiológica. Nas regiões Sudeste e Sul, pela primeira vez, a mortalidade por doenças cardiovasculares superou a mortalidade por doenças infecciosas, o que viria a ocorrer nas regiões Norte, Nordeste e Centro-Oeste duas décadas depois, durante os anos 80. Como pode ser observado na Tabela 16, em 1985, embora em todas as regiões já houvesse uma predominância das doenças cardiovasculares como primeira causa de morte, a mortalidade na Região Norte por doenças infecciosas ainda era cerca de 2,5 vezes maior do que a observada na Região Sudeste.

Segundo Cesse (2007), as capitais brasileiras que experimentam mais precocemente mudanças na estrutura etária, urbanização e desenvolvimento são as que propiciam também, de forma mais precoce, as condições para o crescimento das doenças crônicas não-transmissíveis. De acordo com a autora, as transições epidemiológica e demográfica observadas no Brasil, em lugar de significar uma verdadeira mudança, correspondem, na realidade, a uma sobreposição de padrões, tratando-se, portanto, de processos inconclusos, marcados pelas desigualdades existentes na sociedade.

Tabela 16 - Standard Mortality Ratio (SMR) por grupos de causas para as regiões brasileiras no ano de 1985

\begin{tabular}{l|ccccc}
\hline \multirow{2}{*}{ Grupo de causas } & \multicolumn{5}{|c}{ SMR } \\
\cline { 2 - 6 } & Norte & Nordeste & $\begin{array}{c}\text { Centro- } \\
\text { Oeste }\end{array}$ & Sul & Sudeste* \\
\hline Infecciosas & 253 & 168 & 159 & 88 & 100 \\
Cardiovasculares & 25 & 56 & 89 & 101 & 100 \\
Neoplasias & 75 & 51 & 87 & 118 & 100 \\
Externas & 103 & 93 & 136 & 96 & 100 \\
\hline
\end{tabular}


A Tabela 17, com dados de 2005, mostra que os diferenciais de mortalidade por grupos de causas entre as regiões foram reduzidos, embora persistam importantes diferenças na mortalidade por causas mal definidas, chegando este grupo a ser três vezes maior nas regiões Norte e Nordeste em comparação com o Sul e o Centro-Oeste, o que deve estar relacionado ao acesso e à qualidade da atenção à saúde.

Tabela 17 - Mortalidade proporcional (\%), por grupos de causas (CID-10), segundo região. Brasil - 2005

\begin{tabular}{|c|c|c|c|c|c|c|}
\hline \multirow{2}{*}{ Grupos de causas } & \multicolumn{5}{|c|}{ Região } & \multirow[b]{2}{*}{ BRASIL } \\
\hline & Norte & Nordeste & $\begin{array}{l}\text { Centro- } \\
\text { Oeste }\end{array}$ & Sudeste & Sul & \\
\hline $\begin{array}{l}\text { I- Algumas doenças } \\
\text { infecciosas e parasitárias }\end{array}$ & 7,6 & 5,8 & 5,4 & 5,0 & 4,0 & 5,2 \\
\hline II - Neoplasias (tumores) & 13,0 & 13,4 & 14,6 & 17,1 & 20,0 & 16,3 \\
\hline $\begin{array}{l}\text { IX - Doenças do aparelho } \\
\text { circulatório }\end{array}$ & 24,4 & 31,1 & 30,2 & 32,3 & 32,2 & 31,5 \\
\hline $\begin{array}{l}X \text { - Doenças do aparelho } \\
\text { respiratório }\end{array}$ & 10,7 & 9,2 & 10,2 & 11,4 & 11,5 & 10,8 \\
\hline $\begin{array}{l}\mathrm{XVI} \text { - Algumas afecções } \\
\text { originadas no período } \\
\text { perinatal }\end{array}$ & 7,4 & 5,2 & 3,6 & 2,3 & 2,1 & 3,3 \\
\hline $\begin{array}{l}X X \text { - Causas externas de } \\
\text { morbidade e mortalidade }\end{array}$ & 19,3 & 15,0 & 17,9 & 13,2 & 12,8 & 14,1 \\
\hline Causas mal definidas & 17,7 & 17,2 & 5,2 & 8,1 & 5,8 & 10,4 \\
\hline
\end{tabular}

Fonte: Caderno de Informações em Saúde, Datasus/MS, julho/2007.

Com relação às causas de mortes infantis em menores de um ano, conforme pode ser observado nas Tabelas 18 e 18.1, elaboradas por Cesar Victora para a CNDSS, em todas as regiões há uma significativa diminuição de mortes devidas a infeccções respiratórias e diarréia, principalmente esta última, que, em 1985-1987, era responsável por 17,3\% dos óbitos, caindo para 4,2\% em 2003-2005. Ao mesmo tempo, houve um aumento das causas perinatais e malformações em todas as regiões, embora persistam grandes disparidades. Por exemplo, a proporção de mortes por diarréia na Região Nordeste é cerca de quatro vezes superior a da Região Sudeste. É importante também observar a expressiva queda da mortalidade por causas mal definidas, particularmente na Região Nordeste, caindo de 45,5\% em 1985-1987 para 9,7\% em 2003-2005, o que deve estar relacionado à melhoria do acesso e da qualidade da atenção. 
Tabela 18 - Distribuição percentual das mortes infantis por causa ${ }^{1}$

\begin{tabular}{|c|c|c|c|c|c|c|c|}
\hline Causa & Ano & $\mathrm{N}$ & $\mathrm{NE}$ & SE & $S$ & $\mathrm{CO}$ & BRASIL \\
\hline \multirow{3}{*}{$\begin{array}{l}\text { Causas } \\
\text { perinatais }\end{array}$} & $1985-87$ & $42.1 \%$ & $42.9 \%$ & $48.9 \%$ & $46.4 \%$ & $48.7 \%$ & $46.5 \%$ \\
\hline & $1995-97$ & $61.4 \%$ & $53.9 \%$ & $58.8 \%$ & $53.0 \%$ & $56.7 \%$ & $56.8 \%$ \\
\hline & 200305 & $61.2 \%$ & $62.2 \%$ & $61.0 \%$ & $58.7 \%$ & $57.2 \%$ & $60.9 \%$ \\
\hline \multirow{3}{*}{ Malformações } & $1985-87$ & $4.9 \%$ & $3.6 \%$ & $8.1 \%$ & $11.4 \%$ & $8.6 \%$ & $7.1 \%$ \\
\hline & 1995-97 & $8.5 \%$ & $7.3 \%$ & $12.2 \%$ & $16.2 \%$ & $13.4 \%$ & $11.2 \%$ \\
\hline & 2003-05 & $12.7 \%$ & $11.4 \%$ & $18.3 \%$ & $21.5 \%$ & $20.0 \%$ & $15.7 \%$ \\
\hline \multirow{3}{*}{$\begin{array}{l}\text { Infecções } \\
\text { respiratórias }\end{array}$} & $1985-87$ & $11.5 \%$ & $11.4 \%$ & $15.7 \%$ & $14.2 \%$ & $12.9 \%$ & $13.9 \%$ \\
\hline & $1995-97$ & $8.9 \%$ & $9.7 \%$ & $10.7 \%$ & $11.1 \%$ & $8.7 \%$ & $10.2 \%$ \\
\hline & 2003-05 & $8.2 \%$ & $6.9 \%$ & $6.6 \%$ & $5.9 \%$ & $6.8 \%$ & $6.9 \%$ \\
\hline \multirow{3}{*}{ Diarréia } & $1985-87$ & $30.1 \%$ & $27.0 \%$ & $11.8 \%$ & $12.5 \%$ & $12.9 \%$ & $17.3 \%$ \\
\hline & 1995-97 & $9.3 \%$ & $15.4 \%$ & $4.7 \%$ & $5.0 \%$ & $6.4 \%$ & $8.1 \%$ \\
\hline & 2003-05 & $5.1 \%$ & $7.1 \%$ & $1.8 \%$ & $1.9 \%$ & $3.1 \%$ & $4.2 \%$ \\
\hline \multirow{3}{*}{$\begin{array}{l}\text { Outras } \\
\text { infecções }\end{array}$} & $1985-87$ & $5.3 \%$ & $6.1 \%$ & $5.3 \%$ & $6.0 \%$ & $7.1 \%$ & $5.7 \%$ \\
\hline & 1995-97 & $5.6 \%$ & $6.0 \%$ & $5.6 \%$ & $5.0 \%$ & $6.1 \%$ & $5.6 \%$ \\
\hline & 2003-05 & $5.2 \%$ & $4.2 \%$ & $4.2 \%$ & $3.1 \%$ & $3.8 \%$ & $4.2 \%$ \\
\hline \multirow{3}{*}{ Outras causas } & $1985-87$ & $6.1 \%$ & $9.0 \%$ & $10.2 \%$ & $9.5 \%$ & $9.8 \%$ & $9.5 \%$ \\
\hline & $1995-97$ & $6.3 \%$ & $7.7 \%$ & $8.0 \%$ & $9.7 \%$ & $8.7 \%$ & $8.1 \%$ \\
\hline & 2003-05 & $7.6 \%$ & $8.2 \%$ & $8.1 \%$ & $8.9 \%$ & $9.1 \%$ & $8.1 \%$ \\
\hline \multirow{3}{*}{$\begin{array}{l}\text { Causas mal } \\
\text { definidas }^{2}\end{array}$} & $1985-87$ & $23.9 \%$ & $45.5 \%$ & $6.0 \%$ & $11.0 \%$ & $11.6 \%$ & $23.0 \%$ \\
\hline & 1995-97 & $16.0 \%$ & $25.5 \%$ & $5.0 \%$ & $6.3 \%$ & $6.0 \%$ & $12.6 \%$ \\
\hline & 2003-05 & $11.0 \%$ & $9.7 \%$ & $3.9 \%$ & $4.3 \%$ & $2.7 \%$ & $6.9 \%$ \\
\hline
\end{tabular}

${ }^{1}$ Expressos como percentuais de todas as mortes com causas definidas.

${ }^{2}$ Expresso como percentual de todas as mortes infantis.

Fonte: Cesar Victora, CNDSS.

Quanto ao Coeficiente de Mortalidade Infantil (CMI) específico por causas (Tabela 18.1), vale notar que a mortalidade por diarréia - que era responsável por cerca de 10 mortes para cada mil nascidos vivos no Brasil em 1985-1987 - é responsável por menos de uma morte em 2003-2005, queda que no Nordeste é de 24,4 para 2,4 no mesmo período. Da mesma forma, é dramática a queda do CMI por causas mal definidas, caindo no país como um todo de 14,3 mortes para cada mil nascidos-vivos em 1985-1987 para 1,5 em 2003-2005, sendo que no Nordeste esta queda foi de 41,2 para 3,3. 
Tabela 18.1 - Coeficiente de mortalidade infantil específico por causas (estimados a partir da combinação dos dados do Sistema de Informação sobre Mortalidade - SIM - com as estimativas de mortalidade)

\begin{tabular}{|c|c|c|c|c|c|c|c|}
\hline Causa $^{1}$ & Ano & $\mathrm{N}$ & NE & SE & $S$ & $\mathrm{CO}$ & BRASIL \\
\hline \multirow{3}{*}{ Causas perinatais } & $1985-87$ & 24.8 & 38.9 & 21.8 & 17.5 & 19.9 & 29.0 \\
\hline & 1995-97 & 22.8 & 32.6 & 15.2 & 12.1 & 14.6 & 21.3 \\
\hline & 200305 & 15.8 & 20.9 & 9.1 & 8.7 & 10.5 & 13.7 \\
\hline \multirow{3}{*}{ Malformações } & $1985-87$ & 2.9 & 3.3 & 3.6 & 4.3 & 3.5 & 4.4 \\
\hline & $1995-97$ & 3.1 & 4.4 & 3.2 & 3.7 & 3.4 & 4.2 \\
\hline & 2003-05 & 3.3 & 3.8 & 2.7 & 3.2 & 3.7 & 3.5 \\
\hline \multirow{3}{*}{$\begin{array}{l}\text { Infecções } \\
\text { respiratórias }\end{array}$} & $1985-87$ & 6.7 & 10.3 & 7.0 & 5.4 & 5.3 & 8.7 \\
\hline & $1995-97$ & 3.2 & 5.9 & 2.8 & 2.5 & 2.3 & 3.8 \\
\hline & 200305 & 2.1 & 2.3 & 1.0 & 0.9 & 1.3 & 1.5 \\
\hline \multirow{3}{*}{ Diarréia } & $1985-87$ & 17.7 & 24.4 & 5.3 & 4.7 & 5.3 & 10.8 \\
\hline & $1995-97$ & 3.3 & 9.3 & 1.2 & 1.1 & 1.7 & 3.0 \\
\hline & 2003-05 & 1.3 & 2.4 & 0.3 & 0.3 & 0.6 & 0.9 \\
\hline \multirow{3}{*}{ Outras infecções } & $1985-87$ & 3.1 & 5.5 & 2.4 & 2.3 & 2.9 & 3.5 \\
\hline & $1995-97$ & 2.0 & 3.6 & 1.4 & 1.1 & 1.6 & 2.1 \\
\hline & 2003-05 & 1.3 & 1.4 & 0.6 & 0.5 & 0.7 & 0.9 \\
\hline \multirow{3}{*}{ Outras causas } & $1985-87$ & 3.6 & 8.1 & 4.6 & 3.5 & 4.0 & 5.9 \\
\hline & $1995-97$ & 2.3 & 4.7 & 2.1 & 2.2 & 2.2 & 3.0 \\
\hline & 2003-05 & 1.9 & 2.8 & 1.2 & 1.3 & 1.7 & 1.8 \\
\hline \multirow{3}{*}{$\begin{array}{l}\text { Causas mal } \\
\text { definidas }\end{array}$} & $1985-87$ & 14.1 & 41.2 & 2.7 & 4.1 & 4.7 & 14.3 \\
\hline & $1995-97$ & 5.8 & 15.4 & 1.3 & 1.4 & 1.5 & 4.7 \\
\hline & 2003-05 & 2.8 & 3.3 & 0.6 & 0.6 & 0.5 & 1.5 \\
\hline
\end{tabular}

${ }^{1}$ Distribuindo as mortes por causas mal definidas proporcionalmente em cada grupo de causas conhecidas. Fonte: Cesar Victora, CNDSS.

As tendências positivas observadas nas últimas décadas com relação à renda, escolaridade e saúde se expressam na evolução do índice de desenvolvimento humano (IDH), do Programa das Nações Unidas para o Desenvolvimento (PNUD), que passou de 0,649 em 1975 para 0,800 em 2005. 


\subsection{A Estratificação Socioeconômica e a Saúde}

As condições socioeconômicas, culturais e ambientais de uma dada sociedade, ou seja os determinates mais gerais e distais do modelo de Dahlgren e Whitehead, geram uma estratificação econômico-social dos indivíduos e grupos da população, conferindo-lhes posições sociais distintas, as quais por sua vez provocam diferenciais de saúde. Em outras palavras, a distribuição da saúde e da doença em uma sociedade não é aleatória, estando associada à posição social, que por sua vez define as condições de vida e de trabalho dos indivíduos e grupos.

O modelo de Diderichsen e Hallqvist (1998), adaptado por Diderichsen, Evans e Whitehead (2001), procura mostrar as relações entre a posição social e diversos tipos de diferenciais de saúde, conforme pode ser observado na Figura 2. Neste modelo, (I) representa o processo segundo o qual cada indivíduo ou grupo ocupa uma dada posição social como resultado de diversos mecanismos sociais como o sistema educacional e o mercado de trabalho. De acordo com a posição social ocupada pelos diferentes indivíduos aparecem diferenciais, como o diferencial de exposição a riscos que causam danos à saúde (II), o diferencial de vulnerabilidade à ocorrência de doença frente à exposição a estes riscos (III) e o diferencial de conseqüências sociais ou físicas uma vez contraída a doença (IV). Este modelo também permite identificar alguns pontos de incidência de políticas que atuem seja sobre os mecanismos de estratificação social, seja sobre os diferenciais de exposição, de vulnerabilidade e de conseqüências.

Figura 2 - Diferenciais de saúde segundo a posição social

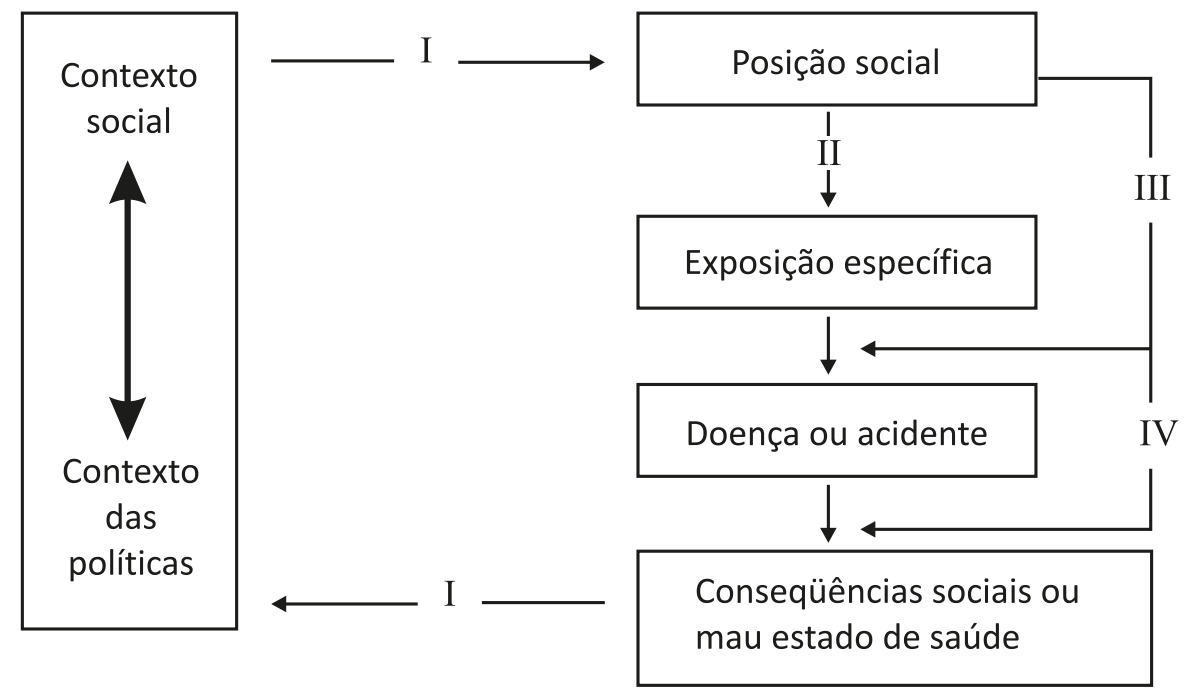

Fonte: Diderichsen e Hallqvist, 1998. 
Por exemplo, a intervenção sobre os mecanismos de estratificação social é das mais cruciais para combater as iniqüidades em saúde, incluindo-se aqui políticas que diminuam as diferenças sociais como as relacionadas ao mercado de trabalho, à educação e à seguridade social. Um segundo conjunto de políticas busca diminuir os diferenciais de exposição a riscos, tendo, por exemplo, como alvo, os grupos que vivem em condições de habitação insalubres, trabalham em ambientes pouco seguros ou estão expostos a deficiências nutricionais. O combate aos diferenciais de vulnerabilidade inclui intervenções que buscam fortalecer a resistência a diversas exposições, como por exemplo, a educação das mulheres para diminuir sua própria vulnerabilidade e a de seus filhos. A intervenção no sistema de saúde busca reduzir os diferenciais de exposição e de vulnerablidade, por meio de ações preventivas (vacinas, educação sobre fatores de risco etc.), bem como os diferenciais de conseqüências ocasionadas pela doença, aqui incluindo melhoria da qualidade dos serviços a toda a população, apoio a deficientes, acesso a cuidados de reabilitação e mecanismos de financiamento eqüitativos que impeçam adicional empobrecimento causado pela doença.

Nesta seção, são apresentadas algumas associações entre estratificação socioeconômica (segundo renda, escolaridade, gênero, cor da pele e local de moradia) e resultados de saúde, destacando as iniqüidades em saúde derivadas dos diferenciais de exposição, vulnerabilidade e conseqüências de acordo com a posição social ocupada por indivíduos e grupos da população.

Renda e escolaridade estão fortemente associados a resultados de saúde. Messias (2003), analisando dados do censo de 2000, mostrou que o PIB per capita, a distribuição de renda e a taxa de analfabetismo estão associados à expectativa de vida.

Os efeitos do nível de instrução se manifestam das mais diferentes formas: na percepção dos problemas de saúde; na capacidade de entendimento das informações sobre saúde; na adoção de estilos de vida saudáveis; no consumo e utilização dos serviços de saúde; e na adesão aos procedimentos terapêuticos.

A realização de exames preventivos para câncer de mama e de colo de útero, assim como de consultas pré-natal são bons exemplos das desigualdades de acesso e utilização de serviços de saúde de acordo com escolaridade, observando-se um nítido gradiente segundo esta variável, como mostram os Gráficos 19, 20 e 21. 
Gráfico 19 - Proporção (\%) de mulheres de 25 anos ou mais de idade que já realizaram alguma vez exame de mamografia, por anos de estudo. Brasil - 2003

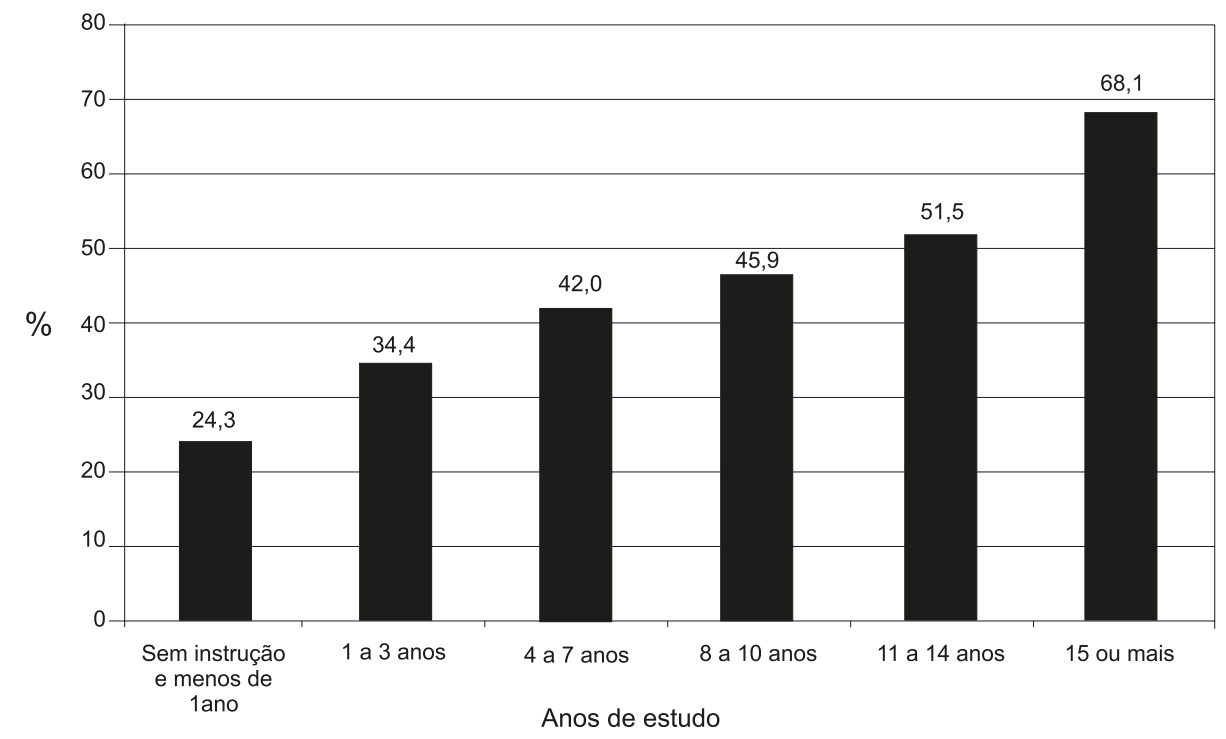

Fonte: Elaboração própria, a partir da Pesquisa Nacional por Amostra de Domicílios (PNAD) 2003 Acesso e Utilização de Serviços de Saúde, IBGE.

Gráfico 20 - Proporção (\%) de mulheres de 25 anos ou mais de idade que realizaram alguma vez exame preventivo para câncer de colo uterino, por anos de estudo. Brasil - 2003

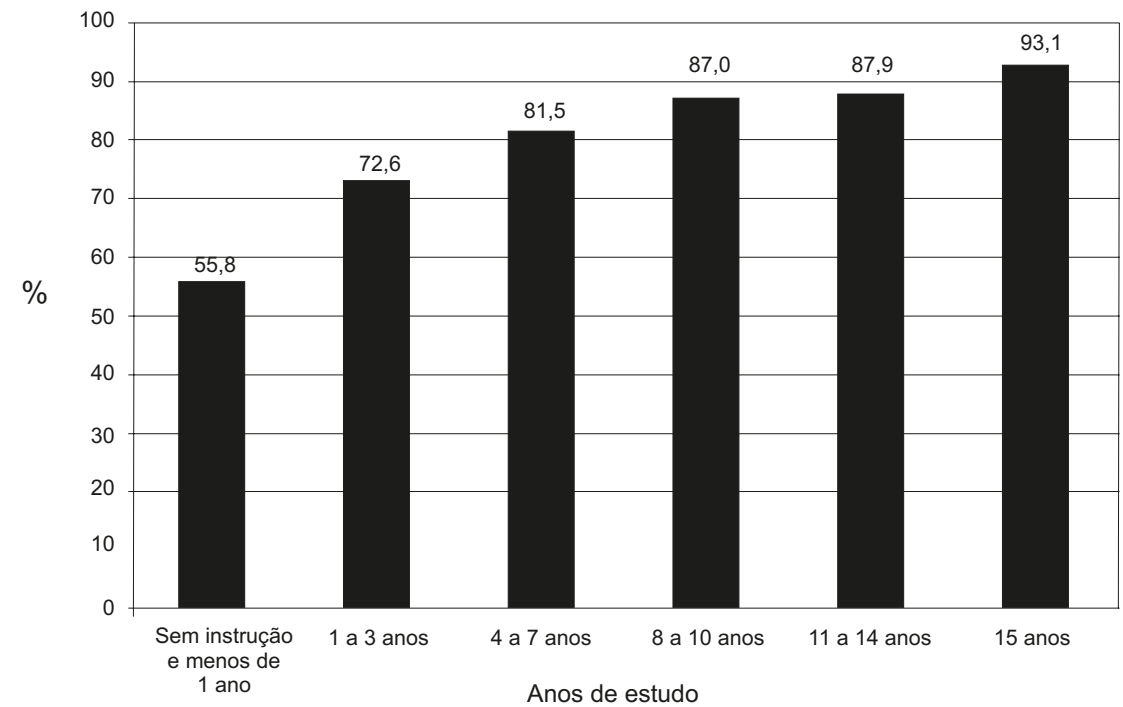

Fonte: Elaboração própria, a partir da Pesquisa Nacional por Amostra de Domicílios (PNAD) 2003 Acesso e Utilização de Serviços de Saúde, IBGE. 
Gráfico 21 - Proporção (\%) de nascidos vivos, por número de consultas de pré-natal e escolaridade da mãe. Brasil-2005

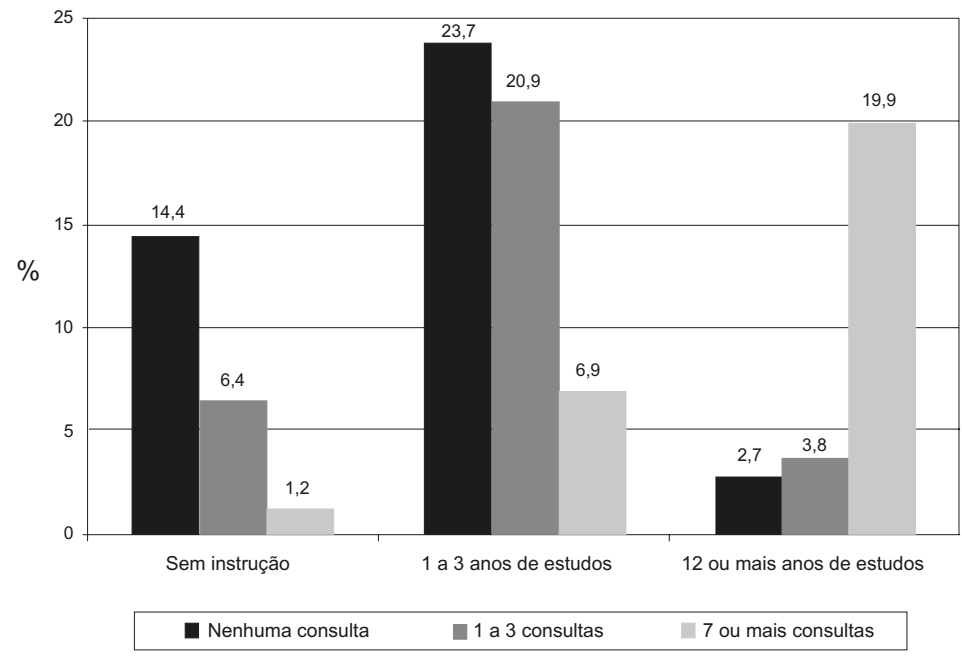

Fonte: Sistema de Informação sobre Nascidos Vivos (Sinasc).

Os Gráficos 22, 22.1 e 22.2 exemplificam os grandes contrastes observados entre municípios no que se refere a indicadores econômicos, sociais e de condições de vida e sua associação com diferenciais de saúde. Os gráficos comparam os diversos indicadores sociais e de saúde dos municípios com maior e menor renda per capita dentro de uma mesma faixa populacional. Os dados são do censo de 2000, já que as demais fontes para estes indicadores, como Pnud2006, não possuem representatividade amostral em nível de município.

Gráfico 22 - Indicadores socioeconômicos de municípios entre 50 e 100 mil habitantes, com menor e maior renda per capita -2000

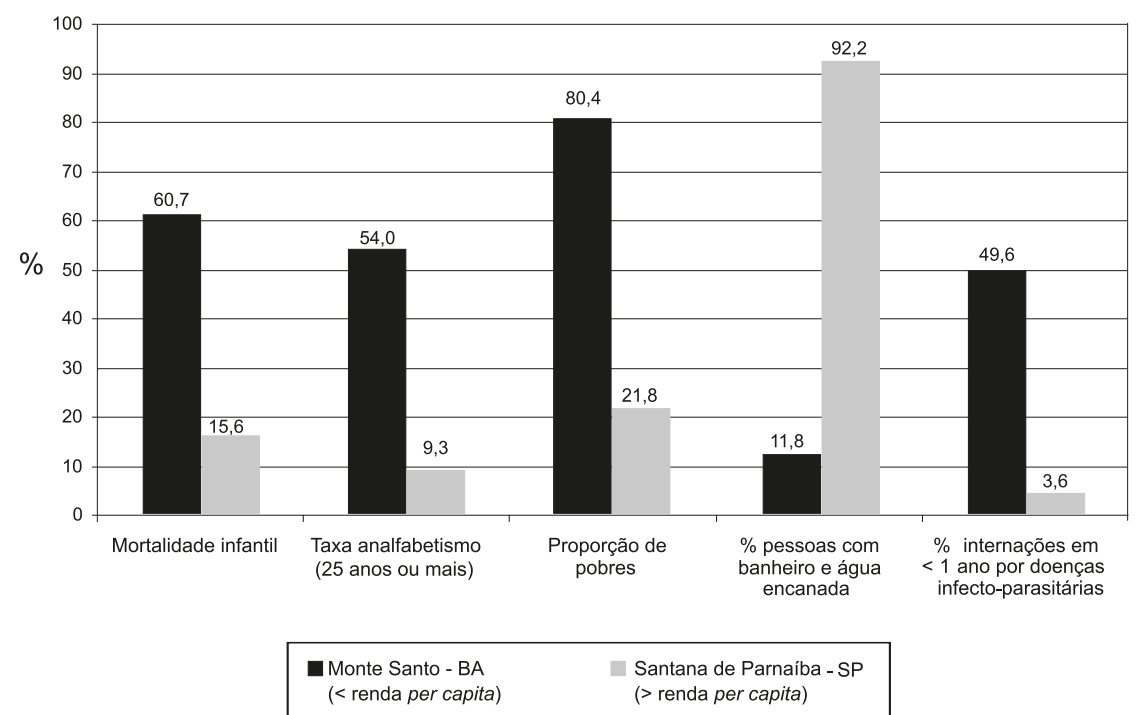

Fonte: Atlas do Desenvolvimento Humano - PNUD; Sistema de Informações Hospitalares do SUS (SIH-SUS) - Datasus. 
Gráfico 22.1 - Indicadores socioeconômicos de municípios entre 100 e 500 mil habitantes com menor e maior renda per capita -2000

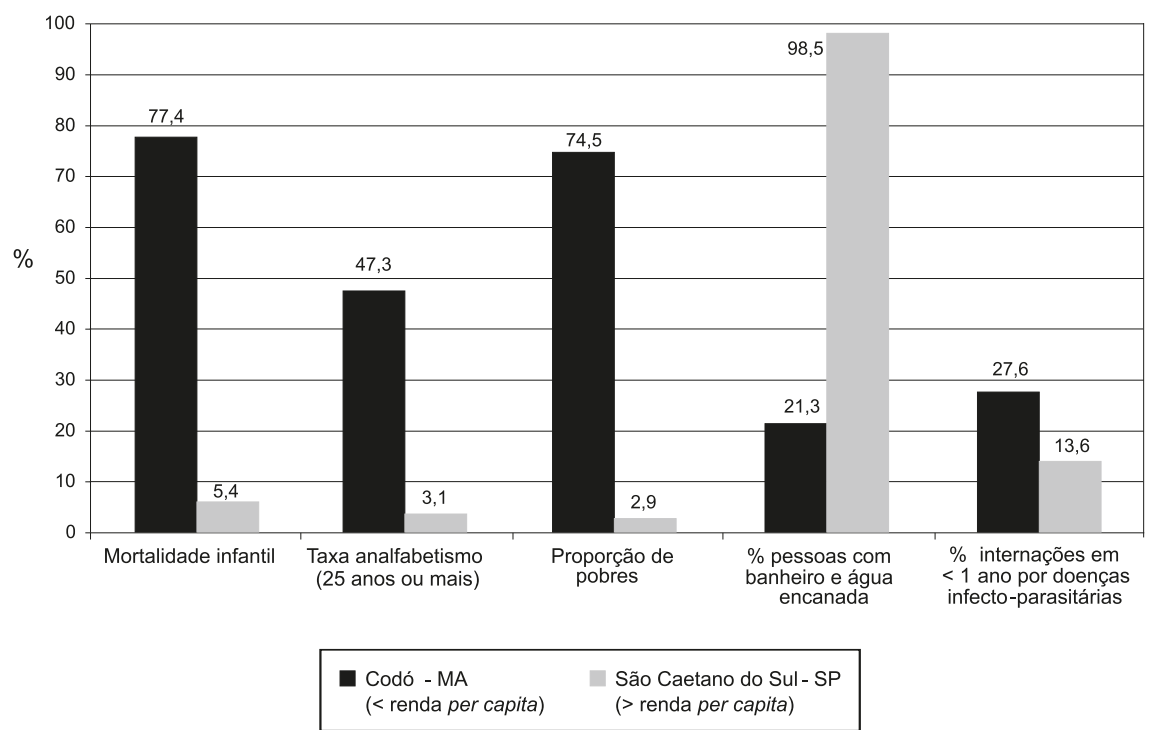

Fonte: Atlas do Desenvolvimento Humano - PNUD; Sistema de Informações Hospitalares do SUS (SIH-SUS) - Datasus.

Gráfico 22.2 - Indicadores socioeconômicos de municípios com mais de 500 mil habitantes com menor e maior renda per capita - 2000

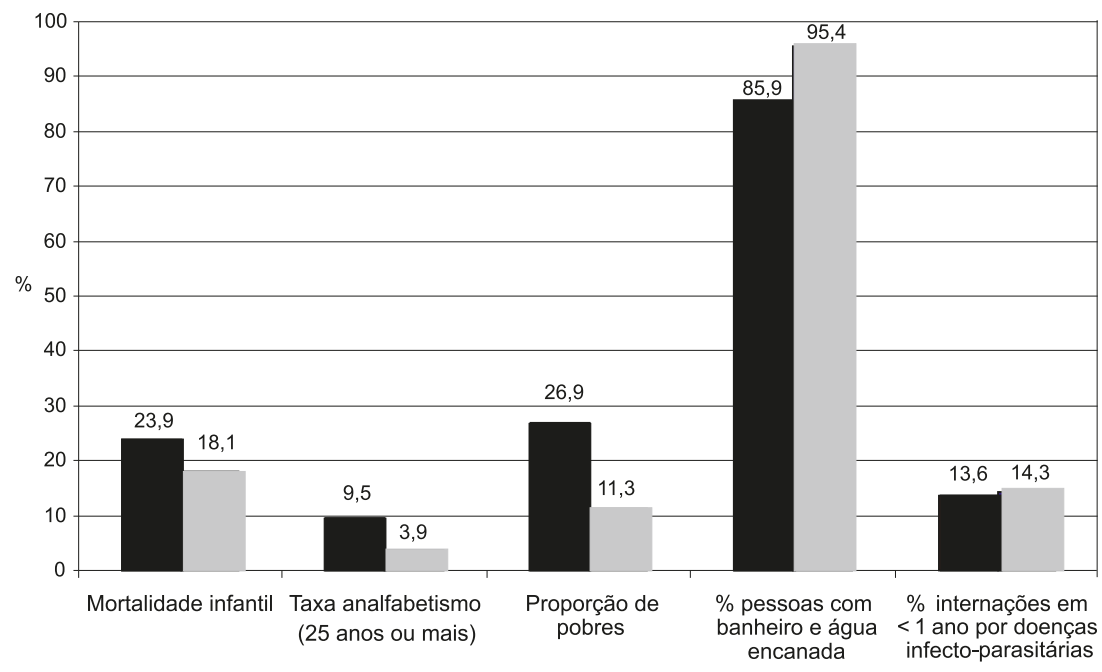

Duque de Caxias - RJ Porto Alegre - RS

(< renda per capita) (> renda per capita)

Fonte: Atlas do Desenvolvimento Humano - PNUD; Sistema de Informações Hospitalares do SUS (SIH-SUS) - Datasus. 
A revisão da literatura publicada nos últimos cinco anos permite identificar uma série de estudos que tratam das relações entre escolaridade, renda e saúde. A seguir são apresentados alguns resultados destes estudos.

Dachs (2002), a partir dos dados da Pesquisa Nacional por Amostra de Domicílios (Pnad), de 1998, avaliou a autopercepção de saúde nas categorias "muito bom”, "bom”, "regular", "ruim" e "muito ruim". Quanto à renda, observou desigualdade importante nos indivíduos dos decis extremos: enquanto $70 \%$ do decil mais baixo tiveram avaliação boa/muito boa, este valor atingiu $87 \%$ no decil mais alto. Já para a avaliação ruim/muito ruim, os valores foram 3,8\% e 1,6\%, respectivamente. Para a escolaridade, estas desigualdades foram mais evidentes: entre os que tinham menos de um ano de estudo, pouco mais da metade (51\%) referiu estado de saúde bom/muito bom, comparados a $90 \%$ daqueles com ensino superior. Quanto à avaliação ruim/muito ruim, os de menor tempo de estudo relataram $13,5 \%$ contra apenas 4,7\% dos indivíduos com nível superior.

Barata et al. (2007) analisaram desigualdades na percepção do estado de saúde de jovens e adultos segundo cor, a partir destes mesmos dados. Considerando apenas gênero/etnia, os homens pretos apresentaram prevalência $23 \%$ maior de saúde regular ou ruim, comparados aos homens brancos. Esta diferença aumentou para 45\%, após ajuste para idade, e diminuiu para $16 \%$ após ajuste para escolaridade e $11 \%$ após ajuste para renda. Isto sugere que uma parte considerável das desigualdades se explica pelo status socioeconômico. Para as mulheres brancas, comparadas aos homens brancos, a prevalência de saúde regular ou ruim foi 49\% maior, após ajuste para todas as variáveis, enfatizando a importância do gênero na autopercepção de saúde.

Lima-Costa, Matos e Camarano (2006) avaliaram condições gerais de saúde, usando como indicadores as seguintes situações: "interrupção das atividades habituais nas duas últimas semanas", "ter estado acamado nas duas últimas semanas" e "dificuldade para realizar alguma atividade da vida diária”. A pesquisa foi baseada nos dados da Pnad de 1998 e 2003, encontrando que os indivíduos com renda menor que 0,67 salários mínimos apresentavam maior freqüência dessas situações quando comparados aos de renda superior. Os valores foram semelhantes nos dois períodos avaliados.

Ishitani et al. (2006), utilizando dados de municípios com melhor qualidade de informação, observaram associação negativa da escolaridade e mortalidade por doenças cardiovasculares. A cada aumento de um ponto percentual na proporção de indivíduos com alta escolaridade, diminui em 3,25 por 100.000 habitantes a taxa de mortalidade. No caso das doenças hipertensivas e cerebrovasculares, manteve-se associação negativa com escolaridade e positiva com taxa de pobreza. Por outro lado, em relação às doenças isquêmicas, a associação com escolaridade também foi negativa, mas com a taxa de pobreza também foi negativa. Portanto, as desigualdades se caracterizam por maior acometimento das populações com menor renda, com exceção das doenças isquêmicas. A escolaridade foi o maior determinante, com forte efeito protetor. 
Os dados da Pnad 2003 foram estudados por Barros et al. (2006), no que se refere à prevalência de doenças crônicas. A escolaridade, ajustada para sexo, idade, cor da pele e macrorregião, mostrou que as pessoas com 0-3 anos de estudo tiveram quase duas vezes mais doenças que aquelas com mais de oito anos de estudo.

Lessa et al. (2006) estudaram os determinantes de hipertensão em Salvador (BA) e mostraram comportamento diferente da escolaridade para homens e mulheres. No sexo feminino, quanto menor o tempo de estudo, maior prevalência de hipertensão, comparada à faixa de alta escolaridade. No sexo masculino, os dois extremos (alta e baixa escolaridade) mostraram prevalências aumentadas, em relação à escolaridade média.

Da Costa et al. (2007) avaliaram fatores socioeconômicos, comportamentais e nutricionais para hipertensão na cidade de Pelotas, em um estudo transversal realizado em 2000. Comparadas com uma renda maior que 10 salários mínimos, todas as outras faixas salariais mostraram prevalência duas vezes maior de hipertensão, não tendo sido encontrada associação com escolaridade.

Marins et al. (2007) investigaram a associação entre fatores socioeconômicos e um índice composto de risco cardiovascular (hipertensão + obesidade + tabagismo + razão cinturaquadril + sedentarismo + alcoolismo). A presença de dois a seis itens constituía risco. As variáveis renda ("baixa" - menor que a mediana do estudo) e escolaridade ("baixa" - menor ou igual a 8 anos de estudo) foram analisadas em uma regressão logística, separadamente para homens e mulheres. Em ambos os sexos, foi encontrada maior importância da escolaridade, com uma freqüência de risco cerca de duas vezes maior em indivíduos com escolaridade baixa.

Kilsztajn et al. (2005), estudando homicídios na Região Metropolitana de São Paulo (38 municípios e 96 distritos do município de São Paulo), encontraram escolaridade baixa (menos de 7 anos de estudo) fortemente associada à taxa de homicídios, ajustada para idade, sexo e cor da pele. Gawrysewski e Costa (2005) também estudaram homicídios nos 96 distritos do município de São Paulo em 2000, observando forte correlação negativa com a renda média, ou seja, maiores coeficientes foram encontrados nos distritos com menor renda e menores coeficientes naqueles com maior renda.

\subsection{Condiçóes de Vida, Ambiente e Trabalho}

As condições materiais de vida e trabalho dos indivíduos e grupos, assim como sua vulnerabilidade aos impactos ambientais estão fortemente influenciadas pela posição social que ocupam e que pode ser definida por meio de uma série de váriavéis como renda, escolaridade, gênero e outras (ver Figura 2). Estas condições de vida e trabalho e seus efeitos psicossociais constituem um dos principais mediadores através dos quais a estratificação socioeconômica influencia a situação de saúde de indíviduos ou grupos, bem como os diferenciais observados entre eles. Analisando as condições materiais de vida e trabalho dos 
diversos grupos sociais, pode-se, em grande parte, responder a questões fundamentais como: onde se originam as iniqüidades em saúde entre grupos sociais? Quais são os caminhos pelos quais os determinantes sociais produzem as iniqüidades em saúde?

Neste item, são apresentados alguns aspectos fundamentais das condições de vida e trabalho, com ênfase nas desigualdades existentes entre estas condições e sua associação com a situação de saúde. Destacam-se as condições de alimentação e nutrição, saneamento básico e habitação, ambientais, de emprego e trabalho, assim como o acesso a serviços de saúde e à informação.

\section{Alimentação e Nutrição}

A alimentação, cujo acesso e qualidade estão claramente influenciados por fatores socioeconômicos, comportamentais e culturais, constitui-se num dos mais importantes determinantes sociais da saúde. Nas últimas décadas, o Brasil vem passando por um processo de transição nutricional, que consiste na substituição de um padrão alimentar baseado no consumo de cereais, feijões, raízes e tubérculos por uma alimentação mais rica em gorduras (especialmente hidrogenadas) e açúcares, além da crescente ingestão de ingredientes químicos. Conforme já mencionado na seção em que foram tratados os processos de transição demográfica e epidemiológica, o processo de transição nutricional é também marcado pela sobreposição de padrões, pela temporalidade indefinida e, sobretudo, pelas desigualdades de acordo com a estratificação socioeconômica.

Essa mudança nos padrões alimentares vem aumentando o risco de sobrepeso e obesidade, condições que contribuem de forma importante para o aparecimento de doenças crônicas e incapacidades, incluindo desde condições debilitantes que afetam a qualidade de vida, tais como a osteoartrite, dificuldades respiratórias, problemas músculo-esqueléticos, problemas de pele e infertilidade, até condições graves como doença coronariana, diabetes tipo 2 e certos tipos de câncer. Segundo o Instituto Nacional de Câncer (Inca, 2006), o sobrepeso e a obesidade são a segunda causa evitável de câncer, atrás apenas do tabagismo.

A Pesquisa de Orçamento Familiar (POF), de 2003, mostrou que o número de brasileiros adultos com excesso de peso tinha praticamente dobrado em relação a 1974, quando foi feito o Estudo Nacional de Despesas Familiares. O percentual de meninos com excesso de peso mais do que triplicou, passando de 3,9\% em 1974-1975 para 17,9\% em 2002-2003. Para as meninas, esse aumento foi de $100 \%$, passando de $7,5 \%$ para $15,4 \%$ no mesmo período. Em 2003, o excesso de peso atingia, em média, quatro em cada dez brasileiros adultos, superando em cerca de oito vezes o déficit de peso entre as mulheres e em quinze vezes entre os homens. Considerando o universo de brasileiros com 20 anos ou mais de idade, o IBGE estima que haja 3,8 milhões de pessoas (ou 4,0\%) com déficit de peso e 38,8 milhões (40,6\%) com excesso de peso, das quais 10,5 milhões são consideradas obesas.

Alguns dos estudos mais recentes que analisam a problemática da alimentação e nutrição no Brasil e o processo de transição nutricional são mencionados a seguir. 
O estudo de Batista-Filho e Rissin (2003) mostra diferenças importantes na prevalência de desnutrição por região e por estrato urbano e rural, sendo o Nordeste rural a região mais afetada com 8,8\%, em oposição ao Centro-Sul urbano, com 5,8\%.

Por outro lado, Veiga, Cunha e Sichieri (2004) observaram que o índice de massa corpórea (IMC) vem aumentando em meninos e meninas, tanto nas regiões Nordeste como Sudeste, embora para as meninas do Sudeste já tenha começado a ocorrer uma reversão da tendência. Magalhães e Mendonça (2003) confirmam esses achados, mostrando que a prevalência de sobrepeso/obesidade (S/O) foi de $8,45 \%$ no Nordeste e $11,53 \%$ no Sudeste, sendo que no Nordeste há maior risco de S/O para meninas tanto na área urbana como na rural e no Sudeste a situação é inversa, com menor risco de S/O para meninas na área urbana, mas não na rural. O estudo de Veiga, Cunha e Sichieri (2004) também confirma o mesmo padrão, mostrando que o IMC aumentou mais entre os meninos; nas meninas, houve aumento na Região Nordeste, ao passo que no Sudeste, ao contrário, começou a haver decréscimo. No estudo de Dutra, Araújo e Bertoldi (2006), não houve diferença para sobrepeso entre meninos e meninas de Pelotas.

Quanto aos idosos, Cunha e Sichieri (2007) encontraram um aumento na prevalência de obesidade no período de 1975 a 1997, atingindo 37,4\% nos homens e 50,6\% nas mulheres, persistindo o baixo peso, embora com prevalência menor, alcançando $13 \%$ na Região Nordeste, em ambos os sexos. O maior incremento de índice de massa corporal (IMC) ocorreu nos homens da zona rural na Região Sudeste. Em idosos de São Paulo (SP), Barbosa et al. (2007) relataram prevalência maior de obesidade nas mulheres (40,5\%), comparadas aos homens (21,6\%). Em idosos de Bambuí (MG), Barreto, Passos e Lima-Costa (2003) apontaram prevalência de obesidade de $12,5 \%$, positivamente associada com sexo feminino e inversamente associada à prática de atividade física. O baixo peso afetou 15\% dos indivíduos estudados e foi mais elevado nos homens de renda mais baixa, sendo a escolaridade protetora para o baixo peso, mas associada positivamente à obesidade. Campos et al. (2006), também estudando idosos, observaram que o aumento da renda domiciliar aumentou a prevalência de sobrepeso e obesidade. A alta escolaridade foi protetora para baixo peso, mas não foi encontrada associação entre escolaridade e obesidade.

Monteiro, Conde e Castro (2003) discutem a importância da escolaridade para o risco de obesidade, a partir de três grandes inquéritos populacionais nas regiões Sudeste e Nordeste do Brasil (1975, 1989 e 1997). Os autores concluem que houve aumento contínuo da obesidade em todos os estratos de escolaridade da população masculina, enquanto nas mulheres este aumento ocorreu de 1975 a 1989, tendendo a se concentrar nas mulheres com baixa escolaridade (menor ou igual a 4 anos) e a se estabilizar ou diminuir nas demais faixas, no período de 1989 a 1997. No estrato de máxima escolaridade, o declínio foi de 25\%.

A complexidade da transição nutricional no Brasil e sua relação com determinantes socioeconômicos foi mostrada por Monteiro, Conde e Popkin (2007), a partir de uma revisão de vários estudos seccionais realizados no país. A análise por sexo e já ajustada para idade 
mostra que, entre os homens, tem havido aumento de obesidade em todas as faixas de renda, com um gradiente: quanto maior a renda, maior a prevalência. Já no caso das mulheres, o incremento da obesidade foi mais acentuado nos dois quintis mais baixos de renda, com uma tendência à queda na maior faixa de renda. O padrão nos adolescentes é semelhante: no estudo de Magalhães e Mendonça (2003), a renda per capita domiciliar mensal elevada só se mostrou associada a sobrepeso e obesidade entre meninos. As meninas de maior renda mostram uma tendência à queda de sobrepeso/obesidade.

Alguns resultados dos estudos apresentados são bastante consistentes. Os estudos de Monteiro, Conde e Popkin (2001, 2007) e Monteiro, Conde e Castro (2003) mostram que a transição nutricional no Brasil se apresenta com uma dupla carga, desnutrição e obesidade. Segundo Doaket al. (2005), essa dupla carga freqüentemente ocorre no mesmo grupo familiar, principalmente no meio urbano, em famílias de baixa renda. Também segundo Monteiro, Conde e Popkin (2001), há uma diferença entre homens e mulheres quanto à associação de renda/escolaridade com a situação nutricional: entre adultos, a obesidade em mulheres associa-se negativamente com educação e renda e entre os homens associa-se positivamente com renda e negativamente com educação. A tendência à obesidade nas camadas mais pobres ocorre mais precocemente entre as mulheres, comparadas aos homens (Monteiro et al., 2004a, 2004b). Dada a complexidade da transição nutricional no país, é importante seguir investigando os principais mecanismos envolvidos na progressão acelerada da obesidade nos estratos menos favorecidos da população brasileira, com vistas a aumentar a efetividade das políticas e programas que buscam incidir sobre este problema.

\section{Saneamento Básico e Habitação}

A Pesquisa Nacional por Amostra de Domicílios (Pnad) registrou melhoria nos índices de cobertura dos serviços de água e esgoto no período de 1999 a 2004. Segundo a Pnad 2004, o percentual de domicílios particulares permanentes atendidos por rede geral de abastecimento de água aumentou de $80 \%$ para $83 \%$ e o percentual de domicílios servidos por esgotamento sanitário adequado (rede coletora ou fossa séptica) aumentou de $65 \%$ para $70 \%$, no referido período. Entretanto, há que se destacar as desigualdades regionais e entre municípios. Em 2005, enquanto nas regiões Sul e Sudeste, respectivamente, 83\% e 91\% da população estavam cobertos pela rede geral de abastecimento de água, na Região Norte a cobertura desses serviços alcançava apenas $54,8 \%$ da população e no Nordeste $72 \%$. Mas não há unanimidade a respeito dos dados: o mais recente levantamento sobre o tema, realizado pelo Centro de Políticas Sociais da Fundação Getulio Vargas (FGV) e pelo Instituto Trata Brasil (Neri, 2007), aponta para o fato de que 53\% da população brasileira ainda não teriam acesso a um saneamento adequado, e, no atual ritmo de ampliação do acesso, a universalização só se daria em 115 anos.

O Gráfico 23 mostra a associação entre a cobertura por saneamento básico e a mortalidade por doença diarréica em menores de 5 anos. 
Gráfico 23 - Indicadores de saneamento básico, segundo região. Brasil

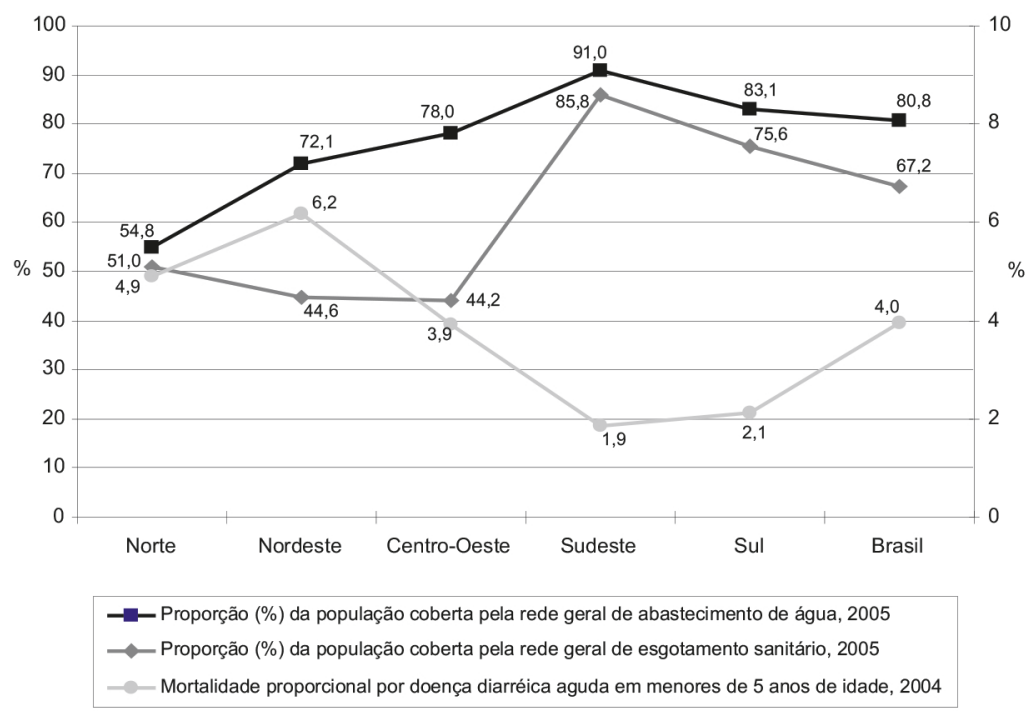

Fonte: IDB 2006 (Indicadores e Dados Básicos), produto da ação integrada do Ministério da Saúde e da Organização Pan-Americana da Saúde (Opas), no âmbito da Rede Interagencial de Informações para a Saúde (Ripsa).

No que se refere às regiões metropolitanas das capitais, as diferenças também são bastante significativas. Por exemplo, a proporção da população coberta pela rede de esgotamento sanitário, em 2005, variava de 44,26\% em Recife e 66,33\% em Fortaleza até 92,21\% em Curitiba e 91,97\% em Porto Alegre (Gráfico 24).

Gráfico 24 - Indicadores de saneamento básico, regiões metropolitanas. Brasil

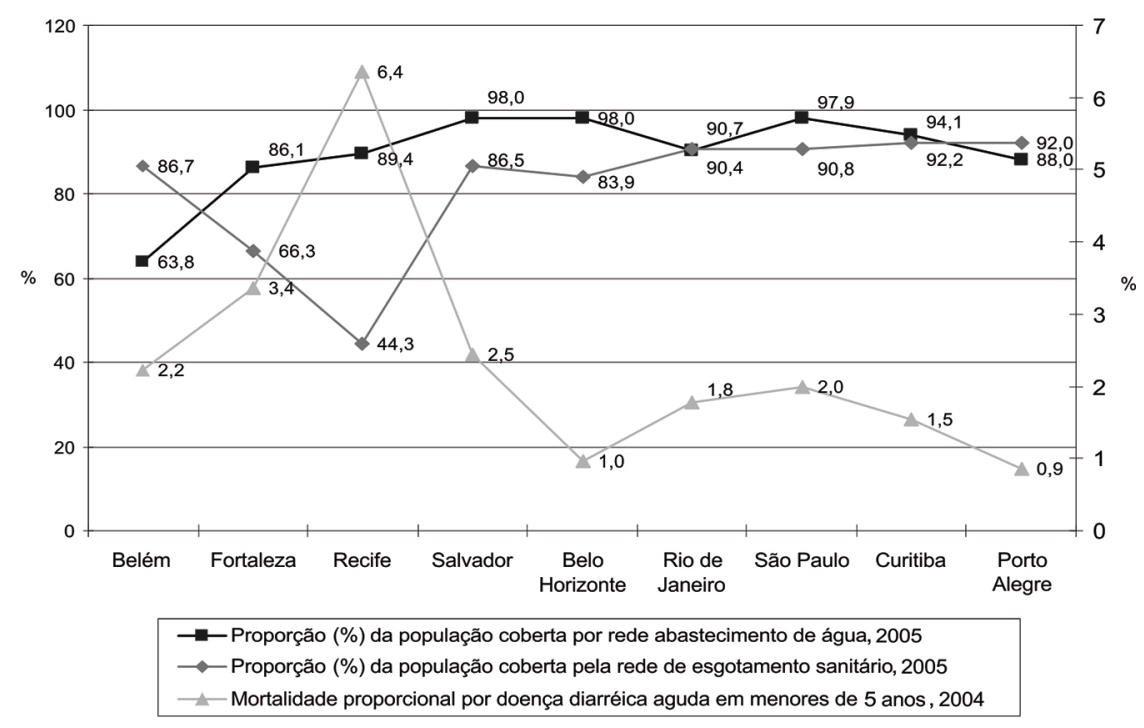

Fonte: IDB 2006 (Indicadores e Dados Básicos), produto da ação integrada do Ministério da Saúde e da Organização Pan-Americana da Saúde (Opas), no âmbito da Rede Interagencial de Informações para a Saúde (Ripsa). 
Entre os estudos que buscam avaliar o impacto do saneamento básico na doença diarréica aguda infantil, merece destaque um estudo realizado em Salvador por Barreto et al. (2007). Este estudo avaliou o efeito, sobre a morbidade por diarréia em menores de 3 anos, de uma intervenção iniciada em 1997, que ampliou a cobertura de serviços de esgoto na cidade de $26 \%$ para $80 \%$ dos domicílios. Foram feitos dois estudos longitudinais: em 1997-1998, antes da intervenção, e em 2003-2004, depois que ela foi completada. Cada estudo acompanhou uma coorte de crianças de 0-36 meses (841 no primeiro e 1.007 no segundo estudo), por um máximo de oito meses. Após os necessários ajustes para outras variáveis potencialmente confusoras, os autores concluíram que a prevalência de diarréia caiu em $22 \%$ entre a primeira e segunda coorte (9,2 dias por criança/ano antes da intervenção para 7,3 dias por criança/ano após a mesma).

\section{Condições de Emprego e Trabalho}

Os problemas de saúde dos trabalhadores estão intimamente relacionados com o grau de desenvolvimento alcançado por um país ou uma região. Os avanços tecnológicos e as mudanças industriais redefiniram o cenário do trabalho no Brasil, com a passagem de uma economia primariamente agrária e de mineração para uma economia industrial, com ênfase nas atividades de comércio e serviço. As características desse processo de transição tiveram por conseqüência importantes problemas sociais e econômicos que se expressam, por exemplo, por um crescimento constante do setor informal, salários baixos, maior insegurança no emprego e grandes diferenças sociais e regionais no que se refere a desemprego e trabalho infantil, como mostra a Tabela 19.

Tabela 19 - Indicadores de condições de emprego e trabalho, segundo região. Brasil

\begin{tabular}{|c|c|c|c|c|c|c|}
\hline \multirow{2}{*}{ Indicadores } & \multicolumn{5}{|c|}{ Região } & \multirow[b]{2}{*}{ BRASIL } \\
\hline & Norte & Nordeste & $\begin{array}{l}\text { Centro- } \\
\text { Oeste }\end{array}$ & Sudeste & Sul & \\
\hline $\begin{array}{l}\text { Taxa de desemprego ( } 10 \\
\text { anos ou mais de idade), } 2005\end{array}$ & 7,9 & 9,0 & 9,6 & 10,9 & 6,1 & 9,3 \\
\hline \multicolumn{7}{|l|}{$\begin{array}{l}\text { Taxa de desemprego ( } 10 \\
\text { anos ou mais de idade), por } \\
\text { cor da pele, 2005: }\end{array}$} \\
\hline Branca & 7,7 & 8,0 & 8,1 & 9,7 & 5,6 & 8,2 \\
\hline Preta & 8,8 & 13,4 & 12,0 & 12,3 & 10,1 & 12,3 \\
\hline Parda & 7,9 & 8,9 & 10,7 & 12,7 & 8,2 & 10,2 \\
\hline $\begin{array}{l}\text { Taxa de trabalho infantil (10 } \\
\text { a } 14 \text { anos de idade), } 2005\end{array}$ & 14,6 & 17,9 & 8,9 & 7,1 & 12,5 & 12,0 \\
\hline \multicolumn{7}{|l|}{$\begin{array}{l}\text { Taxa de trabalho infantil ( } 10 \\
\text { a } 14 \text { anos de idade), por cor } \\
\text { da pele, 2005: }\end{array}$} \\
\hline Branca & 12,6 & 15,0 & 7,6 & 5,9 & 12,5 & 9,6 \\
\hline Preta & 10,2 & 15,3 & 9,3 & 8,1 & 9,4 & 10,8 \\
\hline Parda & 15,3 & 19,2 & 9,6 & 8,7 & 12,7 & 14,4 \\
\hline
\end{tabular}

Fonte: IDB 2006 (Indicadores e Dados Básicos), produto da ação integrada do Ministério da Saúde e da Organização Pan-Americana da Saúde (Opas), no âmbito da Rede Interagencial de Informações para a Saúde (Ripsa).

${ }^{2}$ Esta seção é uma tradução livre de parte do estudo de caso do Brasil coordenado por Vilma Souza Santana (Ufba) para a "Knowledge Network on Employment Conditions and Health - Emconet" da Comissão sobre Determinantes Sociais da Saúde da OMS, tendo como autores Elizabeth Costa Dias, Roberval Passos de Oliveira, Jorge Mesquita Huet Machado, Carlos Mynaio Gómez, Marco António Gomes Pérez, Maria da Graça Luderitz Hoefel e Vilma Sousa Santana. 
Estudos mostram que o desemprego, o trabalho informal e a exclusão do mercado de trabalho estão associados a uma pior condição de saúde entre adultos brasileiros, independentemente de características sociodemográficas como escolaridade, renda e região de residência (Giatti \& Barreto, 2006).

A estes problemas se associam o deterioramento das condições de trabalho e crescentes danos ambientais. Os acidentes de trabalho são um dos subprodutos destas tendências, juntamente com uma grande carga de doenças profissionais e doenças relacionadas ao trabalho, cujas conseqüências contribuem para o agravamento dos problemas sociais que o país enfrenta. Acompanhando as grandes diferenças no desenvolvimento social e econômico das diversas regiões do Brasil, as características da saúde dos trabalhadores e das lesões e doenças relacionadas ao trabalho mostram um padrão misto, caracterizando uma carga dupla de doenças. Verifica-se a presença de algumas doenças já controladas em países desenvolvidos, como a silicose e outras pneumoconioses, envenenamento por chumbo, asbestose, mesotelioma relacionado com o asbesto, ao lado de outras "novas" doenças relacionadas ao trabalho como afecções musculoesqueléticas (como a síndrome do túnel do carpo e outras), doenças dermatológicas causadas por compostos químicos, além dos sintomas e desordens mentais relacionadas ao estresse, como a síndrome do burn-out. A combinação de formas tradicionais e novas de organização do trabalho acaba por determinar altos níveis de exposição aos perigos químicos e físicos, tarefas repetitivas, excessivo uso de força, posturas inadequadas, exposição ao estresse e fatores psicossociais, causando sofrimento e incapacidades temporárias e de longo prazo (Gómez \& Lacaz, 2005).

Contrariamente às doenças "profissionais" tradicionais, a identificação do grau de relação com o trabalho destas novas doenças associadas a condições modernas de trabalho, cuja importância é crescente, depende de estudos epidemiológicos que comparem diferentes grupos de trabalhadores, classificados de acordo com o tipo de trabalho, o tipo de ocupação e/ou o tipo de empresa (Schilling, 1984).

Apesar da importância da carga de doenças e das lesões relacionadas ao trabalho, as estatísticas nacionais e os dados epidemiológicos ainda são dispersos e de baixa qualidade. 0 Ministério da Previdência Social produz relatórios anuais, que se limitam aos trabalhadores formais, excluindo também os empregados públicos civis e militares. Os dados do Sistema Único de Saúde (SUS), a respeito de lesões e doenças relacionadas ao trabalho, são de baixa confiabilidade, apesar da recente obrigação legal de relatá-los às autoridades de saúde pública (Binder \& Cordeiro, 2003).

De acordo com os dados oficiais, referentes unicamente aos trabalhadores formais, 2.700 trabalhadores morreram em 2005 e 491.000 ficaram fora do trabalho, recebendo benefícios do seguro do trabalhador. Ao longo dos últimos 20 anos, vem ocorrendo uma diminuição constante dos acidentes de trabalho fatais, com uma queda de incidência de 26,2 por 100.000 (estimada em 1990) para 11,4 por 100.000 em 2003, correspondendo a uma redução de $56,5 \%$ (Santana, Nobre \& Waldvogel, 2005). Esta tendência foi interpretada como resultante do aumento da participação do setor terciário na economia (o setor de serviços), onde os riscos ocupacionais de acidentes são usualmente baixos, e também da migração dos trabalhadores 
formais para a economia informal (Wünsch Filho, 1999, 2004). Esta tendência de declínio foi também atribuída a mudanças no sistema de notificação (Fachini et al., 2005), já que não há nenhuma evidência de que foram adotadas no país ações eficazes para a prevenção.

Salerno (1998), estudando registros da mortalidade, em uma área altamente industrializada do estado de São Paulo, estimou para 1990 uma taxa de mortalidade por ferimentos decorrentes de acidentes do trabalho de 40,43 por 100.000 , entre trabalhadores subcontratados na indústria de transformação, quatro vezes mais alta que a taxa estimada para trabalhadores diretamente empregados, que foi de 9,39 por 100.000. Embora a mortalidade tenha declinado, em 1995, para 25,97 por 100.000 entre os subcontratados, a diferença aumentou de 6 para 1 quando comparados com os diretamente empregados. A incidência nacional de lesões não-fatais decorrentes de acidentes do trabalho estimada por estatísticas do Ministério da Previdência Social é de 1,6\% (Wünsch Filho, 1999), o que difere significativamente das estimativas obtidas em estudos baseados na comunidade. Por exemplo, no estado de São Paulo, Barata et al. (1998) referem uma incidência de 3,49\% de acidentes do trabalho, menor do que a de 5,8\% encontrada em Salvador, Bahia (Santana \& Loomis, 2004).

Os resultados de diversos estudos baseados na comunidade não mostraram nenhuma evidência de que os trabalhadores informais estão submetidos a um risco mais elevado de acidentes ocupacionais não fatais, quando comparados aos trabalhadores formais, o que sugere que as condições do trabalho são precárias tanto para trabalhadores informais como formais, em áreas urbanas e rurais (Barata, Ribeiro \& Moraes, 2000; Santana \& Loomis, 2004; Barbin Jr. \& Martini, 2006). Entretanto, diversos estudos mostraram, consistentemente, que os transtornos psicológicos menores ou sintomas mentais são mais comuns entre trabalhadores informais (Lurdermir \& Lewis, 2003; Santana et al., 1997).

Vários estudos mostram também a importância da violência, da agressão intencional e dos acidentes de tráfego, no perfil das mortes relacionadas ao trabalho no país (Machado \& Gomez, 1994; Waldvogel, 2002; Nobre, 2007). Grande número de acidentes fatais que ocorrem durante atividades do trabalho não são reconhecidos como mortes relacionadas ao trabalho. Tais ocorrências aparecem nas estatísticas como homicídios ou acidentes de trânsito, o que contribui para o sub-registro de acidentes do trabalho no Brasil (Hennington, Cordeiro \& Moreira Filho, 2004). Tem sido observado um grande número de mortes no trânsito de motoboys - entregadores de mercadorias que usam motocicletas, muito comuns nas grandes cidades e cada vez mais vistos também em áreas rurais, substituindo veículos de tração animal (Diniz, Assunção \& Lima, 2005).

As doenças profissionais e relacionadas ao trabalho podem ser comparadas a um iceberg: somente uma parcela pequena é visível e conhecida. Com o objetivo de melhorar a capacidade dos serviços de saúde para diagnosticar e registrar as doenças relacionadas ao trabalho, o Ministério da Saúde elaborou, em 1999, uma lista nacional de doenças relacionadas ao trabalho que foi endossada pelo Instituto Nacional de Seguridade Social (INSS). Ao redor de 200 eventos, classificados de acordo com a Classificação Internacional de Doenças (CID- 10a ed.), foram listados, utilizando um sistema de dupla entrada pelo risco/exposição e pelo dano de saúde/doença. 
No período de 2000 a 2002, o INSS reconheceu 58.978 casos de doenças relacionadas ao trabalho, o que corresponde somente aos trabalhadores que têm contratos formais e são elegíveis para benefícios, que representam apenas $23 \%$ do total de trabalhadores. Conseqüentemente, grande número de casos permanecem desconhecidos. Um bom exemplo são as doenças respiratórias relacionadas ao trabalho, que mostram uma sobreposição entre o passado, o presente e o futuro. Além dos casos já existentes de silicose, novos casos vêm ocorrendo, apesar dos esforços nacionais para a erradicação desta doença. A situação atual com relação à exposição à silica é bastante diferente do que ocorria no passado, embora ainda haja a necessidade de soluções inovadoras para a vigilância e para os programas de combate às pneumoconioses no país (Castro et al., 2004; Castro, Silva \& Vicentin, 2005; Bon, 2006). Um estudo transversal com trabalhadores de pedreiras estimou uma prevalência de $54 \%$ de silicose, encontrando também diversos casos de sílico-tuberculose (Antão, 2003). A maioria de pacientes de silicose (66\%), registrados em um programa de cuidado à saúde, estavam vinculados a formas arcaicas de processo de trabalho na economia informal (Carneiro et al., 2002).

O mesotelioma pleural maligno e outras doenças respiratórias relacionadas ao asbesto estão começando a aparecer, uma vez que a latência para seu aparecimento é relativamente grande e a história da exposição ocupacional e/ou ambiental ao asbesto no país é relativamente recente (Mendes, 2001; Castro et al., 2005). Estão também aparecendo casos de asma relacionados ao trabalho, que gradativamente está se transformando numa doença respiratória de alta freqüência, apesar de seu escasso reconhecimento por parte dos médicos, o que leva a dificuldades para obtenção de benefícios (Faria et al., 2006; Fernandes, Stelmachi \& Algranti, 2006).

As doenças dermatológicas relacionadas ao trabalho, dado o número elevado de casos, a incidência cumulativa, o impacto econômico e o mau prognóstico, vêm se constituindo num relevante problema de saúde pública. O setor manufatureiro, principalmente o que lida com metais e química, e a construção civil, são responsáveis pela maioria dos casos. Atualmente, um bom número de pacientes vem do comércio por atacado e varejo, serviços, atividades de limpeza e serviços de saúde. Em um estudo transversal realizado com trabalhadores de uma indústria farmacêutica, Melo (1999) estimou uma prevalência de $78 \%$ de doenças de pele, sendo que $23 \%$ daquelas relacionadas ao trabalho não tiveram nenhum registro de seu caráter ocupacional.

Com relação aos distúrbios músculo-esqueléticos relacionados ao trabalho, é amplamente reconhecido que este grupo de afecções está liderando, em nível mundial, a maior carga das conseqüências de condições inadequadas de trabalho (principalmente fatores organizacionais, esforços mecânicos e fadiga) na saúde dos trabalhadores. As áreas do corpo mais afetadas são a coluna, o pescoço e os membros superiores, sendo que a bacia e o joelho são também freqüentemente atingidos. Estima-se que os distúrbios músculoesqueléticos são responsáveis por um terço de todas as causas que requerem afastamento do trabalho. Os setores manufatureiros e de serviços são responsáveis por metade dos casos, enquanto caminhoneiros, profissionais de enfermagem e trabalhadores fora da construção 
civil são responsáveis por um quinto dos mesmos. Entre profissionais de enfermagem de 23 instituições de saúde do estado de Minas Gerais, Murofuse e Marziale (2005) encontraram registros de afecções osteomusculares em 12\% de seus prontuários médicos, sendo que 35\% cumpriam com os critérios para identificá-los como relacionados ao trabalho.

As causas orgânicas e não-orgânicas das desordens mentais também merecem ser mencionadas. Exposições a neurotoxinas, tais como mercúrio, chumbo, manganês ou solventes orgânicos são algumas das causas orgânicas mais comuns de distúrbios mentais relacionados ao trabalho. Os problemas mentais sem causa orgânica são reconhecidos como um dos principais problemas de saúde ocupacional, tanto no Brasil como no resto do mundo, com uma proporção elevada de trabalhadores que relatam níveis médios a elevados de estresse no trabalho, o que os leva a sofrer os conseqüentes efeitos psicológicos adversos. As causas não orgânicas de tensão psicológica resultam: do ambiente físico de trabalho; das tarefas e responsabilidades; da estrutura organizacional; dos relacionamentos interpessoais no trabalho; das mudanças de trabalho; de eventos traumáticos, tais como doença ocupacional ou ferimento por acidente do trabalho.

Os distúrbios mentais não-orgânicos incluem o estresse pós-traumático, doenças psicossomáticas, uso de drogas, ansiedade e depressão. Diversos estudos recentes realizados no Brasil tratam deste problema, como o estudo realizado por Porto et al. (2006) com professores no estado da Bahia, encontrando que a prevalência de distúrbios mentais entre professores submetidos a elevado grau de tensão era 1,5 vezes maior do que entre professores com menor grau de tensão. Os distúrbios mentais foram associados a mudanças ou deslocamentos de trabalho entre trabalhadores da indústria de mineração de ferro (Guimarães \& Teixeira, 2003) e à implantação de um processo de "reestruturação" de uma companhia estatal (Brant \& Dias, 2004), estudos realizados no estado de Minas Gerais.

A perda da audição induzida pelo ruído deve ser incluída como uma afecção relacionada ao trabalho de alta prevalência. De fato, um recente estudo, realizado no estado do Rio de Janeiro, estimou uma prevalência de 15,9\% entre trabalhadores da indústria de metal (Guerra et al., 2005). Em Goiânia, um outro estudo relatou $21 \%$ de prevalência entre trabalhadores da mesma indústria (Araújo, 2002). No estado de Santa Catarina, uma prevalência de 25,9\% foi encontrada por Sakae et al. (2006), nos resultados de exames audiométricos de trabalhadores que atendem ao Serviço Social da Indústria (Sesi). Em diversos ambientes, o ruído coexiste com outros fatores potencialmente perigosos para a audição, de modo que é importante adotar uma certa cautela antes de atribuir o achado de perda de audição a uma única causa (Azevedo, 2004; Mello \& Waismann, 2004).

Entre trabalhadores rurais, apenas $33,7 \%$ possuem contratos formais de trabalho. Além dos problemas relacionados aos pesticidas (Silva et al., 2005), a incidência de ferimentos decorrentes de acidentes do trabalho parece ser mais elevada do que as estimativas relatadas em áreas urbanas. Fehlberg, Santos e Tomasi (2001) encontraram uma incidência de 11\% de acidentes do trabalho entre trabalhadores rurais em um estado do sul do país. o crescimento do consumo dos pesticidas no Brasil levou o país a ser, atualmente, o quarto maior usuário do mundo. Estimativas do Ministério do Meio Ambiente revelam que, nas últimas duas décadas, 
o consumo de pesticidas no país aumentou quatro vezes (Brasil, 2000). Segundo dados do Sistema Nacional de Informações Toxicológicas (Sinitox), a taxa total de envenenamentos humanos agudos por pesticidas foi de 8,0 por 100.000 em 2003, estimando-se que destes 1,25 por 100.000 estavam relacionados ao trabalho. Faria, Fassa \& Fachinni (2007) estimaram uma incidência de envenenamentos agudos entre trabalhadores rurais de 2,2 por 100.000, durante o período de 2001-2002. A prevalência de trabalhadores expostos variou de $3 \%$ a $23 \%$, o que corresponde a cerca de 540.000 trabalhadores envenenados, com um número potencial de mortes de aproximadamente 4.000 trabalhadores por ano (Moreira et al., 2002).

\section{Ambiente e Saúde ${ }^{3}$}

A urbanização, o crescimento do transporte e das indústrias, assim como a expansão da fronteira agrícola, criaram as condições propícias para uma permanente exposição de contingentes populacionais, progressivamente maiores, à poluição atmosférica e dos corpos hídricos. Esta poluição é gerada por fontes fixas e móveis de emissão de poluentes, por acidentes com produtos químicos voláteis e pelas mudanças no uso do solo geradas por atividades agropastoris, provocando, como conseqüência, efeitos adversos sobre a saúde das populações expostas. Segundo a Organização Mundial da Saúde (WHO, 2000), o número estimado de mortes causadas por problemas decorrentes da poluição atmosférica no mundo é de cerca de 3 milhões por ano, o que representa $5 \%$ do total de 55 milhões de mortes que ocorrem anualmente. Em algumas populações, cerca de 30\% a 40\% dos casos de asma e $20 \%$ a 30\% de todas as doenças respiratórias podem ser relacionadas à poluição atmosférica.

O impacto da poluição do ar na saúde, no Brasil, tem sido amplamente documentado na literatura. Vários estudos enfocam os efeitos de curto prazo provocados pela poluição do ar, embora esse fenômeno possa também provocar danos à saúde a médio e a longo prazos. Os estudos epidemiológicos utilizados na maioria das pesquisas sobre a relação "exposiçãoefeito da poluição do ar" fazem uso de dados secundários, tais como o número de óbitos, internações hospitalares, atendimentos realizados na rede básica de saúde, admissões em serviços de urgência por diversas causas, uso de medicamentos, procedimentos específicos, como a nebulização, dentre outros indicadores de saúde escolhidos, que podem ser apresentados de forma diária, semanal ou mensal. Os estudos têm mostrado que aumentos nos níveis de poluentes do ar se associam a aumentos na mortalidade e na morbidade, tanto por problemas respiratórios como cardiovasculares, em especial entre idosos e crianças. Outros efeitos referem-se a perdas econômicas, aumento no absenteísmo escolar, dias de trabalho perdidos, asma e nebulizações.

Crianças e idosos têm sido identificados como os dois grupos etários mais vulneráveis aos efeitos da poluição atmosférica. Esses efeitos atingem, principalmente, o sistema respiratório, por contato direto com o poluente, e o cardiovascular, por ação direta nas células dos vasos e

${ }^{3}$ Esta seção baseia-se no capítulo sobre Ambiente e Saúde da publicação "Brasil 2006: uma análise da situação de saúde no Brasil", do Ministério da Saúde, Secretaria de Vigilância em Saúde. Brasília: Ministério da Saúde, 2006. 620 p.: il. ISBN 85-334-1223-1. Contou também com a contribuição de Roberto Smeraldi. 
do coração ou por resposta inflamatória sistêmica (Godleski et al., 2000). Portanto, apesar de todos estarem sujeitos aos efeitos adversos dos poluentes do ar, são os indivíduos portadores de doenças do pulmão e/ou do coração os mais afetados. Na década de 1990, as primeiras estimativas de efeito da poluição do ar mostraram que a mortalidade total de idosos está diretamente associada com a variação do material particulado inalável (PM10), pois variações de $10 \mu \mathrm{g} / \mathrm{m} 3$ nas suas concentrações aumentam as mortes de idosos em 1,3\% (Saldiva et al., 1995). Entre essas mortes, a maior parte se deve às doenças respiratórias e cardiovasculares (Miraglia et al., 1997). Além do PM10, outros poluentes como o dióxido de enxofre (SO2) e o monóxido de carbono (CO) também estão diretamente ligados a efeitos adversos à saúde.

Os poluentes causam, também, um importante impacto na morbidade. Aumentos no número de atendimentos em pronto-socorro por doenças respiratórias em idosos (Martins et al., 2002a, 2002b) e doenças isquêmicas do coração (Lin et al., 2003) também estão ligados a aumentos de concentrações de $\mathrm{PM} 10, \mathrm{SO}_{2}, \mathrm{CO}, \mathrm{NO}_{2}$, poluentes primários, e $\mathrm{O}_{3}$, um poluente secundário. Todos esses são poluentes comuns em grandes centros urbanos, como a Região Metropolitana de São Paulo. Mais recentemente, foi demonstrado que os efeitos dos poluentes nas doenças cardiovasculares se manifestam também em adultos e que as mulheres podem ser mais acometidas que os homens (Martins et al., 2004; Martins et al., 2006). Entre as crianças e os adolescentes, os efeitos adversos dos poluentes estão amplamente distribuídos por diferentes grupos etários. Ainda no período fetal, aumentos agudos de $\mathrm{NO}_{2}$ e $\mathrm{SO}_{2}$ podem precipitar mortes fetais tardias (Pereira et al., 1998), enquanto a exposição crônica ao longo da gestação pode acarretar diminuição do peso de nascimento (Gouveia, Bremer \& Novaes, 2004). Após o nascimento, nos primeiros 28 dias de vida, a mortalidade neonatal é influenciada pelos poluentes (Lin et al., 2004), e esse efeito adverso pode ser notado, de modo mais intenso, até os 5 anos de idade (Saldiva et al., 1994; Conceição et al., 2001).

Os atendimentos de pronto-socorro e as internações hospitalares por doenças respiratórias são bons indicadores dos efeitos da poluição do ar na saúde de crianças e adolescentes e têm sido amplamente utilizados nos estudos realizados, principalmente na Região Metropolitana de São Paulo. Desses estudos, pode-se concluir que tanto as doenças infecciosas como as doenças inflamatórias são afetadas pelos poluentes (Lin et al., 1999; Braga et al., 1999; Martins et al., 2002a, b; Farhat et al., 2005). Entretanto, o impacto é maior entre as crianças com menos de 2 anos e entre os adolescentes com mais de treze anos de idade (Braga et al., 2001), mostrando, dentro desse grupo etário, diferentes suscetibilidades. Dentre as cidades da referida Região Metropolitana, os maiores efeitos dos poluentes sobre as doenças respiratórias são encontrados na cidade de São Paulo e nas cidades do ABC paulista (Freitas et al., 2002).

Além dos grupos suscetíveis, alguns estudos realizados na Região Metropolitana de São Paulo identificaram alguns aspectos muito importantes para os estudos de epidemiologia ambiental. Mesmo entre crianças, adolescentes e idosos, os efeitos dos poluentes podem ser modulados pela condição socioeconômica daqueles que estão expostos (Sobral, 1989; Martins 
et al., 2004; Martins et al., 2002a, 2002b; Martins et al., 2006). Os indivíduos apresentam respostas diferentes a estímulos semelhantes em função das suas condições de vida. Esse ponto é de fundamental importância na formulação de políticas públicas voltadas para o estabelecimento de metas de redução de emissão de poluentes. Outro ponto importante é a possibilidade de encontrar alterações clínicas e metabólicas, que são precursoras de doenças respiratórias e cardiovasculares, entre indivíduos sadios mas expostos aos poluentes do ar. Esse é o caso do estudo que mostra controladores de tráfego da Companhia de Engenharia de Tráfego da Prefeitura Municipal de São Paulo apresentando alterações da pressão arterial e de marcadores inflamatórios sangüíneos em dias mais poluídos (Santos et al., 2005). Essas alterações podem não ser suficientes para desencadear doenças em indivíduos normais, mas podem explicar o que leva as pessoas com doenças prévias a apresentarem descompensação clínica nos dias mais poluídos.

Os custos financeiros da poluição do ar também foram estimados, nos estudos anteriormente referidos, a partir dos valores estatísticos de referência do valor da morbidade humana para países em desenvolvimento, na faixa de US\$512.000,00. Dessa forma, os custos foram estimados na ordem de grandeza de US\$ 1,5 bilhão por ano, apenas em referida área metropolitana (Saldiva, depoimento pessoal a Roberto Smeraldi, 2008).

Outra questão de grande relevância é a conversão de ecossistemas para dar lugar ao avanço da fronteira de colonização. Ao longo da última década, este fenômeno atingiu, em média, mais de 3,5 milhões de hectares por ano, principalmente na floresta amazônica e no cerrado, mas também na caatinga, pantanal, mata atlântica e pampa (Inpe/Prodes, 2007; Fundação SOS Mata Atlântica, 2007). A conversão de ecossistemas naturais se dá em função de uma série de fatores, incluindo especulação fundiária, aprópriação de terras públicas, movimentos populacionais vinculados a grandes obras de infra-estrutura não planejadas, assentamento de colonos, pressão da pecuária ou de certas commodities agrícolas (como nos casos recentes da cana ou da soja) e atividade madeireira ilegal.

O processo de conversão contribui de inúmeras formas para o agravamento dos problemas de saúde, inclusive porque a fronteira carece de infra-estrutura para o atendimento das populações que a protagonizam. Uma atividade que contribui de forma significativa para o agravamento das doenças respiratórias é a das queimadas, que se dividem em queimadas de derrubadas (vinculadas ao desmatamento e que acontecem uma vez por todas) e queimadas de pastagem ou de renovação de determinadas culturas, como no caso da cana. Em todos os casos, crianças e idosos são especialmente vulneráveis. Em mais de 600 municípios do país, a situação atinge todo ano picos cronicamente emergenciais (Bussamra et al., 2004).

Outra conseqüência do desmatamento é a malária, que, após ter diminuído no começo da década, voltou nos últimos anos ao patamar do final dos anos 90, na faixa de aproximadamente 600 mil casos registrados por ano. A derrubada da floresta e o represamento de igarapés e rios favorecem a proliferação do mosquito transmissor (Anopheles darlingi), que utiliza água parada e limpa para se reproduzir. Dois estudos publicados recentemente reforçam 
essa tese. o primeiro, que utiliza dados de assentamentos rurais de Rondônia, afirma que as áreas de desmatamento recentes têm maiores incidências da doença ("malária de fronteira”) quando comparadas às áreas de desmatamento antigas (Castro et al., 2006). O segundo estudo, realizado na amazônia peruana, revela que nas áreas sob desmatamento, as taxas de picadas do inseto transmissor chegam a ser 278 vezes maiores do que nas áreas florestadas (Vittor et al., 2006). A incidência de malária nos municípios da Amazônia ocorre com maior freqüência nas regiões onde há desmatamento com alta intensidade nos últimos anos - como o centro-oeste do Pará, norte de Rondônia, noroeste do Mato Grosso e sul do Amazonas (Celentano \& Veríssimo, 2007). Assentados da reforma agrária, índios e ribeirinhos são os mais vulneráveis. Áreas não-florestais e fronteiras antigas de desmatamento apresentam menor intensidade da doença.

\section{Acesso a Serviços de Saúde}

Os serviços de saúde possuem a capacidade de diminuir a exposição aos fatores de risco para a saúde de indivíduos e grupos, assim como a vulnerabilidade e, principalmente, as conseqüências da exposição a esses fatores de risco. O acesso eqüitativo aos serviços de saúde é, portanto, de grande importância para diminuir os diferenciais observados em relação a estes aspectos.

A Constituição de 1988, além de reconhecer a saúde como direito de todo cidadão e dever do Estado, estabeleceu as bases do Sistema Único de Saúde (SUS). De acordo com o texto constitucional, o SUS tem três princípios constitucionais e três princípios organizativos. Os princípios constitucionais incluem a universalização da assistência, garantida a todo cidadão; a integralidade da atenção, incluindo todas as ações necessárias à promoção, prevenção, tratamento e reabilitação; e a eqüidade, ofertando serviços e bens segundo as necessidades. Os princípios organizativos são a descentralização da gestão, com participação das esferas federal, estadual e municipal; a regionalização e hierarquização das redes de serviços; e a participação da comunidade na gestão do sistema.

Os números do SUS impressionam pela magnitude. No ano de 2005, foram realizadas cerca de 450 milhões de consultas médicas, 11,8 milhões de internações, 2,6 milhões de partos, 250 milhões de exames laboratoriais, 40 milhões de vacinações, 80 mil cirurgias cardíacas e 20 mil transplantes de órgãos.

O Programa de Saúde da Família (PSF) é um programa de Atenção Básica em Saúde, onde equipes multiprofissionais são responsáveis pelo acompanhamento de um número definido de famílias, localizadas em uma área geográfica limitada. As equipes atuam em ações de promoção da saúde, prevenção, recuperação e reabilitação de doenças e agravos. São formadas por um médico de família, um enfermeiro, um auxiliar de enfermagem e seis agentes comunitários de saúde, podendo, ainda, contar com um dentista, um auxiliar de consultório dentário e um técnico em higiene bucal. Cada equipe é responsável por mil famílias, abrangendo uma população total de 3 mil a 4,5 mil pessoas. O trabalho da equipe se desenvolve nas residências, nas Unidades Básicas de Saúde e na comunidade. 
Iniciado em 1994, o Programa conta, em 2008, com cerca de 27,5 mil equipes (mais de 150 mil profissionais), atuando em 5.131 municípios (92\% do total de municípios brasileiros). Em 2006, o PSF atendia a mais de 80 milhões de pessoas (cobertura de 44\% da população), com um orçamento total de R 2 bilhões (US\$ 900 milhões) por ano (Tabela 20).

Tabela 20 - Indicadores do PSF, segundo região. Brasil - 2006

\begin{tabular}{|c|c|c|c|c|c|c|}
\hline \multirow[b]{2}{*}{ Indicadores } & \multicolumn{5}{|c|}{ Região } & \multirow[b]{2}{*}{ BRASIL } \\
\hline & Norte & Nordeste & $\begin{array}{l}\text { Centro- } \\
\text { Oeste }\end{array}$ & Sudeste & Sul & \\
\hline $\begin{array}{l}\text { População coberta } \\
\text { (1) }\end{array}$ & 5.569 .915 & 32.634 .393 & 5.830 .341 & 26.384 .939 & 11.675 .249 & 82.216 .837 \\
\hline $\begin{array}{l}\text { \% de população } \\
\text { coberta pelo } \\
\text { Programa }\end{array}$ & 37,9 & 63,2 & 43,9 & 33,2 & 42,8 & 44,0 \\
\hline $\begin{array}{l}\text { Média mensal de } \\
\text { visitas por família } \\
\text { (2) }\end{array}$ & 0,1 & 0,1 & 0,1 & 0,1 & 0,1 & 0,1 \\
\hline $\begin{array}{l}\text { \% de cobertura de } \\
\text { consultas de pré- } \\
\text { natal (2) }\end{array}$ & 85,4 & 88,7 & 95,0 & 94,1 & 95,8 & 91,2 \\
\hline
\end{tabular}

(1) Situação no final do ano.

(2) Como numerador e denominador, foi utilizada a média mensal.

Fonte: Caderno de Informações em Saúde, Datasus/MS, julho/2007.

Outro programa cujos avanços merecem ser destacados é o Programa Nacional de Imunização (PNI), que em 2008 completa 35 anos. O PNI logrou superar as grandes diferenças regionais na cobertura de vacinações de anos anteriores, alcançando uma cobertura praticamente universal em menores de um ano a partir de 1999, quando chegou a 94,7\%, enquanto que em 1978, atingia somente 40\% das crianças. O Gráfico 25 mostra os resultados obtidos para a vacinação contra a poliomielite. Este padrão se repete para o sarampo, DPT e outras vacinas incluídas no Programa, o que trouxe como resultado a erradicação da poliomielite (último caso em junho de 1989 e certificado de erradicação concedido pela OMS em 1994) e a diminuição da incidência e mortalidade das demais doenças.

Apesar destes inegáveis avanços na produção de serviços e dos princípios de universalidade e eqüidade que regem o SUS, ainda se observam importantes desigualdades na oferta de recursos e serviços, assim como uma forte influência da posição social dos indivíduos no acesso, utilização e qualidade dos serviços de saúde. 
Gráfico 25 - Cobertura vacinal contra poliomielite, por região. Brasil - 1994 - 2006

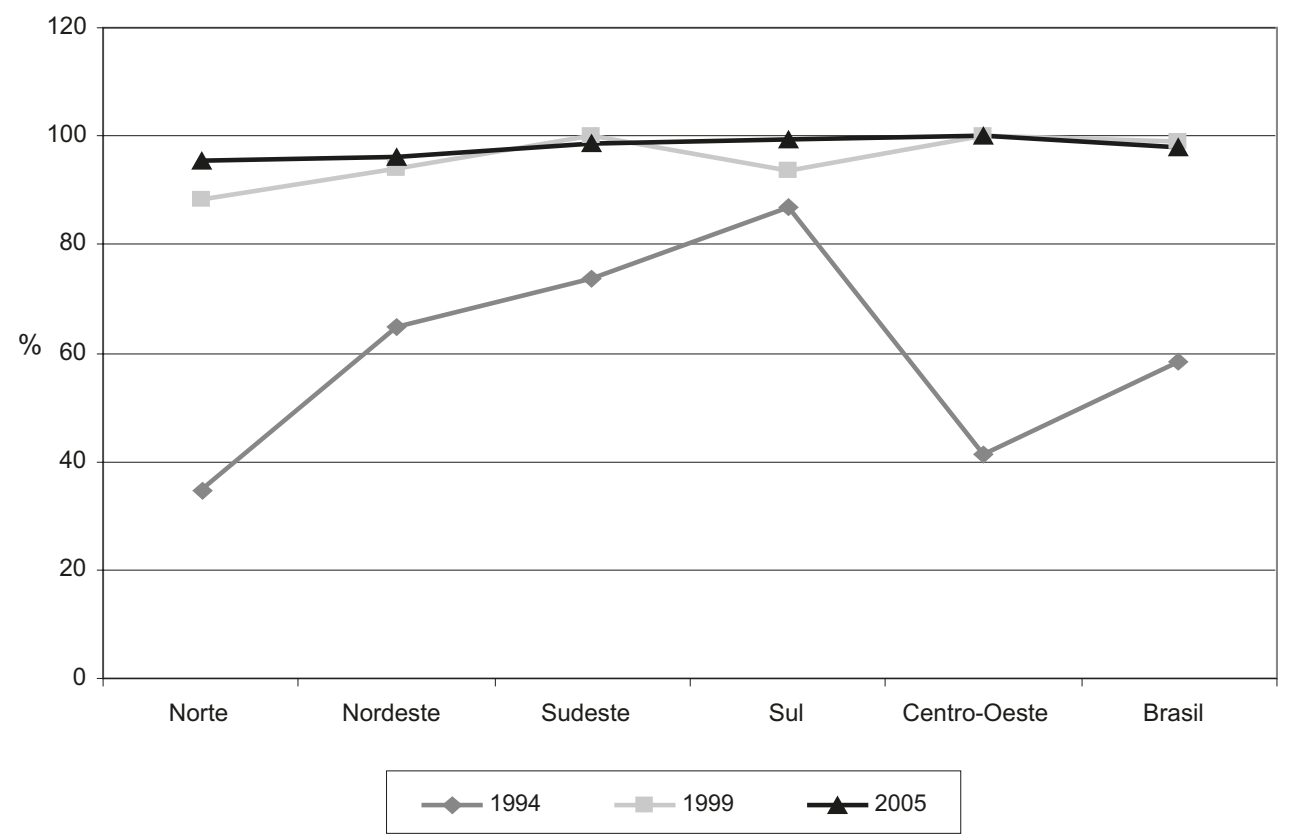

Fonte: Programa Nacional de Imunização (PNI).

O Brasil gasta 7\% do Produto Interno Bruto (PIB) em saúde, cerca de 530 dólares per capita, abaixo de Argentina (US\$1.045), Chile (US\$827) e Uruguai (US\$ 781), para citar alguns países do Cone Sul. A proporção de gasto público/privado, em termos percentuais, é de 49/51, proporção esta que nos países citados (Argentina, Chile e Uruguai) é de 55/45, 53/47 e 71/29, respectivamente (Opas, 2007). A Tabela 21 mostra que o gasto público per capita em saúde é relativamente baixo em todas as regiões e não cumpre uma função compensatória, tendendo a reforçar as desigualdades. A tabela também mostra que as famílias de menor renda gastam uma proporção muito maior de seu orçamento com saúde em comparação com as de maior renda, chegando essa diferença, no caso das regiões Norte, Centro-Oeste e Sul, a ser cerca de 2,5 vezes maior em pontos percentuais. Pode-se também observar que há uma grande disparidade entre as regiões na distribuição de leitos e médicos, particularmente destes últimos, altamente concentrados na Região Sudeste.

A organização dos serviços de saúde no Brasil é do tipo misto, com um sistema público de acesso universal (SUS) e um sistema privado de seguros e planos de saúde, sendo que a cobertura deste último está claramente relacionada ao nível de renda, como mostra o Gráfico 26. 
Tabela 21 - Indicadores de serviços de saúde, segundo região. Brasil

\begin{tabular}{|c|c|c|c|c|c|c|}
\hline \multirow[b]{2}{*}{ Indicadores } & \multicolumn{5}{|c|}{ Região } & \multirow[b]{2}{*}{ BRASIL } \\
\hline & Norte & Nordeste & $\begin{array}{l}\text { Centro- } \\
\text { Oeste }\end{array}$ & Sudeste & Sul & \\
\hline Médicos por mil habitantes, 2005 & 0,8 & 1,0 & 1,7 & 2,3 & 1,7 & 1,7 \\
\hline Leitos por mil habitantes, 2005 & 1,9 & 2,3 & 2,6 & 2,4 & 2,8 & 2,4 \\
\hline $\begin{array}{l}\text { Gasto público total com saúde per } \\
\text { capita (em reais), } 2004\end{array}$ & 308,3 & 252,0 & 325,6 & 360,6 & 306,7 & 358,5 \\
\hline $\begin{array}{l}\text { Despesa familiar com assistência à } \\
\text { saúde como proporção (\%) da } \\
\text { renda familiar, segundo classes de } \\
\text { rendimento, 2003: }\end{array}$ & & & & & & \\
\hline Até 400 reais & 6,6 & 5,3 & 10,4 & 9,7 & 7,6 & 7,1 \\
\hline Mais de 6.000 reais & 2,6 & 4,5 & 3,9 & 5,1 & 3,2 & 4,5 \\
\hline
\end{tabular}

Fonte: IDB 2006 (Indicadores e Dados Básicos), produto da ação integrada do Ministério da Saúde e da Organização Pan-Americana da Saúde (Opas), no âmbito da Rede Interagencial de Informações para a Saúde (Ripsa).

Gráfico 26 - Proporção (\%) da população residente coberta por plano de saúde, por classes de rendimento mensal familiar e região. Brasil - 2003

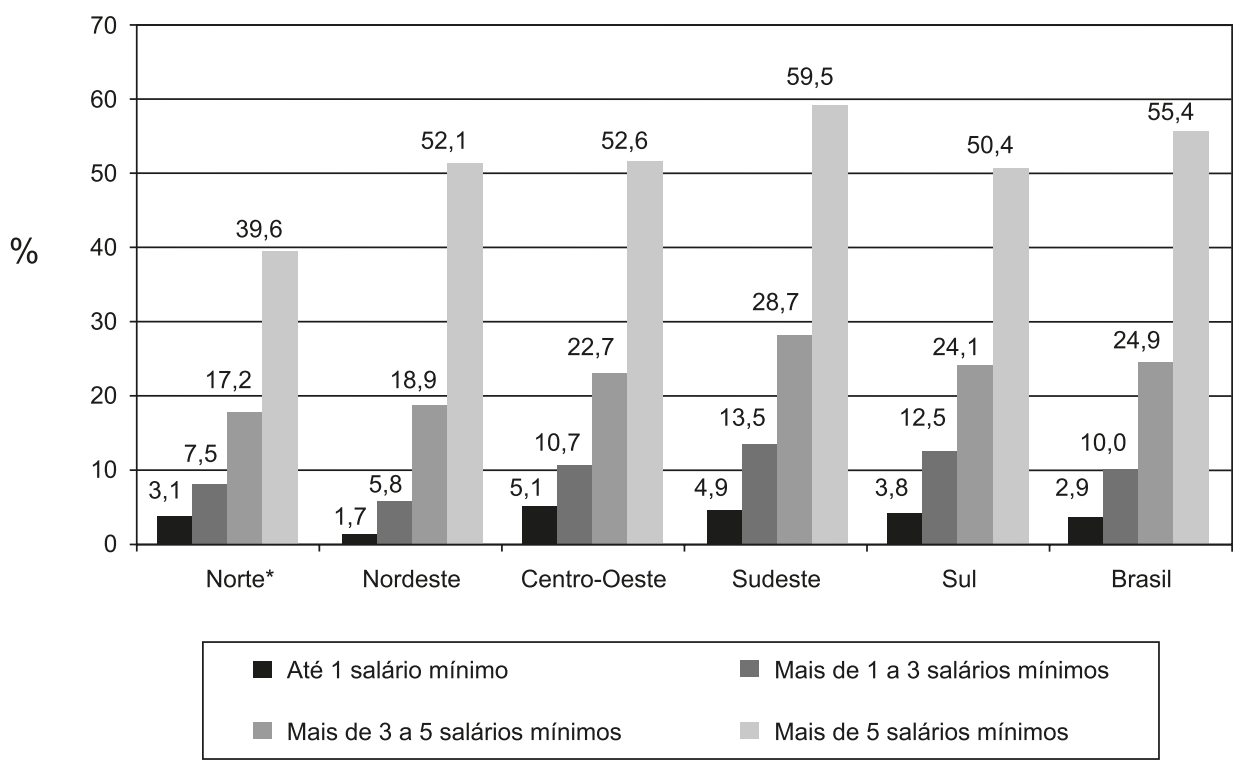

*Exclusive a população rural.

Fonte: Elaboração própria, a partir da Pesquisa Nacional por Amostra de Domicílios (Pnad) 2003 - Acesso e Utilização de Serviços de Saúde. Instituto Brasileiro de Geografia e Estatística (IBGE). 
No Gráfico 27, construído com dados da Pesquisa Nacional por Amostra de Domicílios (Pnad), de 2003, a partir da pergunta sobre onde a pessoa procurou atendimento para uma determinada queixa no período de referência, observa-se uma clara relação entre nível de renda e percentual de pessoas que procuram serviços do SUS ou dos planos de saúde.

Gráfico 27 - Porcentagem de pessoas ocupadas, de 10 anos e mais (na semana de referência), atendidas pelo SUS e/ou que têm plano de saúde, por nível de renda (em salários mínimos per capita). Brasil - 2003

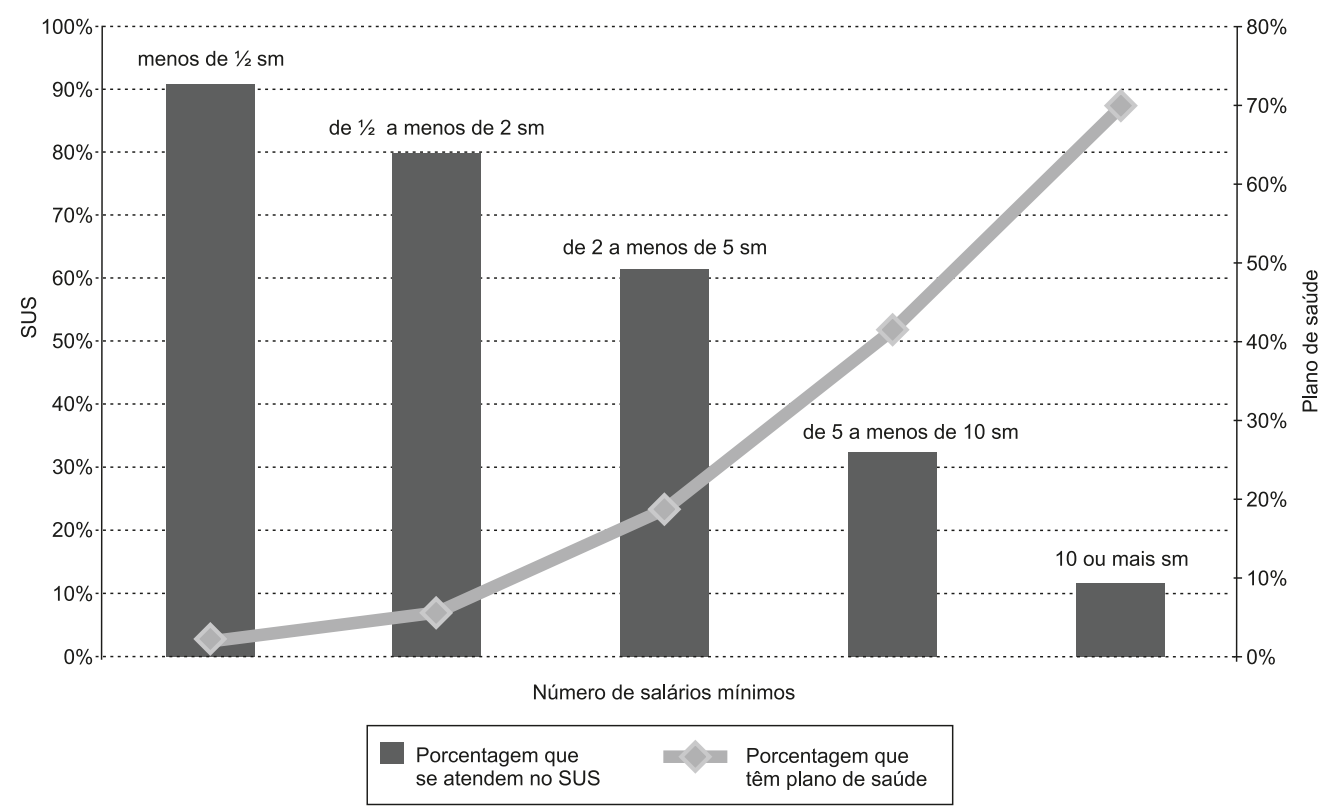

Fonte: Pesquisa Nacional por Amostra de Domicílios (Pnad), 2003.

Dados da Pesquisa Mundial de Saúde mostram uma associação entre melhor nível socioeconômico e maior uso de serviços de saúde, o que, para Viacava, Souza Jr. e Szwarcwald (2005), pode significar um maior uso de serviços pela população mais saudável (Gráfico 28).

As desigualdades sociais no acesso e na utilização de serviços de saúde estão, em grande medida, relacionadas com a estrutura e funcionamento dos sistemas de saúde, o que faz com que tais desigualdades sejam bastante permeáveis às políticas setoriais. Os determinantes da utilização de serviços de saúde estão relacionados às necessidades de saúde (morbidade, gravidade e urgência da doença), aos usuários (idade, sexo, renda, educação, região de moradia), aos prestadores de serviços (especialidade, experiência profissional, tipo de prática, formas de pagamento), à organização da oferta (disponibilidade de médicos, hospitais, ambulatório, acesso geográfico, modo de remuneração) e à política do sistema de saúde (tipo de sistema de saúde, proposta assistencial, distribuição de recursos, legislação, entre outros) (Travassos \& Martins, 2004). 
Gráfico 28 - Porcentagem de pessoas ocupadas de 10 anos e mais (na semana de referência), atendidas por médico e/ou dentista, por nível de renda (em salários mínimos per capita). Brasil - 2003

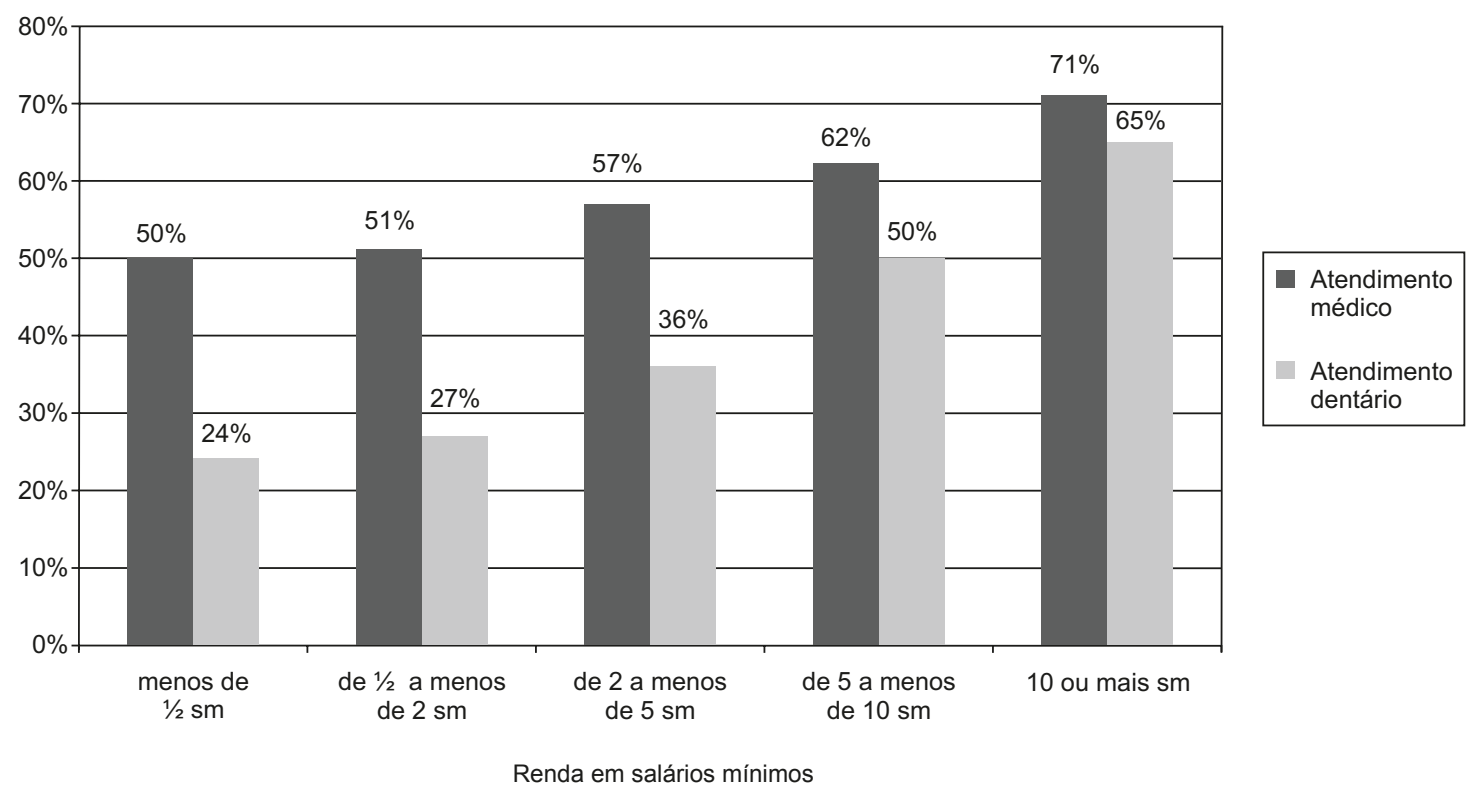

Fonte: Pesquisa Nacional por Amostra de Domicílios (Pnad), 2003.

Na literatura publicada nos últimos cinco anos, há um importante número de estudos dedicados a conhecer a influência destes diversos fatores no acesso e utilização dos serviços de saúde no Brasil.

Castro, Travassos e Carvalho (2005) procuraram identificar o efeito da oferta de serviços de saúde nas internações hospitalares para adultos e crianças, concluindo que a oferta não altera a associação entre a posição social e o uso de internações hospitalares no Brasil. Os autores encontraram que 97 a 99\% da variação na chance de internação são explicados por características do indivíduo, ou seja, apenas 1 a 3\% da variação do uso das internações pode ser atribuído a diferenças na oferta entre as unidades da federação.

Ao analisar o perfil dos indivíduos que procuraram os serviços de saúde nos últimos 15 dias, mas não conseguiram (acesso não realizado), Ribeiro et al. (2006) observaram maior dificuldade para aqueles com pior nível socioeconômico. As tentativas sem êxito de acesso aos serviços de saúde foram maiores entre os usuários do SUS, embora 11,2\% dos indivíduos com cobertura por planos de saúde também não tenham conseguido ser atendidos no mesmo período de referência, mostrando que a posse de planos de saúde não é suficiente para garantir o acesso. Segundo os autores, tal fato sugere que, pelo menos em parte, os problemas de acesso não se esgotam nas características socioeconômicas dos indivíduos, refletindo também problemas de oferta e organização dos serviços de saúde. 
Entretanto, os papéis das variáveis individuais e de necessidade têm se destacado nos estudos recentes. Análise dos dados da Pnad de 2003 revela que as pessoas da classe de maior renda com restrição de atividades rotineiras por motivo de saúde nos 15 dias que antecederam a entrevista têm 59,5\% mais chances de usar serviços de saúde do que aquelas da classe de menor renda. O mesmo efeito é observado em relação à escolaridade: entre os indivíduos com 9 ou mais anos de escolaridade a chance de uso é 20,9\% maior do que a das pessoas de menor escolaridade. Apesar da persistência de um padrão de marcadas desigualdades sociais no uso de serviços de saúde tanto para adultos quanto para as crianças, observa-se uma tendência de redução ao se comparar com as informações obtidas na Pnad de 1998 (Travassos, Oliveira \& Viacava, 2006).

A associação inversa entre renda e uso de serviços de saúde foi observada por Lima-Costa, Matos e Camarano (2006), ao comparar os grupos etários de 20-64 anos e 65 anos e mais, mostrando que as desigualdades sociais afetam igualmente adultos e idosos.

Estudo realizado na cidade de Pelotas mostra que o consumo de consultas médicas é fortemente influenciado pela renda. Indivíduos pertencentes às classes sociais A e B apresentam uma chance $13 \%$ maior de obter uma consulta nos três meses anteriores à entrevista quando comparados com aqueles das classes D e E (Capilheira \& Santos, 2006).

A clientela usuária do SUS é constituída, predominantemente, pela parcela da população de menor renda e baixa escolaridade. Ribeiro et al. (2006), analisando os dados da Região Metropolitana de São Paulo, mostra a presença de um gradiente inversamente proporcional entre as variáveis escolaridade e renda e o atendimento pelo SUS, que se mantém mesmo após o controle de outras variáveis. A chance de um indivíduo com até 3 anos de estudo usar o serviço público é quatro vezes maior do que aquele com 11 anos de estudo ou mais, enquanto naqueles pertencentes aos estratos mais baixos de renda a chance é dezenove vezes maior, quando comparados com os de maior renda.

Pessoto et al. (2007), analisando as desigualdades no uso de serviços de saúde entre o setor público e o setor privado na região metropolitana de São Paulo, mostram que os possuidores de planos de saúde, independentemente da renda, demandam mais serviços de saúde, quando comparados com aqueles sem plano de saúde. Além disso, o tempo médio de espera para consulta, indicador de qualidade no acesso aos serviços de saúde, é menor entre a população beneficiária dos planos de saúde.

Em relação ao tipo de serviço utilizado, os que possuem cobertura por planos de saúde procuram mais clínicas e consultórios, e somente 3,9\% usam as unidades de saúde do SUS, principalmente para vacinação e acesso a medicamentos cedidos pela rede pública. A parte da população usuária apenas do SUS procura mais prontos-socorros do que centros de saúde (duas vezes mais), sendo muito baixa a referência de uso de clínicas e consultórios. Estas desigualdades apontam para uma grande diferença entre a porta de entrada no sistema de saúde para a população usuária do SUS e os consumidores de planos de saúde. A maior 
procura por atendimento de urgência/emergência entre os usuários do SUS reflete menor oferta e/ou acesso à rede de unidades básicas (Ribeiro et al., 2006).

Com relação às diferenças regionais, o artigo de Travassos, Oliveira e Viacava (2006), já citado, comparando os dados dos dois últimos suplementos de saúde da Pnad (1998 e 2003), pode ser considerado o estudo-síntese da questão. Nele foi observado que as desigualdades geográficas no acesso aos serviços de saúde aumentaram no período estudado. Este aumento foi influenciado pela melhora do acesso nas regiões mais desenvolvidas, comparativamente com as menos desenvolvidas. Nos dois anos, as pessoas residentes nas regiões Sul e Sudeste, com restrição de atividades rotineiras por motivo de saúde nos 15 dias que antecederam a entrevista, apresentaram maiores chances de uso dos serviços de saúde do que as residentes nas outras regiões. A chance de uso de serviços na Região Norte foi quase a metade da observada nas regiões Sul e Sudeste (45\% menos chance). Já nas regiões Nordeste e Centro-Oeste as chances foram $40 \%$ e $23 \%$ menores, respectivamente. Na análise desagregada por regiões, persistiu o padrão de desigualdades, influenciadas particularmente pela renda e escolaridade. A Região Sul foi a que apresentou maiores desigualdades sociais. Os moradores do sul do país, e que pertencem à classe social mais alta, apresentaram chance $95 \%$ maior de uso de serviços quando comparados com os de renda mais baixa. Somente as regiões Sudeste e Norte não apresentaram diferenças significativas no uso de serviços por classe de renda, entretanto nestas regiões a escolaridade foi a variável mais associada com desigualdades.

Quanto à assistência à saúde das mulheres, o estudo de Novaes, Braga e Schout (2006), de base nacional, encontrou um gradiente de aumento do acesso ao exame de Papanicolau correspondente ao aumento da renda e da escolaridade, sendo a cobertura desse exame mais elevada nas mulheres de maior renda e escolaridade, quando comparadas às mulheres com renda inferior a um salário mínimo e aquelas analfabetas ou com primeiro grau incompleto. Quadros, Victora e Da Costa (2004), em Pelotas, encontraram que 70\% das mulheres analfabetas não realizaram exame de Papanicolau nos últimos três anos, enquanto apenas $11,8 \%$ das mulheres com doze ou mais anos de estudo não o fizeram. O estudo de Quadros, Victora e Da Costa (2004) também apontou para o menor conhecimento sobre o exame de Papanicolau entre as mulheres de menor escolaridade, com cerca de 30\% dessas mulheres demonstrando ausência de conhecimento sobre esse exame, enquanto que para as mulheres de melhor nível educacional esse valor foi inferior a 5\%. Pinho et al. (2003), em São Paulo, demonstraram menor retorno do resultado do exame de Papanicolau em mulheres de classe social mais baixa e menor escolaridade, revelando um pior seguimento dessas mulheres. Martins, Thuler e Valente (2005) apresentam extensa revisão bibliográfica sobre o tema.

Dois estudos recentes (Oliveira et al., 2006; Pereira et al., 2007) avaliaram desigualdades no diagnóstico e tratamento das lesões pré-malignas de câncer cervical. O primeiro estudo comparou mulheres de renda mais alta, atendidas em clínicas particulares e mulheres de baixa renda, atendidas no serviço público, encontrando que as mulheres de renda alta têm 
acesso mais rápido e mais fácil ao tratamento antes que se desenvolvam lesões pré-malignas. O segundo estudo identificou a prevalência de HPV (human papilomavirus) e outros fatores de risco para câncer cervical. Idade da primeira relação sexual, paridade, idade e tabagismo foram fatores associados, sendo que os mediadores para a progressão das lesões pré-malignas até o câncer foram a idade e o nível de escolaridade, comprovando a importância das desigualdades sociais na detecção e no desenvolvimento do câncer cervical.

Quanto aos exames para rastreamento do câncer de mama, três inquéritos nacionais (Leal et al., 2005; Novaes, Braga \& Schout; 2006; Lima-Costa \& Matos, 2007) avaliaram o acesso ao exame de mamografia em mulheres de diferentes faixas etárias e com diferentes intervalos de tempo (dois ou três anos). Todos encontraram coberturas abaixo do recomendado, com menor acesso em mulheres com menor escolaridade e nível econômico, seja ele medido pela renda ou pela classe social. Lima-Costa e Matos (2007) apontam para um progressivo aumento da realização da mamografia com o aumento da escolaridade e renda familiar per capita, independentemente de todas as demais variáveis consideradas no estudo, sendo essa associação ainda mais forte nas mulheres de 50 a 59 anos. Leal et al. (2005) e Novaes, Braga \& Schout (2006) afirmam que para o exame de mamografia, o gradiente observado segundo escolaridade e nível socioeconômico é ainda maior do que o observado em relação ao exame de Papanicolau, sendo a cobertura de $22 \%$ para mulheres com menos de quatro bens de consumo e de $75 \%$ para aquelas com oito ou mais (Leal et al., 2005). Todos os trabalhos demonstram iniqüidades no acesso a esse exame, associadas a menor escolaridade, poder aquisitivo do usuário e acesso a serviços de saúde.

Com relação a intervenções para contracepção, Vieira et al. (2001) avaliaram o uso de métodos contraceptivos no período 1986-1996, tomando por base dados da Pnad 1986 e da Pesquisa Nacional de Demografia e Saúde (PNDS) realizada em 1996. Encontraram maior proporção de laqueadura tubária nas mulheres de menor escolaridade (37,9\% em analfabetas para 26,0\% nas mulheres com mais de 12 anos de estudo). Padrão inverso foi observado na esterilização masculina, com aumento progressivo do uso desse método conforme aumento da escolaridade, passando de zero em parceiros de mulheres analfabetas a $13,7 \%$ entre os parceiros de mulheres com mais de 12 anos de estudo.

\section{Acesso à Informação}

Um determinante social da saúde, cuja importância nem sempre é reconhecida com o destaque que merece é o acesso à informação. De fato, o acesso a fontes e fluxos de informação em saúde aumenta o conhecimento e a capacidade de ação, permitindo a adoção de comportamentos saudáveis e a mobilização social para a melhoria das condições de vida. Em contrapartida, a falta de acesso de grandes setores da população ao conhecimento e à informação diminui significativamente sua capacidade de decidir e atuar em favor de sua saúde e da coletividade. As iniqüidades de informação são, portanto, especialmente graves, pois, ao reforçar a exclusão, têm o poder de gerar e ampliar outras iniqüidades (Pellegrini Filho, 2002). 
O acesso à informação em saúde está hoje grandemente facilitado pelas novas tecnologias de informação e comunicação (TIC), particularmente a Internet, as quais podem exercer uma grande influência sobre a situação de saúde e, em particular, sobre as iniqüidades em saúde, por meio de diversos mecanismos.

Em primeiro lugar, por sua capacidade de incidir sobre outros importantes determinantes da saúde, como as relações sociais, os processos culturais e outros aspectos fortemente relacionados com o bem-estar físico, mental e social. Em segundo lugar, as novas TIC estão redefinindo o próprio conceito de comunidade, liberando-a dos limites geográficos. As pessoas podem, hoje, estar em constante contato com seus familiares, amigos e colegas, através do mundo, utilizando telefones celulares, e-mails e outras tecnologias. Estas comunidades virtuais estão mudando a maneira como entendemos a criação e manutenção do capital social e, concretamente, podem oferecer importante apoio, principalmente para os que estão isolados pela idade, por deficiência física ou mesmo os que vivem em lugares demasiado distantes.

Em terceiro lugar, as TIC exercem um importante impacto sobre as iniqüidades em saúde, na medida em que permitem ampliar o acesso à informação por parte de grupos excluídos dos processos de tomada de decisões de qualquer tipo, trazendo como conseqüência seu "empoderamento", sua constituição como atores sociais e, em ultima instância, o fortalecimento da sociedade civil e do próprio processo democrático. As TIC permitem a esses grupos aumentar seu conhecimento dos problemas locais e globais, tomar decisões, estreitar suas relações com outros grupos e fortalecer sua organização e inserção em ações coletivas, aumentando a coesão e a cooperação para benefício mútuo.

Entretanto, todo este potencial das TIC está ameaçado se não se resolvem as iniqüidades de acesso a essas tecnologias, também chamadas de brecha digital ou digital divide. Segundo o Ibope/Netratings, no terceiro trimestre de 2007, os usuários de Internet no Brasil, apesar de um crescimento de cerca de $21 \%$ em relação ao ano passado, são atualmente cerca de 39 milhões, uma minoria da população total, que através deste meio consegue acesso a bens e oportunidades para ascender socialmente. Os Gráficos 29 e 30, confeccionados com dados da Pnad 2006, mostram as enormes desigualdades no acesso à Internet desde qualquer local (residência, trabalho, escola, cibercafé etc.), segundo escolaridade, renda e região de moradia, com gradientes que chegam a mais de 60 ou 70 vezes de diferença entre os dois grupos situados nos extremos de renda e escolaridade. 
Gráfico 29 - Percentual das pessoas que utilizaram a Internet, nos últimos três meses, na população de 10 anos ou mais de idade, por grandes regiões, segundo anos de estudo. Brasil - 2005

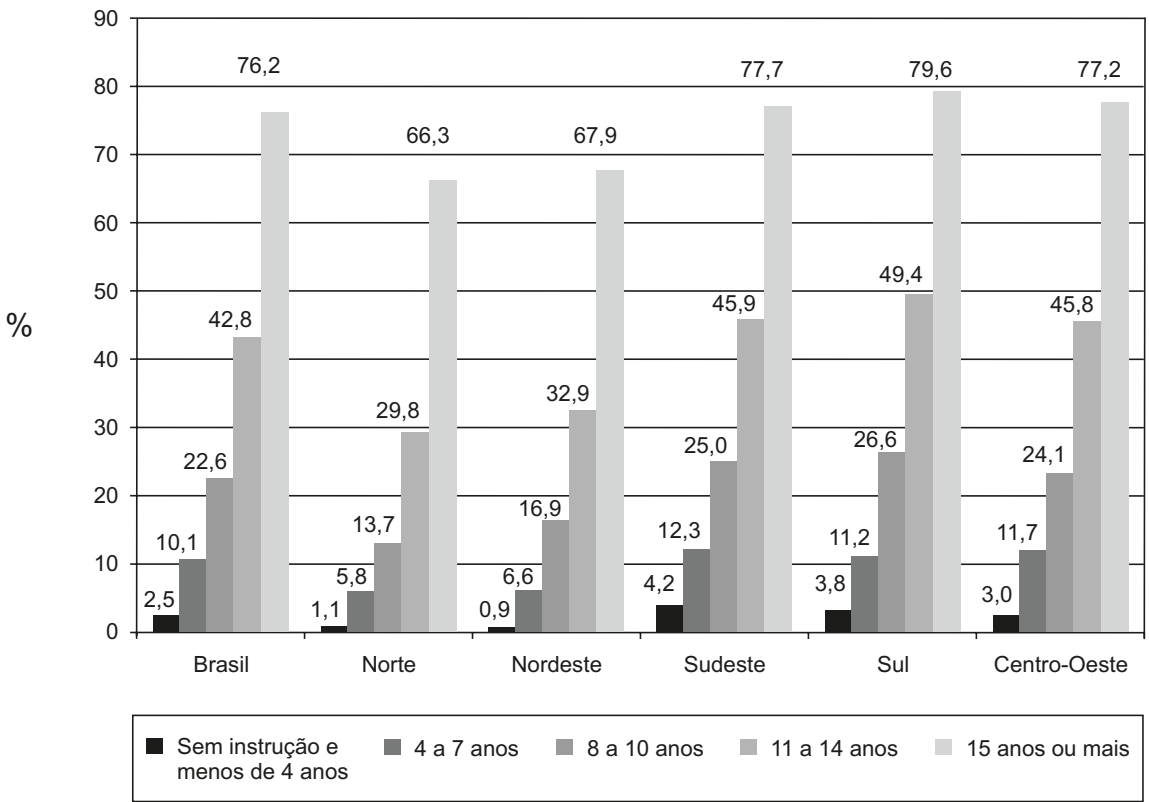

Fonte: Diretoria de Pesquisas, Coordenação de Trabalho e Rendimento, Pesquisa Nacional por Amostra de Domicílios 2005. Instituto Brasileiro de Geografia e Estatística (IBGE).

Gráfico 30 - Percentual das pessoas que utilizaram a Internet, nos últimos três meses, na população de 10 anos ou mais de idade, por grandes regiões, segundo o rendimento mensal domiciliar per capita. Brasil - 2005

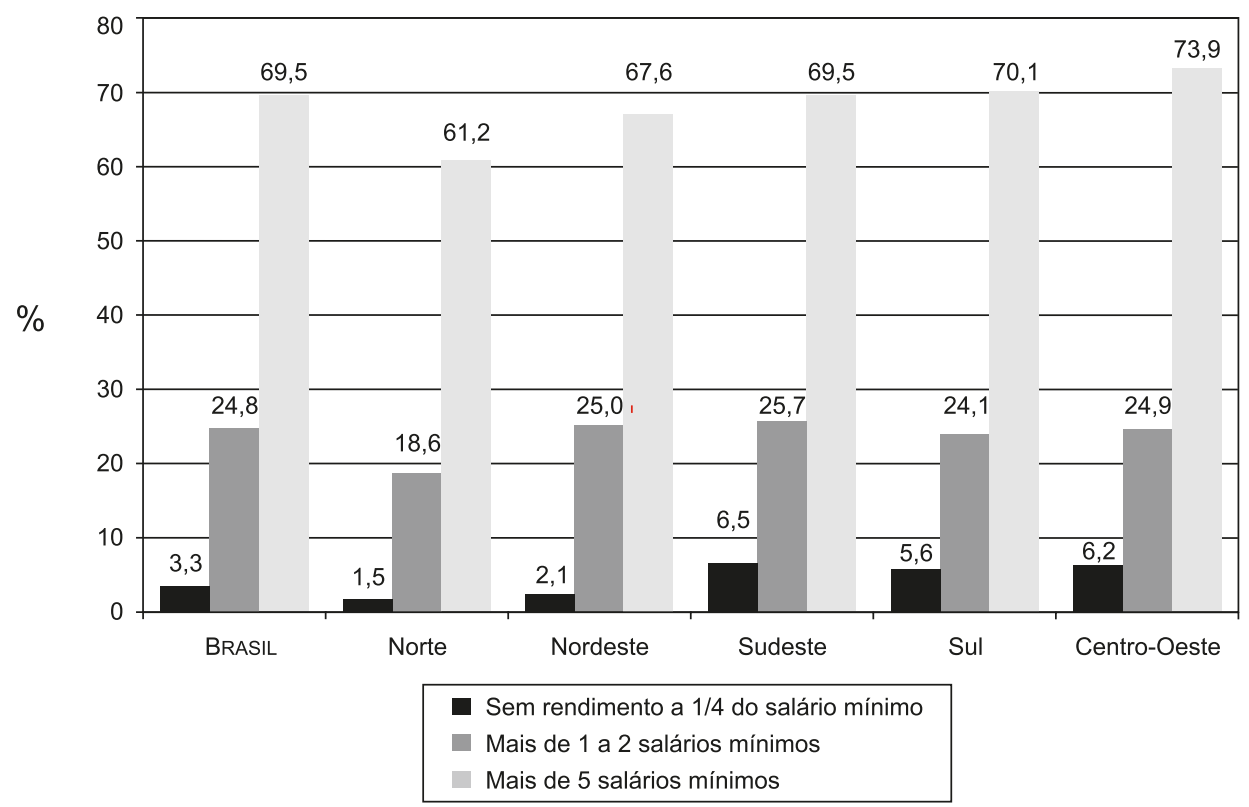

Fonte: Diretoria de Pesquisas, Coordenação de Trabalho e Rendimento, Pesquisa Nacional por Amostra de Domicílios, 2005. Instituto Brasileiro de Geografia e Estatística (IBGE). 
Segundo dados da comScore Networks (www.comscore.com), uma empresa dedicada a coletar dados para medir o avanço das tecnologias digitais, em janeiro de 2007, cerca de 747 milhões de pessoas maiores de 15 anos tinham acesso à Internet em todo o mundo, um aumento de $10 \%$ em relação ao ano anterior. Enquanto o trem e a eletricidade levaram décadas para difundir-se nos países em desenvolvimento, as TIC estão avançando nestes países a uma velocidade bem maior do que nos países desenvolvidos. Entre os 15 países com maior número de usuários, a Índia, a Rússia e a China foram os que tiveram maior incremento, (respectivamente, 33\%, 21\% e 20\%). O Brasil está em quinto lugar em percentual de crescimento, com 16\%. A China é, atualmente, o segundo país em acesso à Internet no mundo, com 86,8 milhões de usuários, atrás apenas dos Estados Unidos, que vem crescendo cerca de $2 \%$ ao ano, alcançando atualmente 153,4 milhões de usuários acima de 15 anos de idade, conforme mostra a Tabela 22.

Tabela 22 - Os quinze países com maior número de usuários de Internet acima de 15 anos de idade*

\begin{tabular}{l|ccc}
\hline \multicolumn{1}{c|}{ Países } & $\begin{array}{c}\text { Jan-06 } \\
(000)\end{array}$ & $\begin{array}{c}\text { Jan-07 } \\
(000)\end{array}$ & $\begin{array}{c}\text { \% de } \\
\text { Mudança }\end{array}$ \\
\hline TotAL MUNDIAL & 676.878 & 746.934 & $10 \%$ \\
\hline Estados Unidos & 150.897 & 153.447 & $2 \%$ \\
China & 72.408 & 86.757 & $20 \%$ \\
Japão & 51.450 & 53.670 & $4 \%$ \\
Alemanha & 31.209 & 32.192 & $3 \%$ \\
Reino Unido & 29.773 & 30.072 & $1 \%$ \\
Coréia do Sul & 24.297 & 26.350 & $4 \%$ \\
França & 23.712 & 24.560 & $33 \%$ \\
Índia & 15.867 & 21.107 & $11 \%$ \\
Canadá & 18.332 & 20.392 & $13 \%$ \\
Itália & 15.987 & 18.106 & $16 \%$ \\
Brasil & 12.845 & 14.964 & $4 \%$ \\
Espanha & 12.206 & 12.710 & $21 \%$ \\
Rússia & 10.471 & 12.707 & $3 \%$ \\
Holanda & 10.772 & 11.077 & $18 \%$ \\
México & 8.624 & & \\
& & 149 & \\
\hline
\end{tabular}

* Exclui acesso desde locais públicos como Internet e cafés ou desde telefone celular 
A própria revolução eletrônica pode contribuir para fazer desaparecer ou diminuir essas diferenças de acesso entre países e no interior dos mesmos. Para aumentar sua rede de comunicação, os países em desenvolvimento não precisam necessariamente reproduzir os mesmos caminhos e os grandes investimentos feitos pelos desenvolvidos. Podem, por exemplo, utilizar diretamente novas tecnologias por satélite, que exigem menos investimentos e manutenção e de fato o estão fazendo. Os telefones celulares permitem estender a comunicação a lugares onde os fios de cobre demorariam muitos anos para alcançar. Novos produtos de baixo custo, como minicomputadores que se ajustam à palma da mão, permitem o acesso à Internet em qualquer lugar e não seria absurdo imaginar que, em alguns anos, os estudantes de baixa renda poderão levá-los às escolas como fazem hoje com as calculadoras manuais que, até há não muito tempo, também tinham preços proibitivos.

Entretanto, o aproveitamento destas e outras oportunidades para superar o problema das iniqüidades de informação depende do estabelecimento de políticas explicitamente desenhadas para tal. Estas políticas devem basear-se no reconhecimento de que o conhecimento, a informação e a Internet são bens públicos e devem, portanto, ser objeto de políticas públicas.

O acesso à Internet está condicionado à existência e disponibilidade de uma infra-estrutura de tecnologia de informação e de telecomunicações. Para possibilitar o acesso a essa infra-estrutura, especialmente àqueles indivíduos que não contam com recursos próprios, é necessário o estabelecimento de uma política de inclusão digital por parte da esfera governamental que, entre outras estratégias, favoreça o acesso em espaços públicos como escolas, bibliotecas e quiosques. Além de facilitar o acesso, as políticas governamentais devem também promover a produção de informação de qualidade. Quando a "explosão da informação" se limita ao predomínio da quantidade sobre o conteúdo pode estimular a passividade dos sujeitos e comprometer o exercício de sua cidadania. Dessa forma, não é o acesso a mais bases de dados, a mais informações, nem a redes mundiais, que por si só irá proporcionar mais conhecimento, se essa informação não está estruturada para incentivar o raciocínio crítico que permite interpretá-la (Branco, 2006).

Segundo Eng et al. (1998), as causas responsáveis pelas diferenças de acesso à Internet estão relacionadas ao custo, barreiras geográficas, nível educacional, características culturais e outros fatores relacionados à capacidade das pessoas para usar serviços de maneira adequada. O autor classifica as barreiras de acesso em três grupos: as relacionadas com a infra-estrutura e hardware; as relacionadas com o tipo de informação e de software; as características dos próprios não-usuários. Para superar estas barreiras, sugere uma série de estratégias que buscam ampliar o acesso à informação e comunicação on-line em domicílios e lugares públicos, como o desenvolvimento de programas que tenham em conta a diversidade de potenciais usuários, apoio à pesquisa sobre temas relacionados ao problema do acesso, garantia da qualidade da informação, capacitação de usuários e de intermediários (entre estes, as organizações comunitárias não-governamentais) e, finalmente, a integração do conceito de acesso universal à informação como parte da política de saúde. 


\subsection{Redes Sociais, Comunitárias E SAúde}

As redes sociais e comunitárias, incluídas no modelo de Dahlgren e Whitehead entre os determinantes sociais da saúde, são constituintes do chamado capital social, entendido este como o conjunto das relações de solidariedade e confiança entre pessoas e grupos. Além do contato com amigos e parentes, diferentes formas de participação social como pertencer a grupos religiosos, associações sindicais, associações de moradores e clubes de recreação também representam formas pelas quais grupos de pessoas mantêm-se em contato e estabelecem vínculos sociais.

O desgaste do capital social é um importante mecanismo através do qual as iniqüidades socioeconômicas impactam negativamente a situação de saúde. Países com frágeis laços de coesão social resultantes dessas iniqüidades são os que menos investem em capital humano e em redes de apoio social e são também onde há menor participação na definição de políticas públicas. Diversos estudos mostram que não são as sociedades mais ricas as que possuem melhores níveis de saúde, mas as que são mais igualitárias e com alta coesão social. Nestas sociedades, as pessoas são mais envolvidas com a vida pública, vivem mais, são menos violentas e avaliam melhor sua própria saúde (Patussi, Hardy \& Sheiham, 2006).

Um importante indicador da riqueza do capital social são as relações de confiança entre as pessoas. Segundo dados da Pesquisa Social Brasileira (PSB), que realizou 2.363 entrevistas entre julho e outubro de 2002 (Almeida, 2007), as relações de confiança no Brasil são extremamente débeis, praticamente limitando-se à confiança em familiares. Como mostra a Tabela 23 , enquanto $84 \%$ das pessoas confiam na família, apenas $15 \%$ confiam na maioria das pessoas.

Tabela 23 - Relações de confiança no Brasil (\% de respondentes) - 2007

\begin{tabular}{l|ccccc}
\hline Resposta & $\begin{array}{c}\text { Confiança na } \\
\text { família }\end{array}$ & $\begin{array}{c}\text { Confiança } \\
\text { nos amigos }\end{array}$ & $\begin{array}{c}\text { Confiança } \\
\text { nos vizinhos }\end{array}$ & $\begin{array}{c}\text { Confiança } \\
\text { nos colegas } \\
\text { de trabalho }\end{array}$ & $\begin{array}{c}\text { Confiança na } \\
\text { maioria das } \\
\text { pessoas }\end{array}$ \\
\hline Não confia & 16 & 70 & 77 & 70 & 85 \\
Confia & 84 & 30 & 23 & 30 & 15 \\
\hline
\end{tabular}

Fonte: PSB in Almeida AC, 2007

A escolaridade está fortemente associada ao capital social. Segundo dados da mesma PSB, há uma enorme diferença entre os entrevistados que possuem nível superior completo e os que se encontram nas demais faixas de escolaridade. Como pode ser observado na Tabela 24, somando-se a confiança nos familiares e nos amigos, para os entrevistados com nível superior, essa proporção chega a 156\%, sendo que nas demais faixas varia de $96 \%$ a $114 \%$. 
Tabela 24 - Relações de confiança no Brasil, segundo escolaridade (\% de respondentes) - 2007

\begin{tabular}{l|c|c|c|c}
\hline \multirow{2}{*}{ Escolaridade } & \multicolumn{2}{|c|}{ Confiança na família } & \multicolumn{2}{c}{ Confiança nos amigos } \\
\cline { 2 - 5 } & Confia & Não confia & Confia & Não confia \\
\hline Analfabeto & 83 & 17 & 31 & 69 \\
Até a 4. série & 82 & 18 & 23 & 77 \\
Da 5. a 8. série & 78 & 22 & 21 & 79 \\
Ensino médio & 86 & 14 & 30 & 70 \\
Superior ou mais & 96 & 4 & 60 & 40 \\
\hline
\end{tabular}

Fonte: PSB in Almeida AC, 2007

Para se ter uma idéia da importância desses achados, Kawachi et al. (1999) estudaram a associação entre as relações de confiança e indicadores de saúde, comparando os diversos estados dos Estados Unidos. Verificaram uma forte associação $(r=.73)$ entre desigualdade de renda e falta de confiança social (social trust), observando que os estados com maior desigualdade de renda eram também aqueles nos quais houve maior proporção de entrevistados que concordaram com a afirmação: "a maioria das pessoas procurará tirar vantagem de você se tiver oportunidade" ("most people would try to take advantage of you if they got the chance"). Observaram também que os estados com altos níveis de falta de confiança entre as pessoas (social mistrust), expressa pela concordância com a frase mencionada, eram os que apresentavam as maiores taxas de mortalidade geral ajustada por idade $(\mathrm{r}=.77)$. Utilizando um modelo ecológico de regressão, esse autores observaram que as variações no nível de confiança social explicavam 58\% da variação da mortalidade geral entre os estados.

São poucos os estudos conduzidos na população brasileira que relacionam redes sociais e comunitárias com agravos em saúde, o que pode ser explicado, em parte, pela falta de domínio de metodologias adequadas para abordar estes objetos. A seguir, são apresentados os resultados de alguns desses estudos.

A relação entre autopercepção em saúde e a participação em atividades sociais, bem como a satisfação com redes sociais, foi estudada em 1.505 idosos em Bambuí (MG), no ano de 1997 (Lima-Costa, Firmo \& Uchôa, 2005). A distribuição da autopercepção em saúde foi de "boa/muito boa" (24,8\%), "justa" (49,2\%) e "ruim/muito ruim" (26,1\%). As análises foram conduzidas de acordo com dois estratos de renda: menor que $\mathrm{R} \$ 500,00$ e igual ou maior a $\mathrm{R} \$ 500,00$. As redes sociais investigadas foram: participação em atividades religiosas e freqüentar clubes e/ou associações. A pior autopercepção em saúde foi associada àqueles idosos insatisfeitos ou muito insatisfeitos com as suas redes sociais, tanto entre aqueles com baixa renda quanto entre aqueles com renda maior. Estes achados foram ajustados para idade, sexo, estilos de vida associados à saúde, doenças e acesso a serviços de saúde. 
Um estudo de Moraes, De Azevedo e Souza (2005) analisou os fatores associados ao envelhecimento bem-sucedido de idosos socialmente ativos da Região Metropolitana de Porto Alegre. O estudo permitiu concluir que a manutenção da independência para as atividades da vida diária, a autonomia e a satisfação com o relacionamento familiar e as amizades foram fatores preditivos independentes do envelhecimento bem-sucedido, tanto para homens como para mulheres.

Um estudo de base domiciliar, em comunidade rural da Zona da Mata de Pernambuco, com 483 adultos (maiores de 19 anos), investigou a associação entre transtornos mentais comuns e apoio social (Costa \& Ludermir, 2005). Casos suspeitos de transtornos mentais comuns foram identificados com a ajuda de um questionário padronizado auto-administrado Self Reporting Questionnaire (SRQ-20) e o apoio social foi avaliado pelo Medical Outcomes Study Questions - Social Support Survey (MOS-SSS) desenvolvido por Sherbourne e Stewart em 1985 (Sherbourne \& Stewart, 1991). Observou-se uma clara associação dos transtornos mentais comuns com o apoio social. Pessoas com baixo apoio social apresentaram maior prevalência de transtornos mentais comuns do que as com alto apoio social. 0 apoio social manteve-se associado aos transtornos mentais comuns mesmo após o ajuste por idade, escolaridade e participação no mercado de trabalho. Os resultados indicam a importância das redes de apoio social para diminuir a prevalência da doença mental, promovendo a interação dos indivíduos e aumentando a confiança pessoal e o poder de enfrentamento dos problemas. Duas hipóteses tentam explicar a ação do apoio social: uma assinala que o apoio social diminuiria os diferentes níveis de estresse (buffering hypothesis); outra considera que os relacionamentos que geram apoio promovem bem-estar mesmo na ausência de estresse (positive effects hypothesis) (Sherman, 2003).

De Antoni, Barone e Soller (2007) investigaram 20 famílias (pai, mãe e filhos) de baixo nível socioeconômico e com histórico de abuso físico parental. A pesquisa visou a conhecer a realidade dessas famílias e a forma como interagem em diferentes ambientes e contextos. Buscou-se, ainda, identificar e analisar indicadores de risco e de proteção em famílias denunciadas por abuso físico. Os indicadores de risco foram descritos como potencializadores da manifestação do abuso físico parental e os de proteção como aqueles que podem impedir ou amenizar a manifestação da violência. Foram identificados como indicadores de proteção de abuso físico parental algumas redes de apoio social e afetiva, valorização das conquistas e desejo de melhoria futura. Cerca de $60 \%$ das famílias pesquisadas citaram como indicadores de proteção a presença da rede de apoio social. A presença de graves e freqüentes indicadores de risco nas famílias pesquisadas pode revelar que o abuso físico é uma forma de manifestação da fragilidade dessas interações.

A associação entre autocuidado com a saúde, representado pela prática de auto-exame das mamas, considerado como um "comportamento marcador" do autocuidado entre mulheres e apoio social, foi investigada por Andrade et al. (2005). Apoio social incluiu cinco diferentes dimensões: material, emocional, afetivo, de informação e de interação positiva. Com este objetivo, 2.240 mulheres do Estudo Pró-Saúde (coorte de funcionários da Universidade do Estado do Rio de Janeiro, Uerj) foram investigadas, no ano de 1999. Observou-se que 44\% informaram realizar o auto-exame das mamas "todo mês" ou "quase todo mês"; 32\%, "às vezes"; e $24 \%$ informaram praticá-lo "raramente" ou "nunca". A chance de relatar prática 
mais freqüente de auto-exame das mamas foi cerca de duas vezes mais elevada entre as mulheres com maior apoio social, quando comparadas com as que contavam com menor apoio. Os resultados foram ajustados para idade, cor da pele/etnia, escolaridade, religião, local de trabalho e transtorno mental comum. Características específicas da população deste estudo, como elevada escolaridade e grande parcela constituída por funcionárias da área de saúde, podem explicar o fato de quase a metade das mulheres relatarem fazer auto-exame das mamas. Os autores sugerem a importância do apoio social no estímulo a práticas de autocuidado de saúde da mulher.

'Emponderamento' é considerado uma dimensão de capital social referente ao processo de interação social, que permite que pessoas aumentem suas habilidades individuais e coletivas, além de desempenharem maior controle sobre suas vidas. O nível de 'emponderamento' foi investigado em relação à ocorrência de cárie dental (Patussi, Hardy \& Sheihan, 2006), observando-se que a cárie dental foi menor em áreas com maiores níveis de 'emponderamento' em relação a áreas com menores níveis, após ajustes para variáveis demográficas, socioeconômicas, uso de flúor, consumo de açúcar, escovação dentária e acesso a cuidados odontológicos. Os autores destacam a importância do papel do 'emponderamento' como um potencial explicador nos níveis de cárie.

\subsection{Comportamentos, Estilos de Vida e Saúde}

Esta seção trata dos comportamentos e estilos de vida relacionados à saúde, que apesar de fortemente influenciados por fatores econômicos, culturais e outros, são entendidos como determinantes sociais proximais, por estarem mais próximos e passíveis de controle e modificação por parte dos indivíduos. De acordo com o Instituto Nacional do Câncer (Inca, 2006), os fatores relacionados a comportamentos e estilos de vida, como tabagismo, baixo consumo de frutas, de legumes e de verduras e consumo de álcool, são os principais determinantes de risco para morte por câncer em países de baixa e média renda. Estima-se que, nestes países, o tabagismo seja responsável por 18\% das mortes por câncer; o baixo consumo de frutas, legumes e verduras, por 6\%; o consumo de álcool, por 5\%. O câncer e outras doenças crônicas são resultado da exposição, ao longo da vida, a vários fatores de risco que, além de concomitantes, podem potencializar-se mutuamente, indicando a necessidade de ações de prevenção que levem em conta a simultaneidade destes fatores ao longo da vida. Esta seção está baseada na revisão da literatura recente sobre dieta, exercício físico, tabagismo e alcoolismo e sua distribuição entre os diversos grupos sociais.

\section{Dieta}

Segundo o Instituto Nacional do Câncer (Inca, 2006), a dieta é considerada como um dos fatores modificáveis mais importantes para o risco de doenças e agravos não-transmissíveis (Dant). De acordo com a Organização Mundial da Saúde (OMS), 80\% dos casos de doenças coronarianas, 90\% dos casos de diabetes tipo 2 e 30\% dos casos de câncer poderiam ser evitados com mudanças factíveis nos hábitos alimentares, níveis de atividade física e uso 
de produtos derivados do tabaco. Uma alimentação inadequada, rica em gorduras, com alimentos altamente refinados e processados, e pobre em frutas, legumes e verduras está associada ao aparecimento de diversas doenças como aterosclerose, hipercolesterolemia, hipertensão arterial, doença isquêmica do coração, infarto agudo do miocárdio, diabetes mellitus e câncer.

Estudos publicados nos últimos cinco anos buscam investigar a influência dos determinantes sociais sobre os hábitos alimentares.

O estudo de Sichieri, Castro e Moura (2003) mostra que o padrão de consumo alimentar é fortemente influenciado por renda e escolaridade, e que a região de moradia é a terceira variável explicativa, associada ao aspecto cultural do consumo. No Nordeste, predomina um padrão tradicional de consumo ("feijão e arroz") enquanto no Sudeste se observa um padrão misto, com a adição de alimentos industrializados e ricos em gorduras e açúcar, principalmente nas classes de maior escolaridade e renda. Jaime e Monteiro (2005), a partir dos dados da Pesquisa Mundial de Saúde (PMS), de 2003, encontraram consumo de frutas e verduras baixo no Brasil como um todo, observando que quanto maior a renda e a escolaridade maior o consumo destes alimentos. Na zona urbana, o consumo adequado de frutas e verduras é o dobro do que se verifica na zona rural.

Levy-Costa et al. (2005), analisando os dados da Pesquisa de Orçamentos Familiares (POF), de 2002/2003, mostram também um padrão transicional de consumo alimentar. Como característica positiva para todas as classes de renda, foi observado um aumento no consumo de proteínas de alto valor biológico; como características negativas, excesso de açúcar e insuficiência de frutas e hortaliças, além do consumo excessivo de gorduras em geral e saturadas. O limite máximo de consumo de açúcar (10\% das calorias totais) foi alcançado em todas as classes de renda, sendo o pior desempenho o das classes intermediárias (15\%). Para o consumo de gorduras, o limite máximo (30\%) foi alcançado a partir da faixa entre 2 e 5 salários mínimos, sendo que para as gorduras saturadas, o desempenho foi pior nas classes mais altas, que ultrapassaram o máximo de 10\% destes nutrientes na dieta.

Alves et al. (2006) definiram cinco tipos de padrão alimentar em mulheres do Rio Grande do Sul, sendo três padrões saudáveis e dois de risco (baixo custo e alto custo). As mulheres das classes C, D e E tiveram maior consumo de alimentos do padrão de risco de baixo custo, enquanto as das classes A e B tiveram maior consumo dos padrões saudáveis e do padrão de risco de alto custo. Os autores sugerem que o custo é um dos determinantes da escolha e consumo dos alimentos. Um estudo abordando, especificamente, a população adolescente de Pelotas, na faixa de 10-12 anos (Neutzling et al., 2007), identificou 11,6\% de obesidade, 83\% de baixo consumo de fibras e $33 \%$ de alto consumo de gorduras. A freqüência de consumo de dieta rica em gorduras foi mais alta nas famílias de classe social elevada e mães com maior escolaridade; de forma inversa, a alta escolaridade materna foi protetora para dieta pobre em fibras.

Um inquérito realizado pelo Inca (Inca, 2006) constatou que o consumo de frutas ou legumes ou verduras cinco vezes ou mais por semana foi superior a $50 \%$ em todas as capitais 
estudadas, embora em algumas delas o consumo de legumes e verduras seja muito baixo, como na Região Norte, onde menos de $25 \%$ da população consomem esses alimentos cinco vezes por semana. Quanto a diferenciais de consumo por gênero e escolaridade, as mulheres e os grupos com maior escolaridade apresentaram maiores percentuais de ingestão destes alimentos. Com relação à leitura das informações nos rótulos de alimentos embalados, os resultados deste estudo indicam que a população verifica a informação sobre prazo de validade (mais de $70 \%$ em 15 capitais), embora o mesmo não ocorra com a informação sobre o valor nutricional, o que pode ser explicado pelo fato de que este tipo de informação implica que o indivíduo tenha conhecimento prévio dos níveis adequados de nutrientes para avaliar a qualidade do produto. O sexo masculino, a população com mais de 50 anos e a de menor escolaridade apresentaram menor proporção de leitura das informações sobre prazo de validade e valor nutricional.

Com base nos resultados encontrados nesta pesquisa, os autores concluem que uma política de nutrição voltada para o incentivo de práticas alimentares saudáveis deve enfocar: o aumento do consumo de frutas, legumes e verduras, principalmente no Norte do país com especial atenção aos grupos de jovens, homens e adultos com menor escolaridade; 0 estímulo a estudos qualitativos e quantitativos sobre o consumo de legumes e verduras que permitam conhecer os fatores que interferem na seleção de alimentos; a redução do consumo de leite integral, de gordura visível da carne e de pele de frango; e a conscientização e instrumentalização dos usuários quanto à leitura de rótulos nas embalagens.

Claro et al. (2007) mostraram a participação direta da renda no padrão de consumo: a cada $1 \%$ no aumento da renda, observa-se um aumento de 0,04\% das frutas, legumes e verduras na composição da dieta; por outro lado, o decréscimo de $1 \%$ no preço destes produtos aumenta sua participação na dieta em $0,2 \%$. Este estudo aponta para a necessidade de políticas públicas voltadas para o barateamento dos alimentos saudáveis. É também interessante o estudo de Jaime et al. (2007), que mostrou, através de ensaio comunitário randomizado, que práticas de educação alimentar podem melhorar a qualidade da dieta, mesmo em populações de baixa renda, sugerindo uma estratégia factível para estas populações. Outras estratégias sugeridas são a utilização da mídia, a capacitação de professores e profissionais de saúde, as mudanças na alimentação escolar e as mudanças na regulamentação de produtos comerciais, conforme já vem sendo em parte adotado no país (Coitinho, Monteiro \& Popkin, 2002).

\section{Atividade Física}

Segundo a OMS (apud Inca, 2006), a prática de atividade física regular reduz o risco de mortes prematuras, doenças do coração, acidente vascular cerebral, câncer de cólon e mama e diabetes tipo II. Atua na prevenção ou redução da hipertensão arterial, diminui o risco de obesidade, auxilia na prevenção ou redução da osteoporose, promove bem-estar, reduz o estresse, a ansiedade e a depressão. Especialmente em crianças e jovens, a atividade física interage positivamente com as estratégias para adoção de uma dieta saudável, desestimula o uso do tabaco, do álcool, das drogas, reduz a violência e promove a integração social. O rápido crescimento das doenças crônicas associadas à inatividade física vem sendo registrado 
tanto nos países desenvolvidos como nos países em desenvolvimento, estimando-se que a inatividade física seja responsável por aproximadamente 2 milhões de mortes no mundo.

Monteiro et al. (2003) entrevistaram 11.000 pessoas do Nordeste e Sudeste do país, para avaliar a prática de atividade física no lazer (AFL). Os resultados mostraram que apenas 13\% dos entrevistados realizavam algum tipo de AFL e apenas 3,3\% cumpriam com o recomendado (30 minutos por cinco ou mais vezes na semana). Os determinantes mais importantes foram renda e escolaridade tanto para homens como para mulheres, sendo que no caso dos homens os autores encontraram maior freqüência de prática de AFL em áreas urbanas, não havendo diferença entre urbano e rural no caso das mulheres.

Vários estudos locais avaliaram fatores socioeconômicos e a prática de atividade física. Matsudo et al. (2002) relataram, para o estado de São Paulo, uma freqüência de 50\% de indivíduos ativos ou muito ativos, de acordo com o Questionário Internacional de Atividade Física (Ipaq). O sedentarismo foi maior nos extremos de classe social (A e E). No Rio de Janeiro, Salles-Costa et al. (2003) estudaram a AFL, em funcionários de uma universidade no estudo Pró-Saúde, observando um predomínio masculino na prática. A idade, a escolaridade e a renda familiar per capita estiveram diretamente associadas à prática de exercícios entre as mulheres e, entre os homens, essa associação positiva se deu com a renda familiar per capita. Os homens se engajaram mais em atividades físicas coletivas e de caráter competitivo e as mulheres em atividades individuais, que requerem menos força física.

Pitanga e Lessa (2005) estudaram atividade física em Salvador (BA), no ano de 2000, usando o mesmo instrumento Ipaq. As variáveis estudadas foram: sexo, idade, estado civil e escolaridade. Tanto para homens como mulheres a baixa escolaridade se mostrou diretamente associada com sedentarismo, com um efeito dose-resposta: fixando em 1 a freqüência de sedentarismo para as pessoas com alta escolaridade, esse valor foi de 1,43 para as de escolaridade média e 1,79 para as com baixa escolaridade. Masson et al. (2005) analisaram mulheres da cidade de São Leopoldo (RS), no ano de 2003. Foi encontrada uma prevalência de sedentarismo de $37 \%$, sem que se verificasse uma associação estatisticamente significativa com renda, escolaridade ou cor da pele. Dias-da-Costa et al. (2005) estudaram adultos de 20-69 anos na cidade de Pelotas em 2000 e relataram 80\% de inatividade física. Baretta, Barreta e Peres (2007) investigaram sedentarismo no município de Joaçaba (SC) e, ao contrário de outros estudos, encontraram associação com renda elevada.

Azevedo et al. (2007) estudaram a prática de AFL em Pelotas, observando que os homens tiveram maior AFL que as mulheres, com uma associação positiva do nível socioeconômico com esta prática em ambos os sexos. Uma associação dose-resposta positiva entre idade e inatividade física foi encontrada nos homens, mas não nas mulheres.

Em adolescentes de 10-12 anos em Pelotas, Hallal et al. (2006) relataram 58,2\% de sedentarismo. Oehlschlaeger et al. (2004), estudando esta mesma cidade, identificaram prevalência de sedentarismo maior nas classes sociais mais baixas, assim como uma relação inversa entre a escolaridade do adolescente e de sua mãe com o sedentarismo. 
Há uma série de lacunas do conhecimento com relação à importância dos determinantes sociais na prática da atividade física. Hallal et al. (2007), em uma recente revisão sistemática da literatura assinalam que, apesar do aumento da produção científica no Brasil acerca deste tema, não se encontram estudos de base nacional sobre o nível de atividade física no país. Esses mesmos autores encontraram muitas deficiências metodológicas, detectando, por exemplo, 26 diferentes definições operacionais de sedentarismo. Há, também, a necessidade de estudos que levem em conta variáveis de natureza qualitativa, como, por exemplo, as concepções acerca do ideal de corpo segundo o gênero, as quais influenciam comportamentos distintos de homens e mulheres no que se refere à prática de exercícios físicos. A superação dessas deficiências de conhecimento é imperativa para subsidiar a definição de políticas de conscientização e incentivo da atividade física, que devem ser diferenciadas e adequadas do ponto de vista sociocultural.

\section{Tabagismo e Alcoolismo}

O tabagismo é, hoje, amplamente reconhecido como doença crônica gerada pela dependência da nicotina, estando inserido na Classificação Internacional de Doenças (CID-10) da OMS. Segundo o Inca (2006), trata-se do mais importante fator de risco isolado de doenças graves e fatais, atribuindo-se ao consumo de tabaco 45\% das mortes por doença coronariana, $85 \%$ das mortes por doença pulmonar obstrutiva crônica, 25\% das mortes por doença cerebrovascular e 30\% das mortes por câncer. Cerca de 90\% dos casos de câncer de pulmão ocorrem em fumantes, e a mortalidade por este tipo de câncer entre fumantes é cerca de 15 vezes maior do que entre os não-fumantes. De acordo com essa mesma publicação, $90 \%$ dos fumantes começam a fumar antes dos 19 anos, sendo que 15 anos é a idade média de iniciação. Cem mil jovens começam a fumar no mundo a cada dia e $80 \%$ deles vivem em países em desenvolvimento.

Três trabalhos recentes foram realizados na cidade de Pelotas. O primeiro (Malcon, Menezes \& Chatkin et al., 2003) estudou adolescentes de 10-19 anos no período de 1999 a 2000. A prevalência de tabagismo foi $12 \%$, similar para os sexos feminino e masculino e os principais fatores associados foram: idade, irmãos e amigos fumantes e baixa escolaridade do adolescente. Em outro estudo (Menezes et al., 2006), foi investigada a coorte de nascimentos de 1993, ao chegar à faixa etária de 10-12 anos, para identificar os fatores de risco, dentre as dimensões socioeconômicas, culturais e comportamentais. Os resultados revelaram tendência linear para o nível socioeconômico: quanto mais baixo, maior a ocorrência de tabagismo precoce na adolescência, sendo duas vezes maior na classe D e três vezes maior na classe E, comparadas à classe A. Outros fatores importantes foram as relações familiares, sendo que viver com o pai biológico foi um fator protetor, enquanto relações ruins com a mãe aumentaram duas vezes a freqüência do evento. Violência familiar, consumo de álcool pelo adolescente e tabagismo materno (tanto na gravidez quanto durante os demais anos) também contribuíram de forma muito importante. Por último, na coorte de 1982, foram estudados os adolescentes do sexo masculino aos 18 anos (no momento do alistamento militar) e uma amostra de meninas, em 
2001 (Menezes, Hallal \& Horta, 2007). A freqüência de tabagismo diário foi de 15,8\% nos homens, sendo que 54,3\% haviam iniciado o hábito entre 13 e 15 anos e 11,5\% antes desta idade. Entre as mulheres, foi $15,4 \%$, com $47 \%$ das fumantes tendo iniciado entre os 13 e 15 anos e 18\% com início antes dos 13 anos. A determinação foi diferente nos sexos: os meninos cujas mães eram solteiras e aqueles com pai apresentando baixa escolaridade fumavam cerca de duas vezes mais; entre as meninas, o hábito foi seis vezes mais freqüente naquelas com famílias de baixa renda, comparadas às de alta renda. Também houve importante associação com mães que fumaram na gravidez e pais alcoólicos.

Um estudo realizado em Belém (PA), em 2005, incluindo apenas escolares menores de 19 anos, apontou prevalência de $11 \%$, sendo $14 \%$ na escola pública e $7 \%$ na privada (Pinto \& Ribeiro, 2007). Os fatores mais associados foram: curiosidade, amigos fumantes, ausência de recomendação para não fumar. Na escola privada, houve associação com classe mais elevada, enquanto na pública foi registrada maior prevalência naqueles com mau desempenho acadêmico. Estudos como este apresentam limitações quanto ao tipo de desenho (transversal) qua não permite relações de causalidade e quanto à base populacional de escolares, já que é lícito supor que os adolescentes que estão fora da escola estejam mais expostos a comportamentos de risco, entre eles, o tabagismo. Estas limitações fazem com que estes estudos não permitam estimar a real prevalência e a determinação deste hábito. Os estudos de coorte em Pelotas têm maior validade e as relações de associação com nível socioeconômico, renda e escolaridade são úteis e confiáveis para o enfrentamento do tabagismo em adolescentes.

Em relação à população adulta, Monteiro et al. (2007) estudaram as mudanças ocorridas na prevalência de tabagismo, tomando como base dois inquéritos nacionais (PNS, 1989 e PMS, 2003). Houve redução importante em todas as faixas etárias, em ambos os sexos e no meio urbano e rural. No entanto, observam-se desigualdades na intensidade da redução, de acordo com o poder aquisitivo e a escolaridade (Gráficos 31, 31.1 e 31.2). No caso do poder aquisitivo, o padrão foi semelhante em homens e mulheres: quanto menor a renda, menor a intensidade da redução; já para a escolaridade, as diferenças foram mais acentuadas nas mulheres: quanto menor a escolaridade, menor a redução. As mulheres com escolaridade igual ou menor de quatro anos apresentaram o dobro da prevalência de tabagismo, comparadas com aquelas com escolaridade entre 9 a 11 anos de estudo. Na verdade, as desigualdades se acentuaram em 2003, apesar do declínio em todas as categorias.

Peixoto, Firmo e Lima-Costa (2007) avaliaram a cessação do hábito de fumar em duas populações adultas (Bambuí, Belo Horizonte, MG). A escolaridade mostrou-se associada com maior freqüência de cessação apenas em Belo Horizonte, não tendo alcançado significância estatística em Bambuí. Em Belo Horizonte, também mostraram associação positiva a idade (maior de 40 anos) e o número de consultas. Em Bambuí, só foi observada associação positiva com a idade. 
Por último, em relação aos idosos, um estudo em Minas Gerais (Peixoto, Firmo \& LimaCosta, 2005) investigou a prevalência e os determinantes em pessoas com idade igual ou superior a 60 anos. Foi encontrada uma prevalência de 31,4\% entre os homens e 10,3\% entre as mulheres. Entre os determinantes, a escolaridade elevada (igual ou superior a 8 anos) mostrou-se protetora tanto para homens quanto para mulheres.

Gráfico 31 - Variação temporal na prevalência de tabagismo (> 18 anos), de acordo com o local de moradia. Brasil - 1989 - 2003

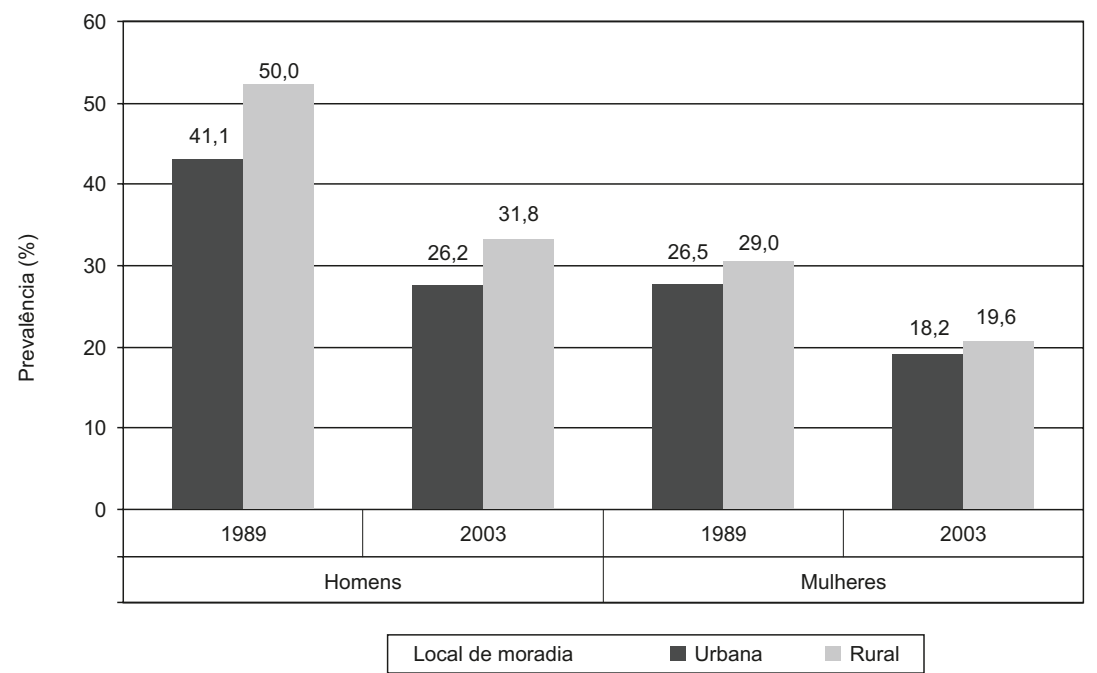

Fonte: Monteiro et al., 2007.

Gráfico 31.1 - Variação temporal na prevalência de tabagismo (> 18 anos), de acordo com os anos de estudo. Brasil - 1989 - 2003

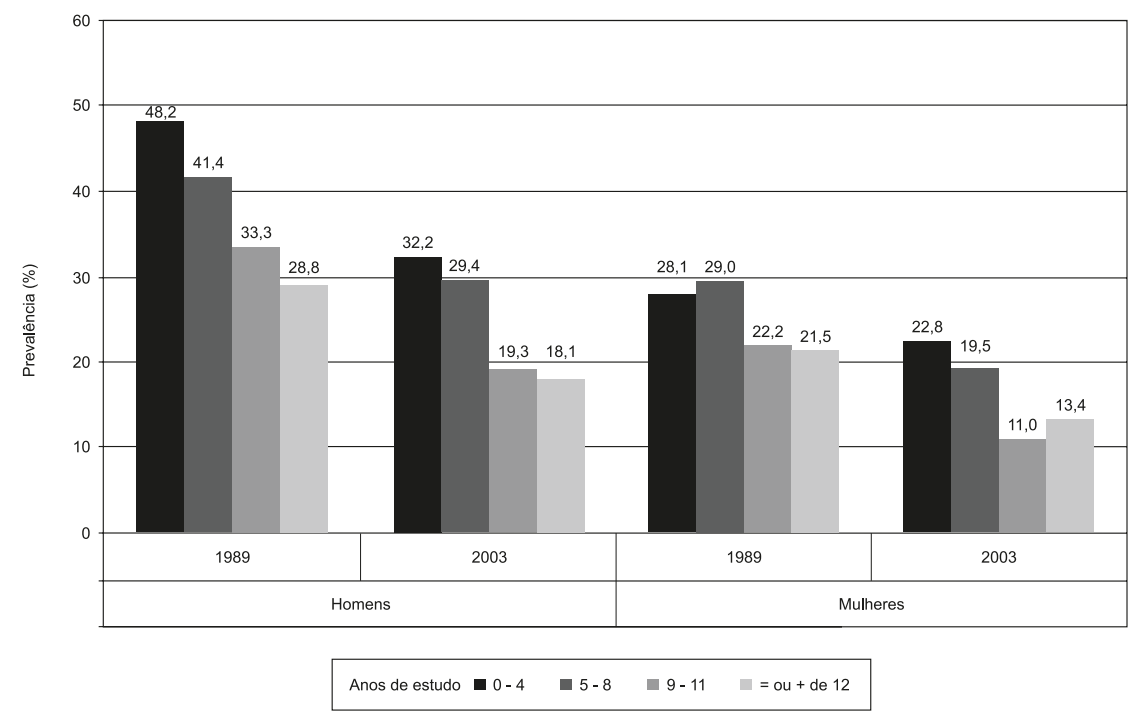

Fonte: Monteiro et al., 2007 
Gráfico 31.2 - Variação temporal na prevalência de tabagismo ( $>18$ anos), de acordo com o poder de compra do domicílio. Brasil - 1989 - 2003

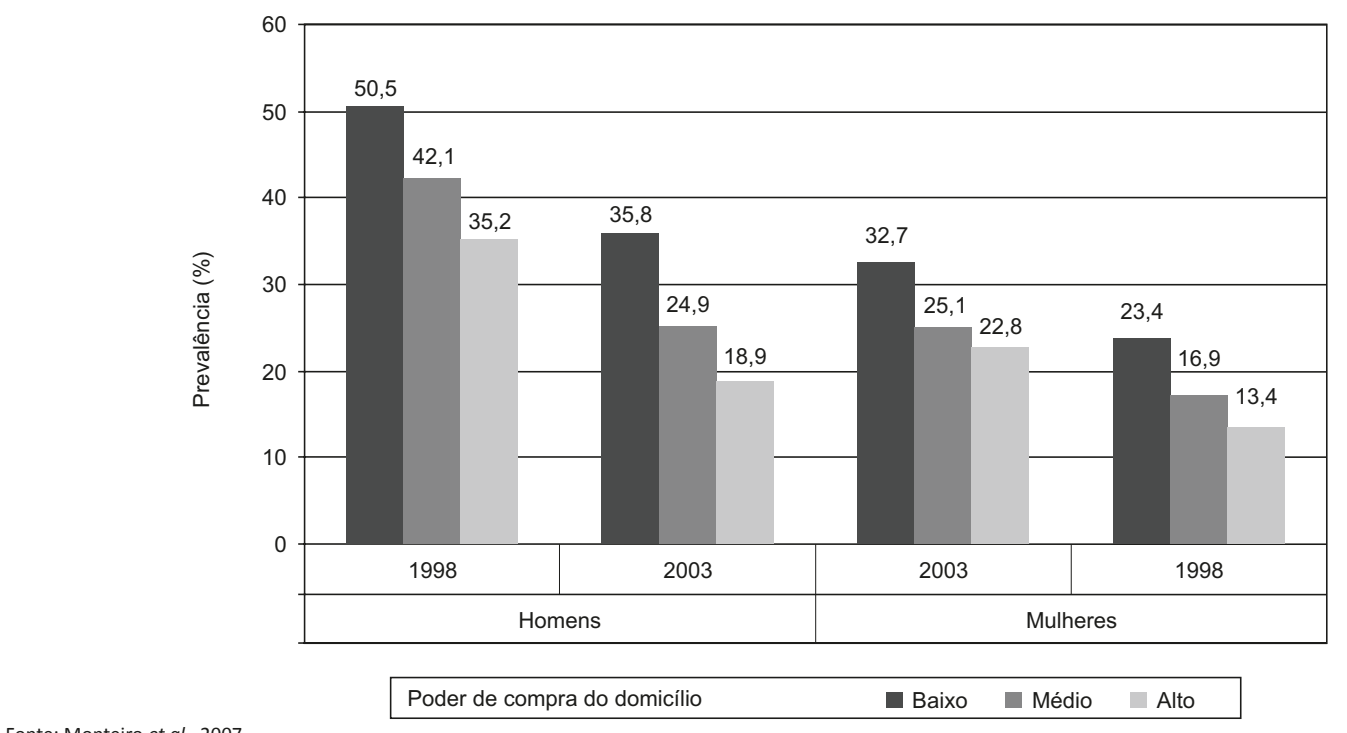

Fonte: Monteiro et al., 2007

O álcool, por sua vez, é uma das poucas drogas psicotrópicas que tem seu consumo admitido e incentivado pela sociedade. Segundo o Inca (2006), a mortalidade e a limitação da condição funcional associada ao consumo de bebidas alcoólicas superam aquelas associadas ao tabagismo. Calcula-se que, mundialmente, o álcool esteja relacionado a 3,2\% de todas as mortes e 6,2 \% das Disabilities Adjusted Life Year (DALY) dos países em desenvolvimento. Nas últimas décadas, o consumo de álcool vem aumentando no mundo todo, sendo que a maior parte deste aumento vem acontecendo em países em desenvolvimento. Embora o consumo moderado de determinadas bebidas alcoólicas possa trazer benefícios para a saúde, o consumo excessivo pode provocar cirrose, pancreatite, acidente cerebrovascular, demência, polineuropatia, miocardite, desnutrição, hipertensão arterial, infarto e certos tipos de cânceres, estando também intimamente associado a causas externas de morbimortalidade, como acidentes de trânsito e violência (WHO, 2007). A estas patologias, deve somar-se o impacto social e familiar do alcoolismo (Meloni \& Laranjeira, 2004), sendo também já bastante conhecida a associação do início precoce do alcoolismo com sua manutenção e severidade na vida adulta (Hingston, Heeren \& Winter, 2006; Bonomo et al., 2004).

Soldera et al. (2004) estudaram os alunos do curso fundamental e de ensino médio de Campinas, em 1998. As escolas foram classificadas em três categorias: públicas localizadas na periferia, públicas localizadas no centro e particulares. A média de idade foi de 15 anos, variando de 11 a 26 anos (os autores não informam o percentual de não adolescentes). A variável de interesse foi o alcoolismo pesado (consumo em 20 dos 30 dias anteriores ao inquérito). Os resultados mostraram uma prevalência de 15,9\% entre os meninos e 7,7\% entre as meninas. Considerando as escolas, o consumo pesado foi maior nas públicas centrais (14,8\%), seguidas das particulares (12,3\%) e das públicas periféricas $(8,6 \%)$. $\mathrm{Na}$ análise multivariada, o fator de maior associação positiva foi já estar trabalhando, 
enquanto o suporte dos pais foi protetor. As classes sociais A e B tiveram maior prevalência. A avaliação destes resultados fica, em parte, prejudicada pela inclusão de participantes maiores de 18 anos.

Souza, Areco e Silveira (2005) também valorizaram o trabalho como variável relacionada com alcoolismo. Avaliaram 2.718 estudantes das escolas públicas de Cuiabá, abrangendo a faixa etária de 10 a 20 anos, dos quais 993 trabalhavam e 1.725 não. Os trabalhadores tinham prevalência de consumo de álcool de $81 \%$, enquanto os não-trabalhadores de $65,8 \%$, sendo esta diferença estatisticamente significante. Na análise multivariada, os fatores associados para ambos os grupos foram: idade (maior nos de 15-20 anos), nível socioeconômico (maior nas classes A, B, C), história de consumo de álcool na família e não morar com os pais.

Em um estudo na Universidade de São Paulo (Silva et al., 2006), foram abordados adolescentes e adultos jovens (15-24 anos), matriculados nos cursos da área da Saúde. O consumo de álcool em qualquer momento nos últimos doze meses foi relatado por 84,7\% dos 926 participantes. Os fatores associados foram: renda familiar elevada e não praticar religião. Não houve análise multivariada neste estudo.

Em estudo sobre a gênese da dependência de drogas e álcool, De Micheli e Formigoni (2004) identificaram três grupos, de acordo com a intensidade do padrão de dependência. Pertencer à classe média baixa aumentou 3,5 vezes a chance de dependência, atraso escolar elevou 4,4 vezes e presença apenas da mãe no lar aumentou 22 vezes este comportamento.

Em inquérito realizado pelo Inca (2006), a prevalência de consumo de bebida alcoólica, nas 15 capitais brasileiras e no Distrito Federal, variou de 32,4\% a 58,6\%. Estas taxas são semelhantes às encontradas em outros países da América Latina, como Colômbia (59,8\%), Costa Rica (40,3\%), República Dominicana (55,0\%), Jamaica (32,0\%), México $(54,0 \%)$ e Panamá (54,2\%). A prevalência de consumo, no caso dos homens, variou de $48,9 \%$ a $72,1 \%$, enquanto que entre mulheres essa variação foi de $19,7 \%$ a $47,5 \%$, devendo-se observar que mesmo a maior taxa encontrada para mulheres $(47,5 \%)$ foi inferior à menor encontrada para homens.

Em sociedades desenvolvidas, principalmente os países europeus, essas diferenças de gênero não são tão evidentes, em torno de 10\% a 20\%. Nos países em desenvolvimento, essas diferenças são maiores, sendo que, na América Latina, essas diferenças variaram de $20 \%$ a $100 \%$, dependendo do país. Esta variação pode ser explicada pelo tipo de bebida consumida com mais freqüência. Em países onde o consumo de vinho é alto, como no Chile, as diferenças entre gênero não chegam a 30\% (68,7\% entre homens e 53,6\% entre mulheres). No México, onde cervejas e destilados são muito mais populares, o percentual de consumo entre o sexo masculino é praticamente o dobro do consumo entre o sexo feminino $(73,0 \%$ entre homens e $37,0 \%$ entre mulheres). Em Porto Alegre, na Região Sul, onde se concentra a produção vinícola do país, observou-se a menor diferença por gênero (40\%).

As diferenças por gênero costumam ser ainda mais marcantes quando se avalia o consumo de risco. Entretanto, as taxas desse indicador, neste estudo, ficaram entre 4,6\% e 11,1\%. Na Região Sul, apesar das taxas de consumo terem sido altas, em comparação às encontradas 
nas outras regiões, as taxas para consumo de risco encontraram-se entre as menores, o que deve estar relacionado às diferenças regionais no tipo de bebida consumida.

Um estudo, na cidade de Rio Grande (RS), realizado em 2000, utilizou o questionário AUDIT, que identifica alcoolismo e desordens no consumo de álcool (Mendoza-Sassi \& Beria, 2004). A prevalência de consumo de álcool foi $43 \%$, sendo $31 \%$ entre mulheres e $56 \%$ entre homens. A prevalência de desordens no consumo foi 7,9\% (2,5\% para as mulheres e 14,5\% para os homens). A análise multivariada para as desordens no consumo do álcool revelou predominância do sexo masculino e relação inversa com classe social. O tabagismo esteve fortemente associado, assim como desordens psiquiátricas menores. Esta última associação mostrou interação com o sexo, sendo bem mais intensa nas mulheres do que nos homens.

Almeida-Filho et al. (2004) realizaram inquérito domiciliar no município de Salvador (BA), com amostra de 2.302 adultos, para avaliar consumo de alto risco, definido como uso diário ou semanal mais episódios de embriaguez, além de qualquer uso de bebidas alcoólicas com embriaguez freqüente (pelo menos uma vez por semana). A prevalência anual de consumo de alto risco foi de $7 \%$, seis vezes maior entre homens do que entre mulheres. Foi encontrada uma associação positiva de prevalência de consumo de alto risco com educação e classe social. Nenhuma relação foi encontrada entre etnicidade e consumo de alto risco, porém bebidas como cachaça e destilados tiveram maior consumo entre pardos e pretos.

Um estudo em Pelotas (Dias-da-Costa et al., 2004), sobre consumo pesado de álcool (>30g/ dia), mostrou prevalência de $14,3 \%$ (29\% nos homens e 3,7\% nas mulheres). Na análise multivariada, foi observada associação do consumo pesado com: sexo masculino (prevalência dez vezes maior entre os homens), idade mais avançada (idade entre 60-69 cerca de 2,5 vezes maior que idade entre 20-29), cor da pele preta ou parda (duas vezes maior que branca), classe social (classe E cerca de 3 vezes maior que classe A), tabagismo (grandes fumantes 4,5 vezes maior que não-fumantes).

Outro aspecto importante, tanto em relação ao alcoolismo quanto ao tabagismo, é a relação destes hábitos com desigualdades sociais. Segundo relatórios da OMS (Monteiro et al., 2007), o tabagismo sofreu uma transição dos países desenvolvidos para aqueles em desenvolvimento, com projeção de aumento para 2020, quando se espera que, de cada dez mortes relacionadas ao tabaco, sete ocorram nestes países. No caso do alcoolismo, a relação é menos evidente; havendo mesmo associação do consumo de álcool com maior renda. Os padrões na distribuição das desigualdades sociais não são universais, podendo diferir por gênero, país, tipo de bebida e classificação de consumo de álcool (Bloomfield et al., 2006). Para os adolescentes, uma revisão sistemática na América Latina (Malcon, Menezes \& Chatkin, 2003) encontrou como principais fatores para o tabagismo: tabagismo entre irmãos e amigos, baixo desempenho escolar, idade, sexo masculino, trabalho remunerado e pais separados.

o enfrentamento destes importantes problemas de saúde depende do conhecimento do padrão de acesso e de consumo dos cigarros e das bebidas alcoólicas, principalmente entre os jovens. 
Para o tabagismo, ficam evidenciadas as desigualdades sociais no início, na redução e na cessação do hábito, em todas as faixas etárias e em ambos os sexos. O artigo de Monteiro et al. (2007), ao descrever o declínio ocorrido na prevalência de tabagismo no Brasil, ressalta o papel das campanhas e medidas adotadas pelo Ministério da Saúde. Tanto a educação da população em relação aos efeitos nocivos do tabaco quanto medidas coercitivas, em relação a preços, proibições de locais para fumo e publicidade, parecem ter efetividade.

Para o mesmo autor, no caso dos adolescentes, é importante atuar ainda mais intensamente em relação aos preços, já que os cigarros no Brasil têm um dos preços mais baixos do mundo. Como mostraram os estudos de Pelotas, os fatores familiares e socioculturais têm enorme influência na aquisição do hábito, requerendo estratégias centradas na família e a participação da escola e da comunidade. Os serviços de saúde devem contribuir com ações educativas em nível de atenção primária, envolvendo a comunidade e tendo o adolescente como alvo. Estes autores propõem ações conjuntas entre governo, entidades educacionais, família e sociedade como um todo.

No caso das mulheres, onde a redução tem sido mais lenta, as estratégias devem levar em conta o apelo estético, psicológico e "glamoroso" do tabagismo. A preocupação com o emagrecimento, o efeito ansiolítico e a aura de modernidade já se cristalizaram como "benefícios" do cigarro para as mulheres (Scarinci et al., 2007).

No caso das populações mais desfavorecidas, a questão do tabagismo é mais grave, pois além de serem mais atingidas, também sofrem mais com as conseqüências danosas do cigarro. A elevação dos preços é uma das medidas mais efetivas neste grupo.

Em pesquisa realizada em quatro capitais brasileiras (Rio de Janeiro, São Paulo, Recife e Porto Alegre), Gigliotti e Laranjeira (2005) mostraram que os fumantes brasileiros estavam motivados a cessar o hábito, com 85\% manifestando o desejo de parar de fumar. As razões estavam ligadas ao conhecimento dos malefícios do cigarro e a preocupações com tabagismo passivo e exemplo para os filhos. Apesar do número reduzido de entrevistados, os resultados são coerentes com o declínio observado no estudo de Monteiro et al. (2007), apontando a boa resposta da população às medidas contra o tabaco.

No caso do alcoolismo, a relação entre desigualdades sociais e adição ao hábito é menos evidente, havendo mesmo discordância entre os estudos quanto à relação entre alcoolismo e classe social (ou renda e escolaridade). Em alguns estudos, a relação é positiva e em outros é inversa. Uma possível explicação é a heterogeneidade de definições, instrumentos e pontos de corte para definir alcoolismo.

Apesar destas discordâncias, pode-se concluir que é necessária uma mínima renda para adquirir bebida alcoólica e, quanto maior a disponibilidade de renda, maior a facilidade do consumo. No entanto, comportamentos mais abusivos ou problemas relacionados com o consumo parecem ocorrer mais nas classes mais desfavorecidas, como mostrou o estudo de Pelotas, de Dias-da-Costa et al. (2004). 
Outro aspecto metodológico é a transversalidade dos estudos, o que limita a inferência de causalidade. Uma última questão se refere à abordagem da análise multivariada. No estudo de Dias-da-Costa et al. (2004), onde o nível socioeconômico foi adequadamente hierarquizado, encontrou-se uma relação inversa com o consumo pesado de álcool. Em outros estudos, onde não há essa adequada hierarquização, o efeito causal dos fatores socioeconômicos pode ser subestimado.

Parece estar bem estabelecida a colinearidade entre tabagismo e alcoolismo. Tanto o alcoolismo é facilitador do hábito de fumar quanto o tabagismo favorece o consumo de álcool.

No caso dos adolescentes, a questão do alcoolismo é bastante complexa, parecendo haver uma grande influência das relações familiares e do meio sociocultural. Existe grande diferença na atitude de 'experimentar' de acordo com as regiões (54\% no Sul e 9\% no Norte e Nordeste). Em relação ao uso regular, a cidade de Porto Alegre (RS) lidera com 15\%. Estas diferenças são explicadas tanto por fatores socioeconômicos quanto pelos hábitos culturais das diferentes nacionalidades que colonizaram o país (Pechansky, Szobot \& Scivoletto, 2004).

Outro aspecto importante, encontrado em vários estudos, foi a relação com o trabalho. Parece que o padrão de comportamento que mimetiza o do adulto, isto é, sair para trabalhar e ter renda própria, pode ser distorcido e reproduzir também o hábito do consumo de álcool.

Para a definição e aperfeiçoamento das estratégias de prevenção, deve-se ainda levar em conta o apelo publicitário em torno do hábito de beber, além de questões culturais e do caráter 'lícito' do consumo de álcool. A prevenção do uso de álcool dependeria, então, da revisão da legislação sobre propaganda de bebidas alcóolicas, cumprimento da legislação que proíbe a venda a menores, ações de saúde e educação para a população escolar adolescente, além de uma abordagem diferenciada para o suporte social e familiar.

\subsection{Saúde Materno-Infantil}

Esta seção consta de dois componentes. O primeiro deles analisa os determinantes da mortalidade na infância no Brasil, destacando entre eles a renda e a escolaridade da mãe. o segundo está baseado em uma revisão da literatura científica sobre diversos aspectos da saúde materno-infantil no Brasil.

\section{Alguns Determinantes da Mortalidade na Infância, no Brasil ${ }^{4}$}

A divulgação do Censo 2000 e das Pesquisas Nacionais por Amostra de Domicílios (Pnads), realizadas no início da presente década, tornaram possível a atualização das estimativas da mortalidade infantil e na infância, viabilizando maior confiabilidade e exatidão dos valores desses indicadores, ao permitir comparações com os derivados do censo de 1991.

É possível, então, refazer e atualizar as estimativas da mortalidade na infância e retomar análises realizadas em trabalho divulgado pela Opas/OMS (Simões, 2002), considerando, não mais as Pnads 1992 e 1999, mas os censos de 1991, 2000 e a Pnad 2005, tendo como controles a escolaridade da mãe e quintis de renda familiar per capita. 
Apesar de alguns avanços na cobertura das políticas públicas ao longo dos anos, ainda persistem fortes desigualdades econômicas e sociais no país, com reflexos negativos nas condições de vida de contingentes importantes de crianças, principalmente, aquelas residentes em áreas e regiões onde o desenvolvimento econômico não se deu na mesma intensidade daquele observado em áreas, como do Centro-Sul do país. A reprodução de estruturas sociais, nas quais a pobreza é predominante, situação típica da Região Nordeste, continua tendo fortes impactos nas precárias condições de vida e de saúde das crianças, refletindo-se nos indicadores de mortalidade infantil e na infância que permanecem elevados, apesar da tendência de declínio observada nos anos mais recentes.

É bem verdade que, a situação social e de saúde dessas crianças poderia estar pior, caso não se estivesse verificando no país uma profunda transformação no padrão demográfico, com impactos nas estruturas etárias. Estas alterações vêm agindo no sentido de reduzir a proporção de crianças menores de 5 anos, sendo, portanto, um facilitador na solução de um conjunto de problemas, a exemplo das questões relacionadas à saúde infantil e na infância, ao elevar os níveis de sua sobrevivência, particularmente nos estratos sociais mais carentes e em regiões menos desenvolvidas.

Indispensável mencionar que os dados de mortalidade fornecem elementos de suma importância no conhecimento dos níveis de saúde da população, além de proverem subsídios para o planejamento das ações das políticas de atenção à saúde dos distintos segmentos populacionais.

A mortalidade na infância ${ }^{5}$ tem sido utilizada como um bom indicador de avaliação das condições de saúde e de vida da população. Em sua fase mais recente (1990/2005), a mortalidade na infância, no Brasil, passa de 53,7 óbitos de menores de 5 anos por 1.000 nascidos vivos, para 28,8\%, ou seja, um decréscimo de 46,4\% (Tabela 25 e Gráfico 32).

Tabela 25 - Taxa de mortalidade na infância, segundo região. Brasil - 1990, 1991, 2000, 2005

\begin{tabular}{l|ccccc}
\hline \multicolumn{1}{c|}{ Região } & 1990 & 1991 & 2000 & 2005 & $\begin{array}{c}\text { Diferença } \\
\text { relativa (\%) }\end{array}$ \\
\hline BRASIL & 53,7 & 50,6 & 35,1 & 28,8 & $-46,4$ \\
Norte & 52,9 & 49,9 & 34,1 & 28,3 & $-46,5$ \\
Nordeste & 87,3 & 81,6 & 50,9 & 38,9 & $-55,4$ \\
Sudeste & 36,6 & 34,7 & 25,3 & 19,2 & $-47,5$ \\
Sul & 35,2 & 33,3 & 22,0 & 18,1 & $-48,8$ \\
Centro-Oeste & 41,0 & 38,7 & 26,2 & 22,6 & $-44,8$ \\
\hline
\end{tabular}

Fonte: Censos Demográficos, 1991-2000 e Pesquisa Nacional por Amostra de Domicílios (PNAD), 2005. Instituto Brasileiro de Geografia e Estatística (IBGE).

${ }^{5} \mathrm{~A}$ taxa de mortalidade na infância (menores de 5 anos) é definida como o número de óbitos de menores de cinco anos de idade, por mil nascidos vivos, em determinado espaço geográfico, no ano considerado. Estima o risco de morte dos nascidos vivos durante os cinco primeiros anos de vida. 
Apesar dos avanços alcançados no indicador, persistem, ainda, profundos contrastes regionais. Durante o período, a Região Nordeste apresentou declínios na mortalidade na infância de aproximadamente 55\%, ou seja, 10 pontos percentuais acima da média nacional. Todavia, merece consideração ressaltar que o valor da taxa, nessa região, em 2005 (38,9\%), ainda representa o dobro da observada para as regiões Sudeste e Sul do país, significando uma melhoria, tendo em vista que, em 1990, essa relação era de 2,5.

Chamam também a atenção os valores da mortalidade na infância da Região Norte, cujos índices são levemente inferiores à média nacional. Esta tem sido, inclusive, uma tendência que se vem notando historicamente e, provavelmente, está correlacionada a fatores positivos decorrentes não só da existência de uma economia de subsistência na área, mas também do fluxo importante de migrantes oriundos do Sul do país, que já apresentavam um padrão de mortalidade relativamente baixo, na época de seu deslocamento para a região.

Gráfico 32 - Mortalidade na infância, segundo região. Brasil - 1990, 1991, 2000, 2005

(\%)

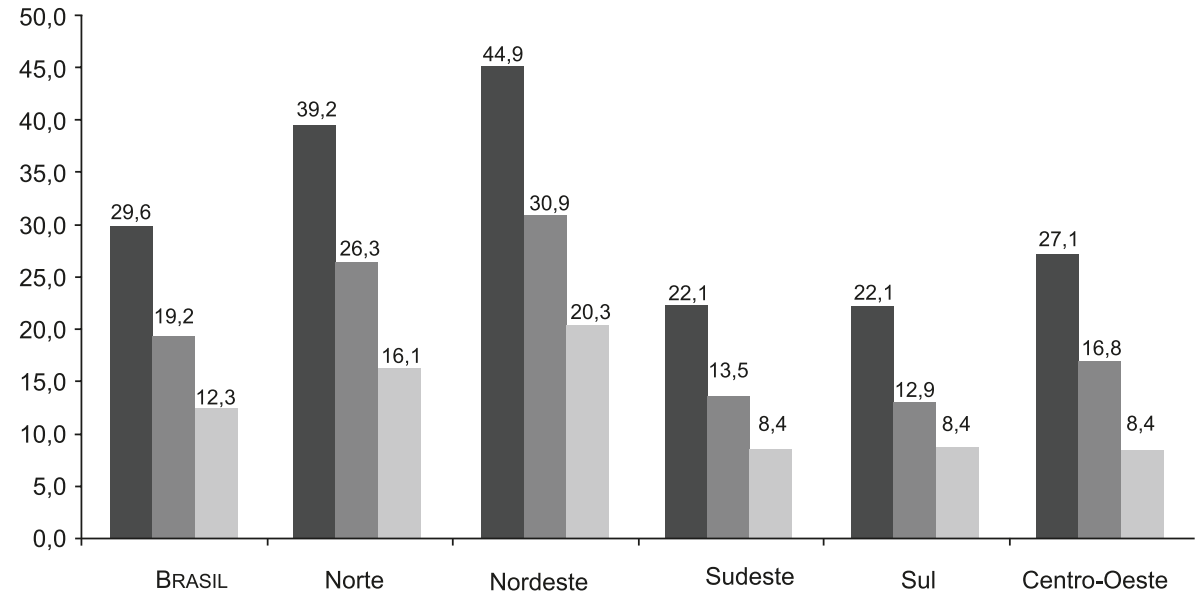

Fonte: Censos Demográficos, 1991-2000 e Pesquisa Nacional por Amostra de Domicílios (PNAD), 2005 Instituto Brasileiro de Geografia e Estatística (IBGE).

Vale apontar também a similaridade entre as taxas de mortalidade na infância das regiões Sudeste, Sul e Centro-Oeste, com valores em torno de $20 \%$. Portanto, se considerarmos a classificação da OMS, essas regiões e, em decorrência, seus estados, já se enquadram na categoria de baixa mortalidade.

As desigualdades educacionais e de renda na mortalidade na infância

Nos estudos dos diferenciais, a educação da mãe tem sido uma das principais variáveis socioeconômicas que tem originado impactos altamente positivos na redução dos índices de mortalidade infantil e na infância, em decorrência da maior percepção que a mãe adquire no trato e cuidado da saúde dos filhos. 
Apesar dos avanços alcançados nos últimos anos na inserção de novas gerações no sistema escolar, quando se considera o grupo de mulheres em idade fértil (15 a 49 anos) verificase que, em algumas regiões, ainda é bastante elevada a proporção dessas mulheres com baixa escolaridade (Tabela 26 e Gráfico 33). Trabalhando com o conceito da Unesco sobre analfabetismo funcional (menos de 4 anos de instrução), constata-se que a Região Nordeste apresenta, historicamente, as mais elevadas proporções de mulheres nesta categoria, cujos valores, que eram de 44,9\% em 1991, vêm declinando ao longo dos anos (39,1\%, em 2000, e 20,3\%, em 2005). Ou seja, no período 1990/2005, ocorre uma redução de 54,8\%, na proporção de mulheres de 15 a 49 anos analfabetas funcionais, similar à média nacional. Entretanto, é importante destacar que, considerando o país como um todo, essa proporção, em 2005, era de $12,3 \%$, sendo que as regiões Sul, Sudeste e Centro-Oeste apresentam valores bem abaixo desse parâmetro (8,4\%). Na Região Norte, esse valor - 16,1\% - é levemente inferior ao observado no Nordeste $(20,3)$.

Tabela 26 - Proporção de mulheres em idade fértil (15 a 49 anos) por anos de estudo, segundo região. Brasil - 1991, 2000, 2005

\begin{tabular}{|c|c|c|c|c|}
\hline \multirow{2}{*}{ Região } & \multirow{2}{*}{ TOTAL } & \multicolumn{3}{|c|}{ Anos de estudo da mulher } \\
\hline & & Menos de 4 & 4 a 7 & 8 ou mais \\
\hline \multicolumn{5}{|c|}{1991} \\
\hline BRASIL & 100,0 & 29,6 & 35,3 & 35,1 \\
\hline Norte & 100,0 & 39,2 & 33,4 & 27,4 \\
\hline Nordeste & 100,0 & 44,9 & 28,9 & 26,3 \\
\hline Sudeste & 100,0 & 22,1 & 37,1 & 40,8 \\
\hline Sul & 100,0 & 22,1 & 41,4 & 36,5 \\
\hline Centro-Oeste & 100,0 & 27,1 & 36,4 & 36,5 \\
\hline \multicolumn{5}{|c|}{2000} \\
\hline BRASIL & 100,0 & 19,2 & 32,0 & 48,8 \\
\hline Norte & 100,0 & 26,3 & 33,5 & 40,2 \\
\hline Nordeste & 100,0 & 30,9 & 31,8 & 37,3 \\
\hline Sudeste & 100,0 & 13,5 & 30,8 & 55,7 \\
\hline Sul & 100,0 & 12,9 & 34,4 & 52,7 \\
\hline Centro-Oeste & 100,0 & 16,8 & 33,4 & 49,8 \\
\hline \multicolumn{5}{|c|}{2005} \\
\hline BRASIL & 100,0 & 12,3 & 24,8 & 62,9 \\
\hline Norte & 100,0 & 16,1 & 26,8 & 57,0 \\
\hline Nordeste & 100,0 & 20,3 & 28,0 & 51,7 \\
\hline Sudeste & 100,0 & 8,4 & 22,1 & 69,4 \\
\hline Sul & 100,0 & 8,4 & 25,1 & 66,4 \\
\hline Centro-Oeste & 100,0 & 8,4 & 25,1 & 66,4 \\
\hline
\end{tabular}

Fonte: Censos Demográficos, 1991-2000 e Pesquisa Nacional por Amostra de Domicílios (Pnad), 2005. Instituto Brasileiro de Geografia e Estatística (IBGE). 
Gráfico 33 - Mulheres de 15 a 49 anos analfabetas funcionais (menos de 4 anos de estudo), segundo região. Brasil - 1991, 2000, 2005

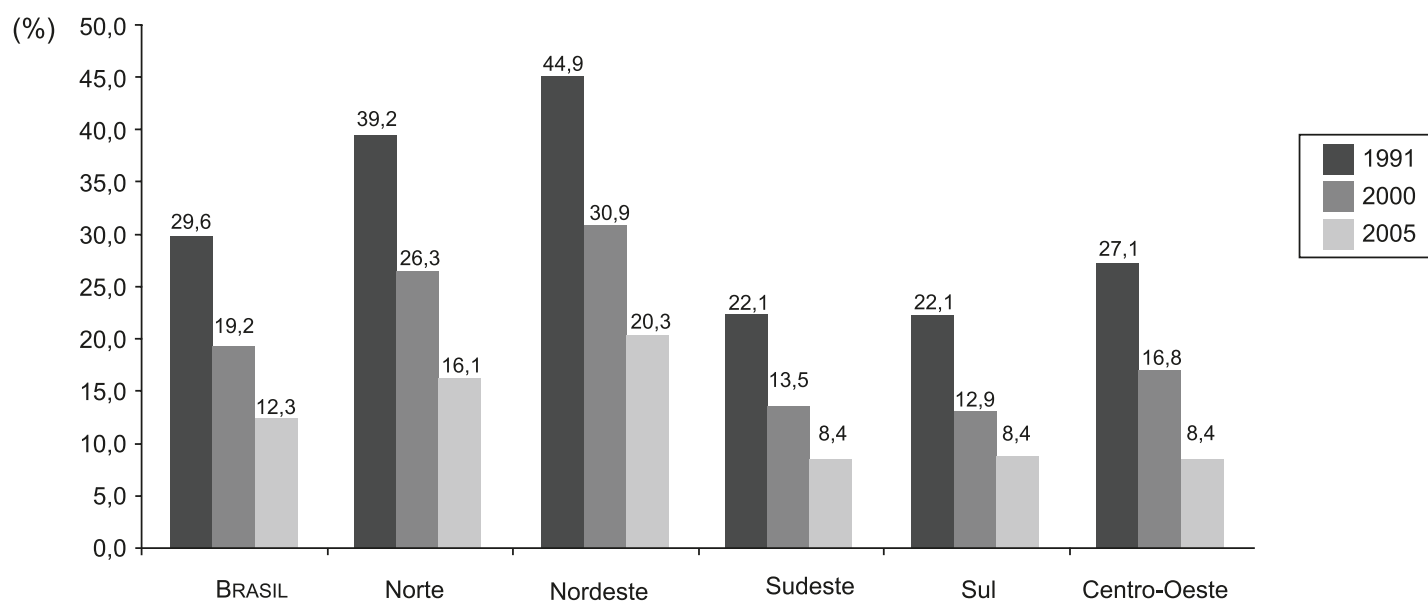

Fonte: Censos Demográficos, 1991-2000 e Pesquisa Nacional por Amostra de Domicílios (PNAD), 2005

Instituto Brasileiro de Geografia e Estatística (IBGE).

O esperado é que a melhora nos indicadores educacionais, notada em todas as regiões brasileiras, durante os últimos 15 anos, tenha repercutido positivamente nos níveis da mortalidade na infância. Este fato é plenamente comprovado com os resultados apresentados na Tabela 27. Existe uma relação inversa entre o nível de educação da mãe e a mortalidade na infância, ou seja, à medida que aumenta a escolaridade materna, diminui de forma intensa a mortalidade de menores de 5 anos. Nesse sentido, para o Brasil como um todo, em 1990, esta mortalidade, que era de $89,7 \%$ em crianças cujas mães tinham menos de quatro anos de instrução, se reduz para 30,3\%, em crianças com mães com nível de instrução superior a oito anos, representando um diferencial de 196,6\%. Este valor é um forte indicativo de que as desigualdades entre os estratos sociais no que diz respeito à mortalidade na infância, no início da década de 1990, eram extremamente elevados.

A Região Nordeste se destacava como a área onde a mortalidade na infância, de filhos de mulheres analfabetas funcionais era a mais elevada dentre as regiões brasileiras, com cifras superiores a $120 \%$, mais que o dobro do estimado, para o mesmo estrato nas demais regióes.

Durante o período foco da análise, 1990/2005, constatam-se quedas nos diferenciais de mortalidade entre os estratos sociais, principalmente, no caso específico da Região Nordeste, decorrentes, possivelmente, da melhora do nível educacional das mulheres em idade fértil, que, durante os últimos 15 anos, acarretou reduções acentuadas na proporção de mulheres enquadradas na categoria de analfabetas funcionais.

Entretanto, a situação continua sendo ainda preocupante nessa região, que permanece apresentando as taxas de mortalidade na infância mais elevadas para crianças com mães de 
baixa instrução. Em 2000, os valores se situavam em 70 óbitos de menores de 5 anos por 1.000 nascidos vivos, o dobro do observado para as regiões Sudeste e Sul. Entre 2000 e 2005, verificase redução nessas diferenças - 56\% contra 30\%, em média - reflexo, provável, de um conjunto de programas que vem sendo implementado no país, particularmente na Região Nordeste.

Tabela 27 - Taxa de mortalidade na infância por anos de estudo da mãe, segundo região. Brasil - 1990, 2000, 2005

\begin{tabular}{|c|c|c|c|c|c|}
\hline \multirow{2}{*}{ Região } & \multirow{2}{*}{ TOTAL } & \multicolumn{3}{|c|}{ Anos de estudo da mãe } & \multirow{2}{*}{ Razão a/b } \\
\hline & & Menos de 4 (a) & 4 a 7 & 8 ou mais (b) & \\
\hline \multicolumn{6}{|c|}{1990} \\
\hline BRASIL & 53,7 & 89,7 & 47,6 & 30,3 & 2,9 \\
\hline Norte & 52,9 & 66,1 & 51,8 & 32,9 & 2,0 \\
\hline Nordeste & 87,3 & 123,5 & 75,8 & 39,9 & 3,1 \\
\hline Sudeste & 36,6 & 56,6 & 34,9 & 22,3 & 2,5 \\
\hline Sul & 35,2 & 57,5 & 33,5 & 18,8 & 3,0 \\
\hline Centro-Oeste & 41,0 & 59,5 & 36,2 & 20,7 & 2,8 \\
\hline \multicolumn{6}{|c|}{2000} \\
\hline BRASIL & 35,1 & 53,7 & 31,5 & 22,9 & 2,3 \\
\hline Norte & 34,1 & 45,6 & 30,0 & 23,4 & 1,9 \\
\hline Nordeste & 50,9 & 70,2 & 41,7 & 28,8 & 2,4 \\
\hline Sudeste & 25,3 & 35,4 & 27,9 & 18,0 & 1,9 \\
\hline Sul & 22,0 & 33,5 & 22,3 & 16,3 & 2,0 \\
\hline Centro-Oeste & 26,2 & 38,1 & 25,2 & 19,4 & 1,9 \\
\hline \multicolumn{6}{|c|}{2005} \\
\hline BRASIL & 28,8 & 39,9 & 25,8 & 18,4 & 2,1 \\
\hline Norte & 28,3 & 37,9 & 24,9 & 18,7 & 2,0 \\
\hline Nordeste & 38,9 & 56,2 & 31,9 & 20,3 & 2,7 \\
\hline Sudeste & 19,2 & 30,2 & 21,2 & 13,7 & 2,2 \\
\hline Sul & 18,1 & 29,2 & 18,3 & 13,3 & 2,2 \\
\hline Centro-Oeste & 22,6 & 33,5 & 21,7 & 16,7 & 2,0 \\
\hline
\end{tabular}

Fonte: Censos Demográficos, 1991-2000 e Pesquisa Nacional por Amostra de Domicílios-PNAD, 2005. 
Apesar dessas melhorias e das conseqüentes reduções nas desigualdades da mortalidade na infância entre o Nordeste e as demais regiões, principalmente neste estrato social específico, há que ressaltar que uma taxa de mortalidade na infância daquela magnitude não deixa de ser inquietante. É importante destacar também as diferenças inter-regionais relativamente baixas entre os níveis de mortalidade na infância no estrato de maior escolaridade. A mortalidade um pouco mais elevada no Nordeste, de certo modo, leva à conclusão de que existem outros fatores, além da educação, que podem estar explicando essa maior mortalidade. Tais fatores podem estar relacionados, por exemplo, às precárias condições socioambientais ainda prevalecentes na região, com fortes impactos sobre as condições de sobrevivência das crianças, mesmo daquelas pertencentes a estratos não tão carentes.

A mesma situação de desigualdade na sobrevivência de crianças se repete quando se considera o impacto de outra variável socioeconômica importante, como é o caso da renda (Tabela 28 e Gráfico 34). Esta variável, quando desagregada por quintis de renda familiar per capita, mostra que a mortalidade na infância é sempre superior para os quintis de renda familiar per capita mais pobre. De modo geral, nota-se que as diferenças entre os três primeiros quintis de renda familiar per capita são pequenas, acentuando-se nos dois últimos quintis, independentemente da unidade espacial analisada.

Ao longo dos últimos 15 anos, verifica-se uma clara tendência de queda da mortalidade na infância em todos os quintis de renda, independentemente da região. Na média nacional, a mortalidade na infância associada ao primeiro quinto era de $72,7 \%$, em 1990, caindo para $40,7 \%$ em 2000 e 33,9\% em 2005. Ou seja, uma queda de aproximadamente $114 \%$. Este fato vai se refletir positivamente na comparação entre o primeiro e último quintis de renda. A diferença, que era de 126\% em 1990, cai para 96\% em 2005.

A Região Nordeste, como esperado, apresenta as maiores taxas de mortalidade na infância em todos os quintis de renda, particularmente, no primeiro quinto, embora a tendência histórica seja também de queda no decorrer dos anos. Se, em 1990, a taxa era de 107,6\%, em 2000 declinou para $64 \%$ e em 2005 para $56,4 \%$. É importante destacar que, ao se comparar esse estrato com o das regiões do Centro-Sul, constata-se diminuição nos diferenciais, no decorrer dos anos.

Tem-se uma visão da tendência da mortalidade na infância, comparando o primeiro com o último quinto de renda familiar per capita. Fica clara a tendência de queda, mas se destaca o último estrato da Região Nordeste, onde a mortalidade na infância, em 2005, não é das mais baixas (24\%) quando comparada com a das regiões do Centro-Sul, que apresentam valores levemente superiores a $10 \%$, reflexo do maior desenvolvimento social e econômico dessas áreas e, conseqüentemente, da oferta mais elevada de serviços, seja de saúde, educação, saneamento e outros. 
Tabela 28 - Taxa de mortalidade na infância, por quintis de renda familiar per capita, segundo região. Brasil - 1990, 2000, 2005

\begin{tabular}{|c|c|c|c|c|c|c|c|}
\hline \multirow[b]{2}{*}{$\begin{array}{c}\text { Grandes } \\
\text { regiões }\end{array}$} & \multirow[b]{2}{*}{ TOTAL } & \multicolumn{5}{|c|}{ Quintis de renda familiar per capita } & \multirow[b]{2}{*}{$\begin{array}{l}\text { Diferença } \\
\text { relativa (\%) }\end{array}$} \\
\hline & & $\begin{array}{c}10 \\
\text { Quintil }\end{array}$ & $\begin{array}{c}2 \stackrel{0}{ } \\
\text { Quintil }\end{array}$ & $\begin{array}{c}30 \\
\text { Quintil }\end{array}$ & $\begin{array}{c}4 \stackrel{2}{9} \\
\text { Quintil }\end{array}$ & $\begin{array}{c}50 \\
\text { Quintil }\end{array}$ & \\
\hline \multicolumn{8}{|c|}{1990} \\
\hline BRASIL & 53,7 & 72,7 & 63,5 & 47,6 & 38,4 & 32,2 & 125,8 \\
\hline Norte & 52,9 & 60,8 & 58,4 & 56,3 & 54,2 & 41,8 & 45,6 \\
\hline Nordeste & 87,3 & 107,6 & 99,2 & 93,1 & 75,7 & 46,0 & 133,8 \\
\hline Sudeste & 36,6 & 44,5 & 38,4 & 33,3 & 28,9 & 22,9 & 94,3 \\
\hline Sul & 35,2 & 43,3 & 35,7 & 32,2 & 25,9 & 22,7 & 90,5 \\
\hline Centro-Oeste & 41,0 & 44,0 & 38,6 & 35,5 & 32,4 & 27,8 & 58,1 \\
\hline \multicolumn{8}{|c|}{2000} \\
\hline BRASIL & 35,1 & 40,7 & 31,9 & 29,0 & 23,6 & 19,5 & 108,6 \\
\hline Norte & 34,1 & 38,0 & 37,6 & 36,6 & 31,9 & 24,5 & 55,0 \\
\hline Nordeste & 50,9 & 64,0 & 58,3 & 53,9 & 49,4 & 30,3 & 111,5 \\
\hline Sudeste & 25,3 & 27,1 & 25,0 & 22,0 & 20,0 & 14,4 & 88,1 \\
\hline Sul & 22,0 & 25,4 & 22,4 & 21,1 & 17,4 & 12,6 & 100,7 \\
\hline Centro-Oeste & 26,2 & 26,5 & 24,4 & 23,4 & 20,4 & 17,2 & 53,8 \\
\hline \multicolumn{8}{|c|}{2005} \\
\hline BRASIL & 28,8 & 33,9 & 30,0 & 26,3 & 20,7 & 17,3 & 95,9 \\
\hline Norte & 28,3 & 33,3 & 31,1 & 30,4 & 26,5 & 22,3 & 49,2 \\
\hline Nordeste & 38,9 & 56,4 & 44,5 & 41,2 & 37,2 & 23,9 & 136,5 \\
\hline Sudeste & 19,2 & 23,1 & 19,0 & 18,0 & 15,2 & 11,0 & 110,9 \\
\hline Sul & 18,1 & 21,4 & 18,4 & 17,3 & 14,3 & 10,1 & 111,5 \\
\hline Centro-Oeste & 22,6 & 22,9 & 21,1 & 20,2 & 17,6 & 14,9 & 54,0 \\
\hline
\end{tabular}

Fonte Censos Demográficos, 1991 e 2000 e Pesquisa Nacional por Amostra de Domicílios (PNAD), 2005. Instituto Brasileiro de Geografia e Estatística (IBGE). 
Gráfico 34 - Taxa de mortalidade na infância, por quintis de renda familiar per capita, segundo região. Brasil - 1990, 2000, 2005

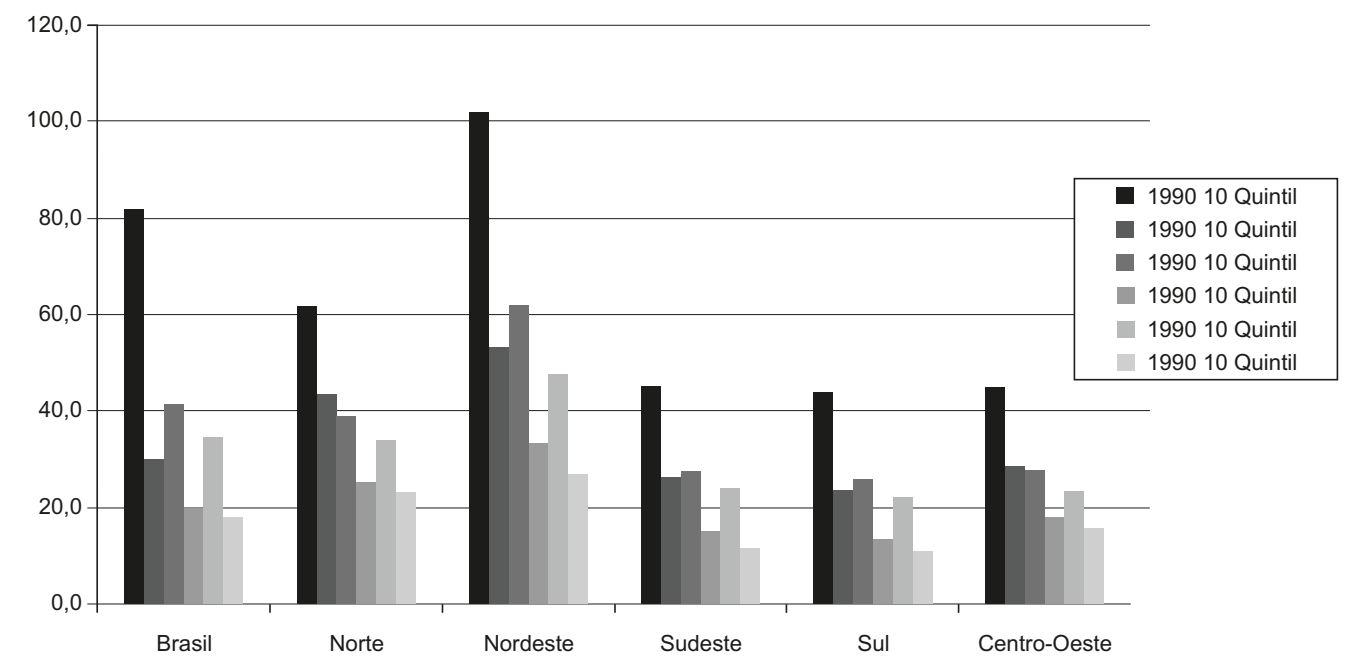

Fonte: Censos Demográficos, 1991-2000 e Pesquisa Nacional por Amostra de Domicílios (Pnad), 2005. Instituto Brasileiro de Geografia e Estatística (IBGE

\section{Revisão da Literatura sobre Saúde Materno-Infantil ${ }^{6}$}

A revisão da produção científica brasileira e internacional sobre os diferenciais em saúde de mães e crianças menores de cinco anos no Brasil, aqui realizada, cobre o período de 1990 até meados de 2007, incluindo publicações que tenham desagregado os desfechos de interesse segundo grupos socioeconômicos.

Os aspectos revisados incluíram:

1. Diferenciais em mortalidade, morbidade, amamentação, situação nutricional (incluindo baixo peso ao nascer, subnutrição e sobrepeso/obesidade), desenvolvimento cognitivo;

2. Diferenciais de acesso, utilização e cobertura de serviços e programas de saúde;

3. Análise de programas ou intervenções com objetivo de superar iniqüidades neste grupo populacional.

\section{Baixo peso ao nascer e nascimentos pré-termo}

O Ministério da Saúde, com dados do Sistema de Informação sobre Nascidos Vivos (Sinasc), estimou em 8,2\% a prevalência de baixo peso ao nascer (BPN), ${ }^{7}$ no Brasil, para o ano de 2004 (Brasil, 2006). Chama a atenção que esta prevalência seja maior no Sul $(8,6 \%)$ e no Sudeste $(9,1 \%)$ do que no Nordeste $(7,4 \%)$, o que também acontece com a prevalência 
de nascimentos pré-termo (menos de 37 semanas completas de gestação). Os diferenciais de baixo peso entre Nordeste e Sudeste também foram descritos em outras publicações (Silva et al., 2005, 2006).

Além da referida publicação do Ministério da Saúde, que assinala diferenças regionais, mas não avalia diferenciais socioeconômicos, dez outras publicações foram identificadas sobre esse tema, sendo nove estudos sobre BPN, cinco sobre nascimentos pré-termo e quatro sobre retardo de crescimento intra-uterino (RCIU) ${ }^{8}$

A maior parte dos estudos mostrou associação entre BPN e baixo nível socioeconômico, embora em vários deles os diferenciais tenham sido discretos. Alguns estudos recentes revelam um aumento de BPN na classe alta, talvez associado a interrupções da gravidez (Silva et al., 2006; Barros et al., 2007). Nascimentos pré-termo e RCIU também estiveram associados com pior situação socioeconômica.

As tendências temporais destes indicadores, pelo menos no Sudeste do país, foram de aumento das prevalências de BPN e pré-termo. Com relação às desigualdades sociais, as prevalências de BPN, em São Paulo, se mantiveram estáveis entre 1984-1985 e 1995-1996, para os recémnascidos do tercil mais baixo de renda familiar - ao redor de $10 \%-$, mas aumentaram no tercil mais alto, de 6,3\% para 8,6\% (Monteiro et al., 2000a). Em Ribeirão Preto, a prevalência de BPN aumentou marcadamente entre 1978-1979 e 1994, tanto entre os recém-nascidos de famílias de baixa renda - de 8,6\% para 13,8\% - como naqueles de famílias mais ricas - de 3,4\% para 9,1\% (Silva et al., 1998). Em Pelotas, o BPN se manteve estável entre os recém-nascidos de renda familiar até um salário mínimo mensal, mas aumentou marcadamente entre aqueles das famílias mais abastadas - de 5,4\% para 11,6\% (Barros et al., 2007). Nesta cidade, os nascimentos pré-termo tiveram um impressionante aumento entre 1982 (6,3\%), 1993 (11,4\%) e 2004 (14,7\%). Entre os recém-nascidos mais pobres, a prevalência de pré-termo aumentou de $7,7 \%$, em 1982 , para $19,8 \%$, em 2004 , enquanto que para os recém-nascidos de famílias ricas este aumento foi de 5,7\%, em 1982, para 13,5\%, em 2004.

Em resumo, os estudos demonstram desigualdades sociais para BPN, RCIU e nascimentos pré-termo, com maiores prevalências sendo observadas entre os recém-nascidos mais pobres. Em contrapartida, o país vem enfrentando um aumento progressivo de nascimentos prétermo e de BPN de proporções epidêmicas, que afeta todos os grupos sociais e que requer cuidadosa investigação.

\section{Amamentação}

A duração mediana da amamentação, no Brasil, tem aumentado progressivamente nas últimas décadas, de 2,5 meses (em 1975) para 9,9 meses (em 1999) (Brasil, 2000). Quanto às desigualdades sociais, foram identificados quatro estudos. Dois analisaram dados de todo o país, sendo um para 1989, baseado na Pesquisa Nacional sobre Saúde e Nutrição -

${ }^{8}$ Retardo de crescimento intra-uterino (RCIU), corresponde a um peso ao nascer para a idade gestacional abaixo do percentil 10 de uma curva de referência. 
PNSN (Venancio \& Monteiro, 1998) e outro para 1996, com base na Pesquisa Nacional sobre Demografia e Saúde - PNDS (Gwatkin et al., 2007). Os dois outros estudos são inquéritos locais, realizados em Pernambuco, em 1997 (Vasconcelos et al., 2006), e em Pelotas (RS), entre 1982 e 2004 (Victora et al., 2007).

A análise do PNSN de 1989 mostrou que, aos seis meses de idade, a prevalência de amamentação entre as crianças do quartil inferior de renda per capita era de $59 \%$, sendo de $53 \%$ para o quartil mais alto. Aos 12 meses, a prevalência para as mais pobres era de $46 \%$, sendo de $24 \%$ para as mais ricas (Venancio \& Monteiro, 1998).

Na PNDS, realizada em 1996, a prevalência de amamentação exclusiva em crianças menores de três meses foi de 40,6\%, sendo $32,7 \%$ no quintil de renda mais baixo e 59,9\% no quintil de maior renda (Gwatkin et al., 2007). Um problema metodológico no questionário utilizado faz com que estes dados provavelmente estejam superestimados, mas de qualquer forma a comparação entre ricos e pobres é válida. Outro indicador disponível na PNDS é o percentual de crianças de 6 a 9 meses que recebiam leite materno mais alimentos complementares, igual a $30,6 \%$, variando de $29,2 \%$ no quintil inferior a $37,2 \%$ no superior.

No estado de Pernambuco, em 1997, em um estudo de crianças menores de dois anos, a mediana da amamentação foi mais alta naquelas com renda familiar per capita superior a dois salários mínimos mensais (201 dias) do que nas de menor renda (108 dias) (Vasconcelos et al., 2006).

Com relação às tendências temporais mais recentes, o estudo das coortes de Pelotas mostrou aumento na duração mediana da amamentação, de 3,1 meses em 1982 para 4,0 em 1993 e 6,8 em 2004. Nas três coortes, as crianças das famílias mais ricas apresentaram maiores prevalências de aleitamento até os seis meses de idade, mas as crianças mais pobres mostraram maiores prevalências a partir desta idade.

Em resumo, os dados sobre amamentação sugerem que esta prática está aumentando em nosso país, sendo que, atualmente, as mães de nível socioeconômico alto tendem a amamentar mais freqüentemente do que as pobres, pelo menos nos primeiros meses de vida de seus filhos.

\section{Estado nutricional}

A desnutrição inclui, por um lado, os déficits de crescimento ou subnutrição, e por outro, o sobrepeso e a obesidade. Foram identificados 15 estudos sobre esse tema, sendo dois deles de abrangência nacional: o de Monteiro et al. (2000a, 2000b, 2000c, 2000d) baseado na PNSN1989 e o de Gwatkin et al. (2007), com base na PNDS-1996. Os outros 13 estudos foram regionais, analisando déficits de peso para idade (P/I), altura ou comprimento para idade (A/I) e peso para altura (P/A), e, no caso de sobrepeso, o excesso de peso para altura.

Na PNSN de 1989, a prevalência de déficit de P/I foi de 7,1\%, sendo 13,6\% para as crianças do quartil mais baixo de renda e $1,4 \%$ para as do quartil mais alto. Portanto, a diferença entre 
os grupos extremos foi de cerca de dez vezes. Na PNDS de 1996, a prevalência de déficit de altura/idade para o país foi de $10,4 \%$, sendo $23,4 \%$ no quintil mais baixo e $2,4 \%$ no mais alto. Todos os outros 13 estudos confirmaram a associação entre pobreza e subnutrição, sendo esta marcadamente mais freqüente no grupo mais pobre do que em todos os demais. Os diferenciais foram sempre superiores para déficits de altura do que de peso.

Além da comparação entre PNSN e PNDS, há apenas dois estudos sobre tendências temporais nas desigualdades sociais em subnutrição. Em São Paulo, a prevalência de déficit de comprimento para idade nas crianças do tercil mais baixo de renda familiar reduziu-se de 30,5\% em 1974-1975 para 3,6\% em 1995-1996. Para as crianças do tercil mais alto, a queda no período foi de $10,1 \%$ para $1,5 \%$. Houve, portanto, uma discreta redução na brecha entre pobres e ricos.

Em Pelotas, uma comparação entre 1982 e 2004 mostrou uma marcada redução nas desigualdades. Em 1982, as crianças do grupo de menor renda familiar tinham uma prevalência de déficit de comprimento para idade de $16,9 \%$, enquanto que entre as mais ricas esta prevalência era de $2,4 \%$, uma razão de sete vezes entre pobres e ricos. Já em 2004 , as prevalências foram de $8,0 \%$ entre as crianças mais pobres e 3,1\% entre as mais ricas, com uma razão entre pobres e ricos de 2,6. Cabe notar que a prevalência de subnutrição é expressa como o percentual de crianças abaixo da média menos dois escores $\mathrm{Z}$ de uma população de referência com adequado estado nutricional. Estatisticamente, espera-se que 2,3\% de uma população bem nutrida esteja abaixo deste ponto de corte. Portanto, nos estudos de São Paulo e Pelotas, a população mais rica já se encontra nesse patamar mínimo, sendo esperado que as diferenças se reduzam na medida em que o estado nutricional da população como um todo melhora.

Dois estudos avaliaram sobrepeso por grupos de renda e sua tendência temporal. Em São Paulo (1995-1996), o sobrepeso (definido por P/A > 2 escores Z) foi de 5,1\% nas crianças de maior renda e 1,9\% nas mais pobres. Avaliando as tendências temporais desta população entre 1974-1975 e 1995-1996, as crianças do tercil inferior de renda apresentaram aumento de $1,6 \%$ para $2,8 \%$, enquanto que entre as pertencentes ao tercil mais alto o sobrepeso caiu de 6,1\% para 5,4\%. Em Pelotas, em uma comparação entre 1982 e 2004, o sobrepeso aumentou de $4,0 \%$ para $8,1 \%$ entre as mais pobres, enquanto que nas mais ricas a prevalência de sobrepeso reduziu de $13,1 \%$ para 9,5\%. Portanto, em ambas as populações - ao contrário da maioria dos desfechos revisados -, o sobrepeso foi maior entre crianças ricas do que entre as pobres. No entanto, as desigualdades estão diminuindo ao longo do tempo, pela redução observada entre as crianças mais ricas e o aumento entre as mais pobres.

Em resumo, persistem os diferenciais socioeconômicos em subnutrição, afetando especialmente as crianças mais pobres, e, no caso de sobrepeso e obesidade, afetando as mais ricas. No entanto, há evidências de que estes diferenciais estejam sendo reduzidos ao longo do tempo. 


\section{Deficiências de micronutrientes}

Seis estudos foram identificados com informações sobre anemia, para distintos grupos socioeconômicos; três do Sul, dois do Nordeste e um do Sudeste. A prevalência global em crianças menores de cinco anos (ou menores de três anos, em alguns estudos) foi muito elevada: 54\% em Criciúma (SC) (Neuman et al., 2000), 48\% na Bahia (Assis et al., 2007), 48\% em Porto Alegre (RS) (Silva et al., 2001), 47\% em São Paulo (SP) (Monteiro et al., 2000d), 41\% em Pernambuco (Araújo et al., 2006) e 30\% em Pelotas (RS) (Assunção et al., 2007). Ademais, todos os estudos mostraram uma associação direta entre a prevalência de anemia e pobreza.

Em relação às tendências temporais, a prevalência de anemia aumentou de 35,6\%, em 19841985, para 46,9\%, em 1995-1996, em São Paulo (Monteiro et al., 2000d). Este aumento ocorreu em todos os grupos sociais, sendo mais marcado entre as crianças do tercil mais pobre da população (de 40,8\% para 55,1\%) do que entre as do tercil mais alto (31,9\% para $38,7 \%$ ).

Além da deficiência de ferro subjacente à maioria dos casos de anemia, em nosso país, outros micronutrientes como vitamina A e zinco também estão associados à saúde e desenvolvimento infantis. Somente um estudo foi localizado (Assis et al., 2007), no qual foram medidos os consumos de retinol e zinco na dieta de crianças baianas menores de 5 anos. A ingesta destes dois micronutrientes foi significativamente menor nas crianças do tercil inferior de nível socioeconômico.

Em resumo, os estudos demonstram altas taxas de anemia em todos os grupos sociais, mas prevalências ainda mais elevadas entre as crianças mais pobres. Desigualdades sociais também foram observadas no estudo que avaliou a ingesta de retinol e zinco em crianças.

\section{Morbidade}

Dez publicações sobre morbidade infantil foram localizadas, todas utilizando dados primários. Duas delas, de abrangência nacional, utilizaram dados da PNDS (Sastry \& Burgard, 2005; Gwatkin et al., 2007) e avaliaram diarréia e infecções respiratórias agudas; dois estudos de casos e controles avaliaram fatores de risco para diarréia (Zona da Mata, Pernambuco) (Silva et al., 2004) e pneumonia (Porto Alegre-RS) (Victora et al., 1994) e um estudo transversal em São Paulo avaliou diarréia, parasitoses intestinais e doença respiratória, além de hospitalizações por diarréia (Benicio et al., 2000; Benicio \& Monteiro, 2000; Ferreira et al., 2000). Três estudos avaliaram hospitalizações, dois no Rio Grande do Sul, nos primeiros cinco anos de idade (Issler et al., 1996) e no primeiro ano de vida (Matijasevich et al., 2007), e um na Bahia, com crianças menores de cinco anos (Assis et al., 2007).

Diferenciais socioeconômicos claros foram observados em todos os desfechos estudados, com exceção do estudo da Bahia, onde a proporção de crianças hospitalizadas no último ano foi semelhante para os três grupos socioeconômicos. Os estudos de tendências temporais demonstraram reduções na prevalência de morbidade para toda a população ao longo do tempo, com exceção do estudo de doença respiratória em São Paulo, onde houve um marcado aumento entre 1984-1985 e 1995-1996. Com relação à evolução das desigualdades sociais, a análise dos estudos não mostra resultados homogêneos. O inquérito de São Paulo mostrou 
uma redução das desigualdades (expressas como a razão da prevalência entre pobres e ricos) em termos de diarréia, mas um aumento das mesmas para doenças respiratórias baixas, assim como um discreto aumento para parasitoses intestinais.

As tendências temporais de hospitalização das coortes de Pelotas mostraram resultados distintos: enquanto entre as crianças mais pobres a prevalência de hospitalização no primeiro ano de vida foi similar entre 1982 e 2004 (26,8\% e 24,5\%, respectivamente), para as mais ricas a prevalência de hospitalização aumentou significativamente no período (3,5\% e 12,6\%, respectivamente). Portanto, nesta população, a brecha entre ricos e pobres diminuiu, não por redução nas mais pobres, mas por aumento entre as mais ricas.

\section{Desenvolvimento cognitivo}

Foram identificados três estudos sobre desenvolvimento cognitivo, todos utilizando o teste de Bailey, um instrumento de triagem capaz de detectar suspeita de atraso de desenvolvimento a ser posteriormente confirmado por outros instrumentos. As crianças avaliadas tinham entre um e dois anos de idade. Um dos estudos foi realizado em Salvador (BA) (Andrade et al., 2005), outro na Zona da Mata de Pernambuco (Grantham-McGregor et al., 1998) e o terceiro em Pelotas (RS) (Halpern et al., 2007). No estudo baiano, a prevalência de suspeita de problemas de desenvolvimento esteve inversamente associada à qualidade de estímulo familiar, que, por sua vez, esteve fortemente relacionado ao nível educacional da mãe. Em Pernambuco, o desenvolvimento cognitivo esteve positivamente associado com melhor situação socioeconômica familiar. Em Pelotas, a prevalência de suspeita de atraso de desenvolvimento foi de $37,1 \%$ em 1993, caindo para 21,4\% em 2004. Com relação às tendências temporais de desigualdades nesta cidade, as prevalências de suspeita de atraso apresentaram queda discretamente maior entre as crianças mais pobres (36\%) do que entre as mais ricas (30\%), e a razão entre pobres e ricos reduziu-se de 1,6 em 1993 para 1,4 em 2004.

Em resumo, os estudos avaliados demonstram maiores prevalências de problemas cognitivos entre as crianças de famílias mais pobres.

Acesso, utilização e cobertura de serviços e programas de saúde

Aqui são examinados os diferenciais socioeconômicos em termos de atenção pré-natal e parto, e assistência médica para crianças menores de cinco anos.

Atenção pré-natal e ao parto

Quatro publicações nacionais e oito estudos locais, três no Sul e cinco no Sudeste, foram localizados, avaliando a cobertura pré-natal e a atenção ao parto, incluindo cesarianas.

A atenção pré-natal foi analisada na base de dados da PNDS de 1996, em duas publicações (Barros et al., 2005; Gwatkin et al., 2007). Para toda a população, a prevalência de pré-natal inadequado foi de $38,4 \%$, sendo $70,7 \%$ no quintil mais pobre e $13,6 \%$ no mais rico (Barros et al., 2005). O percentual de mulheres com uma ou mais consultas variou entre $72,2 \%$ no quintil inferior de bens e 98,1\% no quintil mais rico (Gwatkin et al., 2007). 
Uma publicação recente do Ministério da Saúde, utilizando dados do Sinasc, considerou como pré-natal inadequado a realização de menos do que sete consultas; $74 \%$ das grávidas sem escolaridade apresentaram pré-natal inadequado, em comparação com $21 \%$ daquelas com 12 ou mais anos de estudo (Brasil, 2006). Todos os outros estudos analisados confirmaram a forte associação entre o número de consultas pré-natais ou o início precoce do pré-natal com a situação socioeconômica e educacional das mães.

Em relação à atenção ao parto, a PNDS de 1996 mostrou que 52,5\% das mães do quintil inferior de bens tiveram seu parto atendido por médico, comparadas com $97,6 \%$ no quintil superior (Gwatkin et al., 2007).

Em termos de tendências temporais, o estudo das coortes de nascimento de Pelotas mostrou que a proporção de mães das famílias de menor renda cujos partos foram atendidos por médicos aumentou de 69,4\%, em 1982, para 86,1\%, em 2004. Entre as mães das famílias mais ricas, o percentual aumentou de 93,2\%, em 1982, para 98,2\%, em 2004 (Cesar et al., 2007).

Todos os estudos analisados demonstram o mesmo padrão de maior freqüência de cesarianas entre mulheres de nível socioeconômico elevado. Na PNDS, o índice global foi de 36,4\%, variando de $16,4 \%$ no quintil inferior a $67,6 \%$ no quintil superior (Ronsmans et al., 2006).

Entre os estudos de cesarianas que permitem a avaliação de tendências temporais, o realizado em São Paulo, comparando a atenção em 1984-1985 e 1995-1996 (Monteiro et al., 2000), não mostrou um aumento entre as parturientes do tercil superior de renda. No entanto, esta tendência foi claramente observada entre 1982 e 2004 em Pelotas, onde a prevalência para mulheres com renda familiar superior a 10 salários mínimos mensais aumentou de 46,7\%, em 1982, para 79,1\%, em 2004 (Cesar et al., 2007).

Em resumo, existem fortes diferenciais em atendimento pré-natal e ao parto entre os grupos sociais. Ao mesmo tempo, a falta de atendimento adequado no grupo mais pobre é preocupante e há também evidências de excesso de medicalização entre as mulheres mais ricas, expostas aos riscos de cesarianas desnecessárias.

Atenção à criança

Para o país, três publicações analisaram a atenção de saúde com dados da PNDS de 1996 (Barros et al., 2005; Victora et al., 2005; Gwatkin et al., 2007).

Uma análise de co-cobertura avaliou a utilização de oito intervenções materno-infantis: quatro direcionadas à criança (vacinas BCG, DPT e sarampo e suplemento de vitamina A), três à mãe (toxóide tetânico, atenção pré-natal e atenção do parto por pessoal qualificado) e uma em nível domiciliar (acesso à água potável). As famílias foram estratificadas conforme quintis de índice de bens. A proporção de crianças que receberam seis ou mais destas intervenções variou de $47 \%$ no quintil mais pobre a $90 \%$ no quintil mais rico. Foi observado, ademais, que o quintil inferior apresentou cobertura marcadamente inferior a do segundo grupo mais pobre, no qual a prevalência de cobertura com seis ou mais intervenções já atingiu quase $80 \%$ (Victora et al., 2005). 
Outra análise de dados da PNDS mostrou que, em crianças entre 12-59 meses, a proporção com esquema vacinal incompleto variou de $33,4 \%$ no quintil mais baixo a $15,3 \%$ no mais alto.

Diversos indicadores de acesso a intervenções preventivas e curativas estão disponíveis nas análises da PNDS de 1996 publicadas por Gwatkin et al. (2007). Crianças com vacinas completas para a idade corresponderam a 56,6\% no quintil inferior e $73,8 \%$ no quintil superior. Observou-se, ainda, que $33,4 \%$ das crianças do quintil mais pobre foram levadas a um serviço de saúde quando apresentaram suspeita de pneumonia (tosse com respiração rápida), comparadas com $65,1 \%$ no quintil mais rico. Para episódios de diarréia, estes percentuais foram de $27,2 \%$ e $51,8 \%$, respectivamente. Em contrapartida, o uso de terapia de reidratação oral para a diarréia foi mais comum em crianças pobres $(73,1 \%)$ do que nas ricas $(65,8 \%)$.

Em São Paulo, a proporção de crianças do tercil mais pobre com seis ou mais consultas preventivas no primeiro ano de vida aumentou de 68,8\% em 1984-1985 para 73,9\% em 19951996 (Monteiro et al., 2000c, 2000d). Para as do tercil de renda mais alta, este aumento foi de $87,5 \%$ para $90,2 \%$. Um quadro semelhante foi observado em Pelotas, onde, entre 1982 e 2004, o número médio de consultas preventivas no primeiro ano de vida aumentou de 7,5 para 9,3 entre as mais pobres, e de 10,4 a 11,3 entre as mais ricas (Cesar et al., 2007).

Com relação à atenção especializada neonatal e pediátrica, dois estudos analisaram a distribuição urbana de unidades de tratamento intensivo, ambos na Região Sudeste. No estado do Rio de Janeiro, em 1997-1998, foi realizada uma análise das 74 UTIs disponíveis (Barbosa et al., 2002). O número de leitos intensivos neonatais e pediátricos por habitante mostrou ser adequado para a população como um todo (cerca de 1:3000 crianças), mas 94\% destes se encontram na região metropolitana, que possui $74 \%$ da população infantil. Uma análise restrita à cidade do Rio de Janeiro também mostra distorções, pois áreas mais pobres, onde vive grande parte das crianças, não contam com nenhum leito intensivo.

Em São Paulo (SP) em 2000-2002, 107 UTIs neonatais e pediátricas foram avaliadas (Souza et al., 2004). O número de leitos intensivos por população foi de 1:2700 crianças, mas oscilou, dependendo do núcleo estudado, de 1 leito/600 a 1 leito/6.000 crianças. Os núcleos regionais de saúde com maior população pediátrica apresentaram o menor número de UTIs, e os mais centrais, com menor população pediátrica, apresentaram a maior concentração destas unidades. Cabe aqui ressaltar que, com um bom serviço de referência, estas desigualdades dentro de um município ou região metropolitana não seriam tão importantes.

Em resumo, diversos estudos sobre cobertura de intervenções e utilização de serviços de saúde indicam importantes diferenciais entre crianças ricas e pobres, sempre em detrimento destas últimas.

\section{Mortalidade}

Os estudos brasileiros sobre mortalidade de crianças podem ser divididos em dois grandes grupos: os de base individual, nos quais a informação sobre o desfecho e/ou a situação 
socioeconômica foi coletada de cada família, e os de delineamento ecológico, baseados em informações de desfechos e/ou situação socioeconômica - renda, escolaridade, situação de água e/ou saneamento, índice de qualidade de vida - de bairros ou outros agregados geográficos.

Os estudos em nível individual evidenciaram forte relação inversa entre situação socioeconômica e mortalidade, seja esta do período perinatal, neonatal, pós-neonatal, infantil ou de menores de cinco anos. Diferenciais bastante amplos foram observados entre os grupos socioeconômicos extremos, que chegaram até a sete vezes para mortalidade infantil em um estudo de Pelotas, ao comparar os $20 \%$ mais pobres com os $5 \%$ mais ricos (Victora et al., 1988, 2000). Em Pelotas, os diferenciais entre grupos sociais se mantiveram nas três coortes estudadas em 1982, 1993 e 2004, embora a mortalidade para toda a população tenha caído.

A maioria dos trabalhos sobre mortalidade infantil ou de menores de cinco anos, no Brasil, apresenta delineamento ecológico baseado em áreas geográficas. Esta revisão localizou 23 análises com este delineamento - 12 da Região Sudeste, oito do Nordeste, dois do Sul e um do Centro-Oeste. Com exceção de um estudo conjunto das regiões Sudeste e Nordeste, realizado com dados da PNDS de 1996 (Wagstaff, 2000), as outras publicações analisaram dados de mortalidade para estados, regiões metropolitanas ou municípios de porte médio. Em sua maioria, estes estudos demonstram uma relação inversa entre situação socioeconômica e mortalidade perinatal, neonatal, pós-neonatal, infantil e de menores de cinco anos, mas com diferenciais menos marcados do que os observados em estudos individuais. Este fato é esperado, uma vez que os estudos ecológicos consideram de forma homogênea todas as famílias residentes em uma mesma região ou bairro, desconsiderando importantes diferenças socioeconômicas entre estas. No grupo populacional pertencente ao estrato geográfico mais pobre, portanto, algumas famílias não são tão pobres, o mesmo ocorrendo entre as famílias do estrato mais rico.

Em resumo, estudos epidemiológicos e demográficos com diversos delineamentos confirmam uma forte associação inversa entre nível socioeconômico e mortalidade.

\section{Avaliação de programas e intervenções para superação de iniqüidades em saúde infantil}

Intervenções ou programas visando a reduzir iniqüidades em saúde infantil podem ser avaliados de diferentes formas. A avaliação mais simples consiste em verificar se o programa realmente atingiu os mais pobres. Isto pode ser avaliado a partir de estimativas da cobertura (que percentual das crianças pobres é atendido pelo programa?) e foco (que percentual das crianças atendidas pelo programa são pobres?) (Habicht, Mason \& Tabatabai, 1984). O cálculo do foco - como o próprio nome indica - é particularmente útil para programas focalizados. Avaliações mais complexas incluem medir se o programa reduziu desigualdades sociais, seja em termos de indicadores de processo (como cobertura vacinal ou uso de serviços de saúde), seja de impacto (como mortalidade ou subnutrição). 
Além do Sistema Único de Saúde (SUS), o Brasil possui um grande número de intervenções com possível impacto sobre iniqüidades em saúde e nutrição infantil, como o Programa de Saúde da Família (PSF), os Agentes Comunitários de Saúde (ACS), o Programa Bolsa Família (PBF), a Pastoral da Criança, as Ações Integradas de Combate às Doenças Prevalentes da Infância (AIDPI), além de programas estaduais, como o Viva Criança, no Ceará.

No entanto, a maior parte destes programas, quando avaliados, o foram em relação a seu impacto global sobre a saúde materno-infantil como um todo e não sobre as desigualdades em saúde. Esta avaliação é dificultada pelo fato de que os programas não foram planejados ou implementados de forma a facilitar a medição de seu impacto. Programas de dimensões nacionais, como o Bolsa Família ou o PSF, por exemplo, são difíceis de avaliar, pois não há grupos-controle adequados. Isso não foi o caso, por exemplo, do programa mexicano similar ao Bolsa Família - Progresa, depois reformulado como Oportunidades -, para o qual um processo inicial de aleatorização determinou a ordem de implementação geográfica (Rivera et al., 2004). A avaliação do Progresa revelou que o programa esteve associado a uma melhora na situação nutricional global, sobretudo entre as crianças mais pobres, contribuindo, portanto, para reduzir as desigualdades.

Se a avaliação destes programas em termos de seu impacto global é problemática, mais difícil ainda é a de seu impacto sobre desigualdades em saúde, uma vez que esta última requer tamanhos de amostra maiores e mensuração do nível socioeconômico na população-alvo.

Treze publicações sobre avaliações de programas e intervenções brasileiros com possível impacto sobre desigualdades em saúde materna e infantil foram localizadas, incluindo quatro avaliações do programa Bolsa Família (Andrade et al., 2007a; Andrade et al., 2007b; Conde, Konno \& Monteiro, 2006; Santos et al., 2007), uma do programa Bolsa Alimentação (Morris et al., 2004) e duas da Pastoral da Criança (Cesar, 2005; Neumann et al., 1999). Já o impacto do PSF sobre a mortalidade infantil foi investigado, em nível nacional, em três estudos (Macinko et al., 2006, 2007; Pereira, 2006). Um outro estudo avalia o efeito sobre as iniqüidades em saúde infantil de diversos programas, incluindo o PSF, a Pastoral da Criança, o Programa Nacional de Imunização (PNI) e o programa de Atenção Pré-Natal (Barros et al., 2005). Finalmente, uma análise investigou o impacto sobre desigualdades em saúde de um programa estadual, o Viva Criança (Victora et al., 2000), e outro estudo avaliou o AIDPI (Victora et al., 2006).

Não foram incluídos na revisão estudos sobre melhorias na saúde infantil em um único município, sem grupo de comparação.

\section{Bolsa família}

Duas publicações sobre o impacto global do Programa Bolsa Família (PBF) foram originadas de um estudo realizado na região do semi-árido (que inclui todos os estados nordestinos, com exceção do Maranhão, assim como o norte e nordeste de Minas Gerais), a partir da 
avaliação nutricional das crianças que participaram do Dia Nacional de Vacinação em 2005 (Conde, Konno \& Monteiro, 2006; Santos et al., 2007). O primeiro fato que chama a atenção é a surpreendentemente baixa prevalência de déficits nutricionais nesta população de crianças tão pobres: 6,6\% para A/I (altura/idade), 5,6\% para P/I (peso/idade) e 2,8\% para P/A (peso/ altura). Como esperado, as crianças que participavam do PBF eram bem mais pobres do que não participantes, o que confirma estar o programa focalizado nas famílias pobres. A avaliação dos déficits antropométricos, após ajuste para o número de bens no domicílio e para a escolaridade do chefe de família e da mãe da criança, sugeriu que a participação no PBF reduziu o risco de déficit de A/I em 30\% - de 6,5\% para 4,8\%. O maior benefício do programa parece ter ocorrido com crianças entre 6 e 11 meses de idade, entre as quais a redução do déficit de A/I foi da ordem de $62 \%$ - de 5,3\% para 2,0\%.

O impacto do PBF sobre a nutrição e cobertura vacinal de crianças entre 6 e 60 meses foi avaliado em 2005, com uma amostra restrita a famílias com renda per capita inferior a $\mathrm{R} \$ 200,00$. Não foram encontradas diferenças, em nível nacional ou regional, na situação nutricional e vacinal de crianças participantes do programa, quando comparadas com crianças-controle de famílias não participantes, após emparelhamento por situação socioeconômica (Andrade et al., 2007a, 2007b). Um problema importante desta pesquisa é a falta de informação sobre o tempo de permanência no programa entre as famílias participantes.

O precursor do PBF - Programa Bolsa Alimentação - foi também alvo de avaliação de impacto. Um estudo inicial comparou crianças admitidas no programa com outras que, por motivos administrativos, não foram incluídas apesar de serem elegíveis. Após seis meses, crianças incluídas no programa apresentaram peso inferior ao grupo-controle, o que os autores interpretaram como sendo devido ao temor das mães de que, caso seus filhos ganhassem peso, perderiam o benefício (Morris et al., 2004). Dados não publicados, produzidos pelos mesmos autores, com uma amostra maior de crianças após seis meses de utilização do programa, revelaram que as crianças incluídas no programa ganharam, em média, 27g por mês a mais do que aquelas não incluídas (World Health Organization and Commission on Social Determinants of Health, 2007).

Em resumo, as avaliações do PBF e seu precursor confirmam que estes programas estiveram efetivamente focalizados nos mais pobres. Os achados sobre o impacto global na nutrição infantil não são consistentes, com alguns estudos sugerindo impacto e outros não. Finalmente, nenhum estudo avaliou se houve redução das desigualdades no estado nutricional (ou qualquer outro indicador) como resultado do programa.

Programa de Saúde da Família (PSF)

Três estudos de avaliação do impacto do PSF sobre o coeficiente de mortalidade infantil (CMI) utilizaram delineamentos ecológicos. O primeiro teve como unidades de análise os estados brasileiros, mostrando que o aumento na cobertura do PSF esteve associado com uma redução no CMI, após ajuste para outros determinantes, como água, saneamento, renda familiar, educação feminina, fertilidade, número de médicos e enfermeiras e número de leitos 
hospitalares (Macinko et al., 2006). O mesmo grupo de autores repetiu estas análises usando como unidades de estudo as microrregiões brasileiras, com conclusões similares (Macinko et al., 2007). Estas análises são prejudicadas pelo uso, nas regiões mais pobres do país, de estimativas indiretas de mortalidade infantil, para compensar o sub-registro de óbitos. Tais estimativas, no entanto, resultam da projeção para anos recentes de tendências observadas no passado, não sendo particularmente úteis para investigar o impacto de programas recentes. A avaliação realizada por Pereira (2006) contornou este problema restringindo a análise a municípios com alta cobertura de registro civil, sem depender de estimativas indiretas. Esta autora mostrou que o PSF foi bem focalizado nos municípios mais pobres, sendo que sua implementação esteve associada a reduções na mortalidade infantil, após ajuste para diversos fatores de confusão.

Assim, apesar de limitações metodológicas, há alguma evidência de que o PSF estaria associado a uma redução global da mortalidade infantil nas áreas cobertas, mas não existem evidências sobre seu impacto em termos de desigualdade dentro destas áreas.

\section{Pastoral da criança}

A Pastoral da Criança é um programa de abrangência nacional que visita mensalmente mais de 2 milhões de crianças e gestantes, em 43.000 comunidades de 4.063 municípios brasileiros. As ações de saúde promovidas pela Pastoral priorizam problemas de saúde enfrentados pelas populações mais pobres, como a diarréia, a subnutrição e as infecções respiratórias. As intervenções promovidas incluem diversas medidas de baixo custo e alta efetividade, como a reidratação oral, as imunizações, o controle pré-natal e o aleitamento materno, entre outras. Avaliações independentes mostram aumentos em vários, mas não em todos, os indicadores de cobertura. Em um estudo realizado em Sergipe, em algumas comunidades rurais pobres, a Pastoral era a principal fonte de informações e aconselhamento sobre saúde materno-infantil (Cesar, 2005). Apenas um estudo avaliou especificamente se a Pastoral estava efetivamente alcançando os mais pobres. Esta pesquisa, realizada em Criciúma (SC), mostrou maiores coberturas nos $40 \%$ mais pobres da população, embora revelasse também a dificuldade de manter altas coberturas nos $20 \%$ mais pobres, que são mais difíceis de atingir do que o quintil imediatamente superior (Neumann et al., 1999).

\section{Outros programas}

Uma análise da cobertura de diversos programas (Barros et al., 2005) revelou que os programas nacionais de imunização e de atenção pré-natal apresentam alta cobertura global, mas cobertura inferior entre os pobres, ao contrário do PSF, que mostrou uma alta cobertura entre estes últimos.

A comparação de dois inquéritos populacionais no Ceará, antes (1987) e depois da implementação do programa Viva Criança (1994), mostrou importantes melhoras em vários indicadores de cobertura e nutrição para a população infantil como um todo, mas não houve progresso na redução de desigualdades entre ricos e pobres (Victora et al., 2000). 
A implantação do programa AIDPI, na Região Nordeste, mostrou que o mesmo foi preferencialmente implementado em municípios com maior índice de desenvolvimento humano e localizados mais próximos às capitais estaduais, e não naqueles de alta mortalidade, que mais se poderiam beneficiar do programa (Victora et al., 2006).

Concluindo, observa-se a escassez de avaliações de programas visando a melhorar a saúde das crianças brasileiras em termos de seu impacto sobre a eqüidade. Poucos programas foram avaliados sobre se estavam ou não atingindo os mais pobres, e menos ainda em termos de seu impacto sobre as desigualdades em indicadores de saúde.

\section{Conclusões}

Os estudos sobre saúde materna e infantil estão fortemente concentrados na Região Sudeste, foco de 38 dos 113 estudos incluídos nesta revisão. Vinte e sete publicações tiveram como área de estudo o Nordeste do país, com um número expressivo de análises ecológicas de mortalidade e estudos sobre situação nutricional. A Região Sul foi tema de 23 publicações, observando-se uma distribuição mais homogênea dos indicadores estudados. Chama a atenção a total ausência de estudos dirigidos especificamente à Região Norte, assim como a pobreza de informações sobre a Região Centro-Oeste, alvo de apenas duas publicações. Vinte e três estudos de âmbito nacional foram localizados, poucos deles publicados após o ano 2000. Espera-se que a publicação da recente Pesquisa Nacional sobre Demografia e Saúde da Mulher e da Criança (PNDS-2006), assim como novas publicações do Ministério da Saúde e do IBGE, e investigações de grupos acadêmicos - promovidas por recente edital incentivado pela Comissão Nacional sobre Determinantes Sociais da Saúde (CNDSS) - atualizem as informações sobre desigualdades de saúde materno-infantil.

Alguns temas têm sido alvo de poucos estudos, como as desigualdades socioeconômicas em termos de sobrepeso e obesidade, desenvolvimento cognitivo, amamentação, anemia e atenção à criança. Chama ainda a atenção a quase total ausência de estudos sobre a qualidade da atenção médica recebida por crianças de distintos níveis sociais. Maiores pesquisas sobre estes temas devem ser incentivadas.

A presente revisão apresenta algumas limitações. As desigualdades foram analisadas conforme indicadores de estratificação socioeconômica (renda, índice de bens, escolaridade dos pais e combinações destes), enquanto que os determinantes sociais da saúde incluem outras dimensões, como características culturais e ambientais, redes sociais e comunitárias, entre outras. Mesmo em termos de diferenciais socioeconômicos, as diferentes classificações adotadas nos estudos revisados dificultam a comparação direta entre seus resultados. Em termos metodológicos, as principais deficiências observadas na revisão foram quanto aos estudos ecológicos, que muitas vezes utilizam de forma acrítica dados secundários cuja cobertura e qualidade deixa a desejar.

Apesar dessas limitações, os resultados da revisão não deixam dúvidas sobre a presença de marcadas iniqüidades sociais em saúde e nutrição infantil em todo o país, evidenciadas nos indicadores de mortalidade, morbidade, situação nutricional e utilização de serviços 
de saúde. De todos os indicadores estudados, os pobres quase sempre apresentam situação menos favorável em termos de atenção pré-natal, peso ao nascer (tanto por RCIU como por parto pré-termo), amamentação exclusiva, cobertura vacinal, consultas preventivas, morbidade, subnutrição, deficiências de micronutrientes, desenvolvimento cognitivo, e, conseqüentemente, mortalidade. O Gráfico 35 mostra alguns indicadores selecionados, baseados na PNDS-1996. Observa-se que, para a maioria desses indicadores, o quintil inferior apresenta cobertura notadamente menor do que todos os demais quintis, o que está de acordo com as análises de co-cobertura mencionadas anteriormente (Victora et al., 2005). Este tipo de padrão, descrito como "exclusão marginal" (World Health Organization, 2005), é normalmente observado em países onde a cobertura global é relativamente alta.

Gráfico 35 - Cobertura de intervenções selecionadas conforme os quintis de índice de bens. Brasil - 1996

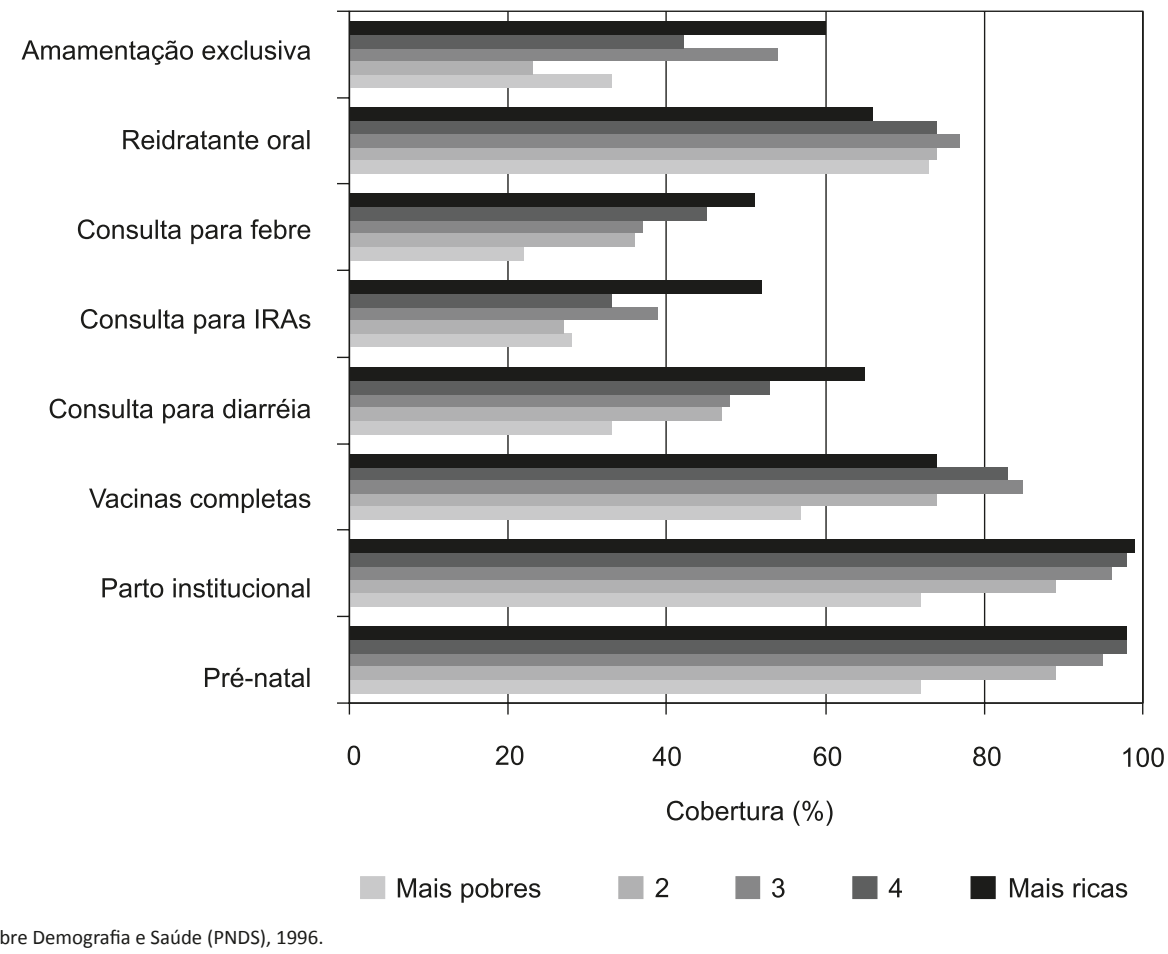

Fonte: Pesquisa Nacional sobre Demografia e Saúde (PNDS), 1996

Os poucos indicadores que são piores entre as mães e crianças de famílias ricas incluem o parto por cesarianas, sobrepeso/obesidade e o uso de terapia de reidratação oral (TRO) durante episódios de diarréia. O padrão de uso de TRO pode ser explicado por ser este tipo de tratamento considerado freqüentemente como "remédio de pobre" (Behague et al., 2002), pois famílias ricas tendem a tratar diarréia em seus filhos com produtos comerciais percebidos como sendo mais sofisticados. Como já foi comentado, pesquisas recentes sobre amamentação mostram que esta prática, que antes era mais comum entre as crianças de famílias pobres, agora é mais comum entre as de nível socioeconômico mais elevado, pelo menos para os primeiros seis meses de vida. 
De maneira geral, os principais indicadores de saúde infantil, mortalidade e desnutrição, têm melhorado substancialmente em todos os estratos da população. Outros indicadores, como o baixo peso ao nascer e o nascimento pré-termo, assim como a anemia, parecem estar aumentando. Embora seja possível documentar tendências temporais para alguns indicadores na população como um todo, são pouquíssimos os estudos que permitem evidenciar tendências em desigualdades sociais - em especial os inquéritos de Monteiro e colaboradores em São Paulo (1984-1985 e 1995-1996), os estudos do Ceará (1987 e 1994) e as coortes de nascimentos de Ribeirão Preto (1978-1979 e 1994) e de Pelotas (1982, 1993 e 2004). Em uma análise baseada nas séries temporais do Ceará e de Pelotas (Victora et al., 2000), foi proposta uma hipótese de que as novas intervenções para redução de morbimortalidade atingiriam, inicialmente, as crianças mais ricas, levando em curto prazo a um aumento nas desigualdades relativas; posteriormente, à medida que as crianças mais ricas atingissem um alto nível de cobertura (ou baixo nível de morbimortalidade), as crianças mais pobres continuariam a melhorar e a desigualdade seria reduzida.

Alguns exemplos da revisão anterior apóiam esta hipótese. A amamentação exclusiva, uma intervenção comportamental disseminada a partir dos anos 90, já é mais comum entre ricos do que pobres. O sobrepeso e a obesidade, tradicionalmente mais comuns entre crianças ricas, já se encontram em declínio neste grupo, mas seguem aumentando entre crianças pobres. A subnutrição já está praticamente erradicada entre crianças ricas, e as desigualdades estão diminuindo, pois continua a cair entre as crianças pobres. Estes exemplos evidenciam a complexa natureza das tendências seculares em indicadores de saúde e nutrição infantis nos diferentes grupos sociais.

Como discutido na revisão das tendências de mortalidade, não há evidências convincentes de que as desigualdades em mortalidade de crianças estejam diminuindo no Brasil. Em contrapartida, alguns estudos sobre a situação nutricional - embora restritos às regiões Sul e Sudeste - sugerem uma redução das disparidades entre crianças pobres e ricas. Kelly et al. (2007: 11) enfatizam que

os fatores que levam a uma melhora geral da saúde - progressos ambientais, bom saneamento e água limpa, melhor nutrição, bons níveis de imunização, melhores moradias - não reduzem as iniqüidades em saúde. Isto ocorre porque os determinantes de uma boa saúde não são os mesmos determinantes das iniqüidades em saúde.

Portanto, a atual queda da mortalidade infantil no Brasil não significa, necessariamente, que as diferenças sociais estejam sendo reduzidas, até porque a mortalidade mesmo no quintil mais rico ainda apresenta ampla margem para redução, quando comparada aos níveis - de 5 por mil ou menos - atingidos pelos países mais avançados (United Nations Children's Fund, 2007).

No que se refere às intervenções e programas de combate às iniqüidades em saúde e nutrição infantil, uma limitação óbvia é a escassez de informações de boa qualidade para sua avaliação. O país conta com um elenco de programas que têm como foco as populações mais pobres, mas a avaliação de seus efeitos sobre a saúde infantil ainda é incipiente. o padrão de exclusão social discutido anteriormente, com coberturas notadamente inferiores em crianças 
do quintil mais pobre, justifica a opção por programas focalizados como o Bolsa Família. Para este programa e seu antecessor (o Bolsa Alimentação), os resultados dos estudos de avaliação de impacto nutricional são conflitantes, e não há estudos de impacto sobre mortalidade, tampouco de seu efeito sobre desigualdades. São necessárias, também, maiores avaliações de programas de grande abrangência com agentes comunitários voluntários, como a Pastoral da Criança, que podem ser de grande importância para corrigir a dificuldade em alcançar as famílias mais excluídas. O PSF já conta com algumas avaliações que sugerem um impacto positivo sobre a saúde infantil como um todo, embora sem informações sobre seu efeito em termos de desigualdades. Finalmente, nota-se a completa ausência de estudos sobre o impacto da implantação do Sistema Único de Saúde (SUS) sobre as desigualdades em mortalidade.

Em resumo, existem marcadas desigualdades socioeconômicas em praticamente todos os indicadores de saúde e nutrição de crianças menores de cinco anos. Estas desigualdades configuram um quadro de iniqüidade, por serem evitáveis e injustas, impedindo que todas as crianças atinjam seu potencial de saúde, crescimento e desenvolvimento.

A solução definitiva das desigualdades socioeconômicas requer amplas transformações na sociedade como um todo, por meio de ações multisetoriais. Não obstante, a documentação destas desigualdades, particularmente no que diz respeito ao acesso, utilização e cobertura de programas de saúde, indica que intervenções médico-sanitárias podem contribuir para sua redução em curto prazo. O setor saúde, em muitas situações, parece estar contribuindo para acentuar ao invés de reduzir as iniqüidades. As persistentes desigualdades evidenciadas nesta revisão devem ser utilizadas no sentido de subsidiar as ações do setor público para reverter este cenário perverso.

A sociedade brasileira atravessa uma fase de rápidas mudanças, com uma redução - embora discreta - na concentração de renda e com quedas rápidas na mortalidade e subnutrição de crianças. Ao mesmo tempo, o SUS amplia o acesso de todos os brasileiros aos procedimentos médico-sanitários, e programas focalizados como o Bolsa Família são direcionados especificamente às populações excluídas. Dentro deste quadro, é lícito esperar que reduções nas iniqüidades em saúde infantil sejam alcançadas em um futuro próximo.

A pesquisa em saúde direcionada para a investigação de desigualdades, assim como o monitoramento permanente das disparidades e a avaliação de programas sob a ótica da eqüidade, são essenciais para que todas as crianças brasileiras alcancem seu potencial de saúde, crescimento e desenvolvimento. 


\section{Addendum*}

Em julho de 2008, foram divulgados os dados da Pesquisa Nacional de Demografia e Saúde da Criança e da Mulher (PNDS-2006), que traça um perfil da população feminina em idade fértil e das crianças menores de 5 anos no Brasil. Trata-se da terceira edição desta pesquisa, realizada pela primeira vez no Brasil em 1986 e reeditada em 1996. A equipe, de cerca de 20 pesquisadores e consultores de diversas instituições, teve coordenação geral de Elza Berquó. A execução do trabalho de campo esteve a cargo do Ibope e o DECIT/MS foi responsável pelo financiamento da pesquisa. Mais detalhes sobre os resultados da pesquisa podem ser encontrados no seguinte endereço: <http://bvsms.saude.gov.br/bvs/pnds/index.php>.

A população-alvo do estudo foram mulheres de 15 e 49 anos de idade e filhos menores de 5 anos. A amostra com representativa nacional, das 5 macrorregiões e dos extratos urbano-rural constou de 14.617 domicílios, tendo sido entrevistadas 15.575 mulheres e incluídas no estudo 5.056 crianças menores de 5 anos (4.957 vivas no momento da entrevista). O trabalho de campo foi realizado de novembro de 2006 a maio de 2007.

Os métodos de coleta de dados incluíram entrevistas domiciliares, mensurações antropométricas (altura e peso de mulheres e crianças e circunferência da cintura de mulheres), coleta de amostras de sangue para dosagens de vitamina A e hemoglobina e informações sobre 0 teor de iodo disponível no sal consumido nos domicílios. Os tópicos pesquisados foram os seguintes: fecundidade e aspectos reprodutivos; planejamento da fecundidade; anticoncepção, gravidez, parto e puerpério; conjugalidade e atividade sexual; saúde da criança; amamentação e alimentação; avaliação antropométrica do estado nutricional de crianças e mulheres; segurança alimentar; acesso a medicamentos; micronutrientes.

Apresenta-se a seguir uma série de tabelas e gráficos com alguns dados comparativos da PNDS-2006 e PNDS-1996.

\section{Fecundidade e Aspectos Reprodutivos}

Taxas de fecundidade por idade e taxa de fecundidade total (TFT)

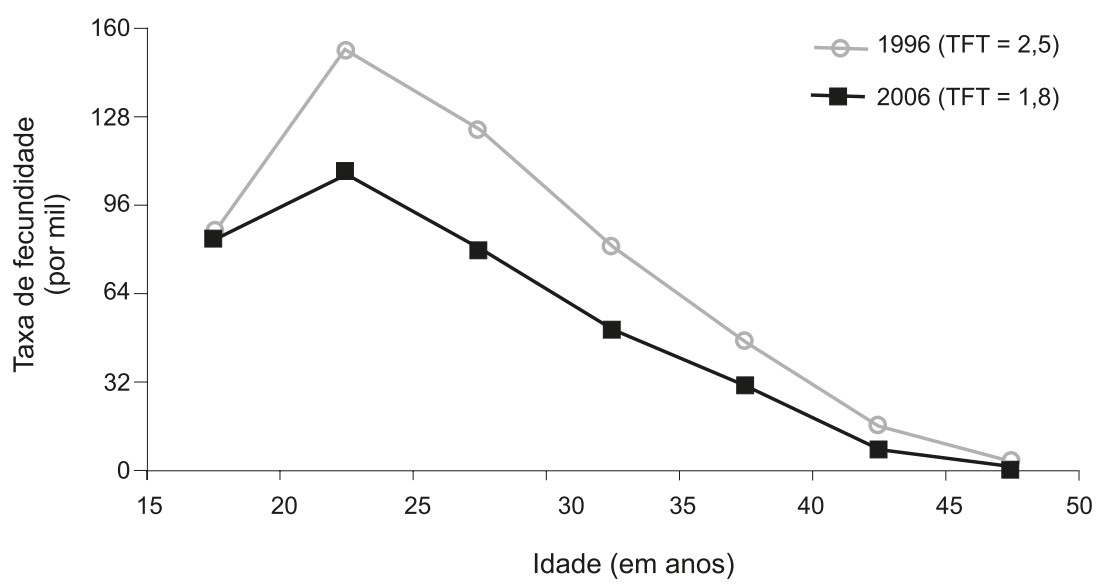

* Resumo de apresentação feita pela dra. Elza Berquó em 3 de julho de 2008 ao Ministério da Saúde. 
Taxas de fecundidade total, segundo as características sociodemográficas

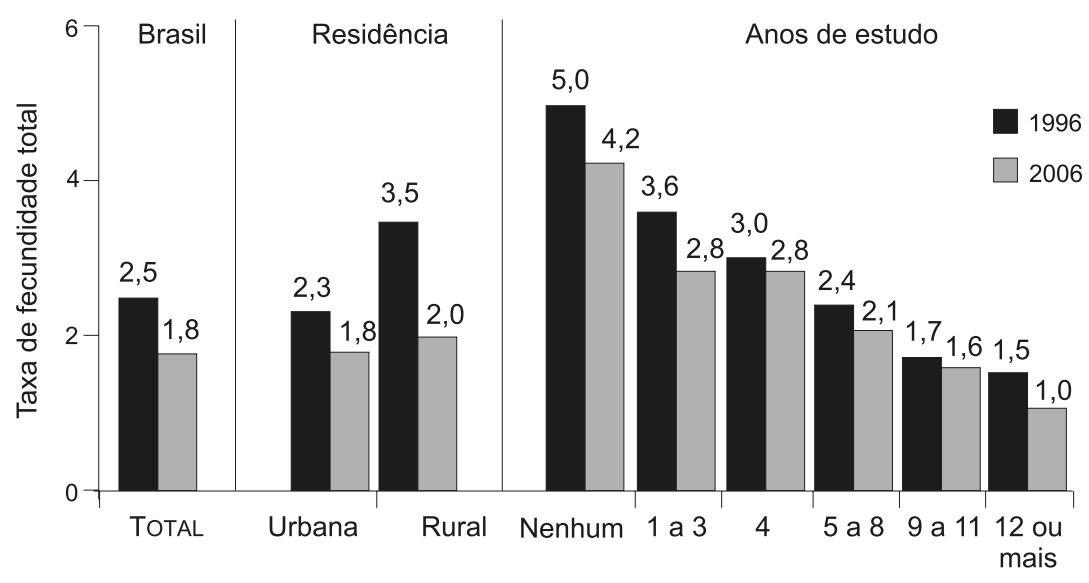

A Pesquisa revelou um rejuvenescimento do processo reprodutivo. A proporção de mulheres de 15 a 19 anos que já são mães aumentou de $14 \%$ para $16 \%$. A idade mediana ao ter o primeiro filho (para mulheres 25 a 49 anos) passou de 22,4 para 21,0 anos. Esta redução ocorreu segundo região, situação de residência e anos de estudo. A fecundidade das mulheres de 15 a 24 anos, que representava $47 \%$ da fecundidade total, passou a representar 53\% em 2006. Em contrapartida, a fecundidade das mulheres de 35 a 49 anos, declinou de $13 \%$ para $11 \%$.

\section{Assistência ao Parto}

Percentual de partos hospitalares e de partos assistidos por médicos ou enfermeiras, nos cinco anos anteriores à entrevista. Brasil, rural e regiões Norte e Nordeste.

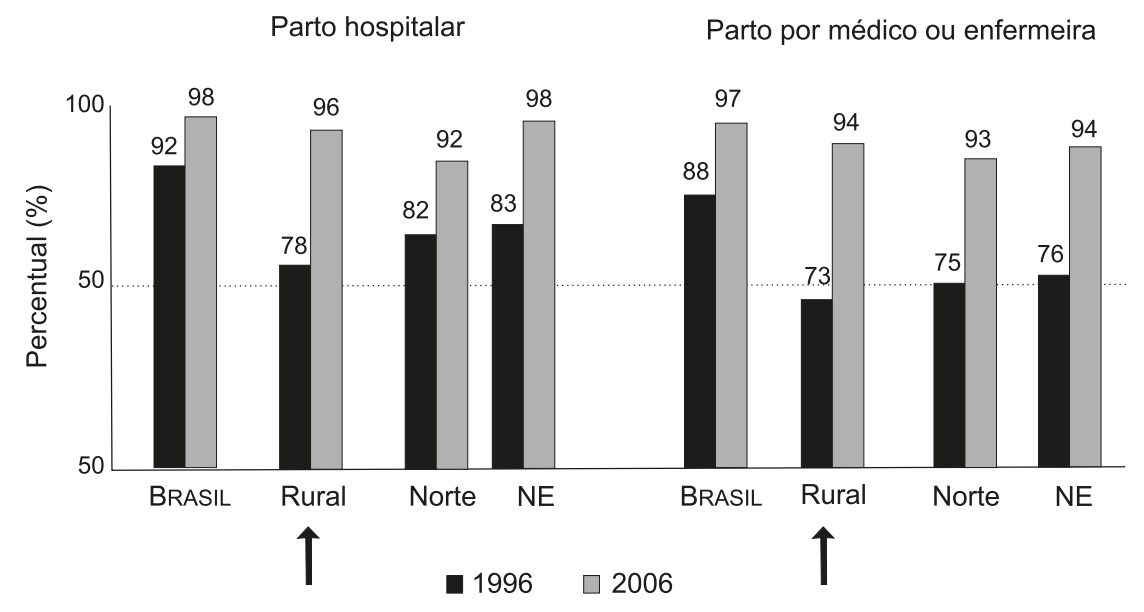


Porcentagem de partos cesáreos nos cinco anos anteriores à entrevista, segundo residência e tipo de serviço de saúde utlizado.

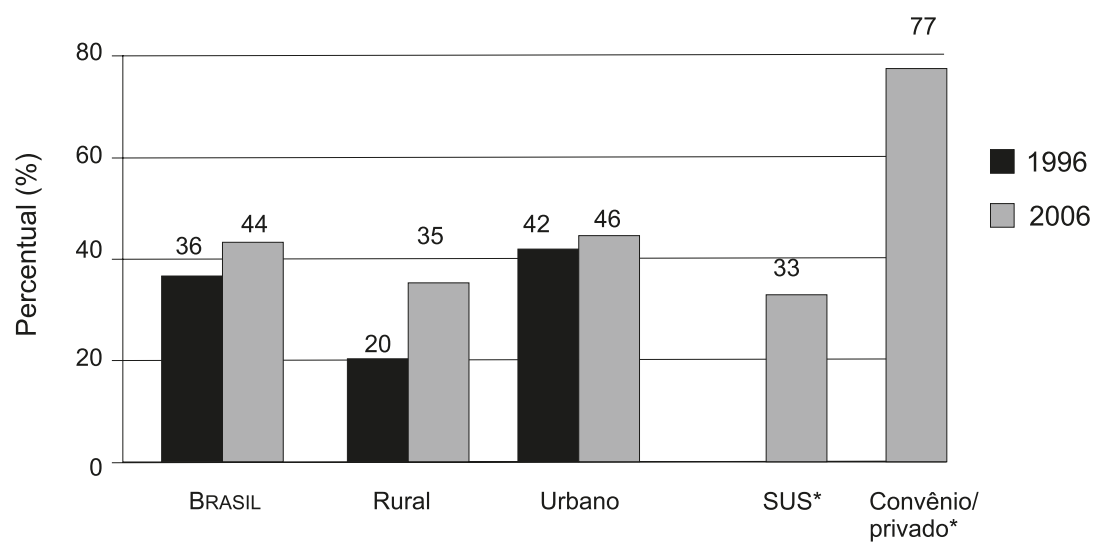

* Dado não disponivel em 1996

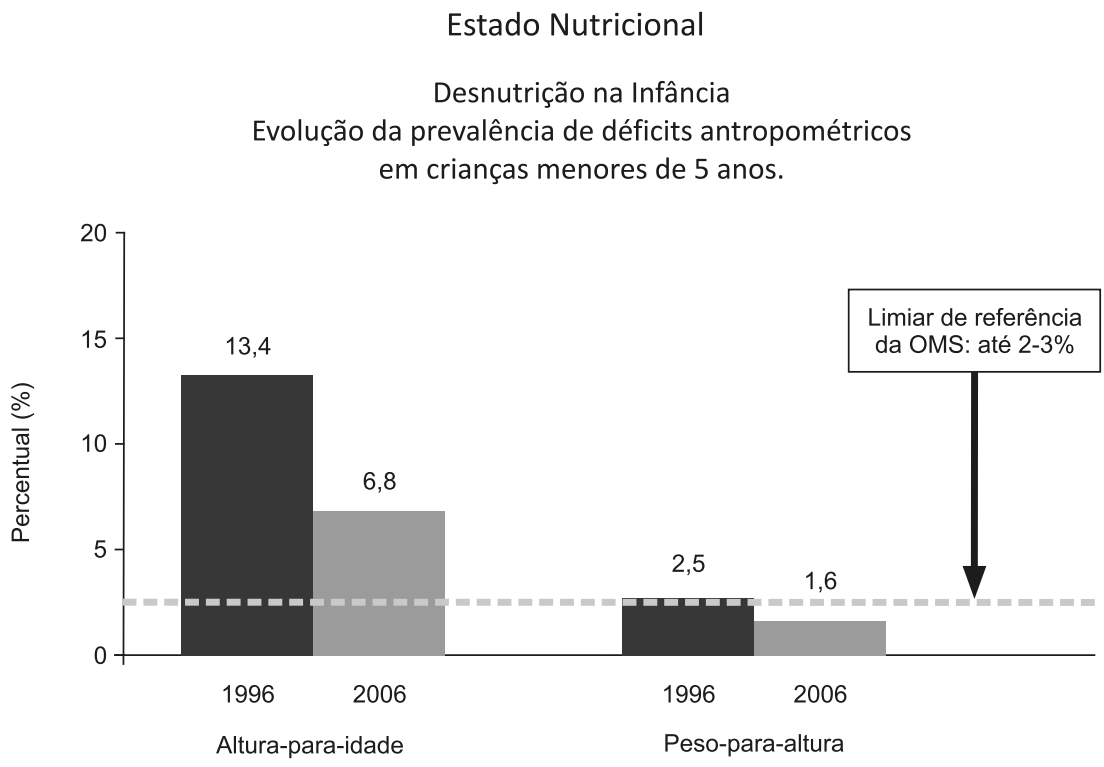


Evolução da prevalência de déficit de altura-para-idade em crianças menores de 5 anos, segundo região.

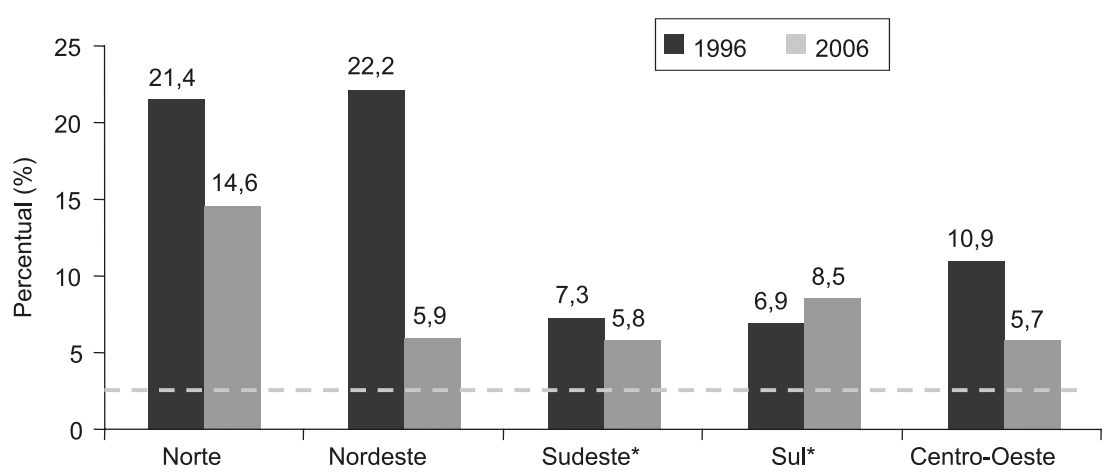

*Variação não significativa.

Evolução da prevalência de déficit de peso-para-altura em crianças menores de 5 anos, segundo região.

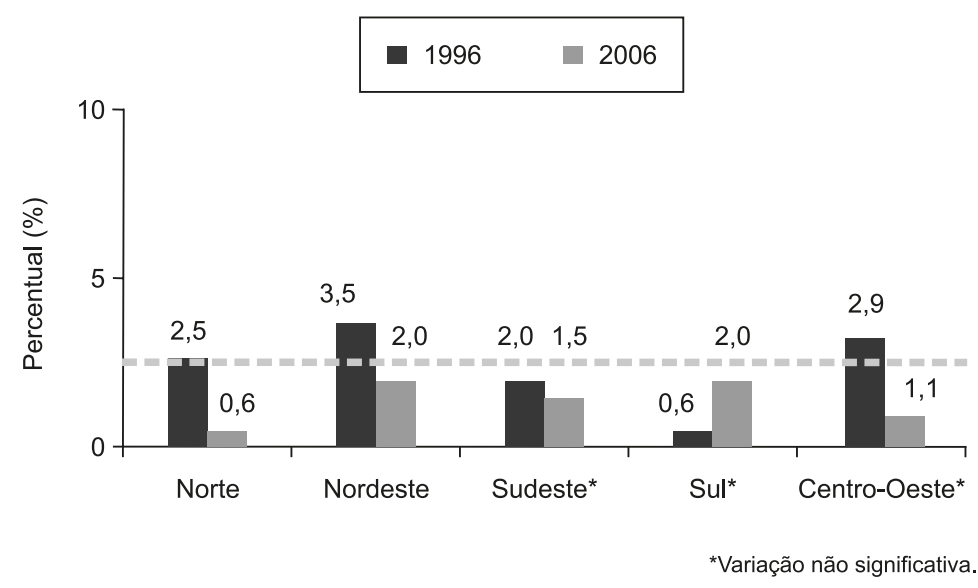




\section{Obesidade na Infância}

Evolução da prevalência de excesso de peso-para-altura em crianças menores de 5 anos, segundo região.

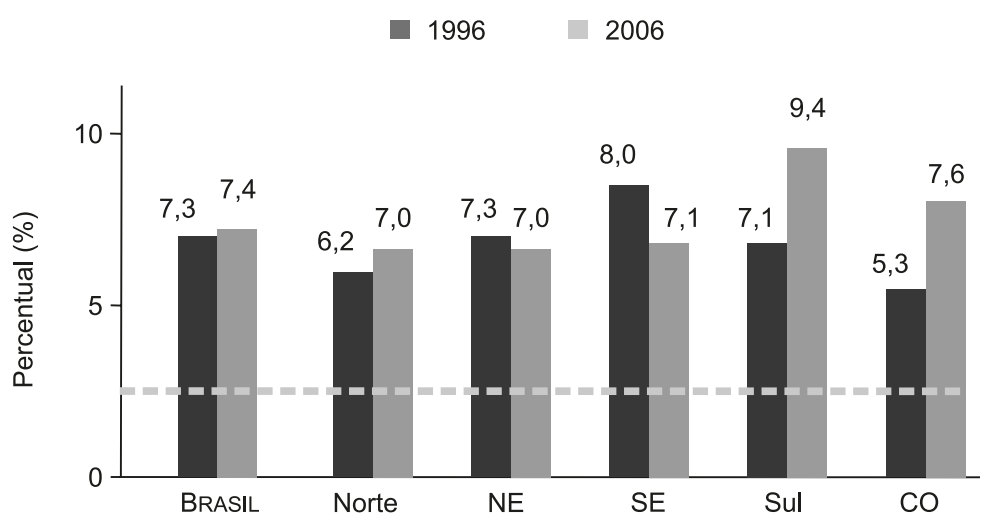

Obs: Variação entre os anos não significativa.

\section{Amamentação}

Percentual de crianças menores de 60 meses alguma vez amamentadas, segundo residência e região.

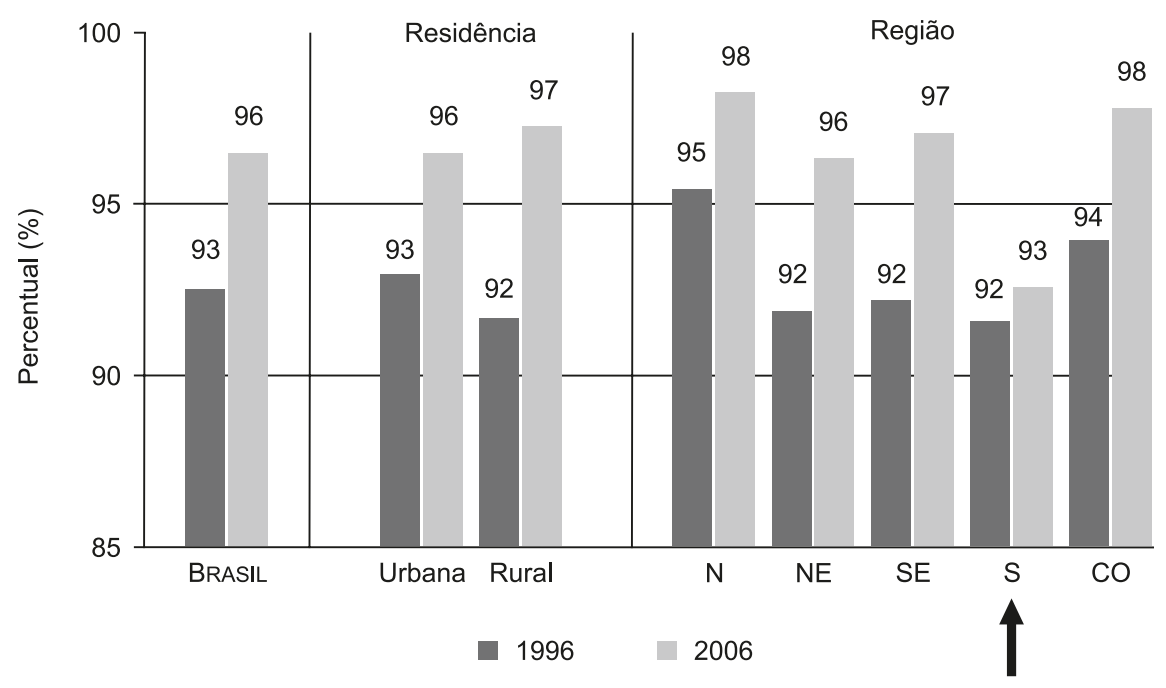


Duração mediana do aleitamento materno (em meses), entre menores de 36 meses de idade, segundo residência e região.

\begin{tabular}{lcccc}
\hline & \multicolumn{2}{c}{$\begin{array}{c}\text { Aleitamento } \\
\text { exclusivo }\end{array}$} & \multicolumn{2}{c}{$\begin{array}{c}\text { Aleitamento } \\
\text { TOTAL }\end{array}$} \\
& 1996 & 2006 & 1996 & 2006 \\
\hline BRASIL & 1,1 & 2,2 & 7,0 & 9,4 \\
Residência & & & & \\
Urbano & 1,3 & 2,2 & 6,7 & 9,3 \\
$\quad$ Rural & 0,7 & 2,1 & 8,9 & 9,7 \\
Região & & & & \\
$\quad$ Norte & 1,4 & 2,1 & 10,3 & 9,7 \\
$\quad$ Nordeste & 0,7 & 2,2 & 9,8 & 9,6 \\
Sudeste & 1,9 & 2,0 & 6,0 & 9,4 \\
Sul & 1,7 & 2,6 & 7,1 & 9,6 \\
$\quad$ Centro-Oeste & 0,7 & 2,5 & 7,0 & 8,6 \\
\hline
\end{tabular}

Prevalência domiciliar de Segurança/Insegurança Alimentar, segundo escolaridade da pessoa de referência. PNDS-2006.

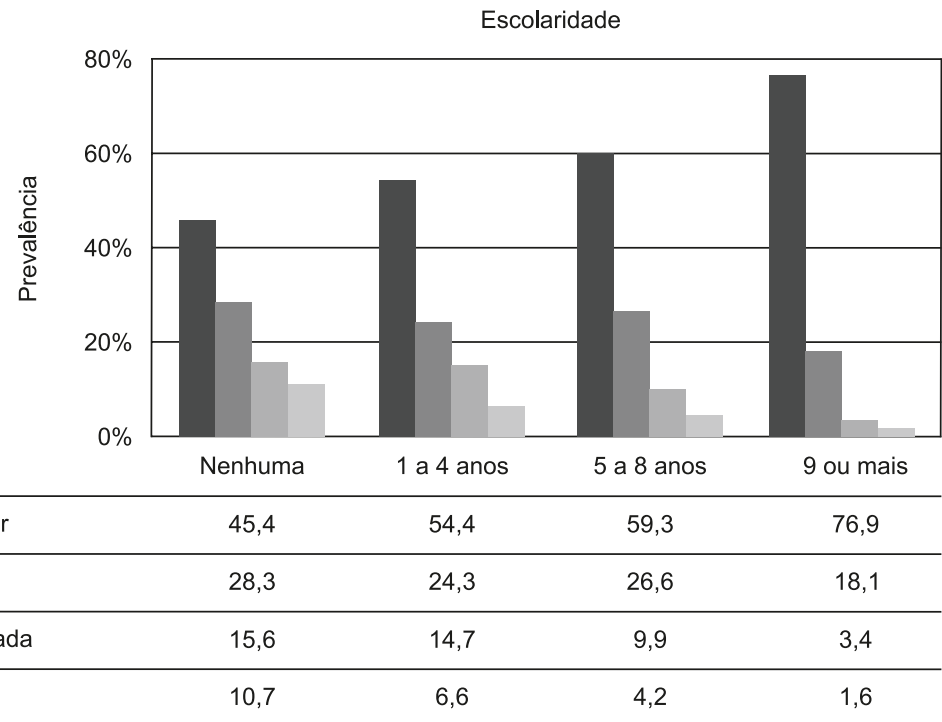




\subsection{SaÚde IndíGenA ${ }^{9}$}

Os povos indígenas no Brasil apresentam um complexo e dinâmico quadro de saúde, diretamente relacionado a processos históricos de mudanças sociais, econômicas e ambientais atreladas à expansão e à consolidação de frentes demográficas e econômicas da sociedade nacional nas diversas regiões do país (Coimbra Jr., Santos \& Escobar, 2003; Coimbra Jr. \& Santos, 2004; Garnelo, Macedo \& Brandão, 2003; Santos et al., 2008). Ao longo dos séculos, tais frentes exerceram importante influência sobre os determinantes dos perfis da saúde indígena, quer seja por meio da introdução de novos patógenos ocasionando graves epidemias; usurpação de territórios; dificultando ou inviabilizando a subsistência; e/ou a perseguição e morte de indivíduos ou mesmo comunidades inteiras. No presente, emergem outros desafios à saúde dos povos indígenas, que incluem doenças crônicas não-transmissíveis, contaminação ambiental, crescente urbanização e dificuldades de sustentabilidade alimentar, para citar uns poucos exemplos.

o perfil de saúde dos povos indígenas é muito pouco conhecido, o que decorre da exigüidade de investigações, da ausência de inquéritos e censos, assim como da precariedade dos sistemas de informações sobre morbidade e mortalidade (Coimbra Jr. et al., 2002; Coimbra Jr., Santos \& Escobar, 2003; Garnelo, Macedo \& Brandão, 2003; Santos \& Escobar, 2001; Santos et al., 2008). Qualquer discussão sobre o processo saúde/doença dos povos indígenas precisa levar em consideração, além das dinâmicas epidemiológica e demográfica, a enorme sociodiversidade existente. São aproximadamente 220 etnias, falantes de algo em torno de 180 línguas e que têm experiências de interação com a sociedade nacional as mais diversas. As estimativas quanto ao total da população indígena no país variam entre 400 a 730 mil pessoas, a depender da fonte, o que perfaz menos de $1 \%$ da população brasileira.

Um documento do Ministério da Saúde, intitulado "Política nacional de atenção aos povos indígenas", não somente explicita a condição de ausência de dados, como também aponta para a magnitude das desigualdades entre a saúde dos povos indígenas e de outros segmentos da sociedade nacional:

Não se dispõe de dados globais fidedignos sobre a situação de saúde... [dos povos indígenas], mas sim de dados parciais, gerados pela Funai [Fundação Nacional do Índio], pela Funasa [Fundação Nacional de Saúde] e diversas organizações não-governamentais ou ainda por missões religiosas que, por meio de projetos especiais, têm prestado serviço de atenção à saúde dos povos indígenas. Embora precários, os dados disponíveis indicam, em diversas situações, taxas de morbidade e mortalidade três a quatro vezes maiores que aquelas encontradas na população brasileira geral. O alto número de óbitos sem registro ou indexados sem causas definidas confirmam a pouca cobertura e baixa capacidade de resolução dos serviços disponíveis. (Funasa, 2002: 10)

${ }^{9}$ Esta seção foi elaborada por Ricardo Ventura Santos e Carlos E. A. Coimbra Jr. 
Com base nos dados disponíveis, não é possível caracterizar de forma satisfatória as condições de saúde dos povos indígenas, dado que estão ausentes os elementos quantitativos necessários para embasar análises abrangentes e sofisticadas. Em geral, é difícil ir além da compilação de estudos de casos específicos, muitos dos quais oriundos da Amazônia. Em anos recentes, foi iniciada a implantação de um sistema de informação específico sobre a saúde indígena (Sistema de Informação da Atenção à Saúde Indígena - Siasi), mas que infelizmente ainda não funciona a contento. Não obstante, restam poucas dúvidas de que as condições de saúde dos povos indígenas sinalizam para uma considerável situação de vulnerabilidade, colocando-as em desvantagem em relação a outros segmentos da sociedade nacional (Coimbra Jr., Santos \& Escobar, 2003; Garnelo, Macedo \& Brandão, 2003; Santos et al., 2008).

A partir dos resultados do mais recente censo demográfico (2000) evidenciou-se que os níveis de escolaridade dos indígenas permanecem muito baixos e que há diferenças importantes nas taxas de fecundidade total das mulheres indígenas urbanas (2,7 filhos) e rurais (5,7 filhos). Os dados censitários mostram também uma taxa de mortalidade infantil para os indígenas em 2000 (51,4 por mil) significativamente mais elevada que a taxa nacional (de 30,1 por mil). A mortalidade infantil indígena é muito superior a dos demais grupos de cor/raça, inclusive das crianças 'pretas' e 'pardas' (34,9 e 33,0 por mil, respectivamente). Chamam atenção também as elevadas taxas de mortalidade infantil dos indígenas nas regiões socioeconomicamente mais desenvolvidas do país (Sudeste e Sul) (IBGE, 2005).

As doenças infecciosas e parasitárias persistem como as principais causas de adoecimento e morte de indígenas no país. A tuberculose se destaca como uma das principais endemias nessas populações. A malária constitui outra endemia amplamente presente nas terras indígenas, sobretudo na Amazônia, onde tem ocasionado surtos que resultam em elevadas taxas de mortalidade. Concomitantemente, as infecções respiratórias agudas e as diarréias são as principais causas de adoecimento e morte nas crianças menores de cinco anos (Coimbra Jr., Santos \& Escobar, 2003; Garnelo, Macedo \& Brandão, 2003; Funasa, 2003, 2006; Santos et al., 2008).

Atualmente, a questão alimentar e nutricional indígena tem adquirido grande visibilidade. Estudos recentes destacam que, de modo geral, a desnutrição atinge mais de um quarto das crianças menores de cinco anos e, não raro, mais da metade delas. A anemia por deficiência de ferro constitui a principal doença carencial verificada nas populações indígenas, afetando principalmente crianças menores de 10 anos e mulheres em idade reprodutiva, com prevalências que chegam a 70-80\% desse segmento populacional (Leite et al., 2007).

Condições precárias de saneamento e habitação, aliadas à baixa cobertura e qualidade dos serviços de saúde, interagem, levando ao agravamento e deterioração das condições nutricionais das crianças indígenas. Sem água potável e tratamento adequado dos dejetos nas aldeias, aumenta a incidência de diarréias e de outras doenças infecciosas e parasitárias. 
A questão da terra constitui outra variável fundamental para a compreensão das condições de saúde e nutrição dos povos indígenas. Um aspecto crucial é que as dimensões das terras indígenas, sobretudo nas regiões Sul, Sudeste e Nordeste do Brasil, e em parte do CentroOeste, são bastante reduzidas em relação às necessidades das comunidades. Um exemplo é aquele dos Guarani-Kaiowá de Mato Grosso do Sul, que vivem uma situação de extrema restrição territorial, com graves conseqüências sobre a situação alimentar.

Outra dimensão particularmente pouco conhecida da epidemiologia dos povos indígenas diz respeito à emergência de doenças crônicas não-transmissíveis, como obesidade, hipertensão arterial, diabetes mellitus e câncer. O surgimento desse grupo de doenças está estreitamente associado a modificações na subsistência, dieta e atividade física, dentre outros fatores, acopladas a mudanças socioculturais e econômicas. No bojo dessas alterações, verifica-se que, concomitante à emergência de doenças crônicas não-transmissíveis, há um crescente número de relatos sobre a ocorrência de suicídio, alcoolismo e drogadicção em diferentes povos indígenas. Observa-se, ainda, aumento importante das mortes por causas externas, sejam estas ocasionadas por acidentes automobilísticos ou uso de maquinário agrícola, como também por violência (Coimbra Jr. et al., 2002; Coimbra Jr., Santos \& Escobar, 2003; Garnelo, Macedo \& Brandão, 2003; Santos et al., 2008).

O conhecimento do perfil epidemiológico em transição dos povos indígenas no Brasil, considerando a grande diversidade étnica que os caracteriza, reveste-se de suma importância para orientar a organização, planejamento e melhoria da qualidade dos serviços de saúde. Em geral, esses serviços encontram-se voltados para lidar com determinados grupos de doenças, sobretudo as infecciosas e parasitárias, que, historicamente, têm (ou tiveram) maior peso na morbidade e mortalidade indígena.

Até o final da década de 1990, os serviços de saúde destinados ao atendimento dos povos indígenas eram geridos pela Fundação Nacional do Índio (Funai). Em larga medida, baseavam-se em atuações eminentemente curativas. A continuidade da atenção básica à saúde nas áreas indígenas não ocorria de forma satisfatória. Mesmo nas décadas de 1960 e 1970, quando já se dispunham de vacinas, antibióticos e outros recursos, não se conseguiu evitar que epidemias de malária, tuberculose ou mesmo de sarampo dizimassem centenas de indígenas recém-contatados no Brasil Central e Amazônia.

A partir de 1999, a responsabilidade pela provisão de serviços de saúde aos povos indígenas passou para a Fundação Nacional de Saúde (Funasa), vinculada ao Ministério da Saúde, concretizando a implantação de um serviço de saúde voltado para os povos indígenas e estruturado segundo divisão territorial em distritos (os chamados "Distritos Sanitários Especiais Indígenas” - DSEIS), vinculados ao Sistema Único de Saúde (SUS). No presente, há 34 distritos implantados em todo o país. Esse novo modelo pauta-se na perspectiva da atenção diferenciada, reconhecendo, ao menos em tese, as especificidades dos povos indígenas. Não obstante, após meia década de implantação, é perceptível que as ações ainda estão bastante distantes quanto a reduzir as enormes disparidades em saúde dos indígenas se comparados aos não-indígenas (Garnelo, Macedo \& Brandão, 2003; Santos et al., 2008). 


\section{RECOMENDAÇÕES}

Esta seção inclui uma série de recomendações para intervenções sobre os determinantes sociais da saúde (DSS), com vistas a contribuir para a superação dos problemas assinalados neste relatório, particularmente para o combate às iniqüidades em saúde. Estas intervenções adotam como referência os princípios e estratégias de Promoção da Saúde, estabelecidos numa série de cinco Conferências Internacionais desde 1986 a 1997, com destaque para a primeira delas, onde se lançou a Carta de Ottawa. Reconhecendo que a paz, a educação, a moradia, a alimentação, a renda, o ecossistema estável, a justiça social e a eqüidade são requisitos fundamentais para a saúde dos povos, a Carta de Ottawa identifica como condiçõeschave para promover a saúde o estabelecimento de políticas públicas saudáveis, a criação de ambientes favoráveis, o fortalecimento das ações comunitárias, o desenvolvimento de habilidades pessoais e a reorientação dos serviços de saúde.

\subsection{As Políticas e Programas em Curso ${ }^{1}$}

Esta década vem assistindo à expansão de políticas e programas voltados para populações de maior vulnerabilidade social. No entanto, embora o alvo de várias dessas iniciativas seja muitas vezes um mesmo grupo populacional e ocorra em um mesmo espaço, os problemas sociais tematizados são abordados de forma setorializada, fragmentada, carentes de articulação entre si. o próprio modelo de organização do nível federal, excessivamente horizontalizado e com poucas instâncias de articulação interna produz uma forma de intervenção que tende à competição entre os agentes públicos, à redundância de ações, à ineficiência do gasto público e à baixa qualidade dos serviços prestados à população.

Há inúmeros fenômenos que concorrem para a produção das condições de saúde da população e que no Brasil são objeto de programas e ações de órgãos pertencentes a diferentes setores sociais. No entanto, estas intervenções não costumam ser categorizadas como sendo da saúde stricto sensu, tampouco costumam ser percebidas, pela população em geral, como determinantes para as condições de saúde. Dessa forma, programas e políticas sociais que embora freqüentemente tenham abrangência intersetorial, apresentam efetividade limitada, não conseguindo atuar adequadamente sobre os mecanismos determinantes das iniqüidades em saúde.

${ }^{1}$ Esta seção é um extrato da revisão e análise das políticas e programas em andamento relacionadas com os determinantes sociais da saúde feita, por encomenda da CNDSS, por Rômulo Paes de Sousa e Jeni Vaitsman (coordenadores); Eliane Hollanda de Carvalho; Sandra Aparecida Venâncio de Siqueira; Alex Molinaro; Maria Elizabeth Salermo Pinho e Gabriela Rieveres Borges de Andrade 
A seguir, é apresentado um mapeamento das ações de políticas sociais que têm relação com os determinantes sociais da saúde e que são executadas, principalmente, por outros ministérios que não o da Saúde. Nesse mapeamento, é verificada a execução orçamentária dessas ações no triênio 2004-2006, sendo identificadas as que são objeto da atuação desses vários órgãos e as que apresentam possibilidades ou potencialidades de articulação com o setor saúde.

\section{Metodologia}

O período de referência para a revisão foi o triênio 2004-2006. Neste período, mais de 390 programas e 4.000 ações governamentais foram executados, anualmente. Foram selecionadas aquelas relacionadas às condições de vida e saúde, que tradicionalmente consistem objeto de estudo e intervenção na área da saúde coletiva, ainda que não necessariamente em objeto de atuação do Ministério da Saúde e seus equivalentes nas esferas subnacionais. Também foram incorporadas aquelas ações relacionadas a temáticas que, nesta década, vêm sendo objeto de ação governamental para a redução de desigualdades sociais e em saúde, selecionando-se programas/ações dirigidas às populações em situações de vulnerabilidade.

As ações foram classificadas segundo as seguintes áreas temáticas: Agricultura, Alimentação, Ambiente/Habitação, Educação/Esporte e Cultura, Proteção Social Não Contributiva, Trabalho e Inclusão Produtiva, Prevenção e Combate à Violência e Promoção de Direitos.

Os órgãos responsáveis/executores das ações estudadas são os seguintes:

1. Ministério da Agricultura, Pecuária e Abastecimento (Mapa)

2. Ministério da Cultura (MinC)

3. Ministério das Cidades (MCID)

4. Ministério do Desenvolvimento Agrário (MDA)

5. Ministério do Desenvolvimento Social e Combate à Fome (MDS)

6. Ministério do Esporte (ME)

7. Ministério da Educação (MEC)

8. Ministério da Integração Nacional (MI)

9. Ministério da Justiça (MJ)

10. Ministério do Meio Ambiente (MMA)

11. Ministério da Saúde (MS)

12. Ministério do Trabalho e Emprego (MTRE)

13. Presidência Da República (PR)

14. Secretaria Especial de Políticas para as Mulheres (PR/SEPM)

15. Secretaria Especial de Direitos Humanos (PR/SEDH)

16. Secretaria Especial de Políticas de Promoção da Igualdade Racial (PR/Seppir)

As fontes de informações básicas foram o Plano Plurianual (PPA), que possui os dados para o período estudado, e o Sistema Integrado de Administração Financeira do governo federal (Siafi), considerando os dados para o período em estudo. O PPA é o instrumento que expressa as diretrizes da ação governamental e as informações programáticas e orçamentárias, em 
relação aos seus vários setores de atuação. Dele foram extraídas as informações referentes à justificativa, aos objetivos e à finalidade, às instituições responsáveis e às articulações interinstitucionais. No tocante aos dados orçamentários, não foram utilizados os valores apresentados no relatório do PPA, já que estes sofrem revisões ao longo de cada ano. Como conseqüência, os dados orçamentários, tal como constam dos relatórios do PPA, muitas vezes não correspondem ao que foi efetivamente executado pelos ministérios. Então, optou-se pelo uso do Siafi como fonte de dados primária e do SIGA Brasil-Senado Federal. Ambas mostraramse fontes mais robustas para analisar o que foi efetivamente executado. A consistência da fonte e dos dados orçamentários utilizados na tabulação foi verificada junto a técnicos do Ministério do Planejamento, Orçamento e Gestão e do Ministério de Desenvolvimento Social e Combate à Fome.

A identificação das ações relevantes quanto aos sete temas definidos foi feita com base na revisão de todos os programas e todas as ações contidas no Cadastro de Ações do PPA, durante o triênio 2004-2006, disponível nas páginas eletrônicas do Ministério do Planejamento, Orçamento e Gestão (MPOG). Com vistas à uniformização da descrição das ações, optouse por extrair do texto da "justificativa" os "objetivos" dos programas, e procedeu-se da mesma maneira com o item "finalidade" das ações orçamentárias selecionadas para cada programa. Selecionaram-se 55 programas e 86 ações consideradas como as mais relevantes em sua relação com os determinantes sociais da saúde, sendo classificadas nas sete áreas temáticas. Apenas as ações cujos resultados finais visavam aos indivíduos, às famílias ou às comunidades foram selecionadas. Ainda que o objetivo principal do trabalho tenha sido o levantamento de ações extra-Ministério da Saúde, algumas ações deste órgão em áreas "extra-saúde" foram selecionadas (Tabela 29 e Gráficos 36 e 37). 
Tabela 29 - Distribuição das ações segundo tema e órgão executor: 2004-2006

\begin{tabular}{|c|c|c|c|c|c|c|c|c|c|c|c|c|c|c|c|c|c|c|}
\hline \multirow{2}{*}{$\begin{array}{l}\overrightarrow{\overleftarrow{\Xi}} \\
\stackrel{\circ}{\circ}\end{array}$} & do & $\stackrel{m}{\sim}$ & 广્f & $\stackrel{N}{-}$ & $\stackrel{\circ}{i}$ & $\vec{\sim}$ & $\stackrel{m}{i}$ & $\stackrel{6}{-1}$ & in & $\vec{\infty}$ & 7 & is & -1 & \& & $\stackrel{\stackrel{n}{m}}{m}$ & $\stackrel{\infty}{n^{\prime}}$ & $\stackrel{n}{m} \underset{\sim}{\sim}$ & : \\
\hline & z & $\sim$ & $\sigma$ & $\neg$ & 6 & $\stackrel{ન}{\neg}$ & $\sim$ & 욱 & เn & $r$ & 5 & 1 & th & 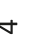 & $m$ & in & $m \rightarrow$ & $\infty$ \\
\hline \multirow{2}{*}{ 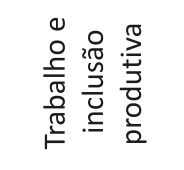 } & வீ & : & : & : & $\stackrel{-}{\therefore}$ & $\stackrel{ }{\therefore}$ & O. & : & $\stackrel{+}{\vec{N}}$ & $\stackrel{m}{\underset{f}{+}}$ & c & 5 & s' & م) & : & 웅 & $\underset{\sim}{m} \underset{\sim}{\stackrel{n}{N}}$ & : \\
\hline & $z$ & & & & $r$ & - & & & $m$ & $\sim$ & & & & $\checkmark$ & & & $N-1$ & A \\
\hline \multirow{2}{*}{ 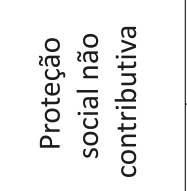 } & வ0 & : & & $\stackrel{\circ}{\circ}$ & : & $\stackrel{\Delta}{i}$ & $\begin{array}{l}0 \\
0\end{array}$ & : & O & $\stackrel{m}{\underset{f}{+}}$ & c & & 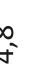 & : & : & $\stackrel{\infty}{+}$ & \begin{tabular}{ll}
$\infty$ & 0 \\
\multirow{*}{*}{} & 0
\end{tabular} & : \\
\hline & z & & & & & $\stackrel{\text { 乞 }}{\sim}$ & & & & $m$ & & & -1 & & & $-r$ & -1 & $\vec{N}$ \\
\hline \multirow{2}{*}{ 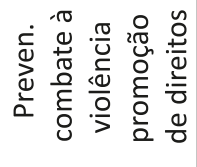 } & do & O & $\stackrel{n}{\sim}$ & $\stackrel{0}{0}$ & : & 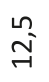 & O & กี & O & $\stackrel{\sim}{\sim}$ & c & & s & :- & $\stackrel{0}{0}$ & : & $\begin{array}{l}0 \\
0\end{array}$ & 웅 \\
\hline & $z$ & & -1 & & & 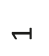 & & -1 & & -1 & & & & & & $\nabla$ & & $\infty$ \\
\hline & do & $\dddot{n}^{n}$ & : & "ूn & $\dddot{m}_{\omega}^{-}$ & : & $\stackrel{\stackrel{n}{\tilde{I}}}{\stackrel{\sim}{ت}}$ & ○ั & O & : & c & 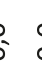 & s. & : & 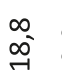 & : & $\because: 0$ & : \\
\hline & $z$ & $r$ & & -1 & $r$ & & $N$ & $\infty$ & & & & & & & $m$ & & & $\stackrel{1}{9}$ \\
\hline \multirow{2}{*}{ 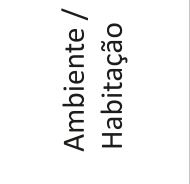 } & வீ & O. & $\begin{array}{l}\infty \\
\infty \\
\rightarrow \\
-1\end{array}$ & $\begin{array}{l}0 \\
0\end{array}$ & : & : & O- & ○ & $\stackrel{n}{\sim}$ & $\stackrel{m}{0}$ & $\begin{array}{l}\infty \\
\infty\end{array}$ & 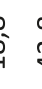 & $\overbrace{}^{-}$ & : & : & : & $\begin{array}{ll}0 & 0 \\
0 & 0\end{array}$ & : \\
\hline & $z$ & & $m$ & & & & & & $\sim$ & -1 & $m$ & 1 & - & & & & & $\stackrel{\bullet}{-1}$ \\
\hline \multirow{2}{*}{ 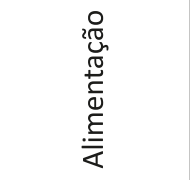 } & do & : & : & : & : & : & : & $\stackrel{m}{m}$ & O & O & $\begin{array}{l}m \\
m \\
m\end{array}$ & s & ñ & 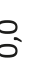 & : & $\stackrel{\circ}{\circ}$ & $\begin{array}{l}0 \\
0\end{array}$ & 웅 \\
\hline & $z$ & & & & & & & -1 & & & $r$ & -1 & -1 & & & & & $m$ \\
\hline \multirow{2}{*}{$\frac{\stackrel{0}{5}}{\frac{10}{3}}$} & do & $\stackrel{\stackrel{\sim}{\sim}}{\underset{\exists}{\sim}}$ & $\stackrel{0}{\circ}$ & ㅇ. & : & 占 & $\begin{array}{l}0 \\
0\end{array}$ & ○ & $\stackrel{\circ}{\circ}$ & O & c & 5 & בี & 웅 & ㅇ. & & $\begin{array}{ll}0 & 0 \\
0\end{array}$ & : \\
\hline & $z$ & $r$ & & & $\sigma$ & $N$ & & & & & & & -1 & & & & & $\infty$ \\
\hline \multirow[t]{2}{*}{ 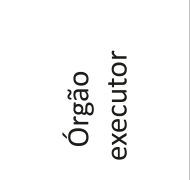 } & & $\frac{\frac{\pi}{2}}{\sum^{\pi}}$ & $\stackrel{O}{\mathrm{U}}$ & : & 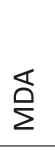 & $\stackrel{\sim}{\Sigma}$ & $\stackrel{山}{\Sigma}$ & $\stackrel{\breve{W}}{\Sigma}$ & $\bar{\Sigma}$ & $\Sigma$ & $\sum_{\Sigma}^{\varangle}$ & 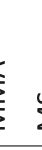 & $\frac{n}{z}$ & 宸 & & $\begin{array}{l}\text { I } \\
\text { 岁 } \\
\text { 品 }\end{array}$ & 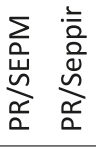 & 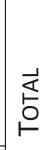 \\
\hline & & $r$ & $\sim$ & $m$ & $\sigma$ & in & 6 & $r$ & $\infty$ & $\sigma$ & ? & 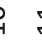 & & స & $\stackrel{m}{-}$ & $\vec{~}$ & $\stackrel{n}{\rightarrow} \stackrel{\sim}{\circ}$ & \\
\hline
\end{tabular}


Gráfico 36 - Participação relativa dos órgãos no total das ações selecionadas: 2004-2006

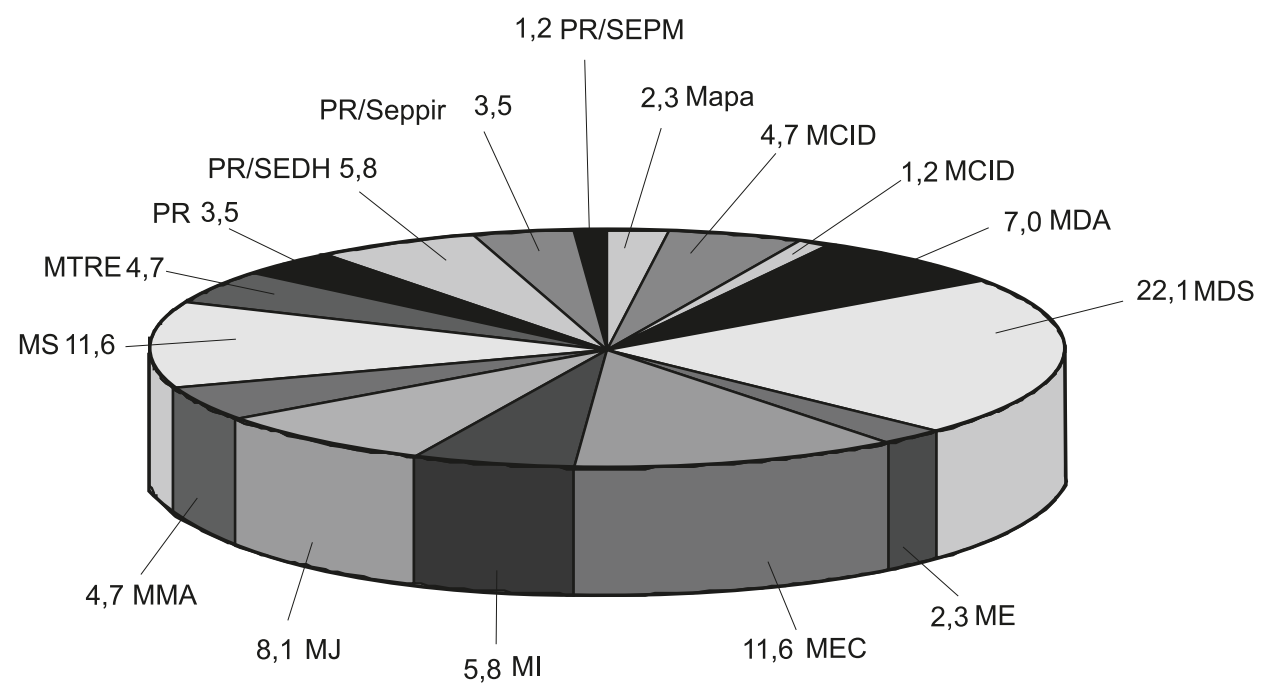

Fonte: Elaboração própria, 2007.

Gráfico 37 - Participação relativa das ações estudadas por tema: 2007

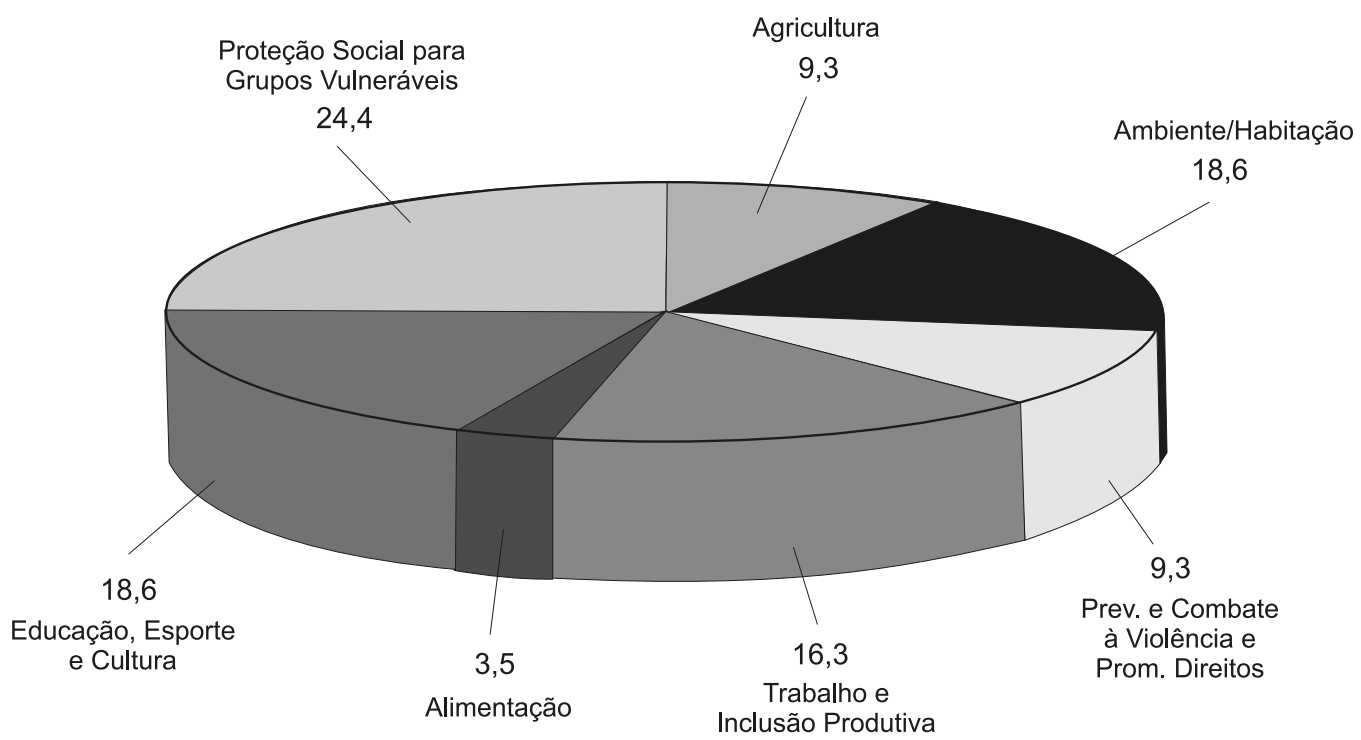

Fonte: Elaboração própria, 2007. 
As 86 ações selecionadas foram executadas por 16 órgãos federais. Na maioria dos casos, um mesmo órgão costuma executar ações transversalmente, em diferentes temáticas. A Secretaria Especial de Políticas de Promoção da Igualdade Racial desenvolveu ações em apenas um tema, Trabalho e Inclusão Produtiva, relacionado ao desenvolvimento de comunidades quilombolas; o mesmo se deu com o Ministério da Cultura, que desenvolveu um único projeto, relativo ao fomento a grupos e redes da diversidade cultural brasileira.

O maior número de ações foi executado na área da Proteção Social Não Contributiva (24,4\% do total), sendo o Ministério do Desenvolvimento Social e Combate à Fome o executor da maioria delas. Trata-se de todo um conjunto de ações de proteção social básica e especial, voltadas para famílias, crianças, adolescentes, idosos e pessoas com deficiência, que, como parte da construção do Sistema Único de Assistência Social, experimentou uma grande expansão no triênio. Ainda que os diferentes tipos de vulnerabilidade venham sendo enfrentados por ações majoritariamente do Ministério do Desenvolvimento Social e Combate à Fome, outros órgãos executaram ações voltadas para grupos com situações específicas de vulnerabilidade e/ou risco. O Ministério da Justiça executou ações de proteção aos indígenas (que, tradicionalmente, estão sob a sua responsabilidade), às mulheres, e às crianças e adolescentes em situação de risco. O Ministério da Saúde contribuiu com o tema por meio de ações de reabilitação de egressos de internações psiquiátricas.

O tema Ambiente/Habitação contribui com 18,6\% do total das ações estudadas. As ações de saneamento, em áreas rurais e indígenas e em municípios de pequeno porte, são executadas, em sua maioria, pelo Ministério da Saúde, ainda que o Ministério do Meio Ambiente e o Ministério das Cidades também estejam envolvidos, em articulação com o Ministério da Saúde, como responsáveis pelos diferentes programas de saneamento rural e urbano, aos quais pertencem as ações selecionadas. As ações voltadas para a melhoria das condições de habitação e prevenção de riscos em assentamentos precários, autoconstrução e mutirão aparecem como de responsabilidade e execução do Ministério das Cidades. O Ministério da Justiça executa ação relativa à conservação e recuperação da biodiversidade em terras indígenas.

A área temática Alimentação corresponde a 3,5\% do total. Deve-se observar que há programas e ações relacionados à aquisição, produção ou melhoria da alimentação que foram classificados em outras áreas temáticas. Os programas de transferência de renda voltados para grupos vulneráveis constituem apoio à melhoria da alimentação dos beneficiários, sendo, portanto, vinculados à área temática Alimentação. Outro exemplo refere-se às ações voltadas para a promoção da agricultura familiar, que visa a ampliar o padrão de renda de famílias de trabalhadores rurais e o acesso à alimentação por grupos em situação de insegurança alimentar.

A área temática Agricultura agrupa três programas, sendo a maior parte executada pelo Ministério do Desenvolvimento Agrário. As ações dirigem-se prioritariamente à capacitação de agricultores familiares, à aquisição de alimentos da agricultura familiar e à disponibilidade de insumos para a atividade agrícola. 
A área temática Trabalho e Inclusão Produtiva agrega programas e ações centradas em capacitação de segmentos específicos em situação de vulnerabilidade (jovens, indígenas, quilombolas e mulheres). As ações voltam-se para capacitação e qualificação dos gruposalvo, fomento ao desenvolvimento sustentável e concessão de auxílio financeiro. O Ministério do Trabalho e Emprego executa quatro destes programas.

A área temática de Prevenção e Combate à Violência e Promoção de Direitos concentra-se no apoio, proteção e capacitação de jovens em situação vulnerável. Secundariamente, esta área dirige-se à proteção de idosos e à educação no trânsito.

\section{Execução Orçamentária de Programas e Ações}

Em relação aos temas abordados, os dados mostram pouca alteração na distribuição de recursos ao longo do triênio (Tabela 30). Proteção Social aos Grupos Vulneráveis foi responsável pela execução de mais de $80 \%$ dos recursos gastos com os programas e ações selecionados. Em 2004, este percentual foi de $86,80 \%$, em 2005 de $86,70 \%$ e, em 2006, de $88,75 \%$. De certa forma, este resultado era esperado na medida em que o maior número de ações executadas encontra-se neste tema. A proteção social a grupos vulneráveis é efetivamente um componente decisivo para a diminuição de desigualdades sociais, e em saúde e indica uma prioridade política no triênio.

Em seguida, encontra-se o tema Alimentação, que executou em média 8,5\% dos recursos. Apesar de o tema ter tido apenas três ações executadas, entre estas encontra-se a merenda escolar com grande volume de recursos executados, o que explica este percentual.

A Tabela 31 traça um paralelo entre a execução orçamentária total dos órgãos responsáveis pelas ações selecionadas e o valor despendido, especificamente, nessas ações. Da execução dos órgãos listados, foram deduzidos os valores referentes às despesas com previdência de inativos e de apoio administrativo, uma vez que o objetivo do levantamento foi identificar as ações-fim. Uma primeira observação derivada da leitura destes dados é de que, no triênio 2004-2006, houve um aumento no aporte total de recursos executados pelos ministérios e nas ações pesquisadas. 
Tabela 30 - Valores totais executados por tema: 2004-2006

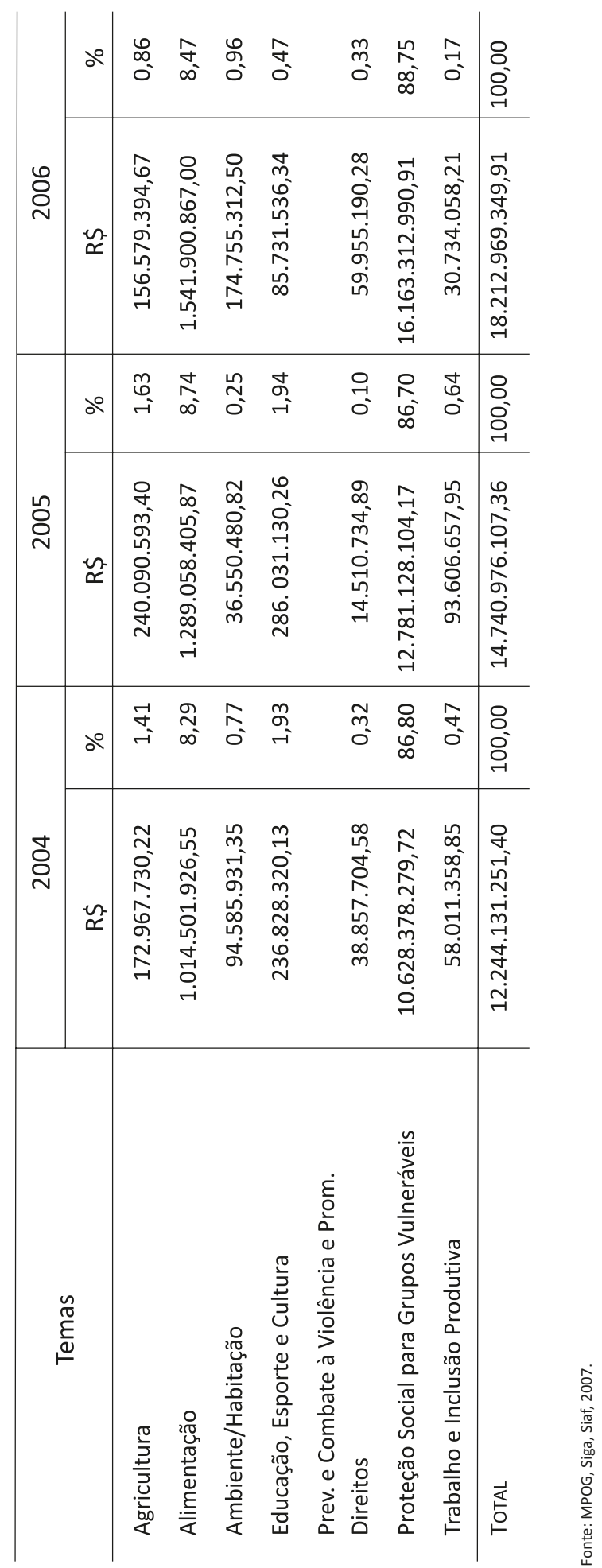


Tabela 31 - Execução orçamentária total do universo pesquisado: 2004-2006 *

\begin{tabular}{|c|c|c|}
\hline \multirow{3}{*}{$\frac{9}{3}$} & 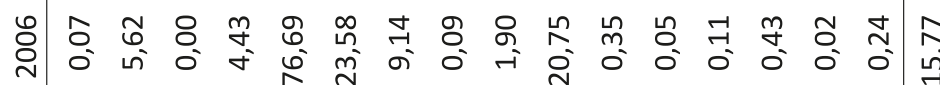 & \\
\hline & 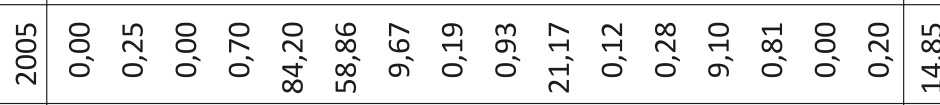 & \\
\hline & 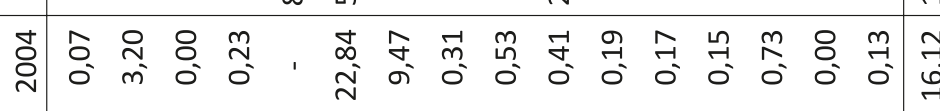 & \\
\hline \multirow{3}{*}{ 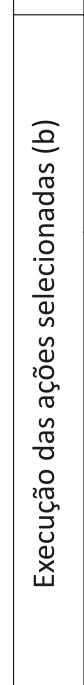 } & 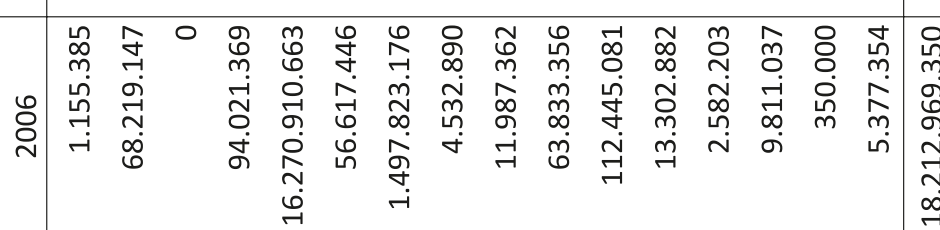 & \\
\hline & 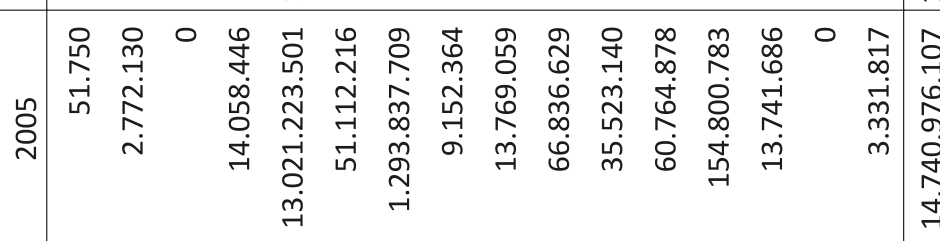 & \\
\hline & 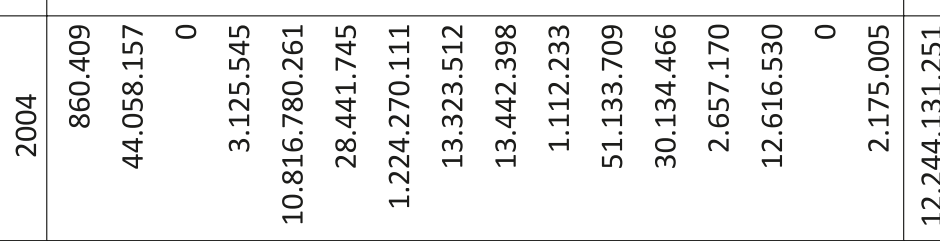 & \\
\hline \multirow{3}{*}{ 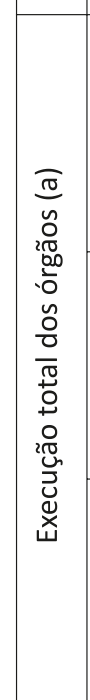 } & 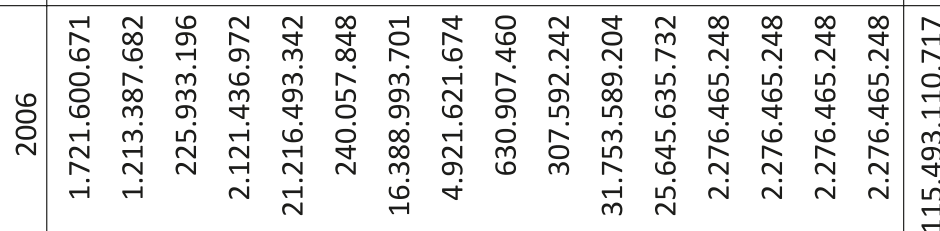 & \\
\hline & 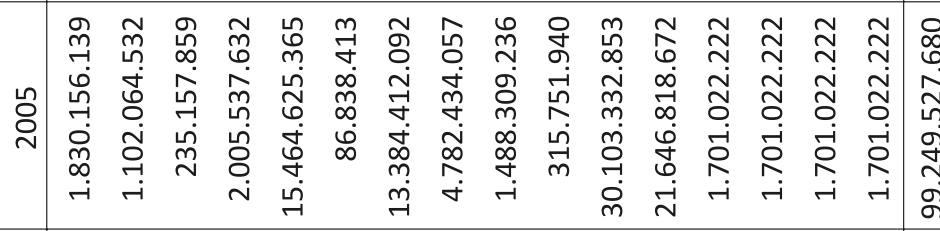 & \\
\hline & 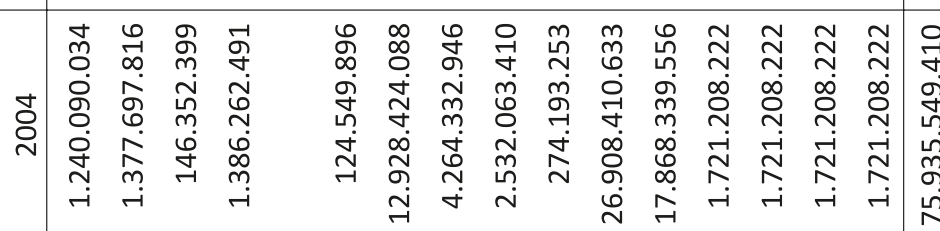 & \\
\hline 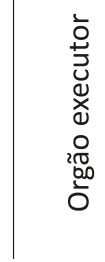 & 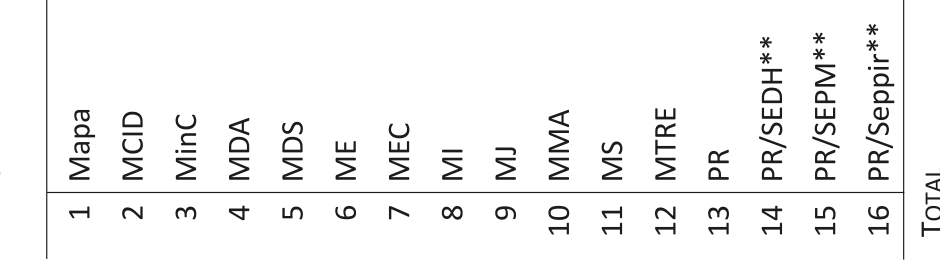 & \\
\hline
\end{tabular}


As ações selecionadas, com execução a cargo do Ministério de Desenvolvimento Social, foram as que apresentaram, ao longo do triênio 2004-2006, o maior dispêndio de recursos em valores absolutos e relativos, correspondendo a 84,2\% do valor total executado em 2005 e $76,7 \%$ em 2006. Cabe destacar que não havia execução orçamentária prevista para o Ministério de Desenvolvimento Social no ano de 2004.

O Ministério da Educação aparece como o segundo órgão na execução de valores com as ações que compõem o universo desta revisão. Nos anos 2004-2005, mais de 1 bilhão e 200 milhões de reais foram executados, subindo estes valores para cerca de 1 bilhão e 500 milhões de reais em 2006. Apesar deste dispêndio, em valores relativos o peso destas ações no orçamento total executado pelo ministério foi de 9,47\% em 2004, 9,67\% em 2005 e 9,14\% em 2006.

Comportamento semelhante apresentou o Ministério da Saúde. Apesar de ter investido mais de 51 milhões de reais no ano de 2004 nas ações selecionadas, mais de 35 milhões em 2005 e mais de 112 milhões em 2006, estas ações responderam por apenas $1 \%$ do valor total do orçamento deste ministério.

A despeito da sua inclusão no Planejamento Plurianual os dados levantados mostram que cerca de $10 \%$ das ações selecionadas não tiveram orçamento executado em nenhum dos anos analisados.

\section{Avaliação dos Programas do Ministério do Desenvolvimento Social e Combate à Fome}

Como mostra o levantamento da execução orçamentária de programas e ações, no triênio 20042006, relacionados aos DSS, a área da proteção social não-contributiva responde por mais de $85 \%$ dos recursos executados, os quais se concentram no Ministério do Desenvolvimento Social. A seguir, são apresentados, de forma resumida, os resultados de alguns estudos de avaliação sobre esses programas, contratados em sua maioria pelo Ministério do Desenvolvimento Social junto a várias instituições de pesquisa. Cabe ressaltar que o pouco tempo de existência dos programas é apontado na literatura como uma dificuldade para uma avaliação mais substantiva de políticas ou programas. Logo, os trabalhos devem ser vistos com cautela na análise de seus resultados e eventuais projeções/especulações.

O principal programa da área de proteção social é o Programa Bolsa Família, criado em 2003 pelo Governo Federal e que alcançou, em 2006, uma cobertura de 11,2 milhões de famílias. Seus objetivos são: promover o acesso à rede de serviços públicos, em especial crianças e gestantes, de saúde, educação e serviço social; combater a fome e promover a segurança alimentar e nutricional; estimular a emancipação sustentada das famílias que vivem em situação de pobreza e extrema pobreza; promover a intersetorialidade, a complementaridade e a sinergia das ações sociais do poder público.

Diferentes estudos foram feitos para avaliar os resultados do Programa Bolsa Família. De modo geral, no que se refere à utilização dos recursos recebidos, todos eles apontam para a alimentação como item principal, seguido de material escolar, roupas/calçados e medicamentos (Oliveira et al., 2007; Instituto Polis, 2007; Silva et al., 2007). 
A pesquisa domiciliar, com desenho quasi-experimental e longitudinal, baseou-se em amostra representativa para três macrorregiões: 1) Nordeste, Sudeste e Sul, 2) Norte e 3) CentroOeste. Os questionários foram coletados em 14.022 domicílios, comparando-se dados de três grupos, pareados entre si: beneficiários do Programa Bolsa Família, beneficiários de outros programas sociais, não-beneficiários de qualquer programa.

O desempenho positivo do programa foi verificado em indicadores educacionais (freqüência, evasão e progressão), que mostram os beneficiários do Programa Bolsa Família com menor taxa de evasão do que os de outros programas sociais e entre aqueles que não são beneficiários de programas sociais (Oliveira et al., 2007). No entanto, constatou-se menor índice de aprovação entre os beneficiários do Programa Bolsa Família, sobretudo em relação ao grupo beneficiário de outros programas. Esse último resultado sugere que há redução da evasão e conseqüente aumento da permanência no sistema escolar de um ano para outro, implicando que os alunos de menor desempenho escolar e com maior probabilidade de evasão estão permanecendo na escola, mas isso não é suficiente para que aumentem o seu desempenho. Logo, a escola necessita adaptar-se a esta nova realidade: enfrentar as dificuldades apresentadas pelos alunos que possuem maior dificuldade de aprendizado e ou sociabilidade. Dessa forma, o aumento de demanda escolar do Programa atingiria, inclusive, os que possuem maior dificuldade de permanecer na escola.

O estudo do Instituto Polis (2007) reitera a dificuldade de acesso aos serviços básicos, sobretudo os de saúde, como um dos obstáculos para o cumprimento das condicionalidades. Com base em mais de 400 entrevistas, realizadas em cada região do país, mais de 80,9\% dos entrevistados consideraram fácil ou muito fácil conseguir vaga em escola pública, mas no caso dos serviços de saúde este percentual caiu para 40,9\%, o que explicaria o fato de apenas $51 \%$ das gestantes entrevistadas nesta pesquisa terem feito mais de cinco consultas durante o pré-natal.

O acesso à renda assegurada pelo Programa Bolsa Família possibilitou a transferência de parcela da população brasileira para a condição de segurança alimentar. Estudo realizado com 3.000 famílias que recebiam o benefício há mais 12 meses e 1.000 famílias com menos de 12 meses, em 53 municípios do país, concluiu que o Programa Bolsa Família modificou o padrão alimentar das famílias, possibilitando a melhora na qualidade e na variedade dos alimentos consumidos. Mais de $90 \%$ das crianças, jovens e adultos pesquisados fazem três refeições ao dia, sendo a quantidade dos alimentos ingeridos considerados satisfatórios por $54 \%$ do total de entrevistados. A pesquisa mostra, ainda, que 48,7\% dos beneficiários gastam os recursos provenientes do benefício com alimentação, seguido por material escolar, com 18,\%, e 10,1\% com remédios (Silva et al., 2007).

Outro aspecto importante dos programas de transferência de renda diz respeito ao seu potencial para a redução da pobreza e da desigualdade no país, uma das mais altas do mundo. Com base na Pesquisa Nacional por Amostra de Domicílios (Pnad) de 2004, Soares et al. (2006) concluíram que, em conjunto, o Benefício de Prestação Continuada (BPC) e o Programa Bolsa Família foram responsáveis por $28 \%$ da redução da queda do Índice de Gini no período de 1995-2004, sendo que o Programa Bolsa Família apresentou maior potencial 
de redução (21\%) do que o Benefício de Prestação Continuada (7\%). No entanto, no que diz respeito à diminuição da pobreza, a situação se inverte, uma vez que o valor mais alto do Benefício de Prestação Continuada é capaz de retirar as famílias beneficiadas da pobreza, enquanto o Programa Bolsa Família é capaz apenas de aliviá-la.

Estudos realizados, em 2005 e 2006, com o objetivo de monitorar a situação nutricional de crianças de populações com maior vulnerabilidade nutricional, aferiram a boa focalização do Programa Bolsa Família e sua contribuição para a redução da desnutrição, isto é, que o Programa está atingindo as populações mais carentes. Nos estudos, foram coletados dados de antropometria (peso e altura) e padrão alimentar de crianças menores de 5 anos do Norte e do semi-árido brasileiro e moradoras em assentamentos rurais do Nordeste e de crianças e adultos indígenas e quilombolas. O estudo da população quilombola (MDS, 2007) em 60 comunidades dispersas em 22 estados brasileiros, com 2.941crianças, mostrou que do total de crianças pesquisadas $11,6 \%$ apresentavam formas crônicas de desnutrição e $2 \%$ apresentaram desnutrição aguda, o que é comparável aos padrões encontrados na região urbana do Nordeste, no ano de 1996. São crianças oriundas da classe E, em 57,5\% dos casos, com 51,7\% das famílias sendo atendidas pelo Programa Bolsa Família; baixa escolaridade, com $47,3 \%$ de chefes de família e 43,8\% de mães possuindo até quatro anos de estudo; rede precária de esgotamento sanitário, com valas a céu aberto em 45,9\% das moradias; e acesso à água proveniente de nascentes ou poços em 43,8\% dos casos.

No semi-árido brasileiro, com base em amostra de 17.587 crianças, distribuídas em 307 municípios da região, verificou-se uma associação positiva entre melhoria das condições de nutrição e participação no Programa Bolsa Família. Concluiu-se que a desnutrição é 30\% mais freqüente entre as crianças não inscritas no Programa Bolsa Família. Os maiores beneficiados são as crianças entre 6 e 11 meses de idade e, neste caso, a participação no programa de transferência de renda reduz o risco de desnutrição crônica em 62,1\% (Monteiro, Conde \& Konno, 2006).

Outra avaliação de impacto foi realizada sobre o Programa Um Milhão de Cisternas. Este programa busca melhorar as condições de sobrevivência das famílias beneficiárias, garantindo o abastecimento de água apropriada para o consumo humano no período da seca. Em dezembro de 2007, o Programa registrava 200 mil cisternas construídas, beneficiando 1 milhão de pessoas. Estudo realizado pela Empresa Brasileira de Pesquisa Agropecuária (Embrapa) para avaliar os impactos em relação ao uso de água proveniente da cisterna e de fontes alternativas à cisterna (Lima et al., 2007) apresenta dados que reforçam a importância do Programa. O estudo foi feito com base em uma amostra estratificada de 4.189 domicílios em um conjunto de 11 regiões com características geoambientais distintas, a partir de zoneamento agroecológico do semi-árido brasileiro.

A partir da introdução da tecnologia da construção de cisternas na região, observou-se impacto positivo na vida dos beneficiários, levando à melhoria da sua condição de vida (redução das despesas das famílias, maior facilidade no preparo de alimentos, redução no tempo dispendido na busca da água e queda na incidência de enfermidades investigadas, 
tais como: diarréia, desidratação, doenças de pele, doenças renais, sensação de cansaço e também na perda de dias de trabalho e visitas ao médico).

Com relação à focalização dos programas de transferência de renda, dados da Pnad 2004, publicados pelo IBGE em 2008, revelam que 15,6\% dos domicílios no país tinham pelo menos um morador recebendo dinheiro de programa social do governo, sendo que, na Região Nordeste, este percentual chegou a 32\%. Nesses domicílios beneficiados, 91\% tinham rendimento domiciliar per capita de até um salário mínimo e 1,1\% de mais de dois salários mínimos. O rendimento mediano mensal dos domicílios que tinham algum morador recebendo dinheiro de programa social do governo ( $R \$ 458)$ estava em patamar inferior ao dos que não tinham ( $\$$ \$ 880).

Quanto às condições habitacionais dos domicílios, o percentual com instalações sanitárias adequadas (instalação sanitária ligada à rede coletora de esgoto ou à fossa séptica) foi de 42,4\% no grupo dos beneficiados e de $73,9 \%$ no dos que não tiveram ajuda monetária de programa social do governo. Em relação ao atendimento por rede geral de abastecimento de água, esses percentuais foram, respectivamente, $69 \%$ e $84,7 \%$.

A proporção de pessoas com pelo menos o equivalente ao ensino médio concluído (11 anos ou mais de estudo) foi de 6,7\% no grupo dos moradores em domicílios que receberam benefício; e atingiu $31 \%$ no dos residentes em moradias que não receberam dinheiro de programa social do governo. Já as proporções de pessoas com 15 anos ou mais de estudo (ou seja, que concluíram pelo menos quatro séries de curso superior) foram, respectivamente, 0,3\% e $6,8 \%$. Na população de 10 anos ou mais de idade, a taxa de analfabetismo foi de $18,2 \%$ para o grupo dos moradores em domicílios em que houve recebimento monetário de programa social do governo e 8,6\% no dos residentes em moradias em que não houve.

As pessoas com emprego registrado (com carteira de trabalho assinada, militares ou funcionários públicos estatutários) representavam 38,3\% dos moradores em domicílios que receberam transferência em dinheiro de programa social do governo e 66,2\% na dos residentes em moradias que não receberam.

\section{Conclusões}

Os valores e o volume de ações indicam que o conjunto temático estudado ocupa lugar de destaque na agenda política do governo federal. o crescimento dos valores envolvidos indica que não houve, de maneira geral, depreciação nos níveis de investimento no setor. Uma proporção razoável desses programas e ações (45\%) manteve-se ao longo do triênio estudado. As ações de maior participação orçamentária no universo estudado apresentaram constância em sua execução.

No que se refere aos programas considerados relevantes para os DSS, pode-se identificar várias situações, entre as quais: a) programas intersetoriais, que pressupõem em seu desenho e desde sua formulação ações transversais em vários setores de intervenção governamental; b) programas setoriais, formulados em diferentes ministérios, mas que se articulam no 
contexto local, para alcançar um público-alvo específico e atingir um ou mais problemas; c) programas setoriais formulados em um único ministério, mas abrangendo vários problemas e grupos-alvo.

A ação intersetorial implica não apenas uma agregação formal de órgãos responsáveis, mas a definição de objetivos claros da ação e atribuições de atividades e responsabilidades. Pressupõe, ainda, a efetiva articulação de atores e organizações envolvidas nas várias etapas dos processos de implementação. Isso é particularmente verdadeiro para um tipo de intervenção na qual ações oriundas de diferentes setores se articulam para enfrentar, de forma integrada, um problema que se manifesta em determinada população-alvo. Além disso, do ponto de vista institucional, a ação intersetorial diz respeito a relações horizontais (entre setores) e verticais (entre níveis federativos). Ou seja, ocorre tanto no nível federal quanto no local, e ainda que um programa tenha sido formulado com desenho intersetorial, como forma de enfrentar as vulnerabilidades de maneira integrada, a implementação de suas ações ocorre no nível local, dependendo de um conjunto de outras condições, entre as quais, as políticas, as organizacionais e as de gestão.

O desenho federativo brasileiro dá poder de decisão às administrações locais em um conjunto de atividades e ações necessárias à implementação de programas e ações do governo federal. Em contrapartida, o modo setorial como se organizam e operam os órgãos governamentais, nos três níveis federativos, limita uma efetiva integração entre ações. Isso ocorre mesmo que o alvo seja um único grupo ou problema social e mesmo que as ações aconteçam em um só espaço ou território, embora existam experiências inovadoras, sobretudo no nível local (Junqueira, Inojosa \& Komatsu, 1997; Andrade, 2006).

As dificuldades de articulação intersetorial das ações governamentais são reproduzidas pelo formato da participação da sociedade civil nos conselhos locais de gestão das políticas sociais, como mostra Andrade (2007) para o município de Piraí, Estado do Rio de Janeiro. Com cerca de 24 mil habitantes e bons indicadores de desempenho e de participação social, o município possui 14 conselhos de políticas sociais criados por lei municipal, sendo que o mesmo grupo de pessoas associadas a entidades sem fins lucrativos de diversos perfis tende a participar dos vários conselhos.

A maior parte dos representantes da sociedade civil nos conselhos tem uma visão mais integrada, menos fragmentada, dos problemas do território onde atuam, do que a visão dos profissionais e gestores, que costuma ser setorial. Embora líderes comunitários identifiquem vários problemas que ultrapassam os limites de um único setor de atuação governamental, os encaminhamentos para a resolução de problemas são endereçados ao setor ao qual o conselho está vinculado, o que limita a efetividade das respostas. O formato setorial dos conselhos também induz à fragmentação setorial das políticas, retirando a possibilidade de eles funcionarem como instâncias integradoras e intersetoriais.

As dificuldades de operar um programa intersetorial podem ser vistas no caso do Programa Bolsa Família. Ainda que um de seus objetivos seja "promover a intersetorialidade, a 
complementaridade e a sinergia das ações sociais do Poder Público" (MDS, 2004), isso não quer dizer que haja uma articulação efetiva e pró-ativa de ações de saúde e educação dirigidas aos beneficiários da transferência de renda. Em muitos municípios, as secretarias setoriais não se articulam para a oferta comum de serviços, e a intersetorialidade do programa ocorre apenas no nível da informação, quando os registros de freqüência escolar e acompanhamento em saúde são enviados pelo Ministério da Educação e pelo Ministério da Saúde ao Ministério de Desenvolvimento Social e Combate à Fome.

Contudo, há exemplos de sinergia e articulação entre programas setoriais. Em Belo Horizonte, encontrou-se a articulação entre ações de diferentes programas sobre um mesmo público-alvo, o dos beneficiários do Programa Bolsa Família. Um exemplo é o encaminhamento de jovens ao Programa de Erradicação do Trabalho Infantil (que é de responsabilidade do Ministério de Desenvolvimento Social e Combate à Fome), de mulheres e jovens a iniciativas de geração de emprego e renda da própria prefeitura e ao Programa de Educação de Jovens e Adultos, do Ministério da Educação. Em Aracaju, profissionais da Secretaria de Assistência Social (Centros de Referência de Assistência Social) faziam visitas domiciliares para encaminhar os membros das famílias à rede de proteção social municipal, com ações promovidas por organizações não-governamentais, como cursos profissionalizantes para jovens e beneficiários, ações de combate à violência contra mulheres e programas para crianças. Programas de alfabetização para idosos e de geração de renda destinavam-se, prioritariamente, ao público do Programa Bolsa Família.

Em conclusão, os dados desta revisão sugerem que, no tocante à articulação das políticas, programas e ações, existe uma baixa articulação entre os temas escolhidos, baixa articulação entre os órgãos executores e baixa articulação do Ministério da Saúde nas ações estudadas. Sugere também fragmentação e provável redundância de ações, concorrência entre órgãos públicos federais e baixa coordenação entre eles. Contudo, para uma análise adequada das relações e da articulação entre órgãos de vários setores e níveis federativos e para uma análise dos desafios para a intervenção intersetorial seria necessário outro desenho de investigação. O objetivo dessa revisão foi identificar, tanto em termos das diretrizes políticoprogramáticas quanto orçamentárias, programas e ações cujo objetivo é a intervenção sobre questões relacionadas aos DSS. Dentro do escopo da metodologia utilizada, baseada nas descrições dos programas e ações do PPA e de sua execução, tal como consta no Siafi, foi possível identificar as relações formais entre os órgãos responsáveis e executores de programas e ações nas áreas temáticas definidas, bem como a relevância orçamentária das ações selecionadas.

A despeito do caráter predominantemente descritivo desta revisão, é possível adiantar algumas implicações em termos de políticas públicas: 1) ampliar o patamar de investimento das ações estudadas; 2) promover a racionalização dos investimentos, concentrando-os nas ações que apresentaram maior consistência ao longo do tempo; 3) promover a articulação dessas ações; 4) integrar os vários órgãos federais envolvidos na execução de programas e ações, inclusive o Ministério da Saúde, em uma agenda comum, pautada pelos DSS. 


\subsection{A Institucionalização de Processos}

As intervenções sobre os DSS, com o objetivo de promover a eqüidade, devem contemplar os diversos níveis assinalados no modelo de Dahlgreen e Whitead, ou seja, devem incidir sobre os determinantes proximais, vinculados aos comportamentos individuais; intermediários, relacionados às condições de vida e trabalho; e distais, referentes à macroestrutura econômica, social e cultural.

São exemplos dessas políticas:

- políticas macroeconômicas e de mercado de trabalho, de proteção ambiental e de promoção de uma cultura de paz e solidariedade que visem a promover um desenvolvimento sustentável, reduzindo as desigualdades sociais e econômicas, as violências, a degradação ambiental e seus efeitos sobre a sociedade;

- políticas que assegurem a melhoria das condições de vida da população, garantindo a todos o acesso à água limpa, esgoto, habitação adequada, ambientes de trabalho saudáveis, serviços de saúde e de educação de qualidade, superando abordagens setoriais fragmentadas e promovendo uma ação planejada e integrada dos diversos níveis da administração pública;

- políticas que favoreçam ações de promoção da saúde, buscando estreitar relações de solidariedade e confiança, construir redes de apoio e fortalecer a organização e participação das pessoas e das comunidades em ações coletivas para melhoria de suas condições de saúde e bem-estar, especialmente dos grupos sociais vulneráveis;

- políticas que favoreçam mudanças de comportamento para a redução de riscos e aumento da qualidade de vida, mediante programas educativos, comunicação social, acesso facilitado a alimentos saudáveis, criação de espaços públicos para a prática de esportes e exercícios físicos, bem como proibição à propaganda do tabaco e do álcool em todas as suas formas.

Para que as intervenções nos diversos níveis do modelo de Dahlgren e Whitehead sejam viáveis, efetivas e sustentáveis, devem estar fundamentadas em três pilares básicos: a intersetorialidade; a participação social e as evidências científicas. Esquematicamente: 

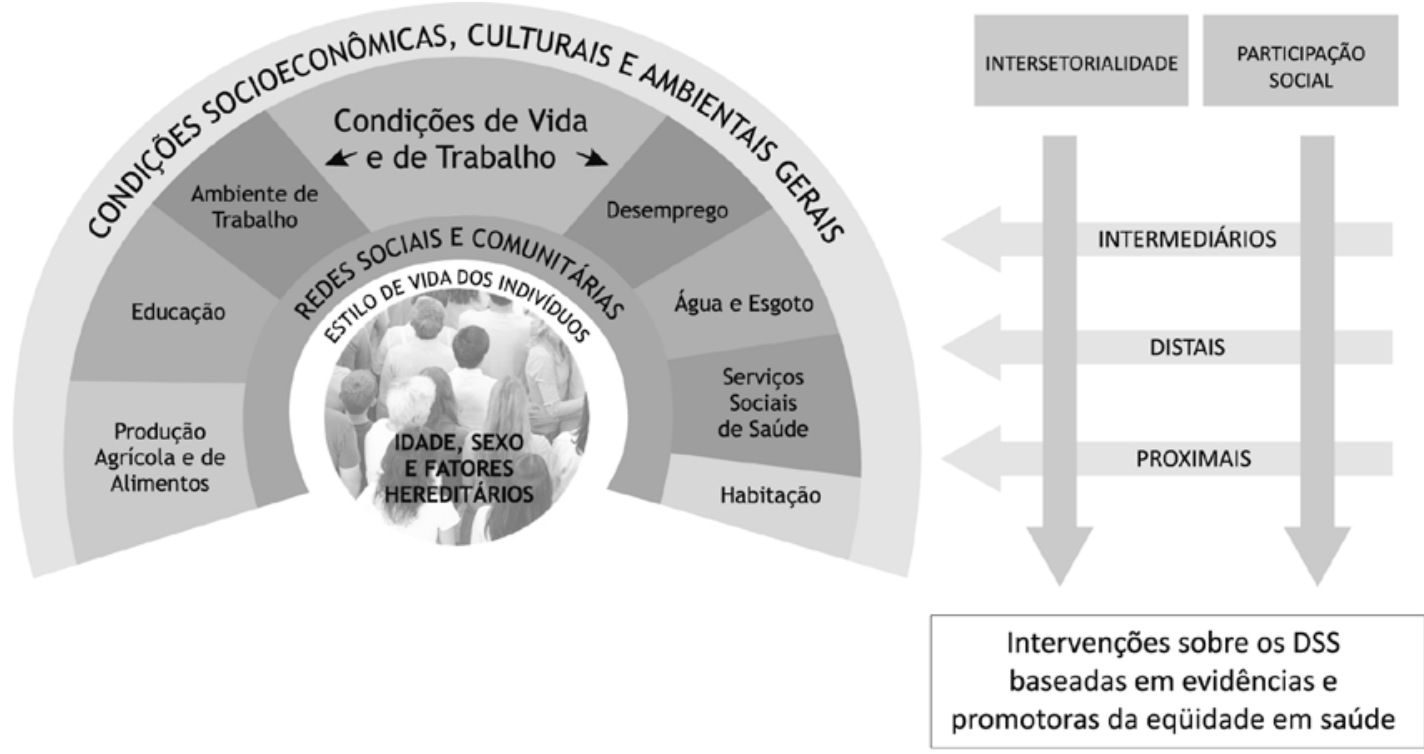

A atuação sobre os diversos níveis de DSS extrapola as competências e atribuições das instituições de saúde, obrigando a ação coordenada dos diversos setores e instâncias governamentais. Com vistas a institucionalizar um processo sustentável de coordenação das ações intersetoriais sobre os DSS, que permita superar os problemas de baixa articulação anteriormente mencionados, a CNDSS recomenda estabelecer, no âmbito da Casa Civil da Presidência da República, uma instância dedicada a Ações Intersetoriais para Promoção da Saúdee Qualidade de Vida. Esta instância deverá se responsabilizar pelo seguimento e avaliação de projetos, programas, intervenções ou políticas relacionadas aos DSS, desenvolvidas pelas diversas instituições que estejam nela representadas. Deverá, também: 1) propor mecanismos de coordenação das ações em curso; 2) constituir-se em uma instância de revisão e aprovação dessas ações, segundo seu impacto na saúde; 3) elaborar projetos de caráter estratégico e captar recursos para a implantação de novas intervenções intersetoriais sobre os DSS. Esta instância, eventualmente, poderá estar vinculada ou fazer parte da Câmara de Política Social, criada pelo Decreto 4.714 (30/05/2003), com a finalidade de "propor políticas públicas no âmbito das matérias relacionadas à área social do governo federal, visando à articulação das políticas e ao acompanhamento da implementação dos programas cujo escopo ultrapasse a competência de um único Ministério".

o Ministério da Saúde deverá funcionar como Secretaria Técnica/Executiva desta instância de coordenação de Ações Intersetoriais para Promoção da Saúde e Qualidade de vida da Casa Civil, através de uma nova Secretaria Nacional ou reconversão de uma Secretaria já existente. Esta nova estrutura do Ministério da Saúde será também responsável por coordenar as ações de Promoção de Saúde em nível do próprio Ministério, devendo, para isso, dispor de recursos humanos e financeiros adequados, suficiente flexibilidade, poder de convocatória e capacidade de projeção interna e externa. 
Recomenda-se que, em um primeiro momento, seja dada prioridade às ações intersetoriais relacionadas à promoção da saúde na infância e adolescência e ao fortalecimento das redes de municípios saudáveis já existentes no país, por meio de um programa continuado de disseminação seletiva de informações, capacitação de gestores municipais e criação de oportunidades e espaços de interação entre gestores para intercâmbio e avaliação de experiências relacionadas aos DSS. Ademais, propõe-se o fortalecimento de duas outras estratégias da promoção da saúde, experimentadas com sucesso em diferentes contextos: as escolas promotoras da saúde es ambientes de trabalho saudáveis.

Para a produção regular de evidências científicas sobre os DSS sugere-se a criação de um programa conjunto MCT/MS para apoio, através de editais periódicos, a projetos de pesquisa sobre DSS e para estabelecimento de redes de intercâmbio e colaboração entre pesquisadores e gestores, visando ao seguimento dos projetos e à utilização dos resultados. Sugere-se, também, estabelecer um sistema de monitoramento das iniqüidades em saúde e de avaliação de impacto das ações intersetoriais sobre a saúde.

Para a promoção da participação social, sugere-se fortalecer os mecanismos de gestão participativa, principalmente os Conselhos Municipais de Saúde. Isso pode se dar por meio de ações de disseminação seletiva de informações e capacitação de lideranças comunitárias com relação aos DSS, além de fortalecimento das ações de comunicação social referentes aos DSS. O objetivo final é conferir a necessária base de apoio político às ações sobre os DSS e 'empoderar' os grupos populacionais vulneráveis, de maneira que possam participar das decisões relativas à sua saúde e bem-estar. 


\section{REFERÊNCIAS E BIBLIOGRAFIA COMPLEMENTAR}

\section{Introdução}

\section{REFERÊNCIAS}

ADLER, N. Research on health inequities. In: NIH CONFERENCE ON UNDERSTANDING AND REDUCING DISPARITIES IN HEALTH: BEHAVIORAL AND SOCIAL SCIENCES RESEARCH CONTRIBUTIONS, 23-24 out 2006, Bethesda. Anais... Maryland: NIH, 2006.

ALMEIDA-FILHO, N. et al. Research on health inequities in Latin America and the Caribbean: bibliometric analysis (1971-2000) and descriptive content analysis (1971-1995). American Journal of Public Health, 93: 2.037-2.043, 2003.

BUSS, P. \& PEllegrini Filho, A. A saúde e seus determinantes. Physis, 17(1): 77-93, 2007.

DAHLGREN, G. \& WHITEHEAD, M. Policies and Strategies to Promote Social Equity in Health. Stockholm: Institute for Future Studies, 1991

PELLEGRINI FILHO, A. Ciencia en Pro de la Salud: notas sobre la organización de la actividad científica para el desarrollo de la salud en América Latina y el Caribe. Washington: OPS/ OMS, 2000.

RAWLS, J. A Theory of Justice. Cambridge: Harvard University Press, 1999.

SEN, A. Development as Freedom. New York: Anchor Books, 2000.

WHITEHEAD, M. The concepts and principles of equity and health. International Journal of Health Services, 22(3): 429-445, 1992.

\section{Análise da Situação de Saúde}

Situação e tendências da evolução demográfica, social e econômica

\section{REFERÊNCIAS}

BERQUÓ, E. \& CAVENAGHI, S. Fecundidade em declínio: breve nota sobre a redução no número médio de filhos por mulher no Brasil. Novos Estudos Cebrap, 74: 11-15, 2006.

BRITO, F. A Transição Demográfica no Brasil: as possibilidades e os desafios para a economia e a sociedade. Belo Horizonte: Cedeplar/UFMG, 2007.

CESSE, E. Epidemiologia e Determinantes Sociais das DCNT no Brasil, 2007. Tese de Doutorado, Recife: Centro de Pesquisas Aggeu Magalhães, Fundação Oswaldo Cruz. 
SIMÕES, C. C. S. A Urbanização Brasileira e Condições de Vida. Rio de Janeiro: Centro de Estudos de Políticas de População e Desenvolvimento, 1985.

\section{BIBLIOGRAFIA COMPLEMENTAR}

UNITED NATIONS DEVELOPMENT PROGRAM (UNDP). Human Development Report 2005. New York: International Cooperation at a Crossroads, 2005.

A estratificação socioeconômica e a saúde

\section{REFERÊNCIAS}

BARATA, R. B. et al. Health inequalities based on ethnicity in individuals aged 15 to 64, Brazil, 1998. Cadernos de Saúde Pública, 23(2): 305-313, 2007.

BARROS, M. B. A. et al. Desigualdades sociais na prevalência de doenças crônicas no Brasil, PNAD-2003. Ciência \& Saúde Coletiva, 11(4): 911-926, 2006.

DA CoSTA, J. S. et al. Prevalência de hipertensão arterial em adultos e fatores associados: um estudo de base populacional urbana em Pelotas, Rio Grande do Sul, Brasil. Arquivos Brasileiros de Cardiologia, 88(1): 59-65, 2007.

DACHS, J. N. W. Determinantes das desigualdades na auto-avaliação do estado de saúde no Brasil: análise dos dados da PNAD/1998. Ciência \& Saúde Coletiva, 7(4): 641-657, 2002 .

DIDERICHSEN, F. \& HALLQVIST, J. Social inequalities in health: some methodological considerations for the study of social position and social context. In: ARVE-PARÈS, B. (Ed.) Inequality in Health: a swedish perspective. Stockholm: Swedish Council for Social Research, 1998.

DIDERICHSEN, F., EVANS, T. \& WHITEHEAD, M. The Social Basis of Disparities in Health in Challenging Inequities in Health: from ethics to action. Oxford: Oxford University Press, 2001.

GAWRYSZEWSKI, V. P. \& COSTA, L. S. Homicídios e desigualdades sociais no município de São Paulo. Revista de Saúde Pública, 39(2): 191-197, 2005.

ISHITANI, L. H. et al. Desigualdade social e mortalidade precoce por doenças cardiovasculares no Brasil. Revista de Saúde Pública, 40(4): 684-691, 2006.

KILSZTAJN, S. et al. Vítimas da cor: homicídios na região metropolitana de São Paulo, Brasil, 2000. Cadernos de Saúde Pública, 21(5): 1.408-1.415, 2005.

LESSA, I. et al. Hipertensão arterial na população adulta de Salvador (BA) - Brasil. Arquivos Brasileiros de Cardiologia, 87(6): 747-756, 2006.

LIMA-COSTA, M. F.; MATOS, D. L. \& CAMARANO, A. A. Evolução das desigualdades sociais em saúde entre idosos e adultos brasileiros: um estudo baseado na Pesquisa Nacional por Amostra de Domicílios (Pnad 1998, 2003). Ciência \& Saúde Coletiva, 11(4): 941-950, 2006. 
MARINS, V. M. R. et al. The association between socioeconomic indicators and cardiovascular disease risk factors in Rio de Janeiro, Brazil. Journal of Biosocial Science, 39: 221-229, 2007.

MESSIAS, E. Income inequality, illiteracy rate, and life expectancy in Brazil. American Journal of Public Health, 93(8): 1.294-1.296, 2003.

Condições de vida, ambiente e trabalho

Alimentação

\section{REFERÊNCIAS}

BARBoSA, A. R. et al. Estado nutricional e desempenho motor de idosos de São Paulo. Revista da Associação Médica Brasileira, 53(1): 75-79, 2007.

BARRETO, S. M.; PASSOS, V. M. \& LIMA-COSTA, M. F. Obesity and underweight among Brazilian elderly: the Bambuí health and aging study. Cadernos de Saúde Pública, 19(2): 605-612, 2003.

BATISTA-FILHO, M. \& RISSIN, A. A transição nutricional no Brasil: tendências regionais e temporais. Cadernos de Saúde Pública, 19, supl. 1: S181-S191, 2003.

CAMPOS, M. A. G. et al. Estado nutricional e fatores associados em idosos. Revista da Associação Médica Brasileira, 52(4): 214-221, 2006.

CUNHA, A. S. \& SICHIERI, R. Trends in underweight, overweight and body mass index among elderly population of Brazil. The Journal of Nutrition, Health \& Aging, 11(1): 15-19, 2007.

DOAK, C. M. et al. The dual burden household and the nutrition transition paradox. International Journal of Obesity, 29(1): 129-136, 2005.

DUTRA, C. L.; ARAÚJO, C. L. \& BERTOLDI, A. D. Prevalência de sobrepeso em adolescentes: um estudo de base populacional em uma cidade no Sul do Brasil. Cadernos de Saúde Pública, 22(1): 151-162, 2006.

INSTITUTO NACIONAL DO CÂNCER (INCA). Inquérito Domiciliar sobre Comportamentos de Risco e Morbidade Referida de Doenças e Agravos Não Transmissiveis: Brasil, 15 capitais e Distrito Federal 2002-2003. Rio de Janeiro: Inca, 2006.

MAGAlHÃES, V. C. \& MENDONÇA, G. S. A. Prevalência e fatores associados a sobrepeso e obesidade em adolescentes de 15 a 19 anos das regiões Nordeste e Sudeste do Brasil, 1996 a 1997. Cadernos de Saúde Pública, 19, supl. 1: S129-S139, 2003.

MONTEIRO, C. A.; CONDE, W. L. \& CASTRO, I. R. R. A tendência cambiante da relação entre escolaridade e risco de obesidade no Brasil (1975-1997). Cadernos de Saúde Pública, 19, supl. 1: S67-S75, 2003. 
MONTEIRO, C. A.; CONDE, W. L. \& POPKIN, B. M. Symposium: obesity in developing countries: biological and ecological factors. Independent effects of income and education on the risk of obesity in the brazilian adult population. The Journal of Nutrition, 131(3): 881S-886S, 2001.

MONTEIRO, C. A.; CONDE, W. L. \& POPKIN, B. M. Income-specific trends in obesity in Brazil: 1975-2003 American Journal of Public Health, 97(10): 1.808-1.812, 2007.

MONTEIRO, C. A. et al. Obesity and inequities in health in the developing world. International Journal of Obesity, 28: 1.181-1.186, 2004a.

MONTEIRO, C. A. et al. Socioeconomic status and obesity in adult populations of developing countries: a review. Bulletin of the World Health Organization, 82(12): 940-946, 2004b.

VEIGA, G. V.; CUNHA, A. S. \& SICHIERI, R. Trends in overweight among adolescents living in the poorest and richest regions of Brazil. American Journal of Public Health, 94(9): $1.544-1.548,2004$.

\section{Saneamento e habitação}

\section{REFERÊNCIAS}

BARRETO, M. et al. Effect of city-wide sanitation programme on reduction in rate of chilhood diarrhoea in northeast Brazil: assessment by two cohort studies. The Lancet, 370(9.599): $1.592-1.593,2007$.

NERI, M. C. Trata Brasil: saneamento e saúde. Rio de Janeiro: Editora FGV, Ibre, CPS, 2007.

Condições de emprego, trabalho e saúde

\section{REFERÊNCIAS}

ANTÃo, V. C. S. Silicose em Artesãos de Pedras Ornamentais no Município de Petrópolis, 2003. Tese de Doutorado, São Paulo: Faculdade de Medicina, Universidade de São Paulo.

ARAÚJO, S. A. Perda auditiva induzida pelo ruído em trabalhadores de metalúrgica. Revista Brasileira de Otorrinolaringologia, 68(1): 47-52, 2002.

AZEVEDo, A. P. M. Efeito de Produtos Químicos e Ruido na Gênese da Perda Auditiva Ocupacional, 2004. Dissertação de Mestrado, Rio de Janeiro: Escola Nacional de Saúde Pública, Fundação Oswaldo Cruz.

BARATA, R. C. B.; RIBEIRO, M. C. S. A. \& MORAES, J. C. Acidentes de trabalho referidos por trabalhadores moradores em área urbana no interior de São Paulo em 1994. Informe Epidemiológico do SUS, 9(3): 199-210, 2000.

BARATA, R. C. B. et al. Intra-urban differentials in death rates from homicide in the city of São Paulo, Brazil, 1988-1994. Social Science \& Medicine, 47(1): 19-23, 1998. 
BARBIN JR., H. \& MARTINI, A. Ethno prevention and community participation in The Alto Jura Extractive Reserve. OSH \& Development, (8): 41-50, 2006.

BINDER, M. C. \& CORDEIRO, R. Sub-registro de acidente do trabalho em localidade do Estado de São Paulo,1997. Revista de Saúde Pública, 37(4): 409-416, 2003.

BON, A. M. T. Exposição Ocupacional à Sílica e Silicose entre Trabalhadores de Marmorarias, no Município de São Paulo, 2006. Tese de Doutorado, São Paulo: Faculdade de Saúde Pública, Universidade de São Paulo.

BRANT, L. C. \& DIAS, E. C. Trabalho e sofrimento em gestores de uma empresa em reestruturação. Cadernos de Saúde Pública, 20(4): 942-949, 2004.

BRASIL. Ministério do Meio Ambiente. Informativo do Ministério do Meio Ambiente. Brasília: Ministério do Meio Ambiente, 2000.

CARNEIRO, A. P. S. et al. Perfil de 300 trabalhadores expostos à sílica atendidos ambulatorialmente em Belo Horizonte. Jornal Brasileiro de Pneumologia, 28(6): 329$334,2002$.

CASTRO, H. A.; SILVA, C. G. \& VICENTIN, G. Estudo das internações hospitalares por pneumoconioses no Brasil, 1984-2003. Revista Brasileira de Epidemiologia, 8(2): 150$160,2005$.

CASTRO, H. A. et al. Perfil respiratório de 457 trabalhadores expostos à poeira de sílica-livre no Estado do Rio de Janeiro. Pulmão RJ, 13(2): 81-85, 2004.

CASTRO, H. A. et al. A vigilância ambiental em saúde de populações expostas ao amianto no Brasil. Cadernos de Saúde Coletiva, 13(1): 195-208, 2005.

DINIZ, E. P. H.; ASSUNÇÃO, A. A. \& LIMA, F. P. A. Prevenção de acidentes: o reconhecimento das estratégias operatórias dos motociclistas profissionais como base para a negociação de acordo coletivo. Ciência \& Saúde Coletiva, 10(4): 905-916, 2005.

FACHINI, L. et al. Sistema de informação em saúde: desafios e perspectivas para o SUS. Ciência \& Saúde Coletiva, 10(4): 857-867, 2005.

FARIA, N. M. X.; FASSA, A. C. \& FACHINNI, L. A. Intoxicação por agrotóxicos no Brasil: os sistemas oficiais de informação e desafios para realização de estudos epidemiológicos. Ciência \& Saúde Coletiva, 12(1): 25-38, 2007.

FARIA, N. M. X. et al. Trabalho rural, exposição a poeiras e sintomas respiratórios entre agricultores. Revista de Saúde Pública, 40(5): 827-836, 2006.

FEHLBERG, M. F.; SANTOS, I. \& TOMASI, E. Prevalência e fatores associados a acidentes de trabalho em zona rural. Revista de Saúde Pública, 35(3): 269-275, 2001.

FERNANDES, A. L. G.; STELMACH, R. \& ALGRANTI, E. Asma ocupacional. Jornal Brasileiro de Pneumologia, 32, supl. 2: S27-S34, 2006. 
GIATTI, L. \& BARRETO, S. M. Situação do indivíduo no mercado de trabalho e iniqüidade em saúde no Brasil. Revista de Saúde Pública, 40(1): 99-106, 2006.

GÓMEZ, C. \& LACAZ, F. A. C. Saúde do trabalhador: novas-velhas questões. Ciência \& Saúde Coletiva, 10(4): 797-807, 2005.

GUERRA, M. R. et al. Prevalência de perda auditiva induzida por ruído em empresa metalúrgica. Revista de Saúde Pública, 39(2): 238-244, 2005.

GUIMARÃES, L. A. \& TEIXEIRA, L. N. Transtornos mentais e trabalho em turnos alternados em operários de mineração de ferro em Itabira (MG). Jornal Brasileiro de Psiquiatria, 52(4): 283-289, 2003.

HENNINGTON, E. A.; CORDEIRO, R. \& MOREIRA FILHO, D. C. Trabalho, violência e morte em Campinas, São Paulo, Brasil. Cadernos de Saúde Pública, 20(2): 610-617, 2004.

LUDERMIR, A. B. \& LEWIS, G. Informal work and common mental disorders. Social Psychiatry and Psychiatric Epidemiology, 38(9): 485-489, 2003.

MACHADO, J. M. H. \& GÓMEZ, C. M. Acidentes de trabalho: uma expressão da violência social. Cadernos de Saúde Pública, 10, supl. 1: 74-87, 1994.

MELLO, A. P. \& WAISMANN, W. Exposição ocupacional ao ruído e químicos industriais e seus efeitos no sistema auditivo: revisão da literatura. Arquivos Internacionais de Otorrinolaringologia, (83): 226-234, 2004.

MELo, M. G. M. Estudo das Dermatoses em Trabalhadores de uma Indústria Farmacêutica, 1999. Dissertação de Mestrado, Rio de Janeiro: Escola Nacional de Saúde Pública, Fundação Oswaldo Cruz.

MENDES, R. Asbesto (amianto) e doença: revisão do conhecimento científico e fundamentação para uma urgente mudança da atual política brasileira sobre a questão. Cadernos de Saúde Pública, 17(1): 7-29, 2001.

MOREIRA, J. C. et al. Avaliação integrada do impacto do uso de agrotóxicos sobre a saúde humana em uma comunidade agrícola de Nova Friburgo, RJ. Ciência \& Saúde Coletiva, 7(2): 299-312, 2002.

MUROFUSE, N. T. \& MARZIALE, M. H. P. Doenças do sistema osteomuscular em trabalhadores de enfermagem. Revista Latino-americana de Enfermagem, 13(3): 364-373, 2005.

NOBRE, L. C. C. Trabalho Precário e Mortes por Acidentes de Trabalho: a outra face da violência, 2007. Tese de Doutorado, Salvador: Universidade Federal da Bahia.

PORTO, L. A. et al. Associação entre distúrbios psíquicos e aspectos psicossociais do trabalho de professores. Revista de Saúde Pública, 40(5): 818-826, 2006.

SAKAE, T. M. et al. Perfil epidemiológico e audiológico dos trabalhadores atendidos pelo Serviço Social da Indústria de Blumenau - Santa Catarina. ACM Arquivos Catarinenses de Medicina, 35(2): 28-34, 2006. 
SALERNO, V. L. Considerações Sobre a Terceirização e as Possíveis Implicações nos Riscos de Acidentes de Trabalho Fatais: estudo da região de Campinas no período de 1990 a 1995 , 1998. Dissertação de Mestrado, São Paulo: Faculdade de Saúde Pública, Universidade de São Paulo.

SANTANA, V. S. \& LOOMIS, D. Informal jobs and nonfatal occupational injuries. The Annals of Occupational Hygiene, 48(2): 147-157, 2004.

SANTANA, V. S.; NOBRE, L. \& WALDVOGEL, B. C. Acidentes de trabalho no Brasil entre 1994 e 2004: uma revisão. Ciência \& Saúde Coletiva, 10(4): 841-856, 2005.

SANTANA, V. S. et al. Informal Jobs: another occupational hazard for women's mental health. International Journal of Epidemiology, 26(6):1.236-1.242, 1997.

SHILLING, R. S. F. More effective prevention in occupational health practice. The Journal of the Society of Occupational Medicine, 39: 71-79, 1984.

SILVA, J. M. et al. Agrotóxico e trabalho: uma combinação perigosa para a saúde do trabalhador. Ciência \& Saúde Coletiva, 10(4): 891-903, 2005.

WALDVOGEL, B. C. Acidentes de Trabalho: os casos fatais, a questão da identificação e da mensuração. Belo Horizonte: Segrac, 2002.

WÜNSCH FILHO, V. Reestruturação produtiva e acidentes de trabalho no Brasil: estrutura e tendências. Cadernos de Saúde Pública, 15(1): 41-51, 1999.

WÜNSCH FILHO, V. Perfil epidemiológico dos trabalhadores. Revista Brasileira de Medicina do Trabalho, 2(2): 103-117, 2004.

\section{BIBLIOGRAFIA COMPLEMENTAR}

CONCEIÇÃO, P. S. A. et al. Acidentes do trabalho atendidos em Serviço de Emergência. Cadernos de Saúde Pública, 19(1): 111-117, 2003.

CORDEIRO, R. et al. Subnotificação de acidentes do trabalho não fatais em Botucatu, São Paulo, 2002. Revista de Saúde Pública, 39(2): 254-260, 2005.

CORREA, P. R. L. \& ASSUNÇÃO, A. A. A subnotificação de mortes por acidentes do trabalho: estudo em três Bancos de Dados. Epidemiologia e Serviços de Saúde, 12(4): 203-212, 2003

GASPARINI, S. M.; BARRETO, S. M. \& ASSUNÇÃO, A. A. Prevalência de transtornos mentais comuns em professores da rede municipal de Belo Horizonte, Minas Gerais, Brasil. Cadernos de Saúde Pública, 22(12): 2.679-2.691, 2006.

RIGOTTO, R. M. Saúde ambiental \& saúde do trabalhador: uma aproximação promissora entre o verde e o vermelho. Revista Brasileira de Epidemiologia, 6(4): 388-404, 2006.

VIANNA, M. I.; SANTANA, V. S. \& LOOMIS, D. Occupational exposures to acid mists and gases and ulcerative lesions of the oral mucosa. American Journal of Industrial Medicine, 45: 238-245, 2004. 
Ambiente e Saúde

\section{REFERÊNCIAS}

BRAGA, A. L. F. et al. Air pollution and pediatric respiratory hospital admissions in São Paulo, Brazil. Journal of Environmental Medicine, 1(2): 95-102, 1999.

BRAGA, A. L. F. et al. Health effects of air pollution exposure on children and adolescents in São Paulo, Brazil. Pediatric Pulmonology, 31: 106-113, 2001.

BUSSAMRA, M. H. F. et al. Educational program for some-induced respiratory diseases in Brazilian Amazon: assessing knownledge about asthma. The Journal of Asthma, 41(1): 35-41, 2004.

CASTRO, M. C. et al. Malaria risk on the Amazon frontier. Proceedings of the National Academy of Sciences of the United States of America, 103(7): 2.452-2.457, 2006.

CELENTANO, D. \& VERÍSSIMO, A. A Amazônia e os objetivos do milênio. Belém: Imazon, 2007. (Série O Estado da Amazônia - Indicadores)

CONCEIÇÃO, G. M. et al. Air pollution and child mortality: a time-series study in São Paulo, Brazil. Environmental Health Perspectives, 109, supl. 3: 347-350, 2001.

FARHAT, S. C. L. et al. Effect of air pollution on pediatric respiratory emergency room visits and hospital admissions. Brazilian Journal of Medical and Biological Research, 38(2): 227-235, 2005.

FREITAS, C. et al. Respiratory diseases and particulate air pollution in the São Paulo Metropolitan Region (SPMR), Brazil. Epidemiology, 13(4): 148, 2002.

FUNDAÇÃo SOS MATA ATLÂNTICA. Atlas da Mata Atlântica 2000-2005. São Paulo: Inpe, 2007.

GODLESKI, J. J. et al. Mechanisms of morbidity and mortality from exposure to ambient air particles. Research Report (Health Effects Institute), 91: 5-103, 2000.

GOUVEIA, N.; BREMER, S. A. \& NOVAES, H. M. Association between ambient air pollution and birth weight in Sao Paulo, Brazil. Journal of Epidemiology and Community Health, 58(1): 11-17, 2004.

INSTITUTO NACIONAL DE PESQUISAS ESPACIAS (INPE/PRODES). Monitoramento da Floresta Amazônica Brasileira por Satélite: dados de entrada usados para o cálculo das estimativas anuais 2000-2007. São José dos Campos: Inpe/Prodes, 2007.

LIN, C. A. et al. Air pollution and respiratory illness of children in Sao Paulo, Brazil. Paediatric and Perinatal Epidemiology, 13(4): 475-488, 1999.

LIN, C. A. et al. Association between air pollution and ischemic cardiovascular emergency room visits. Environmental Research, 92(1): 57-63, 2003. 
LIN, C. A. et al. Air pollution and neonatal deaths in Sao Paulo, Brazil. Brazilian Journal of Medical and Biological Research, 37(5): 765-770, 2004.

MARTINS, L. C. et al. Poluição atmosférica e atendimentos por pneumonia e gripe em São Paulo, Brasil. Revista de Saúde Pública, 36(1): 88-94, 2002a.

MARTINS, L. C. et al. Air pollution and emergency room visits due to pneumonia and influenza in Sao Paulo, Brazil. Journal of Occupational and Environmental Medicine, 44(7): 622627, $2002 b$.

MARTINS, L. C. et al. The effects of air pollution on cardiovascular diseases: lag structures. Revista de Saúde Pública, 40(4): 677-683, 2006.

MARTINS, M. C. et al. Influence of socioeconomic conditions on air pollution adverse health effects in elderly people: an analysis of six regions in Sao Paulo, Brazil. Journal of Epidemiology and Community Health, 58(1): 41-46, 2004.

MIRAGLIA, S. G. E. K. et al. Analysis of the impact of fuel consumption on mortality rates in São Paulo. In: SUCHAROV, L. \& BIDINI, G. (Eds.) Urban Transport and the Environment for the 21st Century. Southampton: Computational Mechanics Publication, 1997.

PEREIRA, L. A. A. et al. Association between air pollution and intrauterine mortality in São Paulo, Brazil. Environmental Health Perspectives, 106: 325-329, 1998.

SALDIVA, P. H. et al. Association between air pollution and mortality due to respiratory diseases in children in São Paulo, Brazil: a preliminary report. Environmental Research, 65(2): 218-225, 1994.

SALDIVA, P. H. et al. Air pollution and mortality in elderly people: a time-series study in São Paulo, Brazil. Archives of Environmental Health, 50(2): 159-163, 1995.

SANTOS, U. P. et al. Effects of air pollution on blood pressure and heart rate variability: a panel study of vehicular traffic controllers in the city of São Paulo, Brazil. European Heart Journal, 26(2): 193-200, 2005.

SOBRAL, H. R. Air pollution and respiratory diseases in children in São Paulo, Brazil. Social Science \& Medicine, 29(8): 959-964, 1989.

VIEIRA, E. M. et al. Características do uso de métodos anticoncepcionais no Estado de São Paulo. Revista de Saúde Pública, 36(3): 263-270, 2001.

VITTOR, A. Y. et al. The Impact of deforestation on malaria risk: association between humanbiting rates of the major South American malaria vector, anopheles darlingi, and the extent of deforestation in the Peruvian Amazon. The American Journal of Tropical Medicine and Hygiene, 2006.

WORLD HEALTH ORGANIZATION (WHO). Fact sheets - air pollution, 2000. Disponível em: <www.who.int/mediacentre/factsheets/fs292/en/index.html> 


\section{BIBLIOGRAFIA COMPLEMENTAR}

BRASIL. Ministério da Saúde. Brasil 2006: uma análise da situação de saúde no Brasil. Brasília: Ministério da Saúde, 2006.

MACHADO, R. B. et al. Estimativas de Perda da Área do Cerrado Brasileiro. Brasília: Conservation International/Programa do Brasil, 2004. Disponível em: <www.aja.org.br/ publications/RelatDesmatamCerrado.pdf $>$

Acesso a Serviços de Saúde

\section{REFERÊNCIAS}

CAPILHEIRA, M. F. \& SANTOS, I. S. Fatores individuais associados à utilização de consultas médicas por adultos. Revista de Saúde Pública, 40(3): 436-443, 2006.

CASTRO, M. S. M.; TRAVASSOS, C. \& CARVALHO, M. S. Efeito da oferta de serviços de saúde no uso de internações hospitalares no Brasil. Revista de Saúde Pública, 39(2): 277-284, 2005.

LEAL, M. C. et al. Healthy lifestyles and access to periodic health exams among Brazilian women. Cadernos de Saúde Pública, 21, supl.: S78-S88, 2005.

LIMA-COSTA, M. F. \& MATOS, D. L. Prevalência e fatores associados à realização da mamografia na faixa etária de 50-69 anos: um estudo baseado na Pesquisa Nacional por Amostra de Domicílios (2003). Cadernos de Saúde Pública, 23(7): 1.665-1.673, 2007.

LIMA-COSTA, M. F.; MATOS, D. L. \& CAMARANO, A. A. Evolução das desigualdades sociais em saúde entre idosos e adultos brasileiros: um estudo baseado na Pesquisa Nacional por Amostra de Domicílios (Pnad 1998, 2003). Ciência \& Saúde Coletiva, 11(4): 941950, 2006.

MARTINS, L. F. L.; THULER, L. C. S. \& VALENTE, J. G. Cobertura do exame de Papanicolaou no Brasil e seus fatores determinantes: uma revisão sistemática da literatura. Revista Brasileira de Ginecologia e Obstetrícia, 27(8): 485-492, 2005.

NOVAES, H. M. D.; BRAGA, P. E. \& SCHOUT, D. Fatores associados à realização de exames preventivos para câncer nas mulheres brasileiras, Pnad 2003. Ciência \& Saúde Coletiva, 11(4): 1.023-1.035, 2006.

OLIVEIRA, L. H. et al. Human papillomavirus status and cervical abnormalities in women from public and private health care in Rio de Janeiro State, Brazil. Revista do Instituto de Medicina Tropical de São Paulo, 48(5): 279-285, 2006.

ORGANIZAÇÃO PAN-AMERICANA DA SAÚDE (OPAS). Saúde nas Américas. Washington: Opas, 2007. v. 1. (Publicação Científica e Técnica, 622) 
PEREIRA, C. R. et al. Human papillomavirus prevalence and predictors for cervical cancer among high-risk women from Rio de Janeiro, Brazil. International Journal of Gynecological Cancer, 17(3): 651-660, 2007.

PESSOTO, U. C. et al. Desigualdades no acesso e utilização dos serviços de saúde na Região Metropolitana de São Paulo. Ciência \& Saúde Coletiva, 12(2): 351-362, 2007.

PINHO, V. F. \& COUTINHO, E. S. Variáveis associadas ao câncer de mama em usuárias de unidades básicas de saúde. Cadernos de Saúde Pública, 23(5): 1.061-1.069, 2007.

PINHO, A. A. et al. Cobertura e motivos para a realização ou não do teste de Papanicolaou no município de São Paulo. Cadernos de Saúde Pública, 19, supl. 2: 303-313, 2003.

QUADROS, C. A.; VICTORA, C. G. \& DA COSTA, J. S. Coverage and focus of a cervical cancer prevention program in southern Brazil. Revista Panamericana de Salud Pública, 16(4): 223-232, 2004.

RIBEIRO, M. C. S. A et al. Perfil sociodemográfico e padrão de utilização de serviços de saúde para usuários e não-usuários do SUS - Pnad 2003. Ciência \& Saúde Coletiva, 11(4): 1.011-1.022, 2006.

TRAVASSOS, C. \& MARTINS, M. Uma revisão sobre os conceitos de acesso e utilização de serviços de saúde. Cadernos de Saúde Pública, 20, supl. 2: S190-S198, 2004.

TRAVASSOS, C.; OLIVEIRA, E. X. G. \& VIACAVA, F. Desigualdades geográficas e sociais no acesso aos serviços de saúde no Brasil: 1998 e 2003. Ciência \& Saúde Coletiva, 11(4): 975-986, 2006.

VIACAVA, F; SOUZA JR., P. R. B. \& SZWARCWALD, C. L. Coverage of the Brazilian population 18 years and older by private health plans: an analysis of data from the World Health Survey. Cadernos de Saúde Pública, 21, supl. 1: S119-S128, 2005.

VIEIRA, E. M. et al. Características do uso de métodos anticoncepcionais no Estado de São Paulo. Revista de Saúde Pública, 36(3): 263-270, 2001.

Acesso à Informação

REFERÊNCIAS

BRANCO, M. A. F. Informação e Saúde: uma ciência e suas políticas em uma nova era. Rio de Janeiro: Editora Fiocruz, 2006.

ENG, T. R. et al. Access to health information and support: a public highway or a private road? Jama, 280(15): 1.371-1.375, 1998. 
PELLEGRINI FILHO, A. Inequidades de acceso a la información e inequidades de salud. Revista Panamericana de Salud Pública, 11(5/6): 409-413, 2002.

Redes Sociais, Comunitárias e Saúde

\section{REFERÊNCIAS}

ALMEIDA, A. C. A Cabeça do Brasileiro. Rio de Janeiro: Record, 2007.

ANDRADE, C. R. et al. Apoio social e auto-exame das mamas no Estudo Pró-Saúde. Cadernos de Saúde Pública, 21: 379-386, 2005.

COSTA, A. G. \& LUDERMIR, A. B. Transtornos mentais comuns e apoio social: estudo em comunidade rural da Zona da Mata de Pernambuco, Brasil. Cadernos de Saúde Pública, 21: 73-79, 2005.

DE ANTONI, C.; BARONE, L. R. \& KOLLER, S. H. Indicadores de risco e de proteção em famílias fisicamente abusivas. Psicologia: teoria e pesquisa, 23(2): 125-132, 2007.

KAWACHI, I. et al. Social capital, income inequality and mortality. In: KAWACHI, I.; KENNEDY, B. P. \& WILKINSON, R. G. (Eds.) The Society and Population Health Reader. New York: The New Press, 1999.

LIMA-COSTA, M. A.; FIRMO, J. O. A. \& UCHÔA, E. Differences in self-rated health among older adults according to socioeconomic circumstances: the Bambuí Health and Aging Study. Cadernos de Saúde Pública, 21(3): 830-839, 2005.

MORAES, J. F.; DE AZEVEDO \& SOUZA, V. B. Factors associated with the successful aging of the socially-active elderly in the metropolitan region of Porto Alegre. Revista Brasileira de Psiquiatria, 27(4): 302-308, 2005.

PATUSSI, M. P.; HARDY, R. \& SHEIHAM, A. The potential impact of neighborhood empowerment on dental caries among adolescents. Community Dentistry and Oral Epidemiology, 34(5): 344-350, 2006.

SHERBOURNE, C. D. \& STEWART, A. L. The MOS social support survey. Social Science \& Medicine, 32: 705-714, 1991.

SHERMAN, A. M. Social relations and depressive symptoms in older adults with knee osteoarthritis. Social Science \& Medicine, 56: 247-257, 2003.

Comportamentos, estilos de vida e saúde

Dieta

\section{REFERÊNCIAS}

ALVES, A. L. S. A. et al. Padrões alimentares de mulheres adultas residentes em área urbana no Sul do Brasil. Revista de Saúde Pública, 40(5): 865-873, 2006. 
COITINHO, D.; MONTEIRO, C. A. \& POPKIN, B. M. What Brazil is doing to promote healthy diets and active lifestyles. Public Health Nutrition, 5(1A): 263-267, 2002.

CLARO, R. M. et al. Renda, preço dos alimentos e participação de frutas e hortaliças na dieta. Revista de Saúde Pública, 41(4): 557-564, 2007.

INSTITUTO NACIONAL DO CÂNCER (INCA). Inquérito Domiciliar sobre Comportamentos de Risco e Morbidade Referida de Doenças e Agravos Não Transmissiveis: Brasil, 15 capitais e Distrito Federal 2002-2003. Rio de Janeiro: Inca, 2006.

JAIME, P. C. \& MONTEIRO, C. A. Fruit and vegetable intake by Brazilian adults, 2003. Cadernos de Saúde Pública, 21, supl.: S19-S24, 2005.

JAIME, P. C. et al. Educação nutricional e consumo de frutas e hortaliças: ensaio comunitário randomizado. Revista de Saúde Pública, 41(1): 154-157, 2007.

LEVY-COSTA, R. B. et al. Disponibilidade domiciliar de alimentos no Brasil: distribuição e evolução (1974-2003). Revista de Saúde Pública, 39(4): 530-540, 2005.

NEUTZLING, M. B. et al. Freqüência de consumo de dietas ricas em gordura e pobres em fibra entre adolescentes. Revista de Saúde Pública, 41(3): 336-342, 2007.

SICHIERI, R.; CASTRO, J. F. G. \& MOURA, A. S. Fatores associados ao padrão de consumo alimentar da população brasileira urbana. Cadernos de Saúde Pública, 19, supl. 1: S47S53, 2003.

\section{BIBLIOGRAFIA COMPLEMENTAR}

COSTA, R. S. et al. Associação entre fatores sociodemográficos e prática de atividade física de lazer no estudo Pró- Saúde. Cadernos de Saúde Pública, 19: 1.095-1.105, 2003.

Atividade Física

REFERÊNCIAS

AZEVEDO, M. R. et al. Gender differences in leisure-time physical activity. International Journal of Public Health, 52(1): 8-15, 2007.

BARETTA, E.; BARETTA, M. \& PERES, K. G. Nível de atividade física e fatores associados em adultos no Município de Joaçaba, Santa Catarina, Brasil. Cadernos de Saúde Pública, 23(7): 1.595-1.602, 2007.

DIAS-DA-COSTA, J. S. et al. Epidemiology of leisure-time physical activity: a populationbased study in southern Brazil. Cadernos de Saúde Pública, 21(1): 275-282, 2005.

HALLAL, P. C. et al. Prevalência de sedentarismo e fatores associados em adolescentes de 1012 anos de idade. Cadernos de Saúde Pública, 22 (6): 1.277-1.287, 2006.

HALlAL, P. C. et al. Evolução da pesquisa epidemiológica em atividade física no Brasil: revisão sistemática. Revista de Saúde Pública, 41(3): 453-460, 2007. 
INSTITUTO NACIONAL DO CÂNCER (INCA). Inquérito Domiciliar sobre Comportamentos de Risco e Morbidade Referida de Doenças e Agravos Não Transmissíveis: Brasil, 15 capitais e Distrito Federal 2002-2003. Rio de Janeiro: Inca, 2006.

MASSON, C. R. et al. Prevalência de sedentarismo nas mulheres adultas da cidade de São Leopoldo, Rio Grande do Sul, Brasil. Cadernos de Saúde Pública, 21(6): 1.685-1.695, 2005.

MATSUDO, S. M. M. et al. Nível de atividade física da população do Estado de São Paulo: análise de acordo com o gênero, idade, nível socioeconômico, distribuição geográfica e de conhecimento. Revista Brasileira de Ciência e Movimento, 10(4): 41-50, 2002.

MONTEIRO, C. A. et al. A descriptive epidemiology of leisure-time physical activity in Brazil, 1996-1997. Revista Panamericana de Salud Pública, 14(4): 246-254, 2003.

OEHLSCHLAEGER, M. H. K. et al. Prevalência e fatores associados ao sedentarismo em adolescentes de área urbana. Revista de Saúde Pública, 38(2): 157-163, 2004.

PITANGA, F. J. \& LESSA, I. Prevalência e fatores associados ao sedentarismo no lazer em adultos. Cadernos de Saúde Pública, 21(3): 870-877, 2005.

SALLES-COSTA, R. et al. Gênero e prática de atividade física de lazer. Cadernos de Saúde Pública, 19, supl. 2: S325-S333, 2003.

Tabagismo e alcoolismo

\section{REFERÊNCIAS}

ALMEIDA-FILHO, N. et al. Alcohol drinking patterns by gender, ethnicity, and social class in Bahia, Brazil. Revista de Saúde Pública, 38(1): 45-54, 2004.

BLOOMFIELD, K. et al. Social inequalities in alcohol consumption and alcohol-related problems in the study countries of the EU concerted action 'Gender, Culture and Alcohol Problems: a multi-national study'. Alcohol and Alcoholism, 41(1), supl.: 26-36, 2006.

BONOMO, Y. A. et al. Teenage drinking and the onset of alcohol dependence: a cohort study over seven years. Addiction, 99(12): 1.520-1.528, 2004.

DE MICHELI, D. \& FORMIGONI, M. L. Drug use by Brazilian students: associations with family, psychosocial, health, demographic and behavioral characteristics. Addiction, 99(5): 570-578, 2004.

DIAS-DA-COSTA, J. S. et al. Heavy alcohol consumption and associated factors: a populationbased study. Revista de Saúde Pública, 38(2): 45-54, 2004.

GIGLIOTTI, A. \& LARANJEIRA, R. Habits, attitudes and beliefs of smokers in four Brazilian capitals. Revista Brasileira de Psiquiatria, 27(1): 37-44, 2005.

HINGSON, R. W.; HEEREN, T. \& WINTER, M. R. Age at drinking onset and alcohol dependence: age at onset, duration, and severity. Archives of Pediatrics \& Adolescent Medicine, 160(7): 739-746, 2006. 
INSTITUTO NACIONAL DO CÂNCER (INCA). Inquérito Domiciliar sobre Comportamentos de Risco e Morbidade Referida de Doenças e Agravos Não Transmissíveis: Brasil, 15 capitais e Distrito Federal 2002-2003. Rio de Janeiro: Inca, 2006.

MALCON, M. C.; MENEZES, A. M. B. \& CHATKIN, M. Prevalência e fatores de risco para tabagismo em adolescentes. Revista de Saúde Pública, 37(1): 1-7, 2003.

MELONI, J. N. \& LARANJEIRA, R. The social and health burden of alcohol abuse. Revista Brasileira de Psiquiatria, 26, supl. 1: S7-S10, 2004.

MENDOZA-SASSI, R. A. \& BÉRIA, J. U. Prevalence of alcohol use disorders and associated factors: a population-based study using AUDIT in southern Brazil. Addiction, 98: 799804,2004

MENEZES, A. M. B.; HALlAL, P. C. \& HORTA, B. L. Early determinants of smoking in adolescence: a prospective birth cohort study. Cadernos de Saúde Pública, 23(2): 347 $354,2007$.

MENEZES, A. M. B. et al. Smoking in early adolescence: evidence from the 1993 Pelotas birth cohort study. The Journal of Adolescent Health, 39: 669-677, 2006.

MONTEIRO, C. A. et al. Population-based evidence of a strong decline in the prevalence of smokers in Brazil (1989-2003). Bulletin of the World Health Organization, 85(7): 527 $534,2007$.

PECHANSKY, F.; SZOBOT, C. M. \& SCIVOLETTO, S. Alcohol use among adolescents: concepts, epidemiological characteristics and etiopatogenic factors. Revista Brasileira de Psiquiatria, 26, supl. 1: 14-17, 2004.

PEIXOTO, S. V.; FIRMO, J. O. A. \& LIMA-COSTA, M. F. Factors associated to smoking habit among older adults (The Bambuí Health and Aging Study). Revista de Saúde Pública, 39(5): 746-753, 2005.

PEIXOTO, S. V.; FIRMO, J. O. A. \& LIMA-COSTA, M. F. Fatores associados ao índice de cessação do hábito de fumar em duas diferentes populações adultas (Projetos Bambuí e Belo Horizonte). Cadernos de Saúde Pública, 23(6): 1.319-1.328, 2007.

PINTO, D. S. \& RIBEIRO, S. A. Variables related to smoking initiation among students in public and private high schools in the city of Belém, Brazil. Jornal Brasileiro de Pneumologia, 33(5): 558-564, 2007.

SCARINCI, I. C. et al. Sociocultural factors associated with cigarette smoking among women in Brazilian worksites: a qualitative study. Health Promotion International, 22(2): 146$154,2007$.

SILVA, L. V. E. R. et al. Factors associated with drug and alcohol use among university students. Revista de Saúde Pública, 40(2): 1-8, 2006.

SOLDERA, M. et al. Uso pesado de álcool por estudantes dos ensinos fundamental e médio de escolas centrais e periféricas de Campinas (SP): prevalência e fatores associados. Revista Brasileira de Psiquiatria, 26(3): 174-179, 2004. 
SOUZA, D. P. O.; ARECO, K. N. \& SILVEIRA, F. D. X. Alcohol and alcoholism among Brazilian adolescent public-school students. Revista de Saúde Pública, 39(4): 1-8, 2005.

WORLD HEALTH ORGANIZATION (WHO). Alcohol, 2007. Disponível em: <www.who.int/ topics/alcohol_drinking/en> Acesso em: 08 dez. 2007.

\section{BIBLIOGRAFIA COMPLEMENTAR}

MALCON, M. C. et al. Prevalência e fatores de risco para tabagismo em adolescentes na América do Sul: uma revisão sistemática da literatura. Revista Panamericana de Salud Pública, 13: 222-228, 2003.

WORLD HEALTH ORGANIZATION (WHO). The tobacco atlas, 2007. Disponível em: <www. who.int/tobacco/statistics/tobacco_atlas/en> Acesso em: 07 dez 2007.

\section{Saúde materno-infantil}

\section{REFERÊNCIAS}

ANDRADE, M. V. et al. Política de Transferência de Renda e Condição Nutricional de Crianças: uma avaliação do Bolsa Família. Belo Horizonte: Cedeplar, 2007 a.

ANDRADE, M. V. et al. Política de Transferência de Renda e Impactos na Imunização das Crianças: o Programa Bolsa Família. Belo Horizonte: Cedeplar, 2007b.

ANDRADE, S. A. et al. Family environment and child's cognitive development: an epidemiological approach. Revista de Saúde Pública, 39(4): 606-611, 2005.

ARAÚJO, O. M. A. et al. Concentração de hemoglobina e anemia em crianças no Estado de Pernambuco, Brasil: fatores sócio-econômicos e de consumo alimentar associados. Cadernos de Saúde Pública, 22(10): 2.169-2.178, 2006.

ASSIS, A. M. O. et al. Desigualdade, pobreza e condições de saúde e nutrição na infância no Nordeste brasileiro. Cadernos de Saúde Pública, 23(10): 2.337-2.350, 2007.

ASSUNÇÃO, M. C. F. et al. Anemia em menores de seis anos: estudo de base populacional em Pelotas, RS. Revista de Saúde Pública, 41(3): 328-335, 2007.

BARBOSA, A. P. et al. Terapia intensiva neonatal e pediátrica no Rio de Janeiro: distribuição de leitos e análise de eqüidade. Revista da Associação Médica Brasileira, 48(4): 303-311, 2002 .

BARROS, A. J. D. et al. Brazil: are health and nutrition programs reaching the neediest? Reaching the poor: with health, nutrition, and population services: what works, what doesn't, and why. Washington: The World Bank, 2005.

BARROS, A. J. D. et al. Desnutrição e obesidade infantis em duas coortes de base populacional no Sul do Brasil: tendências e diferenciais. Cadernos de Saúde Pública, 2007. (No prelo) 
BARROS, F. C. et al. Preterm births, low birthweight, and intra-uterine growth restriction in three birth cohorts in southern Brazil. 1982, 1993 and 2004. Cadernos de Saúde Pública, 2007. (No prelo)

BEHAGUE, D. P. et al. Making medicine for the poor: primary health care interpretations in Pelotas, Brazil. Health Policy and Planning, 17(2): 131-143, 2002.

BENicio, M. H. \& MONTEIRO, C. A. Tendência secular da doença diarréica na infância na cidade de São Paulo (1984-1996). Revista de Saúde Pública, 34, supl. 6: 83-90, 2000.

BENICIO, M. H. et al. Tendência secular da doença respiratória na infância na cidade de São Paulo (1984-1996). Revista de Saúde Pública, 34, supl. 6: 91-101, 2000.

BRASIL. Ministério da Saúde. Pesquisa de Prevalência de Aleitamento Materno nas Capitais e Distrito Federal. Brasília: Ministério da Saúde, 2000.

BRASIL. Ministério da Saúde. Saúde Brasil 2006: uma análise da desigualdade em saúde. Brasília: Ministério da Saúde, 2006.

CESAR, J. A. Community Health Workers in Sergipe, Brazil: Implications for their future role in maternal and child health, 2005. Tese de Doutorado, London: London School of Hygiene and Tropical Medicine.

CESAR, J. A. et al. Utilization of maternal and child health services in three population-based cohorts in Southern Brazil, 1982-2004. Cadernos de Saúde Pública, 2007. (No prelo)

CONDE, W. L.; KONNO, S. C. \& MONTEIRO, C. A. Analysis of the 2005 Health and Nutrition Day. Brasília: Ministry for Social Development and Fight Against Hunger, 2006. (Cadernos de Estudos. Desenvolvimento Social em Debate.)

FERREIRA, M. U. et al. Tendência secular das parasitoses intestinais na infância na cidade de São Paulo (1984-1996). Revista de Saúde Pública, 34, supl. 6: 73-82, 2000.

GRANTHAM-McGREGOR, S. M. et al. The development of low birth weight term infants and the effects of the environment in northeast Brazil. The Journal of Pediatrics, 132(4): 661666, 1998.

GWATKIN, D. R. et al. Socio Economic Differences in Health, Nutrition, and Population within Developing Countries: an overview. Washington: The World Bank, 2007.

HABICHT, J. P.; MASON, J. \& TABATABAI, H. Basic concepts for the design of evaluation during programme implementation. In: SAHN, D.; LOCKWOOD, R. \& SCRIMSHAW, N. (Eds.) Methods for the Evaluation of the Impact of Food and Nutrition Programmes. Tokyo: UNU, 1984.

HALPERN, R. et al. Developmental status at 12 months of age according to birthweight and family income: a comparison between two birth cohort studies in Pelotas, Brazil: 1993 and 2004. Cadernos de Saúde Pública, 2007. (No prelo) 
ISSLER, R. M. et al. Poverty levels and children's health status: study of risk factors in an urban population of low socioeconomic level. Revista de Saúde Pública, 30(6): 506-511, 1996.

KELLY, M. P. et al. Commission on the Social Determinants of Health: measurement and evidence knowledge network. Geneva: World Health Organization, 2007.

LEAL, M. C. et al. Desigualdades raciais, sociodemograficas e na assistência ao pré-natal e ao parto, 1999-2001. Revista de Saúde Pública, 39(1): 100-107, 2005.

MACINKO, J. et al. Evaluation of the impact of the Family Health Program on infant mortality in Brazil, 1990-2002. Journal of Epidemiology and Community Health, 60(1): 13-19, 2006.

MACINKO, J. et al. Going to scale with community-based primary care: An analysis of the family health program and infant mortality in Brazil, 1999-2004. Social Science \& Medicine, 65(10): 2.070-2.080, 2007.

MATIJASEVICH, A. et al. Hospitalization during infancy in three population-based studies in Southern Brazil: trends and differentials. Cadernos de Saúde Pública, 2007. (No prelo)

MONTEIRO, C. A. Evolução da nutrição infantil nos anos 90. In: MONTEIRO, C. A. Velhos e Novos Males da Saúde no Brasil: a evolução do país e de suas doenças. São Paulo: Hucitec, 2000.

MONTEIRO, C. A. et al. Tendência secular do peso ao nascer na cidade de São Paulo (19761998). Revista de Saúde Pública, 34, supl. 6: 26-40, 2000 a.

MONTEIRO, C. A. et al. Evolução da desnutrição infantil. In: MONTEIRO, C. A. (Org.) Velhos e Novos Males da Saúde no Brasil: a evolução do país e de suas doenças. São Paulo: Hucitec, 2000b.

MONTEIRO, C. A. et al. Evolução da assistência materno-infantil na cidade de São Paulo (1984-1996). Revista de Saúde Pública, 34, supl. 6: 19-25, 2000c.

MONTEIRO, C. A. et al. Tendência secular da anemia na infância na cidade de São Paulo (1984-1996). Revista de Saúde Pública, 34, supl. 6: 62-72, $2000 d$.

MORRIS, S. S. et al. Conditional cash transfers are associated with a small reduction in the rate of weight gain of preschool children in northeast Brazil. The Journal of Nutrition, 134(9): 2.336-2.341, 2004.

NEUMAnN, N. A. et al. A Pastoral da Criança em Criciúma, Santa Catarina, Brasil: cobertura e características sócio-demográficas das famílias participantes. Cadernos de Saúde Pública, 15(3): 543-552, 1999.

NEUMAN, N. A. et al. Prevalência e fatores de risco para anemia no Sul do Brasil. Revista de Saúde Pública, 34(1): 56-63, 2000. 
PEREIRA, R. A. G. Programa de Saúde da Família: determinantes e efeitos de sua implantação nos municípios brasileiros, 2006. Tese de Doutorado, Salvador: Instituto de Saúde Coletiva, Universidade Federal da Bahia.

RIVERA, J. A. et al. Impact of the Mexican program for education, health, and nutrition (Progresa) on rates of growth and anemia in infants and young children: a randomized effectiveness study. Jama, 291(21): 2.563-2.570, 2004.

RONSMANS, C. et al. Socioeconomic differentials in caesarean rates in developing countries: a retrospective analysis. The Lancet, 368(9.546): 1.516-1.523, 2006.

SANTOS, L. M. P. et al. Perfil nutricional de crianças menores de cinco anos do semi-árido brasileiro. Avaliação de Políticas e Programas do MDS - Resultados. v. 1. In: VAITSMAN, J. \& PAES-SOUSA, R. Segurança Alimentar e Nutricional. Brasília: Ministério do Desenvolvimento Social e Combate à Fome, 2007.

SASTRY, N. \& BURGARD, S. The prevalence of diarrheal disease among Brazilian children: trends and differentials from 1986 to 1996. Social Science \& Medicine, 60(5): 923-935, 2005.

SILVA, A. A. et al. Trends in low birth weight: a comparison of two birth cohorts separated by a 15-year interval in Ribeirão Preto, Brazil. Bulletin of the World Health Organization, 76(1): 73-84, 1998.

SILVA, A. A. et al. Why are the low birthweight rates in Brazil higher in richer than in poorer municipalities? Exploring the epidemiological paradox of low birthweight. Paediatric and Perinatal Epidemiology, 19(1): 43-49, 2005.

SILVA, A. A. et al. Which factors could explain the low birth weight paradox? Revista de Saúde Pública. 40(4): 648-655, 2006.

SILVA, G. A. et al. Fatores de risco para doença diarréica no lactente: um estudo caso-controle. Cadernos de Saúde Pública, 20(2): 589-595, 2004.

SILVA, L. S. M. et al. Prevalência e determinantes de anemia em crianças de Porto Alegre, RS, Brasil. Revista de Saúde Pública, 35(1):66-73, 2001.

SIMÕES, C. C. S. Perfis de Saúde e de Mortalidade no Brasil: uma análise de seus condicionantes em grupos populacionais específicos. Brasília: Opas, 2002.

SOUZA, D. C. et al. Disponibilidade de unidades de terapia intensiva pediátrica e neonatal no município de São Paulo. Jornal de Pediatria, 80(6): 453-460, 2004.

UNITED NATIONS CHILDREN'S FUND (UNICEF). State of the Worlds Children 2007: women and children the double dividend of gender equality. New York: Unicef, 2007.

VASCONCELOS, M. G. L. et al. Duração e fatores associados ao aleitamento materno em crianças menores de 24 meses de idade no estado de Pernambuco. Revista Brasileira de Saúde Materno Infantil, 6(1): 99-105, 2006. 
VENANCIO, S. I. \& MONTEIRO, C. A. A tendência da prática da amamentação no Brasil nas décadas de 70 e 80. Revista Brasileira de Epidemiologia, 1(1): 40-49, 1998.

VICTORA, C. G. et al. Epidemiologia da Desigualdade: um estudo longitudinal de 6.000 crianças brasileiras. São Paulo: Hucitec, 1988.

VICTORA, C. G. et al. Risk factors for pneumonia among children in a Brazilian metropolitan area. Pediatrics, 93(6 Pt 1): 977-985, 1994.

VICTORA, C. G. et al. Explaining trends in inequities: evidence from Brazilian child health studies. The Lancet, 356(9.235): 1.093-1.098, 2000.

VICTORA, C. G. et al. Co-coverage of preventive interventions and implications for childsurvival strategies: evidence from national surveys. The Lancet, 366(9.495): 1.460$1.466,2005$.

VICTORA, C. G. et al. Are health interventions implemented where they are most needed? District uptake of the integrated management of childhood illness strategy in Brazil, Peru and the United Republic of Tanzania. Bulletin of the World Health Organization, 84(10):792-801, 2006.

VICTORA, C. G. et al. Breastfeeding and feeding patterns in three birth cohorts in southern Brazil: trends and differentials. Cadernos de Saúde Pública, 2007. (No prelo)

WAGSTAFF, A. Socioeconomic inequalities in child mortality: comparisons across nine developing countries. Bulletin of the World Health Organization, 78(1): 19-29, 2000.

WORLD HEALTH ORGANIZATION (WHO). The World Health Report 2005: make every mother and child count. Geneva: WHO, 2005.

WORLD HEALTH ORGANIZATION (WHO) / COMMISSION ON SOCIAL DETERMINANTS OF HEALTH. Bolsa Alimentação Programme, Brazil: an illustrative example, PPHC-KN. Geneva: Secretariat and NHD Department/WHO, 2007.

\section{BIBLIOGRAFIA COMPLEMENTAR}

ALMEIDA, R. M. R. V.; MARINS, V. M. R. \& VALLE, J. Breastfeeding, socio-economic conditions and nutritional status of children younger than 12 months in Brazil. Annals of Tropical Paediatrics, 19(3): 257-262, 1999.

ANDRADE, C. L. et al. Desigualdades sócio-econômicas do baixo peso ao nascer e da mortalidade perinatal no Município do Rio de Janeiro, 2001. Cadernos de Saúde Pública, 20 supl. 1: S44-S51, 2004.

ANDRADE, S. M. et al. Condições de vida e mortalidade infantil no Estado do Paraná, Brasil, 1997/2001. Cadernos de Saúde Pública, 22(1): 181-189, 2006.

ARAGÃO, V. M. F. et al. Risk factors for preterm births in São Luís, Maranhão, Brazil. Cadernos de Saúde Pública, 20(1): 57-63, 2004. 
ASHWORTH, A. et al. Postnatal growth patterns of full-term low birth weight infants in Northeast Brazil are related to socioeconomic status. The Journal of Nutrition, 27(10): 1.950-1.956, 1997.

BEZERRA GUIMARAES, M. J. et al. Infant mortality rate and social disparity at Recife, the metropolis of the North-East of Brazil. Sante, 10(2): 117-121, 2000.

BLACK, R. E. \& WRITING TEAM, L. N. S. Why does undernutrition matter? The importance, determinants and consequences of maternal and childhood undernutrition. The Lancet, 2008. (No prelo)

BLACK, R. E. et al. Where and why are 10 million children dying every year? The Lancet, 361(9.376): 2.226-2.334, 2003.

CASTRO, S. S. et al. Mortalidade infantil e exclusão social em Presidente Prudente, SP 2000 a 2002. Estudos Geográficos, 1(2): 17-24, 2003.

COSTA, M. C. et al. Mortalidade infantil e condições de vida: a reprodução das desigualdades sociais em saúde na década de 90. Cadernos de Saúde Pública, 17(3): 555-567, 2001.

DAHLGREN, G. \& WHITEHEAD, M. Policies and Strategies to Promote Social Equity in Health. Stockholm: Institute for Future Studies, 1991.

DE ONIS, M. et al. Estimates of global prevalence of childhood underweight in 1990 and 2015. Jama, 291(21): 2.600-2.606, 2004.

DRACHLER, M. L. et al. Desigualdade social e outros determinantes da altura em crianças: uma análise multinível. Cadernos de Saúde Pública, 19(6): 1.815-1.825, 2003.

DUCHIADE, M. P. \& BELTRAO, K. I. Infant mortality by cause of death in the Rio de Janeiro metropolitan area, 1976-1986: association with socioeconomic, climatic and air pollution variables. Revista Brasileira de Estudos de População, 9(2): 15-37, 1992.

FRANCA, E. et al. Associação entre fatores sócio-econômicos e mortalidade infantil por diarréia, pneumonia e desnutrição em região metropolitana do Sudeste do Brasil: um estudo caso-controle. Cadernos de Saúde Pública, 17(6): 1.437-1.447, 2001.

FREITAS, P. F. et al. Desigualdade social nas taxas de cesariana em primiparas no Rio Grande do Sul. Revista de Saúde Pública, 39(5): 761-767, 2005.

FUNDO DAS NAÇÕES UNIDAS PARA A INFÂNCIA (UNICEF). Retrato Estatístico dos Direitos da Criança e do Adolescente. Brasília: Unicef, 2006.

GOLDANI, M. Z. et al. Narrowing inequalities in infant mortality in Southern Brazil. Revista de Saúde Pública, 36(4): 478-483, 2002.

GOLDANI, M. Z. et al. Trends in prenatal care use and low birthweight in southeast Brazil. American Journal of Public Health, 94(8): 1.366-1.371, 2004.

GUIMARAES, M. J. et al. Condição de vida e mortalidade infantil: diferenciais intra-urbanos no Recife, Pernambuco, Brasil. Cadernos de Saúde Pública, 19(5): 1.413-1.424, 2003. 
GUIMARÃES, Z. A. et al. Declínio e desigualdades sociais na mortalidade infantil por diarréia. Revista da Sociedade Brasileira de Medicina Tropical, 34(5): 473-478, 2001.

GURGEL, R. et al. Diarrhoea mortality in Aracaju, Brazil. Annals of Tropical Paediatrics, 17(4): 361-365, 1997.

GWATKIN, D. R. Health inequalities and the health of the poor: what do we know? What can we do? Bulletin of the World Health Organization, 78(1): 3-18, 2000.

HALPERN, R. et al. Atenção pré-natal em Pelotas, Rio Grande do Sul, Brasil, 1993. Cadernos de Saúde Pública, 14(3): 487-492, 1998.

LEAL, M. C. \& SZWARCWALD, C. L. Evolução da mortalidade neonatal no Estado do Rio de Janeiro, Brasil, de 1979 a 1993. Análise por grupo etário segundo região de residência. Revista de Saúde Pública, 30(5): 403-412, 1996.

LEAL, M. C. \& SZWARCWALD, C. L. Características da mortalidade neonatal no Estado do Rio de Janeiro na década de 80: uma visão espaço-temporal. Revista de Saúde Pública, 31(5): 457-465, 1997.

LEAL, M. C. et al. Fatores associados à morbi-mortalidade perinatal em uma amostra de maternidades públicas e privadas do Município do Rio de Janeiro, 1999-2001. Cadernos de Saúde Pública, 20, supl. 1: S20-S33, 2004a.

LEAL, M. C. et al. Uso do índice de Kotelchuck modificado na avaliação da assistência pré-natal e sua relação com as características maternas e o peso do recém-nascido no Município do Rio de Janeiro. Cadernos de Saúde Pública, 20, supl. 1: S63-S72, 2004b.

MALTA, D. C. et al. A mortalidade infantil em Belo Horizonte, Minas Gerais, Brasil, por área de abrangência dos Centros de Saúde (1994-1996). Cadernos de Saúde Pública, 17(5): $1.189-1.198,2001$

MENEZES, A. M. et al. Infant mortality in Pelotas, Brazil: a comparison of risk factors in two birth cohorts. Revista Panamericana de Salud Pública, 18(6): 439-446, 2005.

MONTEIRO, C. A. \& CONDE, W. L. Tendência secular da desnutrição e da obesidade na infância na cidade de São Paulo (1974-1996). Revista de Saúde Pública, 34, supl. 6: 52-61, 2000.

MONTEIRO, M. F. The effect of maternal education on the risk of infant mortality. Revista Brasileira de Estudos de População, 7(1): 74-86, 1990.

MORAIS NETO, O. L. et al. Diferenças no padrão de ocorrência da mortalidade neonatal e pósneonatal no Município de Goiânia, Brasil, 1992-1996: análise espacial para identificação das áreas de risco. Cadernos de Saúde Pública, 17(5): 1.241-1.250, 2001.

NUNES, A. et al. Medindo as Desigualdades em Saúde no Brasil: uma proposta de monitoramento. Brasília: Paho, 2001.

PUCCINI, R. F. et al. Equidade na atenção pré-natal e ao parto em área da Região Metropolitana de São Paulo, 1996. Cadernos de Saúde Pública, 19(1): 35-45, 2003. 
RIBAS, D. L. et al. Saúde e estado nutricional infantil de uma população da região centrooeste do Brasil. Revista de Saúde Pública, 33(4): 358-365, 1999.

RIBEIRO, V. S. et al. Infant mortality: comparison between two birth cohorts from Southeast and Northeast, Brazil. Revista de Saúde Pública, 38(6): 773-779, 2004.

RONDO, P. H. et al. The influence of maternal nutritional factors on intrauterine growth retardation in Brazil. Paediatric and Perinatal Epidemiology, 11(2): 152-166, 1997.

SANTOS, L. M. et al. Situação nutricional e alimentar de pré-escolares no semi-árido da Bahia (Brasil): I. Avaliação antropométrica. Revista de Saúde Pública, 29(6): 463471, 1995.

SASTRY, N. Trends in socioeconomic inequalities in mortality in developing countries: the case of child survival in Sao Paulo, Brazil. Demography, 41(3): 443-464, 2004.

SILVA, L. M. et al. Desigualdades na mortalidade, espaço e estratos sociais. Revista de Saúde Pública, 33(2): 187-197, 1999.

SOUZA, A. C. et al. Relationship between health services, socioeconomic variables and inadequate weight gain among Brazilian children. Bulletin of the World Health Organization, 77(11): 895-905, 1999.

SOUZA, A. C. et al. Underlying and proximate determinants of diarrhoea-specific infant mortality rates among municipalities in the state of Ceara, north-east Brazil: an ecological study. Journal of Biosocial Science, 33(2): 227-244, 2001.

STRUFALDI, M. W. et al. Prevalência de desnutrição em crianças residentes no Município de Embu, São Paulo, Brasil, 1996-1997. Cadernos de Saúde Pública, 19(2): 421-428, 2003.

SURKAN, P. J. et al. Maternal social and pyschological conditions and physical growth in low-income children in Piaui, Northeast Brazil. Social Science \& Medicine, 64(2): 375 $388,2007$.

SZWARCWALD, C. L. et al. Desigualdade de renda e situação de saúde: o caso do Rio de Janeiro. Cadernos de Saúde Pública, 15(1): 15-28, 1999.

SZWARCWALD, C. L. et al. Health conditions and residential concentration of poverty: a study in Rio de Janeiro, Brazil. Journal of Epidemiology and Community Health, 54(7): 530-536, 2000.

SZWARCWALD, C. L. et al. Medidas de desigualdad en salud: la discusión de algunos aspectos metodológicos con una aplicación para la mortalidad neonatal en el Municipio de Rio de Janeiro, 2000. Social Science \& Medicine, 55(12): 2.083-2.092, 2002a.

SZWARCWALD, C. L. et al. Health inequality indicators: a discussion of some methodological approaches as applied to neonatal mortality in the Municipality of Rio de Janeiro, 2000. Cadernos de Saúde Pública, 18(4): 959-970, 2002b. 
UNITED NATIONS DEVELOPMENT PROGRAM (UNPD). Human Development Report 2005: international cooperation at a crossroads. New York: UNDP, 2005.

VICTORA, C. G. et al. Applying an equity lens to child health and mortality: more of the same is not enough. The Lancet, 362(9.379): 233-241, 2003.

WAGSTAFF, A. et al. Child health: reaching the poor. American Journal of Public Health, 94(5): 726-736, 2004.

WHITEHEAD, M. \& DAHLGREN, G. Levelling Up (Part. 1): a discussion paper on concepts and principles for tackling social inequities in health. Copenhagen: WHO Regional Office for Europe, 2006.

WORLD HEALTH ORGANIZATION (WHO). Assessing Infant and Young Child Feeding: progress towards developing simple indicators (Informal meeting). Geneva: WHO, 2006.

ZAMBONATO, A. M. et al. Risk factors for small-for-gestational age births among infants in Brazil. Revista de Saúde Pública, 38(1): 24-29, 2004.

Saúde Indígena

\section{REFERÊNCIAS}

COIMBRA JR., C. E. A., SANTOS, R. V. \& ESCOBAR, A. L. Epidemiologia e Saúde dos Povos Indigenas no Brasil. Rio de Janeiro: Editora Fiocruz, 2003.

COIMBRA JR., C. E. A. \& SANTOS, R. V. Emerging health needs and epidemiological research in indigenous peoples in Brazil. In: SALZANO, F. M. \& HURTADO, A. (Eds.) Lost Paradises and the Ethics of Research and Publication. Oxford: Oxford University Press, 2004.

COIMBRA JR., C. E. A. et al. The Xavante in Transition: health, ecology and bioanthropology in Central Brazil. Ann Arbor: University of Michigan Press, 2002.

FUNDAÇÃO NACIONAL DE SAÚDE (FUNASA). Política Nacional de Atenção à Saúde dos Povos Indigenas. 2. ed. Brasília: Funasa, 2002.

FUNDAÇÃO NACIONAL DE SAÚDE (FUNASA). Relatório Morbimortalidade 2002. Brasília: Funasa, 2003.

FUNDAÇÃO NACIONAL DE SAÚDE (FUNASA). Boletim Informativo. Brasília: Funasa, 2006.

GARNELO, L.; MACEDO, G. \& BRANDÃO, L. C. Os Povos Indígenas e a Construção das Políticas de Saúde no Brasil. Brasília: OPS, 2003.

INSTITUTO BRASILEIRO DE GEOGRAFIA E ESTATÍSTICA (IBGE). Tendências Demográficas: uma análise dos indigenas com base nos resultados da amostra dos censos demográficos 1991 e 2000. Rio de Janeiro: IBGE, 2005.

LEITE, M. S. et al. Alimentação e nutrição dos povos indígenas no Brasil. In: KAC, G.; SICHIERI, R. \& GIGANTE, D. P. (Orgs.) Epidemiologia Nutricional. Rio de Janeiro: Editora Fiocruz, 2007. 
SANTOS, R. V. \& ESCOBAR, A. L. (Orgs.) Saúde dos povos indígenas no Brasil: perspectivas atuais. Cadernos de Saúde Pública, 17(2): 258-445, 2001.

SANTOS, R. V.et al. Saúde dos povos indígenas e políticas públicas no Brasil. In: GIOVANELLA, L. et al (Orgs.) Políticas e Sistema de Saúde no Brasil. Rio de Janeiro: Editora Fiocruz, 2008. (No prelo)

\section{BIBLIOGRAFIA COMPLEMENTAR}

PAGliARO, H.; AZEVEDo, M. \& SANTOS, R. V. (Orgs.) Demografia dos Povos Indígenas no Brasil. Rio de Janeiro: Editora Fiocruz, 2005.

SANTOS, R. V. \& COIMBRA JR, C. E. A. (Orgs.) Saúde e Povos Indígenas. Rio de Janeiro: Editora Fiocruz, 1994.

\section{Recomendações}

As políticas e programas em curso

\section{REFERÊNCIAS}

ANDRADE, G. R. B. A Dinâmica da Participação de Representantes da Sociedade Civil em Conselhos de Políticas Sociais no Município de Piraí - RJ, 2007. Tese de Doutorado, Rio de Janeiro: Escola Nacional de Saúde Pública, Fundação Oswaldo Cruz.

ANDRADE, L. O. M. A Saúde e o Dilema da Intersetorialidade. São Paulo: Hucitec, 2006.

BRASIL. Ministério do Desenvolvimento Social e Combate à Fome. Art. $4^{\circ}$ do Decreto 5209, 17 set. 2004. Regulamenta a lei 10.836 , de 9 de janeiro de 2004, que cria o programa Bolsa Família, e dá outras providências. Diário Oficial, Brasília, 2004.

BRASIL. Ministério do Desenvolvimento Social e Combate à Fome. Chamada Nutricional Quilombola, 2006: resumo executivo. Brasília: Ministério do Desenvolvimento Social e Combate à Fome, 2007.

INSTITUTO POLIS. Pesquisa de opinião com beneficiários do Programa Bolsa Família. In: VAITSMAN, J. \& PAES-SOUSA, R. (Orgs.) Avaliação de Politicas e Programas do MDS: resultados. Brasília: Ministério do Desenvolvimento Social e Combate à Fome, 2007. v. 2.

JUNQUEIRA, L. A. P.; INOJOSA, R. M. \& KOMATSU, S. Descentralização e intersetorialidade na gestão pública municipal no Brasil: a experiência de Fortaleza. In: CONCURSO DE ENSAYOS DEL CLAD. 'EL TRÁNSITO DE LA CULTURA BUROCRÁTICA AL MODELO DE LA GERENCIA PÚBLICA: PERSPECTIVAS, POSIBILIDADES Y LIMITACIONES', 11, 1997, Caracas. Anais... Caracas, 1997.

LIMA, S. M. V. et al. Avaliação do impacto social do Programa Cisternas. In: VAITSMAN, J. \& PAES-SOUSA, R. (Orgs.) Avaliação de Políticas e Programas do MDS: resultados. Brasília: Ministério do Desenvolvimento Social e Combate à Fome, 2007. v. 1. 
MONTEIRO, C. A.; CONDE, W. L. \& KONNO, S. C. Análise do inquérito Chamada Nutricional 2005. In: BRASIL. Ministério do Desenvolvimento Social e Combate à Fome, Secretaria de Avaliação e Gestão da Informação (Orgs.) Chamada Nutricional: um estudo sobre a situação nutricional das crianças no semi-árido brasileiro. Brasília: Ministério do Desenvolvimento Social e Combate à Fome, Secretaria de Avaliação e Gestão da Informação, 2006. (Cadernos de Estudos: Desenvolvimento Social em Debate, 4).

OLIVEIRA, A. M. H. C. et al. Primeiros resultados da análise da linha de base da pesquisa de avaliação de impacto do Programa Bolsa Família. In: VAITSMAN, J. \& PAES-SOUSA, R. (Orgs.) Avaliação de Políticas e Programas do MDS: resultados. Brasília: Ministério do Desenvolvimento Social e Combate à Fome, 2007. v. 2.

SILVA, M. C. M. et al. Programa Bolsa Família e segurança alimentar das famílias beneficiárias: resultados para o Brasil e regiões. In: VAITSMAN, J. \& PAES-SOUSA, R. (Orgs.) Avaliação de Políticas e Programas do MDS: resultados. Brasília: Ministério do Desenvolvimento Social e Combate à Fome, 2007. v. 2.

SOARES, F. V. et al. Programas de Transferência de Renda no Brasil: impactos sobre a desigualdade. Brasília: Ipea, 2006. (Texto para Discussão, 1228) 


\section{ANEXOS}

\section{Anexo I}

\section{RelatóRio de AtividADEs dA CNDSS}

As atividades desenvolvidas pela CNDSS estiveram organizadas em cinco linhas de ação, que buscaram responder aos objetivos e atribuições definidos no Decreto Presidencial que a criou, em 13 de março de 2006. No âmbito de cada uma destas linhas, foram desenvolvidas diversas atividades, que contaram com a participação de especialistas, profissionais e participantes de instituições colaboradoras, além de membros da Comissão.

A Comissão foi apoiada técnica e operacionalmente por uma Secretaria Técnica (ST), instalada na Fiocruz. A ST esteve integrada por Alberto Pellegrini Filho e Alice Branco, com o apoio administrativo de Fátima Correa. Contou também com o apoio de diversos profissionais e setores da Fiocruz, para o desenvolvimento de suas atribuições e para a administração técnica e financeira dos projetos desenvolvidos no âmbito das diversas linhas de ação. Maiores detalhes sobre estas linhas de ação e atividades correspondentes podem ser encontrados em <www.determinantes.fiocruz.br $>$.

A primeira linha de ação se refere à Produção e Disseminação de Conhecimentos e Informações, que teve por objetivo produzir conhecimentos e informações sobre as relações entre os determinantes sociais e a situação de saúde, particularmente as iniqüidades em saúde, com vistas a fundamentar políticas e programas. No âmbito desta linha de ação, foi lançado um edital de pesquisa, em junho de 2006, em parceria com o Ministério da Saúde e o Conselho Nacional de Desenvolvimento Científico e Tecnológico (CNPq). Seu objetivo foi apoiar o desenvolvimento de projetos sobre DSS, incluindo avaliação de intervenções sobre estes determinantes. Em setembro de 2006, foram selecionados 21 projetos (listados no anexo Ia), totalizando cerca de três milhões de reais. Os projetos tiveram início em fevereiro/março de 2007, tendo sido criada uma comunidade virtual, integrada pelos pesquisadores envolvidos, além de gestores e outros convidados. A criação desta comunidade virtual teve por objetivo acompanhar o andamento dos projetos e identificar eventuais implicações de seus resultados intermediários para políticas e programas. Aspectos metodológicos de interesse comum e temas relacionados aos DSS são também objeto de discussões no âmbito desta comunidade virtual.

Outro projeto incluído nesta linha de ação se refere à compilação, revisão e análise de sistemas de informação, com o objetivo de facilitar o acesso ao acervo de dados, informações e indicadores relativos a DSS, produzidos no Brasil, por distintas fontes. Foi feita a identificação dos sistemas de informação e a organização do acervo selecionado, de forma a facilitar o acesso ao público não especialista e a análise de seu potencial de uso. Os acervos serão colocados à disposição do 
público no Portal sobre Determinantes Sociais da Saúde, que será lançado no primeiro semestre de 2008 e terá o mesmo endereço atualmente utilizado para a página da CNDSS (www.determinantes. fiocruz.br). Este acervo deverá ser permanentemente atualizado, acompanhando as alterações dos sistemas de informação.

Ainda no âmbito desta primeira linha de ação, foi realizado em Brasília, em setembro de 2006, um Seminário Metodológico sobre Avaliação de Intervenções para Combate às Iniqüidades em Saúde. O seminário teve o objetivo de revisar o "estado da arte" das metodologias de avaliação existentes, assim como a experiência nacional e internacional em sua utilização. Contou com a participação de especialistas nacionais e internacionais, membros da CNDSS, membros do Grupo de Trabalho intersetorial (ver linha de ação Políticas e Programas) e outros convidados. As apresentações realizadas durante o seminário, assim como um relatório das principais discussões e recomendações, podem ser encontrados na página da CNDSS.

A segunda linha de ação se refere a Políticas e Programas e teve por objetivo promover, coordenar e avaliar políticas, programas e intervenções governamentais e não governamentais sobre os DSS, realizadas em nível local, regional e nacional. A principal atividade relacionada a esta linha de atuação foi dar apoio técnico e operacional ao Grupo de Trabalho (GT), estabelecido pelo Decreto Presidencial que criou a CNDSS e integrado por representantes de diversos níveis da administração pública. O GT, embora criado em março de 2006, só foi formalmente estabelecido em 18 de dezembro do mesmo ano, por meio da Portaria no 3.178 do Ministro da Saúde. Através de reuniões e outros meios de comunicação, criaram-se oportunidades para intercâmbio de informações e discussão de temas de interesse comum entre seus membros, mas o potencial do GT como instrumento de coordenação das ações das diversas instituições que o integram não foi plenamente realizado. A revisão e análise de políticas e programas em curso incluída neste Relatório também se inscreve nesta linha de ação.

A CNDSS teve contribuição decisiva na elaboração do Protocolo de Intenções, assinado em setembro de 2007, entre o Ministério da Saúde, Fundação Oswaldo Cruz, Conass e Conasems para o fortalecimento de ações intersetoriais de promoção da saúde nas esferas estadual e municipal. Mais especificamente, este Protocolo de Intenções e os projetos que o integram têm como objetivos:

- capacitar gestores e tomadores de decisão, em âmbito municipal e estadual, para promover e executar ações setoriais e intersetoriais de promoção da saúde;

- facilitar o acesso a gestores e lideranças comunitárias, a dados, informações e literatura, que respondam a suas necessidades e demandas para promoção de intervenções sobre os DSS;

- facilitar, aos gestores de âmbito municipal e estadual, espaços e oportunidades de intercâmbio e troca de experiências sobre intervenções, visando a promoção da saúde e o combate às iniqüidades;

- proporcionar metodologias e mecanismos, em âmbito municipal e estadual, para a definição e execução de políticas e programas intersetoriais de promoção da saúde;

- promover a produção e disseminação de conhecimento original sobre iniqüidades em saúde e, particularmente, sobre desenho e avaliação de intervenções sobre seus determinantes sociais. 
A terceira linha de ação se refere à Mobilização da Sociedade Civil e teve por objetivo chamar a atenção de diversos setores da sociedade sobre a importância dos DSS e sobre as possibilidades de atuação sobre eles. Esse chamado à tomada de consciência, em especial sobre a gravidade das iniqüidades em saúde, foi feito por meio da participação da Secretaria Técnica e membros da Comissão em diversos congressos, conferências, cursos, painéis e mesas-redondas, organizados por entidades científicas, profissionais de saúde, gestores, ONGs e outras entidades. Foram também utilizados diversos meios de comunicação massiva como a televisão, inclusive programas do Canal Saúde produzidos pela Fiocruz, e uma série de matérias e artigos publicados em revistas de ampla circulação como a revista Radis e jornais diários. Artigos científicos foram também publicados em revistas como os Cadernos de Saúde Pública, Physis e outras, para divulgação da CNDSS e para promoção do debate sobre os DSS entre os profissionais de saúde pública.

No âmbito desta linha, destaca-se a realização de um fórum de entidades da sociedade civil em Brasília, em abril de 2007, para explorar oportunidades de atuação conjunta em favor da eqüidade em saúde. Em abril de 2008, foi realizado, em Porto Alegre, o Fórum Saúde e Comunicação, com a participação de mais de 500 profissionais de saúde e dos meios de comunicação, para discutir, desde suas diferentes perspectivas, conceitos, estratégias e experiências, visando fortalecer a comunicação para a promoção da saúde. Merece também destaque a elaboração, em agosto de 2006, de uma Carta Aberta assinada por todos os membros da CNDSS aos candidatos à Presidência da República (Anexo Ib), com o objetivo de promover o debate público de políticas e programas de governo relacionados aos determinantes sociais da saúde (DSS).

A quarta linha de ação corresponde à Construção e Manutenção de Portal sobre Determinantes Sociais da Saúde (www.determinantes.fiocruz.br). Além de registrar as atividades que foram desenvolvidas pela CNDSS, incluindo documentos e apresentações por ela produzidos, o Portal tem por objetivo coletar e registrar informações e conhecimentos sobre DSS disponíveis nos sistemas de informação e na literatura científica nacional e internacional, constituindo-se num espaço de referência para os interessados no tema. O Portal sobre DSS deve também se consolidar como um ambiente de interação entre diversos atores relacionados aos DSS, como pesquisadores, profissionais de saúde, gestores, membros de organizações da sociedade civil e público em geral. Com o término do mandato da CNDSS, o Portal será mantido e atualizado pelo Instituto de Comunicação e Informação Científica e Tecnológica da Fiocruz (Icict/Fiocruz).

A quinta linha de ação se refere à Cooperação Internacional, que inclui Cooperação com a Comissão sobre Determinantes Sociais da Saúde da OMS (CSDH) e com os países da América Latina, para promoção do enfoque de DSS em suas políticas de saúde e/ou criação de suas respectivas comissões nacionais. Com relação à cooperação com a Comissão da OMS, foram realizadas diversas atividades conjuntas de caráter técnico e, no que se refere à organização colaborativa de eventos, merecem destaque: 1) a realização da 6ª Reunião da CSDH em setembro de 2006, no Rio de Janeiro, conjuntamente com a $2^{\text {a }}$ Reunião da CNDSS; 2) a organização do $1^{\circ}$ Fórum de Consulta da Sociedade Civil dos países da América Latina, em abril de 2007, em Brasília, em colaboração com OEA, MS e OPS/OMS; 3) a reunião das Redes de Conhecimento (Knowledge Networks), em setembro de 2007, no Rio de Janeiro. 
Anexo I A

\begin{tabular}{|c|c|c|c|c|c|c|c|c|c|c|c|c|c|c|c|c|c|c|c|c|c|}
\hline 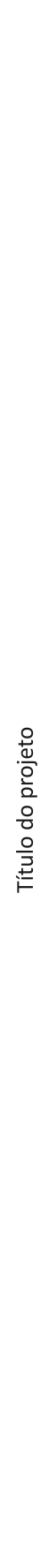 & 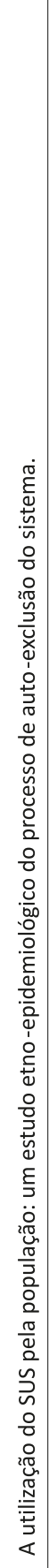 & 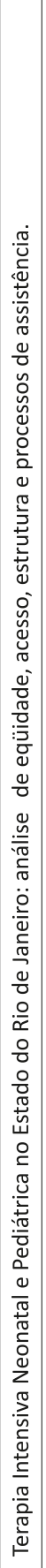 & 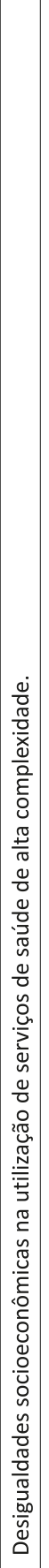 & 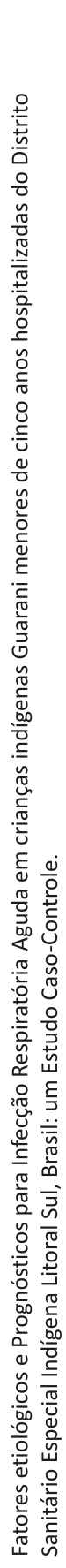 & 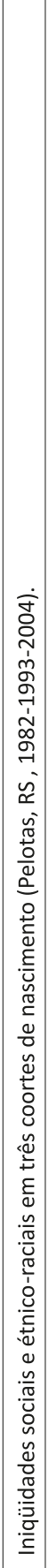 & 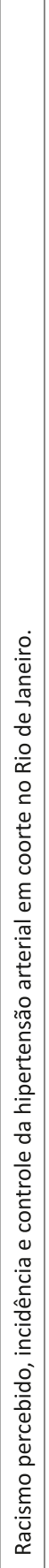 & 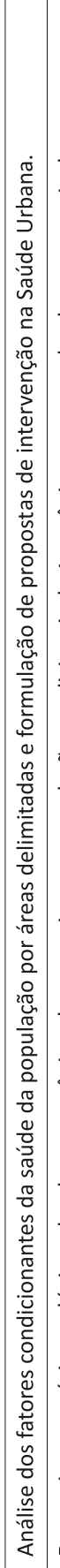 & 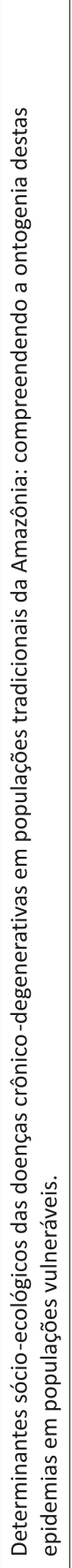 & 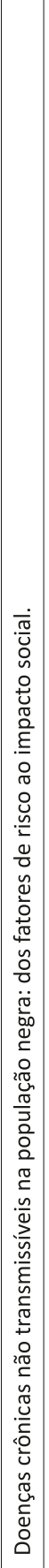 & 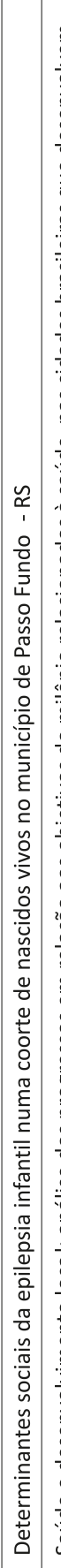 & 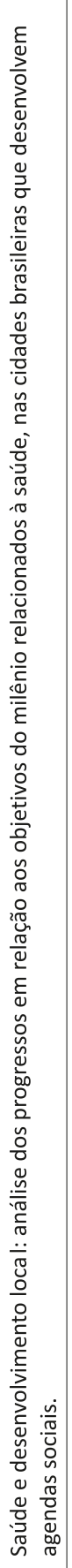 & 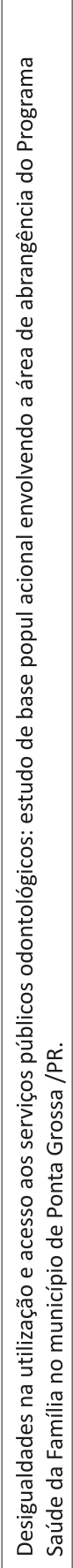 & 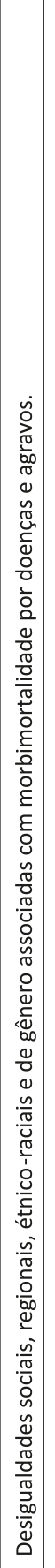 & 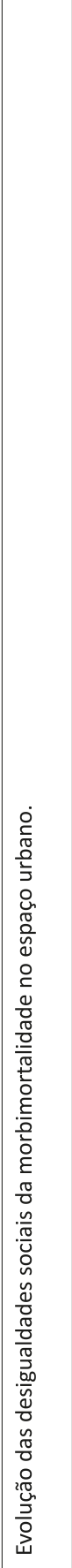 & 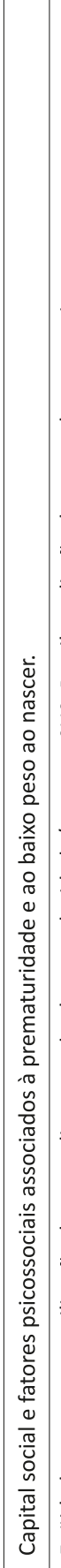 & 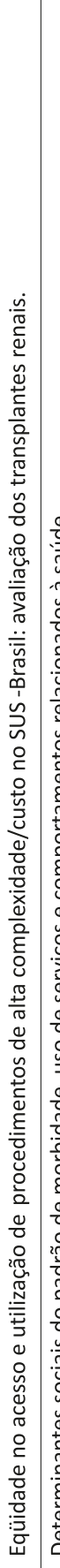 & 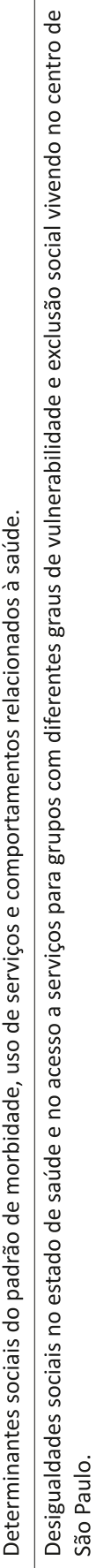 & 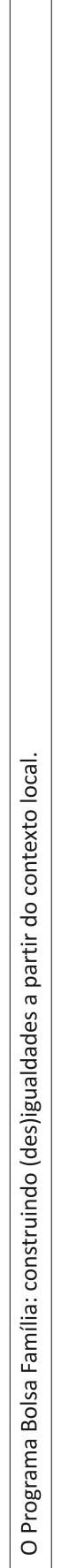 & 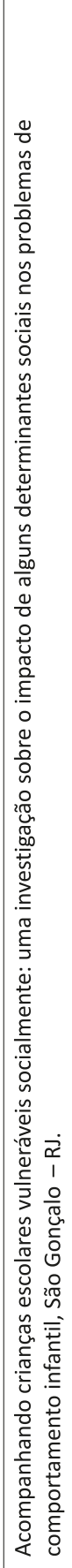 & 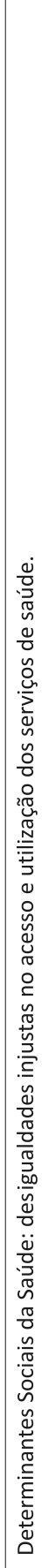 & 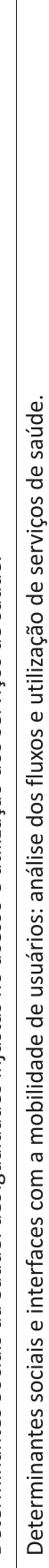 \\
\hline 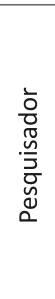 & 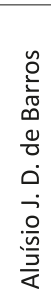 & 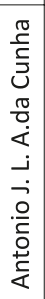 & 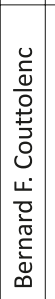 & 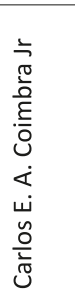 & 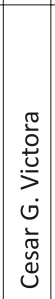 & 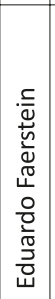 & 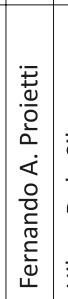 & 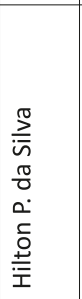 & 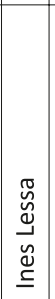 & 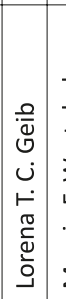 & 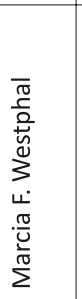 & 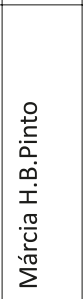 & 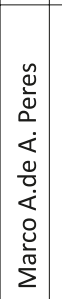 & 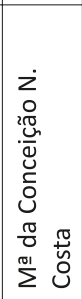 & 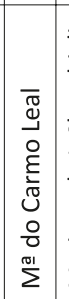 & 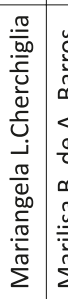 & 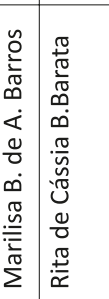 & 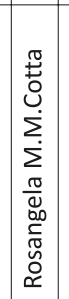 & 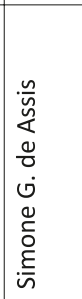 & 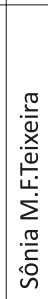 & 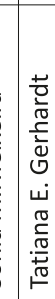 \\
\hline
\end{tabular}




\section{Anexo I B}

\section{Carta Aberta da Comissão Nacional sobre Determinantes Sociais da Saúde aos CANDidatos À PREsidênCIA dA República}

Agosto de 2006

Srs.(a) Candidatos(a) a Presidente do Brasil,

Nós, membros da Comissão Nacional sobre Determinantes Sociais da Saúde,

Preocupados com as enormes desigualdades em saúde no Brasil que, além de injustas, são evitáveis e desnecessárias;

Sabedores de que essas desigualdades são resultado do desemprego, da violência, da falta de perspectivas e das precárias condições de vida a que está submetida grande parte da população brasileira, acentuadas pelas dimensões de gênero e etnia;

Convencidos de que políticas públicas baseadas em informações confiáveis e com amplo apoio político dos diversos segmentos da sociedade brasileira podem reverter esse quadro, tal como ocorre em outros países com desenvolvimento econômico igual ou inferior ao nosso,

Instamos os Srs(a). Candidatos(a) à Presidência da República do Brasil a incluir em seus programas de governo ações concretas para a melhoria das condições de saúde, particularmente de promoção da eqüidade em saúde,

Que tenham por referência o conceito de saúde tal como a concebe a Organização Mundial da Saúde, como um estado de completo bem-estar físico, mental e social e não meramente a ausência de doença ou enfermidade,

Que cumpram o preceito constitucional de reconhecer a saúde como um "direito de todos e dever do Estado, garantido mediante políticas sociais e econômicas que visem à redução do risco de doença e outros agravos e ao acesso universal e igualitário às ações e serviços para sua promoção, proteção e recuperação",

Que contemplem os determinantes sociais da saúde em todos os seus níveis, incluindo:

- Políticas que favoreçam mudanças de comportamento para a redução de riscos e aumento da qualidade de vida mediante programas educativos, comunicação social, acesso facilitado a alimentos saudáveis, criação de espaços públicos para a prática de esportes e exercícios físicos, bem como proibição à propaganda do tabaco e do álcool em todas a suas formas;

- Políticas que favoreçam ações de promoção da saúde, da paz e da justiça social, buscando estreitar relações de solidariedade e confiança, construir redes de apoio e fortalecer a organização e participação das pessoas e das comunidades em ações coletivas para melhoria de suas condições de saúde e bem estar, especialmente dos grupos sociais vulneráveis; 
- Políticas que assegurem a melhoria das condições de vida da população, garantindo a todos o acesso à água limpa, esgoto, habitação adequada, ambientes de trabalho saudáveis, serviços de saúde e de educação de qualidade, superando abordagens setoriais fragmentadas e promovendo uma ação planejada e integrada dos diversos níveis da administração pública e

- Políticas macroeconômicas e de mercado de trabalho, de proteção ambiental e de promoção de uma cultura de paz e solidariedade que visem promover um desenvolvimento sustentável, reduzindo as desigualdades sociais e econômicas, as violências, a degradação ambiental e seus efeitos sobre a sociedade.

Estamos seguros de que um futuro governo que trate das questões de saúde sob o enfoque dos determinantes sociais, formulando e avaliando suas políticas em função do impacto sobre a qualidade de vida e a eqüidade e não apenas sobre a melhoria das médias dos indicadores de saúde, estará correspondendo plenamente aos anseios da população brasileira por um país mais justo e humano.

Paulo M. BusS - médico, presidente da Fundação Oswaldo Cruz, membro titular da Academia Nacional de Medicina, coordenador da Comissão;

Adib Jatene - médico, ex-professor da Universidade de São Paulo, ex-ministro da Saúde do Brasil, membro titular da Academia Nacional de Medicina;

Aloísio Teixeira - economista, reitor da Universidade Federal do Rio de Janeiro;

Cesar Victora - médico, professor de epidemiologia, Universidade Federal de Pelotas, membro titular da Academia Brasileira de Ciências;

Dalmo Dallari - advogado, professor de direito da Universidade de São Paulo, membro da Comissão Internacional de Juristas;

Eduardo Eugênio Gouvêa Vieira - empresário, presidente da Federação das Indústrias do Estado do Rio de Janeiro;

Elza Berquó - demógrafa, pesquisadora do Centro Brasileiro de Análise e Planejamento, membro titular da Academia Brasileira de Ciências;

Jaguar - cartunista;

Jairnilson Paim - médico, professor de planejamento de saúde da Universidade Federal da Bahia;

Lucélia Santos - atriz;

Moacyr Scliar - médico, escritor e membro da Academia Brasileira de Letras;

Roberto Smeraldi - ambientalista, diretor da Organização da Sociedade Civil de Interesse Público Amigos da Terra-Amazônia Brasileira;

Rubem César Fernandes - antropólogo, coordenador do Movimento Viva Rio;

Sandra de Sá - cantora;

Sônia Fleury - cientista política, professora de políticas públicas e de saúde da Fundação Getulio Vargas;

Zilda Arns - médica, coordenadora da Pastoral da Criança. 


\title{
Anexo II
}

\section{Decreto Presidencial oue criou a Comissão Nacional sobre Determinantes Sociais DA SAÚDE:}

\author{
Presidência da República \\ Casa Civil \\ Subchefia para Assuntos Jurídicos
}

DECRETO DE 13 DE MARÇO DE 2006

Institui, no âmbito do Ministério da Saúde, a Comissão sobre Determinantes Sociais da Saúde (CNDSS).

O PRESIDENTE DA REPÚBLICA, no uso da atribuição que lhe confere o art. 84, inciso VI, alínea "a", da Constituição,

\section{DECRETA:}

Art. $1^{\circ}$ Fica instituída, no âmbito do Ministério da Saúde, a Comissão Nacional sobre Determinantes Sociais da Saúde - CNDSS, com o objetivo de:

I - apoiar e articular a atuação do Poder Público, instituições de pesquisa e da sociedade civil sobre determinantes sociais relacionados à melhoria da saúde e redução das iniqüidades sanitárias;

II - promover modelos e práticas efetivas relacionadas aos determinantes sociais da saúde e voltados à inserção da eqüidade em saúde nas políticas de governo;

III - contribuir para a formulação e implementação de políticas, planos e programas de saúde baseados em intervenções sobre os determinantes sociais que condicionam o nível de saúde;

IV - organizar e gerar informações e conhecimentos voltados a informar políticas e ações sobre os determinantes sociais da saúde; e

V - mobilizar setores de governo e a sociedade civil para atuar na prevenção e solução dos efeitos negativos de determinantes sociais da saúde.

Art. $2^{\circ}$ A CNDSS será composta por dezessete membros, de livre escolha e designação pelo Ministro de Estado da Saúde, entre brasileiros de renomado conhecimento e liderança em temas da área da saúde e integrantes de instituições acadêmicas, de notável saber.

Art. $3^{\circ}$ Com vistas ao atendimento de seus objetivos, a CNDSS deverá:

I - reunir dados sobre intervenções eficazes e propor políticas relativas aos principais determinantes sociais, com ênfase nas populações de baixa renda;

II - articular redes de especialistas, líderes sociais e pesquisadores com vistas a reunir 
conhecimentos sobre intervenções e políticas efetivas para enfrentar os determinantes sociais da saúde, priorizando contextos sócio-políticos de baixa renda;

III - fomentar debate social amplo e atuar para que o Poder Público, as organizações da sociedade civil e agências internacionais relacionadas implementem políticas para intervir sobre os determinantes sociais que condicionam o nível de saúde; e

IV - elaborar programa de ação a médio e longo prazo para incorporar as suas recomendações às políticas, planos e programas relacionados com a saúde, bem como para promover a sua implementação no âmbito da União, dos Estados, do Distrito Federal e dos Municípios.

Art. $4^{\circ}$ Para promover a articulação com as áreas de governo e prestar apoio técnico aos trabalhos da CNDSS, fica constituído Grupo de Trabalho, cujos membros serão designados pelo Ministro de Estado da Saúde, mediante indicação do respectivo representante pelos dirigentes máximos das seguintes instituições:

I - Casa Civil da Presidência da República;

II - Ministério da Saúde;

III - Ministério do Planejamento, Orçamento e Gestão;

IV - Ministério da Fazenda;

V - Ministério do Desenvolvimento Social e Combate à Fome;

VI - Ministério da Educação;

VII - Ministério da Ciência e Tecnologia;

VIII - Ministério da Cultura;

IX - Ministério do Esporte;

X - Ministério das Cidades;

XI - Ministério do Meio Ambiente;

XII - Ministério do Trabalho e Emprego;

XIII - Ministério da Previdência Social;

XIV - Ministério do Desenvolvimento Agrário;

XV - Secretaria Especial de Políticas de Promoção da Igualdade Racial da Presidência da República;

XVI - Secretaria Especial de Políticas para as Mulheres, da Presidência da República;

XVII - Conselho Nacional de Secretários de Saúde (Conass);

XVIII - Conselho Nacional de Secretários Municipais de Saúde (Conasems); e

XIX - Conselho Nacional de Saúde. 
Parágrafo único. A Organização Pan-Americana da Saúde no Brasil (Opas) poderá indicar representante para integrar o Grupo de Trabalho de que trata este artigo.

Art. $5^{\circ}$ A CNDSS, no prazo de até trinta dias após a sua primeira reunião, submeterá à aprovação do Ministro de Estado da Saúde proposta de seu regimento interno, que disporá sobre o seu funcionamento.

Art. $6^{\circ}$ Os serviços prestados pelos membros da CNDSS e do Grupo de Trabalho, considerados de relevante interesse público, não serão remunerados.

Art. $7^{\circ}$ A CNDSS terá prazo de dois anos para conclusão de seus trabalhos, com apresentação de relatório final ao Ministro de Estado da Saúde.

Art. $8^{\circ}$ Este Decreto entra em vigor na data de sua publicação.

Brasília, 13 de março de 2006; 1850 da Independência e 1180 da República.

LUIZ INÁCIO LULA DA SILVA

Saraiva Felipe 


\section{Anexo II A}

\section{PoRTARIA Ministerial nOMEANDO OS InTEGRANTES DA CNDSS}

PORTARIA No 532, DE 14 DE MARÇO DE 2006

O MINISTRO DE ESTADO DA SAÚDE, no uso das atribuições que lhe confere o art. 87, parágrafo único, inciso IV, da Constituição Federal, e tendo em vista o art. $2^{\circ}$ do Decreto de 13 de março de 2006, que institui, no âmbito do Ministério da Saúde, a Comissão Nacional sobre Determinantes Sociais da Saúde (CNDSS), resolve:

Art. $1^{\circ}$ Designar os membros da Comissão Nacional sobre Determinantes Sociais da Saúde (CNDSS) com a finalidade de apoiar e articular a atuação do Poder Público, as instituições de pesquisa e da sociedade civil sobre determinantes sociais relacionados à melhoria da saúde e à redução das iniqüidades sanitárias.

I - Paulo Marchiori Buss - Fundação Oswaldo Cruz - que o coordenará;

II - Adib Jatene - Academia Nacional de Medicina;

III - Aloísio Teixeira - Universidade Federal do Rio de Janeiro - UFRJ;

IV - Ana Lúcia Gazzola - Universidade Federal de Minas Gerais - UFMG;

V - César Victora - Universidade Federal de Pelotas - UFPel;

VI - Dalmo Dallari - Universidade de São Paulo - USP;

VII - Eduardo Eugênio Gouvêa Vieira - Federação das Indústrias do Estado do Rio de Janeiro - Firjan;

VIII - Elza Salvatori Berquó - Centro Brasileiro de Análise e Planejamento - Cebrap;

IX - Sérgio de Magalhães Gomes Jaguaripe (Jaguar) - cartunista;

X - Jairnilson Paim - Universidade Federal da Bahia - Ufba;

XI - Maria Lucélia dos Santos - Atriz;

XII - Moacyr Scliar - Academia Brasileira de Letras;

XIII - Roberto Smeraldi - Amigos da Terra Amazônia Brasileira;

XIV - Rubem César Fernandes - Movimento Viva Rio;

XV - Sandra de Sá - Cantora;

XVI - Sônia Fleury - Cientista Política Fundação Getúlio Vargas; e

XVII - Zilda Arns Neumann - Pastoral da Criança.

Art. $2^{\circ}$ Os serviços prestados pelos membros da CNDSS são considerados de relevante interesse público, e não serão remunerados.

Art. $3^{\circ}$ A CNDSS terá prazo de trinta dias, após sua primeira reunião, para apresentar a proposta do regimento interno que disporá sobre seu funcionamento.

Art. $4^{\circ}$ A CNDSS terá prazo de dois anos para conclusão de seus trabalhos, com apresentação de relatório final.

Art. $5^{\circ}$ Esta Portaria entra em vigor na data de sua publicação

\section{SARAIVA FELIPE}




\section{Anexo III}

\section{INIQÜIDADES EM SAÚDE NO BRASIL: NOSSA MAIS GRAVE DOENÇA ${ }^{1}$}

\section{Introdução}

As iniqüidades em saúde entre grupos e indivíduos, ou seja, as desigualdades de saúde que além de sistemáticas e relevantes são também evitáveis, injustas e desnecessárias, segundo a definição de Margareth Whitehead, são um dos traços mais marcantes da situação de saúde do Brasil. A mortalidade infantil, cuja média nacional é de 25 por mil nascidos-vivos (NV), apresenta grandes disparidades regionais, observando-se taxas inferiores a 10 por mil NV, em alguns municípios do Sul e Sudeste e valores maiores do que 50 por mil NV, em áreas do Nordeste. Segundo o relatório da Unicef, de junho 2003, sobre eqüidade na infância e adolescência no Brasil, a taxa de mortalidade em menores de 5 anos (TMM5), em 1999, era de 57,4 por mil nascidos vivos, variando de 81,6 para o quintil de renda mais baixo a 29,8 para o mais alto. De acordo com a escolaridade da mãe, a TMM5 variava de 93 para mães com menos de 4 anos de estudo a 30,4 para aquelas com mais de 8 anos de estudo. O filho de uma mulher com até um ano de escolaridade tem uma probabilidade 23 vezes maior de chegar analfabeto à adolescência, se comparado com o filho de uma mulher com 11 anos de estudo.

Há muito se reconhece que os principais determinantes dessas iniqüidades estão relacionados às formas como se organiza a vida social. Já em meados do século XIX, Virchow entendia que a "ciência médica é intrínseca e essencialmente uma ciência social", que as condições econômicas e sociais exercem um efeito importante sobre a saúde e a doença e que tais relações devem submeterse à pesquisa científica. Entendia também que o próprio termo "saúde pública" expressa seu caráter político e que sua prática deve conduzir necessariamente à intervenção na vida política e social para indicar e eliminar os obstáculos que dificultam a saúde da população.

Desde então muito se avançou na construção de modelos explicativos que analisam as relações entre a forma como se organiza e se desenvolve uma determinada sociedade e a situação de saúde de sua população. Um dos principais desafios destes modelos explicativos é o estabelecimento de uma hierarquia de determinações entre os fatores mais globais de natureza social, econômica, política e as mediações através das quais estes fatores incidem sobre a situação de saúde de grupos e pessoas. É este complexo de mediações que permite entender porque não há uma correlação constante entre os macro-indicadores da riqueza de uma sociedade, como o Produto Interno Bruto (PIB), com os indicadores de saúde. Evidentemente, o volume de riqueza gerado por uma sociedade é um elemento fundamental para proporcionar melhores condições de vida e de saúde, mas há inúmeros exemplos de países com PIB total ou PIB per capita bem superior a outros que, apesar disso, possuem indicadores de saúde muito mais satisfatórios.

Nos últimos anos, aumentaram também, em quantidade e qualidade, os estudos sobre as relações entre a saúde das populações, as desigualdades nas condições de vida e o grau de desenvolvimento da trama de vínculos e associações entre indivíduos e grupos. Estes estudos permitem constatar que, uma vez superado determinado limite de crescimento econômico de um país, um crescimento 
adicional da riqueza não se traduz em melhorias significativas das condições de saúde. A partir desse nível, o fator mais importante para explicar a situação geral de saúde de um país não é sua riqueza total, mas a maneira como ela se distribui.

Em outras palavras, a desigualdade na distribuição de renda não é prejudicial à saúde somente dos grupos mais pobres, mas é também prejudicial para a saúde da sociedade em seu conjunto. Grupos de renda média em um país com alto grau de iniqüidade de renda possuem uma situação de saúde pior do que a de grupos com renda inferior, mas que vivem em uma sociedade mais eqüitativa. Um estudo comparativo entre os estados dos Estados Unidos da América revelou que os indivíduos que vivem em estados com grandes diferenças de renda possuem pior saúde do que aqueles com ingressos equivalentes, mas que vivem em estados mais igualitários. o Japão não é o país com maior expectativa de vida do mundo por ser o país mais rico ou porque os japoneses fumam menos ou fazem mais exercício, mas porque é um dos países mais igualitários do mundo.

Estudos vêm demonstrando que o principal mecanismo através do qual as iniqüidades de renda produzem um impacto negativo na situação de saúde é o desgaste do chamado capital social, ou seja, das relações de solidariedade e confiança entre pessoas e grupos. Segundo vários autores, o desgaste do capital social em sociedades ineqüitativas explicaria, em grande medida, porque sua situação de saúde é inferior a de sociedades onde as relações de solidariedade são mais desenvolvidas. A debilidade dos laços de coesão social, ocasionada pelas iniqüidades de renda, corresponde a baixos níveis de capital social e de participação política. Países com grandes iniqüidades de renda, escassos níveis de coesão social e baixa participação política são os que menos investem em capital humano e em redes de apoio social, que são fundamentais para a promoção e proteção da saúde individual e coletiva.

No caso do Brasil, o fardo é duplo, pois além de apresentar graves iniqüidades na distribuição da riqueza, há grandes setores de sua população vivendo em situação de pobreza que não lhes permite ter acesso a mínimas condições e bens essenciais à saúde. Além da renda dos $20 \%$ mais ricos ser 26 vezes maior do que a renda dos $20 \%$ mais pobres, $24 \%$ da população economicamente ativa possuem rendimentos menores que 2 dólares por dia. 0 tema da pobreza também vem chamando a atenção de muitos autores, o que vem gerando uma mudança na maneira como a entendemos e nas formas para combatê-la. Para estes autores, a pobreza não é somente a falta de acesso a bens materiais, mas é também a falta de oportunidades e de possibilidades de opção entre diferentes alternativas. Pobreza é, também, a falta de voz frente às instituições do Estado e da sociedade e uma grande vulnerabilidade frente a imprevistos. Nesta situação a capacidade dos pobres de atuar em favor de sua saúde e da coletividade está bastante diminuída.

Para ser coerente com esta nova maneira de entender a pobreza, as estratégias para combatêla devem incluir tanto a geração de oportunidades econômicas, como medidas que favoreçam a construção de redes de apoio e o aumento das capacidades desses grupos para conhecer melhor os problemas locais e globais, para estreitar suas relações com outros grupos, para fortalecer sua organização e participação em ações coletivas, para constituir-se, enfim, em atores sociais e ativos participantes das decisões da vida social.

Infelizmente, estes e outros importantes avanços no conhecimento dos determinantes sociais das condições de saúde e, em particular, das iniqüidades em saúde, encontrados na literatura científica 
brasileira e internacional, não são acompanhados por um correspondente avanço na utilização desse conhecimento para a definição de políticas de saúde no país.

Isto se deve, em grande medida, à debilidade das relações entre o processo de produção do conhecimento e o processo de tomada de decisão sobre políticas e programas de saúde, o qual deveria basear-se em conhecimentos e evidências. Ambos os processos costumam desenvolver-se por separado, com lógicas, agentes e espaços institucionais específicos. Por outro lado, a aproximação entre pesquisa em saúde e políticas de saúde com vistas à promoção da eqüidade não significa a despolitização das decisões sobre políticas em nome de uma racionalidade centralizadora baseada em evidência científica.

Em geral, não há prescrições categóricas de políticas baseadas em resultados objetivos de pesquisas, mas um leque de opções que a ciência ajuda a delimitar. A seleção entre estas opções se faz por meio de um processo que é essencialmente político, envolvendo diversos atores, com interesses diferenciados e eventualmente contraditórios. Para que haja maior utilização de resultados de investigação para a definição de políticas, é necessário instrumentalizar a atuação desses diferentes atores, particularmente dos que usualmente estão excluídos do processo de decisão, buscando diminuir as enormes iniqüidades de acesso a informações e conhecimentos.

Não há, portanto nenhuma contradição entre, por um lado, a promoção de políticas baseadas em evidência e, por outro, a ampliação da participação social na definição das mesmas. Na realidade, para que as políticas de saúde se consolidem como políticas públicas voltadas a atender ao interesse público e à promoção da eqüidade, é necessário o fortalecimento do processo democrático de definição destas políticas, multiplicando os atores envolvidos, os espaços e oportunidades de interação entre eles e instrumentalizando sua participação com o acesso eqüitativo a informações e conhecimentos pertinentes.

\section{A Comissão Nacional de Determinantes Sociais em Saúde - CNDSS}

Preocupado com as iniqüidades que se verificam nas condições de saúde da população e no acesso aos serviços de saúde e a outros serviços públicos que influenciam a situação de saúde, o governo brasileiro decidiu criar a Comissão Nacional sobre Determinantes Sociais da Saúde (CNDSS), no bojo de um movimento mundial em torno deste tema, proposto pela Organização Mundial da Saúde (OMS).

Na Assembléia Mundial da Saúde de 2004, o então Diretor Geral da OMS, Lee Jong-Wook, propôs a criação de uma comissão para recomendar políticas públicas de saúde e externas ao setor, assim como intervenções que visem a melhoria das condições de saúde e a diminuição das iniqüidades. A Comissão sobre Determinantes Sociais da Saúde (CSDH-OMS) foi criada em março de 2005, com vigência de 3 anos.

A CSDH-OMS é um fórum estratégico mundial formado por lideranças políticas, científicas e da sociedade civil organizada. A Comissão tem como meta global a busca de eqüidade em saúde. Lidera um processo mundial de organização do conhecimento sobre os determinantes sociais em saúde, com vistas a fortalecer as práticas e as políticas voltadas para a diminuição das iniqüidades. 
Entre os objetivos da CSDH-OMS, merecem destaque:

- a sistematização de evidências sobre experiências e formulação de políticas que enfocam os determinantes sociais em saúde;

- o fomento do debate junto à sociedade, para a implantação de ações de enfrentamento dos determinantes sociais em saúde;

- a definição de compromissos de médio e longo prazo, com vistas a incorporar as desigualdades em saúde como tema central da agenda da OMS.

Em julho de 2005, a Organização Pan-americana da Saúde (Opas) reuniu, em Washington, os países da região das Américas e apresentou a proposta da CSDH-OMS, despertando o interesse dos países sobre a temática. Após essa reunião, a Fundação Oswaldo Cruz (Fiocruz) e a Secretaria de Vigilância em Saúde (SVS), do Ministério da Saúde, lideraram o processo para a definição de uma agenda de atividades no Brasil, buscando respostas sociais organizadas para o enfrentamento dos determinantes sociais em saúde no país.

Em março de 2006, ao completar tão somente um ano da criação da Comissão mundial, apressa-se o Brasil a participar desta iniciativa, com o lançamento da Comissão Nacional sobre Determinantes Sociais da Saúde (CNDSS) no país.

A CNDSS é fruto de um processo de construção da Reforma Sanitária, que já dura pelo menos quatro décadas, e que teve como um de seus pontos culminantes a incorporação pela Constituição Federal do Brasil, aprovada em 1988, do artigo 196, determinando que "a saúde é direito de todos e dever do Estado, garantido mediante políticas sociais e econômicas que visem à redução do risco de doença e de outros agravos e ao acesso universal e igualitário às ações e serviços para sua promoção, proteção e recuperação".

Apesar deste e de outros avanços alcançados nas últimas décadas, constatados pela melhoria de alguns índices de desenvolvimento social e pela criação do Sistema Único de Saúde (SUS), com base nos princípios de solidariedade e universalidade da assistência, grandes parcelas da população brasileira ainda sofrem problemas geradores de importantes iniqüidades em saúde, como o desemprego, a falta de acesso à moradia digna, ao sistema de saneamento básico, a serviços de saúde e de educação de qualidade e a um meio ambiente protegido.

o monitoramento dessas iniqüidades e o estudo sistemático e aprofundado de seus determinantes deverão permitir identificar pontos mais vulneráveis ao impacto de políticas públicas que buscam combatê-las. Para que essas políticas sejam mais efetivas, é necessário, portanto, por um lado, aumentar os conhecimentos sobre determinantes sociais em saúde, suas hierarquias e mediações e, por outro lado, facilitar a incorporação desses conhecimentos na definição e implantação das políticas. São estes os mais importantes desafios que a CNDSS se propõe a enfrentar, com vistas a colaborar na construção de uma sociedade mais justa, igualitária e humana.

Serão suas principais linhas de atuação:

- estimular a melhoria da qualidade e completude das informações sociodemográficas nos sistemas de informação oficiais da saúde, de forma a permitir o monitoramento das desigualdades sociais em saúde; 
- introduzir a temática dos determinantes sociais da saúde e das conseqüências das desigualdades na formação dos profissionais de saúde;

- fomentar e mobilizar os profissionais e gestores de saúde em prol de políticas públicas focadas, explicitamente, na busca da eqüidade em saúde;

- mobilizar a sociedade civil para a defesa do princípio da eqüidade na execução das políticas públicas pertinentes;

- criar instrumentos que possibilitem a circulação, na sociedade, dos conhecimentos e direitos relativos aos determinantes sociais da saúde;

- criar fóruns intersetoriais para o debate do tema e estabelecimento de compromissos pactuados de enfrentamento do problema, incluindo a discussão de modelos de políticas de curto, médio e longo prazo;

- estimular a produção de conhecimentos sobre os determinantes sociais em saúde através de linhas específicas de financiamento à pesquisa e de apoio à formação de investigadores;

- incluir metas para redução das desigualdades sociais em saúde, de maneira explícita, nas políticas sociais;

- articular-se com outras iniciativas de políticas públicas de redução da pobreza e de riscos à saúde, a exemplo do Conselho Nacional de Desenvolvimento Econômico e Social (CNDES), Fome Zero, Conselho Nacional de Segurança Alimentar (Consea) e outros;

- promover a defesa e indução de ações para o enfrentamento das desigualdades sociais em saúde, no Brasil, junto as três esferas de governo, nos âmbitos executivo e legislativo;

- garantir a inclusão e a execução, refletidas nos orçamentos públicos das três esferas de governo, de ações dirigidas à redução das iniqüidades em saúde. 


\section{Anexo III A}

Discurso proferido pelo Dr. Adib Jatene na cerimônia de entrega do relatório da CNDSS ao Exmo. Presidente da República em $1^{\circ}$ agosto de 2008

Os membros da Comissão sobre Determinantes Sociais da Saúde entregam neste ato o relatório final do seu trabalho intitulado "Causas Sociais das Iniqüidades em Saúde no Brasil".

Nossa Comissão foi criada por V. Exa . em atendimento e recomendação da Organização Mundial da Saúde de março de 2005. Estamos entre os primeiros países que acolheram a recomendação baseada em que a saúde é um fenômeno social, ou seja, são as condições de vida e trabalho os principais responsáveis pela saúde das pessoas e das comunidades.

O Brasil possui características peculiares por ter ingressado no desenvolvimento industrial e tecnológico com mais de 200 anos de atraso, o que resultou em urbanização acelerada com ênfase no desenvolvimento econômico e desprezo pelo desenvolvimento social. Isso gerou desigualdade social e concentração escandalosa de renda e de conhecimento em parcela minoritária da população. Nossa Comissão buscou elaborar o relatório dentro da tradição do movimento sanitário brasileiro exprimindo o reconhecimento de que saúde é um bem público construído com a participação solidária de todos os setores da sociedade brasileira.

O relatório procurou atender a três compromissos básicos.

o primeiro deles é o compromisso com a eqüidade. As iniqüidades em saúde são moralmente indefensáveis e seu combate é imperativo obrigando a intervenção sobre os determinantes que os geraram e que, sendo produto de ação humana equivocada, podem e devem ser transformados pela ação humana. É um comportamento eminentemente ético.

O segundo é o compromisso com a ação que implica elaborar recomendações concretas de políticas, programas e intervenções capazes de combater e corrigir as iniqüidades ora existentes. Essas intervenções exigem uma sólida base de apoio político que associa a lucidez da tomada e posições administrativas com um despertar da consciência dos diversos setores da população sobre a gravidade do problema das iniqüidades em saúde e sobre a urgente necessidade de combatê-las.

Já se vão 30 anos desde que a Organização Mundial da Saúde cunhou na sua Assembléia Geral em Alma-Ata o slogan "Saúde para todos no ano 2000" e em 2008 ainda assistimos, estarrecidos, ao grande descompasso entre o extraordinário desenvolvimento econômico e tecnológico ao lado de um subdesenvolvimento social mesmo em países desenvolvidos. Parece que o que conta são as coisas que as pessoas têm e não as pessoas.

O terceiro compromisso é com a evidência. As recomendações da Comissão estão solidamente fundamentadas em evidências científicas que permitem entender como operam os DSS na geração das iniqüidades e como e onde devem incidir as intervenções para combatê-las. Graças aos sistemas de informação de abrangência nacional, hoje disponíveis, bem como a quantidade e qualidade da produção científica nacional e internacional sobre o tema foi possível reunir sólidas evidências sobre o impacto dos diversos determinantes sociais na atual situação da saúde do país, em particular na geração das iniqüidades. 
Nosso relatório registra também os importantes avanços na situação de saúde dos brasileiros. Apenas dois exemplos: em 1960, a expectativa de vida de um brasileiro, na região Nordeste era de 49 anos, enquanto na Região Sul era de 69 anos. Em 2006, a expectativa de vida no Nordeste subiu para 69,5, enquanto no sul subia para 74,5 anos. A diferença de 20 anos reduziu-se para cinco anos. A proporção de óbitos de menores de um ano sobre o total de óbitos reduziu-se de $24 \%$, em 1980, para 5\% em 2005.

Ao lado de inegáveis avanços, nosso relatório aponta também os importantes desafios que todos temos de enfrentar para atender as metas de um país que colocou na sua Constituição que: "saúde é direito de todos, e dever do Estado", devendo ser oferecido com eqüidade e integralidade para todos.

Gostaria, antes de terminar, enfatizar que o trabalho da Comissão Nacional foi facilitado pela participação de diversas instituições, em particular da Fiocruz, que sediou a Secretaria Técnica da Comissão coordenada, magnificamente por Alberto Pellegrini Filho, a quem todos, por meu intermédio, agradecem.

Devo ressaltar o apoio político dos mais altos escalóes do governo, principalmente dos ministros da Saúde, Saraiva Felipe, Agenor Álvares e José Gomes Temporão. O ministro Temporão tem sido um batalhador incansável, para que o Ministério da Saúde seja efetivamente voltado para a promoção de saúde e bem-estar da população, e não apenas um Ministério da doença.

Em nome dos demais membros da Comissão gostaria de agradecer a oportunidade que nos foi dada de, modestamente, contribuir para que nossa sociedade seja cada vez mais humana e justa, e que nos permita conquistar segurança e paz. 


\section{SUMÁRIO EXECUTIVO}

\section{INTRODUÇÃo}

Em março de 2005, a Organização Mundial da Saúde (OMS) criou a Comissão sobre Determinantes Sociais da Saúde (Commission on Social Determinants of Health, CSDH), com o objetivo de promover, em âmbito internacional, uma tomada de consciência sobre a importância dos determinantes sociais na situação de saúde de indivíduos e populações e sobre a necessidade do combate às iniqüidades em saúde por eles geradas. Um ano depois, em 13 março de 2006, por meio de Decreto Presidencial, foi criada, no Brasil, a Comissão Nacional sobre Determinantes Sociais da Saúde (CNDSS), com um mandato de dois anos.

A CNDSS esteve integrada por 16 expressivas lideranças de nossa vida social, cultural, científica e empresarial. Sua constituição diversificada é uma expressão do reconhecimento de que a saúde é um bem público, construído com a participação solidária de todos os setores da sociedade brasileira.

Os objetivos da CNDSS podem ser assim resumidos:

- gerar informações e conhecimentos sobre os determinantes sociais da saúde no Brasil;

- contribuir para a formulação de políticas que promovam a eqüidade em saúde;

- mobilizar diferentes instâncias do governo e da sociedade civil sobre este tema.

Para alcançar seus objetivos, a CNDSS se apóia em três compromissos básicos:

Compromisso com a eqüidade: apesar dos importantes avanços dos últimos anos na melhoria do valor médio de seus indicadores de saúde, o Brasil está entre os países com maiores iniqüidades em saúde, ou seja, desigualdades de saúde entre grupos populacionais que além de sistemáticas e relevantes são também evitáveis, injustas e desnecessárias.

O compromisso da CNDSS com a eqüidade, visando a assegurar o direito universal à saúde, não é apenas uma decisão racional, mas, fundamentalmente, um compromisso ético e uma posição política.

Compromisso com a evidência: a CNDSS procura fundamentar suas análises e recomendações em sólidas evidências científicas, pois são estas que permitem, por um lado, entender como operam os determinantes sociais na geração das iniqüidades em saúde e, por outro, como e onde devem incidir as intervenções para combatê-las e que resultados podem ser esperados em termos de efetividade e eficiência. 
Compromisso com a ação: o compromisso maior da Comissão e que dá sentido à sua existência é o combate às iniqüidades em saúde por meio da atuação sobre os determinantes sociais que as geraram, os quais, sendo produto da ação humana, podem e devem ser modificados pela ação humana. O compromisso com a ação está alicerçado nas evidências científicas, conforme já assinalado, e numa ampla base de sustentação política, produto da conscientização e mobilização de diversos setores da sociedade.

Os diversos estudos sobre os DSS e as iniqüidades em saúde permitiram a construção de modelos que procuram esquematizar a trama de relações entre os vários níveis de determinantes sociais e a situação de saúde. Entre estes modelos, a CNDSS resolveu adotar o de Dahlgren e Whitehead (1991), que serve de base para orientar a organização de suas atividades e os conteúdos do presente relatório. A escolha se justifica por sua simplicidade, por sua fácil compreensão para vários tipos de público e pela clara visualização gráfica dos diversos DSS. Nesse modelo, os DSS estão dispostos em diferentes camadas, segundo seu nível de abrangência, desde uma camada mais próxima aos determinantes individuais até uma camada distal onde se situam os macrodeterminantes.

\section{Análise da Situação de Saúde}

\subsection{Situação e Tendências da Evolução Demográfica, Social e Econômica do País}

o Brasil vem passando por grandes transformações econômicas, sociais e demográficas, particularmente nas quatro últimas décadas, com significativas repercussões nas condições de vida e trabalho da população e, conseqüentemente, em sua situação de saúde.

O censo demográfico de 1960 revelava que 55\% da população economicamente ativa, portanto sua maioria, dedicavam-se à agricultura, enquanto os restantes $45 \%$ se dedicavam aos setores secundário e terciário. Já na década seguinte, essa proporção se inverte, com 54\% da população empregada na indústria ou no setor serviços. Segundo o último censo de 2000 , apenas $19 \%$ da população estavam empregados no campo, ou seja, uma queda de 55\% para $19 \%$ em quatro décadas. Nesse mesmo período, a população empregada pelo setor serviços passou de $27 \%$ a $60 \%$, enquanto que a dedicada à indústria, depois de uma ascensão de $17 \%$ a 29\% entre 1960 e 1980, caiu para $21 \%$ no censo de 2000.

Evidentemente, essa redistribuição acelerada da população economicamente ativa (PEA) do setor agrícola para os setores industriais e de serviços implicou um processo de urbanização também extraordinariamente acelerado. Em 1960, a maioria da população (55\%) possuía seu domicílio na zona rural. Na década seguinte, a proporção se inverteu, com 56\% da população residindo na área urbana, proporção que cresceu explosivamente desde então para atingir $81 \%$, em 2000.

Os processos de industrialização e urbanização acelerada foram responsáveis por importantes mudanças nos padrões de fecundidade da população. Segundo dados do Censo, a taxa média geométrica de crescimento anual da população passou de 2,89\%, no período 1960/1970, para 
1,64\% no período 1991/2000. A taxa de fecundidade, que era de 6,3 filhos por mulher em idade fértil em 1960, caiu para 2,3 em 2000, devendo situar-se em 2,0 em 2006, segundo projeções do IBGE. Embora a queda acelerada da taxa de fecundidade ocorra em todas as regiões do país, existem importantes diferenças segundo a escolaridade das mulheres. De acordo com dados da Pesquisa Nacional por Amostra de Domicílios (Pnad), de 2006, a taxa de fecundidade total que, em 2005, era de 2,1 filhos por mulher em idade fértil, variava de 4 para mulheres com até três anos de estudo a 1,5 para as que possuíam oito ou mais anos de estudo. Apesar das baixas taxas atuais de fecundidade, a população brasileira ainda deve crescer de maneira expressiva nas próximas décadas, como resultado da fecundidade passada. Haverá, também, uma importante modificação na estrutura etária, com envelhecimento da população, causado pela diminuição da fecundidade e aumento da expectativa de vida.

As quatro décadas entre 1960 e 2000 também foram marcadas por importantes transformações econômicas. Segundo o Ipeadata, o Produto Interno Bruto (PIB) per capita passou de 2.060 dólares, em 1960, para 5.250 em 2000 e 5.720 em 2006 (em valores constantes do dólar de 2006). A agropecuária, responsável por 25 \% do PIB em 1960, caiu sua participação para $8,9 \%$ em 2004, com um crescimento de 209\% nesse período, enquanto a indústria, que correspondia a $18 \%$ do PIB em 1960 , passou a responder por $42 \%$ do PIB em 2004 , com um crescimento de $1.727 \%$ no período.

Entretanto, esse extraordinário aumento da riqueza produzida e a modernização da economia não significaram melhoria importante na distribuição de renda. Mesmo com as melhorias recentes na distribuição de renda, relacionadas ao controle da inflação, à estabilidade macroeconômica (proporcionadas pelo Plano Real), à valorização do salário mínimo e aos programas de transferência de renda intensificados nos últimos anos, a distribuição de renda no Brasil continua entre as piores do mundo. Com base em um Índice de Gini de 0,57 em 2003, o relatório do Programa das Nações Unidas para o Desenvolvimento (Pnud), de 2007, situa o Brasil em $11^{\circ}$ lugar entre os países com mais alta concentração de renda (em 2006, o Índice de Gini caiu para 0,54).

$\mathrm{Na}$ esfera do desenvolvimento social, ocorreram também grandes mudanças nas últimas décadas, destacando-se, entre elas, as ocorridas na educação. Em 1940, 56\% da população brasileira era analfabeta, percentual que cai para 40\% no em 1960 e 13,6\% no ano 2000 . Segundo a Pnad, em 2006, havia 12,3\% de analfabetos entre as pessoas com 5 ou mais anos de idade, observando-se, entretanto, importantes diferenças regionais, já que este percentual na região Sul era de $7,6 \%$, enquanto no Nordeste era de $22,10 \%$. Há, também, importantes diferenças de acordo com a renda familiar. A média de analfabetos de 10,4\%, entre as pessoas com 15 ou mais anos de idade, variava de $17,9 \%$ para as pessoas com rendimento mensal familiar per capita menor que meio salário mínimo até 1,3\% para as pessoas com mais de dois salários mínimos.

Ainda segundo a Pnad 2006, há também extraordinário avanço da escolaridade no nível fundamental, com cobertura quase universal entre 7 a 14 anos, em todas as regiões, tanto na área urbana como rural. No caso do ensino médio, a taxa de freqüência líquida entre 15 
a 17 anos ainda é bastante baixa para o Brasil como um todo (cerca de 47\%), com grandes variações segundo região e segundo situação do domicílio (urbano/rural), enquanto para o ensino fundamental é de 95\%, sem grandes disparidades segundo estas variáveis.

Os importantes avanços e contradições no desenvolvimento econômico-social das últimas décadas são também observados na situação de saúde. Segundo o IBGE, a taxa de mortalidade infantil (TMI), que era de 124 óbitos no primeiro ano de vida para cada mil nascidos vivos em 1960, caiu para 48,3 em 1990; 35,26 em 2000 e 25,1 em 2006. Quanto à esperança de vida ao nascer, houve um ganho de mais de 20 anos, entre 1960 e 2006, para o Brasil como um todo, passando de 51,6 a 72,4. Embora persistam importantes diferenças regionais, como por exemplo, a expectativa de vida no Nordeste, em 2006, ainda é dois anos menor do que era a do Sul em 1990, há uma tendência à diminuição dessas diferenças. Em 1960, um brasileiro que nascesse no Nordeste tinha uma expectativa de vida 20 anos menor do que a de outro brasileiro nascido na região Sul, diferença essa que cai para cinco anos em 2006.

As tendências positivas observadas nas últimas décadas com relação à renda, escolaridade e saúde se expressam na evolução do índice de desenvolvimento humano (IDH), do PNUD, que passou de 0,649 em 1975 para 0,800 em 2005.

\subsection{A Estratificação Socioeconômica e a Saúde}

As condições socioeconômicas, culturais e ambientais de uma dada sociedade, ou seja, os determinates mais gerais e distais do modelo de Dahlgren e Whitehead, geram uma estratificação econômico-social dos indivíduos e grupos da população, conferindo-lhes posições sociais distintas, as quais por sua vez provocam diferenciais de saúde. Em outras palavras, a distribuição da saúde e da doença em uma sociedade não é aleatória, estando associada à posição social que, por sua vez, define as condições de vida e trabalho dos indivíduos e grupos.

Nesta seção, são apresentadas algumas associações entre estratificação socioeconômica (segundo renda, escolaridade, gênero, cor da pele e local de moradia) e resultados de saúde, destacando as iniqüidades em saúde derivadas da posição social ocupada por indivíduos e grupos da população.

A realização de exames preventivos para câncer de mama e de colo de útero, assim como de consultas pré-natal são bons exemplos das desigualdades de acesso e utilização de serviços de saúde, de acordo com escolaridade, observando-se um nítido gradiente segundo esta variável. A proporção de mulheres de 25 anos ou mais de idade que já realizaram alguma vez exame de mamografia varia de $24,3 \%$, para as mulheres sem instrução ou com menos de um ano de estudo, até $68,1 \%$ para as com 15 anos ou mais. A proporção de mulheres de 25 anos ou mais de idade que realizaram alguma vez exame preventivo para câncer de colo uterino varia de 55,8\%, para as com menos de um ano de estudo, até 93,1\% para as com 15 anos ou mais. Entre as mulheres com 12 ou mais anos de estudo, 20\% de seus filhos nasceram após um pré-natal com sete ou mais consultas, ao passo que para aquelas sem 
instrução esse percentual cai para 1,2\%. Inversamente, entre as mulheres sem instrução, $14,4 \%$ de seus filhos nasceram sem que houvesse nenhuma consulta pré-natal, porcentagem que cai para $2,7 \%$ entre as com 12 ou mais anos de estudo.

\subsection{Condições de Vida, Ambiente e Trabalho}

Neste item, apresentam-se alguns aspectos fundamentais das condições de vida e trabalho, com ênfase nas desigualdades existentes entre estas condições e sua associação com a situação de saúde. Destacam-se as condições de alimentação e nutrição, saneamento básico e habitação, condições de emprego e trabalho, ambiente e saúde, acesso a serviços de saúde e acesso à informação.

\section{Alimentação e Nutrição}

Nas últimas décadas, o Brasil vem passando por um processo de transição nutricional, que consiste na substituição de um padrão alimentar baseado no consumo de cereais, feijões, raízes e tubérculos por uma alimentação mais rica em gorduras e açúcares. Conforme ocorre com os processos de transição demográfia e epidemiológica, o processo de transição nutricional é também marcado pela sobreposição de padrões, pela temporalidade indefinida e, sobretudo, pelas desigualdades de acordo com a estratificação socioeconômica.

Essa mudança nos padrões alimentares vem aumentando o risco de sobrepeso e obesidade, condições que contribuem de forma importante para o aparecimento de doenças crônicas e incapacidades. A Pesquisa de Orçamento Familiar (POF), de 2003, mostrou que o número de brasileiros adultos com excesso de peso tinha praticamente dobrado em relação a 1974, quando foi feito o Estudo Nacional de Despesas Familiares. Em 2003, o excesso de peso atingia, em média, quatro em cada dez brasileiros adultos, superando em cerca de oito vezes o déficit de peso entre as mulheres e em quinze vezes entre os homens. Considerando o universo de brasileiros com 20 anos ou mais de idade, o IBGE estima que haja 3,8 milhões de pessoas (ou 4,0\%) com déficit de peso e 38,8 milhões (40,6\%) com excesso de peso, das quais 10,5 milhões são consideradas obesas.

\section{Saneamento Básico e Habitação}

A Pesquisa Nacional por Amostra de Domicílios (Pnad) registrou melhoria nos índices de cobertura dos serviços de água e esgoto no período de 1999 a 2004. Segundo a Pnad 2004, o percentual de domicílios particulares permanentes atendidos por rede geral de abastecimento de água aumentou de $80 \%$ para $83 \%$ e o percentual de domicílios servidos por esgotamento sanitário adequado (rede coletora ou fossa séptica) aumentou de $65 \%$ para $70 \%$, no referido período. Entretanto, há que se destacar as desigualdades regionais e entre municípios. Em 2005, enquanto nas regiões Sul e Sudeste, respectivamente $83 \%$ e $91 \%$ da população estavam cobertos pela rede geral de abastecimento de água, nas regiões Norte e Nordeste a cobertura desses serviços alcançava apenas $54,8 \%$ e $72 \%$ da população, respectivamente. 
No que se refere às regiões metropolitanas das capitais, as diferenças também são bastante significativas. Por exemplo, a proporção da população coberta pela rede de esgotamento sanitário, em 2005, variava de 44,26\% em Recife e 66,33\% em Fortaleza até 92,21\% em Curitiba e 91,97\% em Porto Alegre.

\section{Condições de Emprego e Trabalho}

Os problemas de saúde dos trabalhadores estão intimamente relacionados com o grau de desenvolvimento alcançado por um país ou uma região. Acompanhando as grandes diferenças no desenvolvimento social e econômico das diversas regiões do Brasil, as características da saúde dos trabalhadores e das lesões e doenças relacionadas ao trabalho mostram um padrão misto, caracterizando uma carga dupla de doenças. Verifica-se a presença de algumas doenças já controladas em países desenvolvidos, como a silicose e outras pneumoconioses, envenenamento por chumbo e asbestose, ao lado de outras "novas" doenças relacionadas ao trabalho, como afecções musculoesqueléticas, doenças dermatológicas causadas por compostos químicos, além dos sintomas e desordens mentais relacionadas ao estresse. A combinação de formas tradicionais e novas de organização do trabalho acaba por determinar altos níveis de exposição aos perigos químicos e físicos, tarefas repetitivas, excessivo uso de força, posturas inadequadas, exposição ao estresse e fatores psicossociais, causando sofrimento e incapacidades temporárias e de longo prazo .

De acordo com os dados oficiais, referentes, unicamente, aos trabalhadores formais, em 2005, 2.700 trabalhadores morreram e 491.000 ficaram fora do trabalho recebendo benefícios do seguro do trabalhador. No período de 2000 a 2002, o INSS reconheceu 58.978 casos de doenças relacionadas a trabalho, o que corresponde a uma cobertura de somente $23 \%$ dos trabalhadores, aqueles que têm contratos formais e são elegíveis para benefícios. Conseqüentemente, um grande número de casos permanece desconhecido.

\section{Ambiente e Saúde}

O impacto da poluição do ar na saúde, no Brasil, tem sido amplamente documentado na literatura. Os estudos têm mostrado que aumentos nos níveis de poluentes do ar se associam a aumentos na mortalidade e na morbidade, tanto por problemas respiratórios como cardiovasculares, em especial entre idosos e crianças. Outros efeitos referem-se a perdas econômicas, aumento no absenteísmo escolar, dias de trabalho perdidos, asma e nebulizações.

$\mathrm{Na}$ década de 1990, as primeiras estimativas de efeito da poluição do ar mostraram que a mortalidade total de idosos está diretamente associada com a variação do material particulado inalável (PM10), pois variações de $10 \mu \mathrm{g} / \mathrm{m} 3$ nas suas concentrações aumentam as mortes de idosos em 1,3\%. Entre essas mortes, a maior parte se deve às doenças respiratórias e cardiovasculares. Os efeitos dos poluentes podem ser modulados pela condição socioeconômica daqueles que estão expostos. Os indivíduos apresentam respostas diferentes a estímulos semelhantes em função das suas condições de vida. Esse ponto é de fundamental 
importância na formulação de políticas públicas voltadas para o estabelecimento de metas de redução de emissão de poluentes.

\section{Acesso a Serviços de Saúde}

Apesar de inegáveis avanços na produção de serviços e dos princípios de universalidade e eqüidade que regem o SUS, ainda se observam importantes desigualdades na oferta de recursos e serviços, assim como uma forte influência da posição social dos indivíduos no acesso, utilização e qualidade dos serviços de saúde.

Dados da Pnad de 2003 mostram que as pessoas da classe de maior renda têm 59,5\% mais chances de usar serviços de saúde do que aquelas da classe de menor renda. o mesmo efeito é observado em relação à escolaridade: entre os indivíduos com nove ou mais anos de escolaridade a chance de uso é 20,9\% maior do que a das pessoas de menor escolaridade. Apesar da persistência de um padrão de marcadas desigualdades sociais no uso de serviços de saúde, tanto para adultos quanto para as crianças, observa-se uma tendência de redução ao se comparar com as informações obtidas na Pnad de 1998.

\section{Acesso à Informação}

Um determinante social da saúde, cuja importância nem sempre é reconhecida com o destaque que merece é o acesso à informação. O acesso à informação em saúde está hoje grandemente facilitado pelas novas tecnologias de informação e comunicação (TIC), particularmente a Internet, as quais podem exercer grande influência sobre a situação de saúde e, em particular, sobre as iniqüidades em saúde. Entretanto, este potencial das TIC está ameaçado se não se resolvem as iniqüidades de acesso a essas tecnologias, também chamadas de brecha digital ou digital divide. Segundo o Ibope/Netratings, no terceiro trimestre de 2007, os usuários de Internet no Brasil, apesar de um crescimento de cerca de $21 \%$ em relação ao ano passado, são atualmente cerca de 39 milhões, uma minoria da população total, que através deste meio consegue acesso a bens e oportunidades para ascender socialmente. Dados da Pnad 2006 revelaram enormes desigualdades no acesso à Internet segundo escolaridade, renda e região de moradia, com gradientes que chegam a mais de 60 ou 70 vezes de diferença entre os dois grupos situados nos extremos de renda e escolaridade.

\subsection{Redes Sociais, Comunitárias e Saúde}

As redes sociais e comunitárias são constituintes do chamado capital social, entendido como o conjunto das relações de solidariedade e confiança entre pessoas e grupos. O desgaste do capital social é um importante mecanismo através do qual as iniqüidades socioeconômicas impactam negativamente a situação de saúde. Países com frágeis laços de coesão social resultantes dessas iniqüidades são os que menos investem em capital humano e em redes de apoio social e são também onde há menor participação na definição de políticas públicas. 
São poucos os estudos conduzidos na população brasileira que relacionam redes sociais e comunitárias com agravos em saúde, o que pode ser explicado, em parte, pela falta de domínio de metodologias adequadas para abordar estes objetos. Estudos com populações de idosos mostraram que a manutenção da independência para as atividades da vida diária, autonomia e satisfação com relacionamento familiar e amizades foram fatores preditivos independentes do envelhecimento bem-sucedido, tanto para homens como para mulheres. Estudos sobre associação entre transtornos mentais comuns e apoio social mostram que pessoas com baixo apoio social apresentaram maior prevalência de transtornos mentais comuns do que as com alto apoio social. O apoio social manteve-se associado aos transtornos mentais comuns mesmo após o ajuste por idade, escolaridade e participação no mercado de trabalho.

\subsection{Comportamentos, Estilos de Vida e Saúde}

Esta seção está baseada na revisão da literatura recente sobre dieta, exercício físico, tabagismo e alcoolismo e sua distribuição entre os diversos grupos sociais.

\section{Dieta}

O consumo de frutas e verduras é baixo, no Brasil como um todo, e quanto maior a renda e a escolaridade, maior o consumo destes alimentos. Há uma participação direta da renda no padrão de consumo: a cada $1 \%$ no aumento da renda, observa-se um aumento de 0,04\% das frutas, legumes e verduras (FLV) na composição da dieta; por outro lado, o decréscimo de 1\% no preço destes produtos aumenta sua participação na dieta em $0,2 \%$.

\section{Tabagismo}

Comparando dois inquéritos nacionais (Pesquisa Nacional de Saúde - PNS/1989 e Pesquisa Mundial de Saúde - PMS/2003), houve redução importante no hábito de fumar, em todas as faixas etárias, em ambos os sexos e no meio urbano e rural. No entanto, observam-se desigualdades na intensidade da redução, de acordo com o poder aquisitivo e a escolaridade. No caso do poder aquisitivo, o padrão foi semelhante em homens e mulheres: quanto menor a renda, menor a intensidade da redução; já para escolaridade, as diferenças foram mais acentuadas nas mulheres: quanto menor a escolaridade, menor a redução. As mulheres com escolaridade igual ou menor a quatro anos apresentaram o dobro da prevalência de tabagismo comparado com aquelas com escolaridade entre 9 a 11 anos de estudo. Na verdade, as desigualdades se acentuaram em 2003, apesar do declínio em todas as categorias.

\section{Alcoolismo}

Em um inquérito realizado pelo Instituto Nacional do Câncer (Inca), a prevalência de consumo de bebida alcoólica, nas 15 capitais brasileiras e no Distrito Federal, variou de 32,4\% a 58,6\%. A prevalência de consumo nos homens variou de $48,9 \%$ a $72,1 \%$, enquanto que em mulheres essa variação foi de $19,7 \%$ a 47,5\%, devendo-se observar que mesmo a maior taxa encontrada para mulheres $(47,5 \%)$ foi inferior a menor encontrada para homens. 
Em sociedades desenvolvidas, principalmente os países europeus, essas diferenças de gênero não são tão evidentes, em torno de $10 \%$ a $20 \%$. Nos países em desenvolvimento, essas diferenças são maiores, sendo que na América Latina, essas diferenças variaram de $20 \%$ a $100 \%$, dependendo do país. Esta variação pode ser explicada pelo tipo de bebida consumida com mais freqüência. Em Porto Alegre, na região Sul, onde se concentra a produção vinícola do país, observou-se a menor diferença por gênero (40\%).

As diferenças por gênero costumam ser ainda mais marcantes quando se avalia o consumo de risco. Entretanto, as taxas desse indicador, neste estudo, ficaram entre 4,6\% e 11,1\%. Na região Sul, apesar das taxas de consumo terem sido altas, em comparação às encontradas nas outras regiões, as taxas para consumo de risco encontraram-se entre as menores, o que deve estar relacionado às diferenças regionais no tipo de bebida consumida.

\subsection{Saúde Materno-Infantil}

Esta seção consta de dois componentes. O primeiro deles analisa os determinantes da mortalidade da infância no Brasil e regiões, destacando entre eles a renda e escolaridade da mãe. O segundo está baseado numa revisão da literatura científica sobre diversos aspectos da saúde materno-infantil no Brasil.

\section{Alguns determinantes da mortalidade na infância no Brasil}

A mortalidade na infância, ou seja, em menores de cinco anos tem sido utilizada como um bom indicador de avaliação das condições de saúde e de vida da população. Em sua fase mais recente (1990/2005), a mortalidade na infância, no Brasil, passa de 53,7 óbitos de menores de 5 anos por 1.000 nascidos vivos, para $28,8 \%$, ou seja, um decréscimo de $46,4 \%$.

Apesar dos avanços alcançados no indicador, persistem, ainda, profundos contrastes regionais. Durante o período, a região Nordeste apresentou declínios na mortalidade na infância de aproximadamente $55 \%$, ou seja, 10 pontos percentuais acima da média nacional. Todavia, o valor da taxa, nessa região, em 2005 (38,9\%), ainda representa o dobro da observada para as regiões Sudeste e Sul do país, significando uma melhoria, na medida que, em 1990, essa relação era de 2,5.

Existe uma relação inversa entre o nível de educação da mãe e a mortalidade na infância, ou seja, a medida em que aumenta a escolaridade materna, diminui de forma intensa a mortalidade de menores de 5 anos. Neste sentido, para o Brasil como um todo, em 1990, enquanto esta mortalidade, que era de $89,7 \%$ em crianças cujas mães tinham menos de quatro anos de instrução, se reduz para 30,3\% em crianças com mães com nível de instrução superior a oito anos, representando um diferencial de $196,6 \%$.

A mesma situação de desigualdade na sobrevivência de crianças se repete quando se considera o impacto de outra variável socioeconômica importante, como é o caso da renda. Esta variável, quando desagregada por quintis de renda familiar per capita, mostra que a mortalidade na infância é sempre superior para os quintis de renda familiar per capita mais pobre. De modo geral, nota-se que as diferenças entre os três primeiros quintis de renda 
familiar per capita são pequenas, acentuando-se nos dois últimos quintis, independentemente da unidade espacial analisada.

\section{Revisão da literatura sobre saúde materno-infantil}

Foi feita uma revisão da produção científica brasileira e internacional sobre os diferenciais em saúde de mães e crianças menores de cinco anos no Brasil, segundo grupos socioeconômicos e cobrindo o período de 1990 até meados de 2007.

Os resultados da revisão não deixam dúvidas sobre a presença de marcadas iniqüidades sociais em saúde e nutrição infantil em todo o país, evidenciadas nos indicadores de mortalidade, morbidade, situação nutricional e utilização de serviços de saúde. De todos os indicadores estudados, os resultados mostram que os pobres quase sempre apresentam situação menos favorável em termos de atenção pré-natal, peso ao nascer (tanto por retardo no crescimento intra-uterino como por parto pré-termo), amamentação exclusiva, cobertura vacinal, consultas preventivas, morbidade, subnutrição, deficiências de micronutrientes, desenvolvimento cognitivo e, conseqüentemente, mortalidade.

Os poucos indicadores que são piores entre as mães e crianças de famílias ricas incluem o parto por cesarianas, sobrepeso/obesidade e o uso de terapia de reidratação oral durante episódios de diarréia. Pesquisas recentes sobre amamentação mostram que esta prática, que antes era mais comum entre as crianças de famílias pobres, agora é mais comum entre as de nível socioeconômico mais elevado, pelo menos para os primeiros seis meses de vida.

\subsection{Saúde Indígena}

O mais recente censo demográfico (2000) mostra que os níveis de escolaridade dos indígenas permanecem muito baixos e que há diferenças importantes nas taxas de fecundidade total das mulheres indígenas urbanas (2,7 filhos) e rurais (5,7 filhos). Os dados censitários mostram, também, uma taxa de mortalidade infantil para os indígenas em 2000 (51,4 por mil nascidos vivos) significativamente mais elevada do que a taxa nacional (de 30,1 por mil). A mortalidade infantil indígena é muito superior a dos demais grupos de cor/raça, inclusive das crianças "pretas" e "pardas" (34,9 e 33,0 por mil, respectivamente).

As infecções respiratórias agudas e as diarréias são as principais causas de adoecimento e morte nas crianças menores de cinco anos. A desnutrição atinge mais de um quarto das crianças menores de cinco anos e, não raro, mais da metade delas. Condições precárias de saneamento e habitação, aliadas a baixa cobertura e qualidade dos serviços de saúde, interagem, levando ao agravamento e deterioração das condições nutricionais das crianças indígenas.

\section{RECOMENDAÇõES}

Esta seção inclui uma série de recomendações para intervenções sobre os DSS, com vistas a contribuir para a superação dos problemas assinalados neste relatório, particularmente para o combate às iniqüidades em saúde. 


\subsection{As Políticas e Programas em Curso}

Foi feito um mapeamento das ações de políticas sociais que têm relação com os determinantes sociais da saúde e que são executadas, principalmente, por outros ministérios que não o da Saúde, verificando sua execução orçamentária no triênio 2004-2006, e identificando as que são objeto da atuação desses vários órgãos e apresentam possibilidades ou potencialidades de articulação com o setor saúde.

Os valores e o volume de ações envolvidas indicam que o conjunto temático estudado ocupa lugar de destaque na agenda política do governo federal. O crescimento dos valores envolvidos indica que não houve, de maneira geral, depreciação nos níveis de investimento no setor.

No tocante à articulação das políticas, programas e ações, os dados sugerem: 1) baixa articulação entre os temas escolhidos, 2) baixa articulação entre os órgãos executores, 3) baixa articulação do Ministério da Saúde quanto a sua participação nas ações estudadas, 4) fragmentação das ações, 5) provável redundância de ações, 6) concorrência entre órgãos públicos federais e baixa coordenação entre estes. A despeito do caráter descritivo desta revisão, é possível adiantar algumas implicações em termos de políticas públicas: 1) ampliar o patamar de investimento das ações estudadas; 2) promover a racionalização dos investimentos, concentrando-os nas ações que apresentaram maior consistência ao longo do tempo; 3) promover a articulação dessas ações e integrar os vários órgãos federais envolvidos na execução de programas e ações, inclusive o Ministério da Saúde, em uma agenda comum pautada pelos determinantes sociais da saúde.

\subsection{A Institucionalização de Processos}

As intervenções sobre os DSS, com o objetivo de promover a eqüidade em saúde, devem contemplar os diversos níveis assinalados no modelo de Dahlgreen e Whitead, ou seja, devem incidir sobre os determinantes proximais, vinculados aos comportamentos individuais, intermediários, relacionados às condições de vida e trabalho e distais, referentes à macroestrutura econômica, social e cultural. Para que as intervenções nos diversos níveis do modelo sejam viáveis, efetivas e sustentáveis, devem estar fundamentadas em três pilares básicos: a intersetorialidade; a participação social e as evidências científicas.

Com vistas a institucionalizar um processo sustentável de coordenação das ações intersetoriais sobre os DSS, que permita superar os problemas de baixa articulação anteriormente mencionados, a CNDSS recomenda estabelecer, no âmbito da Casa Civil da Presidência da República, uma instância de Ações Intersetoriais para Promoção da Saúde e Qualidade de Vida, que deverá se responsabilizar pelo seguimento e avaliação de projetos, programas, intervenções ou políticas relacionadas aos DSS, desenvolvidas pelas diversas instituições representadas.

Essa instância deve ser coordenada pela Casa Civil da Presidência da República. O Ministério da Saúde deverá funcionar como Secretaria Técnica/Executiva. Recomenda-se que, em um primeiro momento, seja dada prioridade às ações intersetoriais relacionadas à promoção da saúde na infância e adolescência, e ao fortalecimento das redes de municípios saudáveis. Ademais, propõe-se o fortalecimento de duas outras estratégias da promoção da saúde, 
experimentadas com sucesso em diferentes contextos: as escolas promotoras da saúde e os ambientes de trabalho saudáveis.

Para a produção regular de evidências científicas sobre os DSS, sugere-se a criação de um programa conjunto MCT/MS para apoio, através de editais periódicos, a projetos de pesquisa sobre DSS e para estabelecimento de redes de intercâmbio e colaboração entre pesquisadores e gestores, visando ao seguimento dos projetos e utilização de resultados. Sugere-se, também, estabelecer um sistema de monitoramento das iniqüidades em saúde e de avaliação do impacto de ações intersetoriais sobre a saúde.

Para a promoção da participação social, com vistas a conferir a necessária base de apoio político às ações sobre os DSS e para 'empoderar' os grupos populacionais vulneráveis, sugere-se fortalecer os mecanismos de gestão participativa, principalmente os Conselhos Municipais de Saúde.

\section{ANEXO}

As atividades desenvolvidas pela CNDSS estiveram organizadas em cinco linhas de ação. No âmbito de cada uma dessas linhas, foram desenvolvidas diversas atividades que contaram com a participação de especialistas, profissionais e participantes de instituições colaboradoras, além de membros da Comissão.

A primeira linha de ação se refere à Produção e Disseminação de Conhecimentos e Informações, tendo por objetivo produzir conhecimentos e informações sobre as relações entre os determinantes sociais e a situação de saúde, particularmente as iniqüidades em saúde, com vistas a fundamentar políticas e programas.

A segunda linha de ação se refere a Politicas e Programas e teve por objetivo promover, coordenar e avaliar políticas, programas e intervenções governamentais e não governamentais sobre os DSS, realizadas em nível local, regional e nacional.

A terceira linha de ação se refere à Mobilização da Sociedade Civil e teve por objetivo chamar a atenção de diversos setores da sociedade sobre a importância dos DSS e sobre as possibilidades de atuação sobre eles.

A quarta linha de ação corresponde à Construção e Manutenção de Portal sobre DSS (www. determinantes.fiocruz.br), com o objetivo de coletar e registrar informações e conhecimentos sobre DSS, disponíveis nos sistemas de informação e na literatura científica nacional e internacional, constituindo-se em um espaço de referência para os interessados no tema.

A quinta linha de ação se refere à Cooperação Internacional, que inclui cooperação com a Comissão sobre Determinantes Sociais da Saúde da OMS (CSDH) e com os países da América Latina, para promoção do enfoque de DSS em suas políticas de saúde e/ou criação de suas respectivas comissões nacionais. 


\section{EXECUTIVE SUMMARY}

\section{INTRODUCTION}

In March 2005, the World Health Organization (WHO) created the Commission on Social Determinants of Health $(\mathrm{CSDH})$ to internationally promote awareness of the importance of social determinants on the health conditions of individuals and populations and of the need to fight inequalities generated by these determinants. One year later, on March 13th 2006, by means of a presidential decree, the National Commission on Social Determinants of Health (CNDSS) was created with a two-year mandate.

The CNDSS is composed of 16 social, cultural, scientific and business leaders in the country. The diversity in the constitution of the CNDSS expresses the acknowledgment that health is a public good that should be constructed with the participation of all sectors of Brazilian society.

The goals of the CNDSS are summarized as the following:

- To produce information and knowledge on social determinants of health in Brazil;

- To contribute to the formulation of policies that promote health equity;

- To mobilize different sectors of government and civil society concerning the issue.

In order to meet its goals, the CNDSS has three basic commitments:

Commitment to Equity: Despite the latest advancements in its average health indicators, Brazil is one of the worst countries concerning health inequities, which are systematic and relevant, as well as avoidable, unfair and unnecessary health inequalities between population groups. These health inequities are the product of the large inequalities that exist between the various social and economic strata of the Brazilian population. In a country with one of the worst income distributions. CNDSS's commitment to equity - to assure the universal right to health - is not simply a rational decision, but fundamentally an ethical commitment and a political stance.

Commitment to evidence: The CNDSS seeks to base their analyses and recommendations on solid scientific evidence, given that they aid in understanding, on the one hand, how social determinants operate in producing health inequalities and, on the other hand, how and where interventions should be implemented to fight them, and which results might be expected in terms of effectiveness and efficiency.

Commitment to action: Fighting health inequalities by addressing social determinants that produced them is not only the Commission's greatest commitment, but also its raison d'etre. Social determinants are a product of human action and, therefore, can and should be changed by human action. The commitment to action is based, firstly, on collecting scientific evidence, and secondly, on creating a broad political base, which is the result of the awareness and mobilization of several sectors in society. 
The various existing studies concerning the SDHs and health inequities allowed the formulation of models to understand the web of relations between the various levels of social determinants and the health situation. Among these models, CNDSS adopted Dahlgren and Whitehead's, which guided the organization of activities and contents in the present report. The model was chosen because it is simple, easilily understood by different types of public, and features clear graphic visualization of the many Social Determinants of Health. The model separates SDHs in layers, beginning with individual determinants and reaching a more distant layer of macro-determinants.

\section{Analysis of the Health Situation}

\subsection{The Current Situation and Trends in Demographics, Social and Economic Development}

Brazil has been undergoing major economic, social and demographic transformations especially over the last four decades -, which significantly influences the lives and working conditions of the population and, consequently, their health conditions.

The 1960 census showed that $55 \%$ of the economically active population - that is, the majority - was dedicated to agriculture, while the remaining $45 \%$ worked in the secondary (industry) and tertiary (services) sectors. By the end of the following decade, the situation had been inverted: $54 \%$ of the population was employed in industry or in services. According to the latest Brazilian census (carried out in 2000), only 19\% of the population was employed in agriculture, which is a drop from $55 \%$ to $19 \%$ in four decades. During the same period, the percentage of the population employed by the service sector went from $27 \%$ to $60 \%$, and industry, which accounted for $17 \%$ in 1960 , rose to $29 \%$ in 1980 , then declined to $21 \%$ in 2000 .

It is clear that this accelerated redistribution of the economically active population from the agricultural sector to industry and services resulted in an extraordinarily rapid process of urbanization. In 1960, most of the population, that is $55 \%$, dwelled in rural areas. This proportion became inverted in the following decade, when $56 \%$ of the population resided in urban areas, a proportion which continues to grow exponentially and had reached $81 \%$ by 2000 .

Both the processes of industrialization and accelerated urbanization were responsible for important changes in fertility rate patterns. According to the Census, the average geometric growth rate of the population went from $2.89 \%$ in $1960 / 1970$ to $1.64 \%$ between in the 1991 and 2000 censuses. In 1960 every fertile woman had, on average, 6.3 children. This went down to 2.3 in 2000, and, according to the projections of the Brazilian Institute for Geography and Statistics (IBGE), in 2006, it should have reached 2.0\%. Even though this accelerated decline in the birthrate has been occurring in all regions of the country, there are important differences in relation to women's educational levels. According to the National 
Household Sample Survey (PNAD) of 2006, the total fertility rate for 2005 was of 2.1 children per fertile woman. However, women with up to 3 years of school bore 4 children and women with up to 8 years of school or more had had 1.5 children. Despite the current drops in fertility rates, the Brazilian population should still have an expressive growth in the next few decades due to past fecundity. There will also be another important change in the country's age structure as the population grows older due to the decrease in fertility rates and the increase in life expectancy.

The four decades between 1960 and 2000 were also marked by important economic transformations. According to IPEADATA (the database of the Institute for Applied Economic Research), the per capita GDP went from US\$2,060 in 1960 to US\$ 5,250 in 2000 and US\$ 5,750 in 2006 (in constant values with 2006 as reference). Agricultural activity was responsible for $25 \%$ of the GDP in 1960, but fell to $8.9 \%$ in 2004 , having grown $209 \%$ in the period. Industrial activity accounted for 18\% of the GDP in 1960 and 42\% in 2004, for growth of $1,727 \%$ in the period.

However, this extraordinary growth in wealth and the modernization of the economy did not translate into an improvement in wealth distribution. Despite recent improvements, income distribution in Brazil is still one of the worst in the world. Based on the 2003 Gini Coefficient (0.57), the United Nations Development Program 2007 report placed Brazil in 11th place based on the income concentration rate (in 2006, the Gini Coefficient dropped to 0.54).

As for social development, great changes have taken place in the last few decades, especially in the field of education. In 1940,56\% of the Brazilian Population was illiterate, a percentage which declined to $40 \%$ in 1960 and $13.6 \%$ in the year 2000 . According to the PNAD $12.3 \%$ of the population five years of age or older was illiterate in 2006 . This illiteracy rate, however, has significant regional differences, as it is around $7.6 \%$ in the South and $22.1 \%$ in the Northeast. Important disparities also exist in relation to family income. The average illiteracy rate for individuals 15 years of age or older was $10.4 \%$. For people with a per capita monthly family income of less than half of a minimum wage salary it was $17.9 \%$, while it was only $1.3 \%$ for those with over two minimum wage salaries.

According to the PNAD carried out in 2006, there had been extraordinary progress in elementary and middle school rates, which attained almost universal coverage for ages between 7 and 14 in almost all regions, urban and rural. In regard to high school education, the net attendance rate between the ages of 15 and 17 is still quite low for Brazil as a whole (around 47\%), with large regional and urban/rural dweller disparities, whereas for the elementary and middle school the index is 95\%, without large disparities.

The important advancements and contradictions in the social and economic development of the country in the last few decades have also been observed in health. According to the IBGE, the child mortality rate, which in 2006 was of 124 deaths in the first year of life per thousand children born alive, dropped to 48.3 in 1990, 35.26 in 2000 and 25.1 in 2006. Life expectancy in the country also rose by over 20 years (from 51.6 years to 72.4 years) between 1960 and 2006. Although significant regional differences continue to exist, such as 
between the Northeast and the South where there was a 2-year difference in life expectancy in 1990, there is a trend for these differences to decrease. In 1960, the life expectancy of a Northeastern Brazilian was 20 years less than a Southern Brazilian, but by 2006, this difference had decreased to 5 years.

The positive trends observed in the last few decades related to income, schooling and health have been translated into an improvement in the Human Development Index of the UNDP 0.649 in 1975 and 0.800 in 2005.

\subsection{Social and Economic Stratification and Health}

The social, economic, cultural and environmental conditions of any given society - that is, the distal determinants in Dahlgren and Whitehead's model - stratify population groups socially and economically, producing health differences. In other words, the distribution of health and disease in a society is not random and is associated with the social position of the individual, which, in turn, defines the life and working conditions of people and social groups.

This section presents a few associations between social and economic stratification (according to income, schooling, gender and dwelling place) and health outcomes, pointing out health inequities related to the social position of individuals and population groups.

Preventive breast and cervical câncer examinations, as well as prenatal exams, are a good example of the inequalities in the access to and use of health services due to the level of schooling, with a clear gradient. The percentage of women 25 years of age or over that have already had a mammogram ranges from $24.5 \%$ in women without any or up to one year of schooling to $68.1 \%$ in those with at least 15 years of study. The proportion of women aged 25 or over that have had cervical cancer screening exams ranges from $55.8 \%$ in those with one year of education or less to $93.1 \%$ for those with at least 15 years of study. Among women with at least 12 years of schooling, $20 \%$ give birth after having had seven or more doctors visits, whereas this percentage drops to $1.2 \%$ among women with no instruction. Inversely, $14.4 \%$ of children born to women with zero years of schooling.are born without the benefit of any sort of prenatal exam - a percentage that goes down to $2.7 \%$ among women with at least 12 years of education.

\subsection{Living Conditions, Labor and Health}

In this section, a few fundamental aspects of life and working conditions, especially concerning their relation to health, are presented. Food and nutrition, basic sanitation and housing, employment and working conditions, environmental and health conditions, and the access to health services and information are pointed out.

Food and Nutrition

Over the last few decades, Brazil has been going through a nutritional transition, which consists of the replacement of a nutritional standard based on the consumption of cereal grains, beans, roots and tubers for one richer in fats and sugars. As it occurs with the 
demographic and epidemiological transition processes, this nutritional transition is also marked by overlapping patterns, by an undefined time frame, and especially by inequalities related to social and economic stratification.

This change in nutritional standards has led to an increased risk of becoming overweight or obese, factors which significantly contribute to the onset of chronic diseases and disabilities. The 2003 Family Budget Survey showed that the number of overweight adult Brazilians had practically doubled since 1974, when the National Study on Family Expenses was carried out. In 2003, four in every 10 Brazilian adults were overweight, a rate 8 times larger than that of underweight women and 15 times larger than that of underweight men. Considering Brazilians 20 years of age or over, the IBGE estimates that 3.8 million people $(4.0 \%)$ suffer from weight deficit and 38.8 million (40,6\%) from excess weight, 10.5 million of which are considered obese.

\section{Basic sanitation and housing}

The National Household Sample Survey (PNAD) registered an improvement in water and sewage coverage rates from 1999 to 2004. According to the 2004 PNAD, the percentage of private dwellings covered by the water system rose from $80 \%$ to $83 \%$ and the percentage of homes with adequate sanitation (either connected to the sewage collection system or having septic system) rose from $65 \%$ to $70 \%$ in the period mentioned. There are, however, inequalities between regions and municipalities. In 2005, while the South and Southeast regions, respectively $83 \%$ and $91 \%$ of the population was covered by the water system, the coverage in the North and Northeast reached only $54.8 \%$ and $72 \%$ respectively. When comparing metropolitan areas of state capitals, the differences are also significant. For instance, the percentage of the population covered by the sewage system in 2005 varied from $44.46 \%$ in Recife and $66.33 \%$ in Fortaleza to $92.21 \%$ in Curitiba and $91.97 \%$ in Porto Alegre.

\section{Working and employment conditions}

The health problems faced by workers are intimately related to a country or region's level of development. When comparing regional differences in social and economic development, worker health and work-related injuries and diseases show a mixed pattern, which typifies the so-called "double disease burden". This term refers to the presence of some diseases that have already been controlled in developed countries, such as silicosis and other lung diseases, lead poisoning and asbestosis, as well as "new" work-related diseases, such as musculoskeletal diseases, dermatological diseases caused by chemical compounds, and stress-related mental symptoms and disorders. The combination of traditional and new forms of labor leads to high levels of exposure to chemical and physical problems, repetitive tasks, excessive straining, inadequate posture, exposure to stress and psycho-social factors, causing both temporary and long-term suffering and disabilities.

Official data on formal labor show that, in 2005, 2,700 workers died and 491,000 were out of work receiving insurance benefits. Between the years 2000 and 2002, the National Social Security Institute registered 58,978 cases of work-related diseases, which covers only $23 \%$ 
of workers - that is, those who had been hired formally and are, therefore, eligible to receive benefits. Consequently, a great number of cases remain unreported.

\section{Environment and Health}

The impact of air pollution in Brazil has been well documented in scientific literature. Studies have shown that increases in the levels of air pollutants are associated with increased mortality ad morbidity rates related to respiratory and cardiovascular problems, especially in children and the elderly. Other consequences include economic loss, school absenteeism, lost days of work and asthma.

In the 1990's, the first estimates of the effects of air pollution showed that the total mortality of elderly individuals is directly associated with variations in the concentration of inhalable particles (PM10) in the air, since a difference of $10 \mu \mathrm{g} / \mathrm{m} 3$ increases deaths of elderly individuals by $1.3 \%$. The majority of these deaths are related to respiratory and cardiovascular diseases. The effects of these pollutants can be modulated by the social and economic conditions of those exposed. Individuals display different responses to similar stimuli due to their differences in terms of life conditions. This is fundamental for the formulation of public policies designed to reduce the emission of these pollutants.

Access to Health Services

Despite the undeniable progress in health services and the principles of universality and equity that govern the Brazilian Unified Health System (SUS), important inequalities in the offer of resources and services - as well as the strong influence an individual's social position has on her access, use and quality of services - are still being observed.

Data from the 2003 PNAD, showed that individuals with higher incomes have $59.5 \%$ more chances of using health services than those with lower incomes. The same relation is observed concerning education: individuals with nine or more years of school have a $20.9 \%$ greater chance of using health services than those with less education. When compared to the 1998 PNAD, despite the persistence of marked social inequalities in the use of health services, a continuous reduction in inequalities, in regard to both children and adults, can be observed.

\section{Access to Information}

One of the social determinants of health whose importance is not always adequately recognized is access to information. Accessing health information has been greatly facilitated by new information and communication technology, such as the Internet, which may have important consequences for health , especially in respect to health inequalities. Their potential, however, will be threatened if inequalities in the access to these technologies -the so-called "digital divide" - are not solved. According to a IBOPE/Netratings study, in the third trimester of 2007 , despite a $21 \%$ increase over the previous year, only thirty-nine million Brazilians use the Internet. Through this medium this minority has better access to goods and services as well as opportunities to progress socially. The 2006 PNAD shows enormous inequalities in 
access to the Internet, depending on educational level, income and dwelling place. In some cases, the differences between groups are extreme: 60 to 70 times.

\subsection{Social and Community Networks and Health}

Social and community networks are part of the so-called "social capital", that is, the set of relationships of solidarity and trust between individuals and groups. The deterioration of this social capital is an important mechanism through which social and economic inequities negatively affect the health situation. Countries with fragile social bonds caused by these inequalities invest the least in human capital and in social support networks and have the lowest indexes of social participation in the definition of public policies.

There are a small number of studies in Brazil relating social and community networks to disease burdens, which could be partially explained by the lack of expertise in adequate methodologies to approach these subject-matters. Studies conducted with the elderly show that remaining independent in daily activities and maintaining satisfaction with family and friends were prognostic factors independent of the process of aging well, for both men and women. Studies on the association between mental disorders and social support showed that people with less social support have a greater prevalence of mental disorders than people with higher social support. The connection between mental disorders and social support was observed even after the data were controlled by age, schooling and participation in the job market.

\subsection{Behavior, Life-Styles and Health}

This section is based on a review of a recent scientific literature on diet, physical exercise, tobacco consumption and alcohol abuse among various social groups.

\section{Diet}

The consumption of fruits and vegetables is low in Brazil as a whole, but the greater the individual's income and education, the higher their consumption. There is a direct effect of income on this consumption pattern: for each $1 \%$ increase in the individual's income, there was a $0.04 \%$ increase in the consumption of fruits and vegetables. On the other hand, a $1 \%$ drop in income caused a $0.2 \%$ decrease in the participation of these foods in the diet.

\section{Tobacco}

Comparing the two available national surveys, the National Health Survey, of 1989, and the World Health Survey, of 2003, there was an important reduction in tobacco consumption in all age groups, sexes, and in both urban and rural areas. However, inequalities in intensity of reduction were observed concerning education level and purchasing power. As to purchasing power, the pattern was similar for both men and women, that is, the lower the income, the lower the intensity of reduction. As for education, the differences were more apparent in the case of women: the lower the level of education, the lower the reduction. Women with up to four years of study showed prevalence levels twice as large for tobacco consumption 
than those with nine to ten years of education. In reality, despite the drop in all categories, inequalities were heightened in 2003.

\section{Alcohol}

According a study carried out by the National Câncer Institute (INCA, 2006), the prevalence of alcohol consumption in the 15 Brazilian state capitals and the Federal District varied from $32.4 \%$ to $58.6 \%$. The prevalence varied from $48.9 \%$ to $72.1 \%$ in men and from $19.7 \%$ to $47.5 \%$ in women. It should be pointed out that the highest female rate was lower than the lowest male rate.

In developed countries, especially in Europe, gender differences in alcohol consumption are not as evident, only around 10 to $20 \%$. In developing countries, these differences are larger, and, in Latin America, depending on the country, these differences vary from $20 \%$ to $100 \%$. This variation could be explained by the kind of drink mostly consumed. The lowest gender variation (40\%) was observed in Porto Alegre, in the South $\mathrm{x}$, where there is a concentration in the production of wine.

Gender differences tend to be even greater concerning "risk consumption". In this study, however, the rates for this indicator varied from $4.6 \%$ to $11.1 \%$. In the South, despite the fact that consumption rates were high in comparison with other regions, risk consumption rates were among the lowest, which is probably related to regional differences regarding the most consumed drink.

\subsection{Mother and Child Health}

This section is divided into two parts. The first is based on the determinants of child mortality throughout Brazil, especially family income and the mother's educational level. The second is based on a review of recent scientific literature on various aspects of mother and child health in Brazil.

\section{A Few Conditioning Factors in Childhood Mortality in Brazil and its Regions}

Child mortality, that is, the mortality of children under five years of age, is employed as an indicator of the health and life conditions of a population. Recently (from1990 to 2005), infant mortality in Brazil went from 53.7 deaths of under-fives per thousand live born to 28.8 , which is a decrease of $46.4 \%$.

Despite the progress in the indicators, deep regional contrasts continue to exist. Throughout the period, child mortality in the Northeast dropped 55\%, that is, 10 percent above the national average. It should be mentioned, however, that the rate in that region, in 2005 , (38.9\%) was still twice as high as the rate in the Southeast and South. This shows that progress has been made since, in 1990, the ratio between those regions was 2:5.

There is an inverse relationship between the mother's education and child mortality, that is, the more years of schooling the mother has, the lower the mortality rate for children under five years of age. Thus, for Brazil as a whole, in 1990, the child mortality rate for mothers 
with less than four years of school was of $89.7 \%$. For mothers with more than eight years of school, this number goes down to $30.3 \%$ - a $196.6 \%$ difference.

The inequality between child survival levels is also affected when income, another important socio-economic variable, is considered. When desegregated by per capita income fifths, child mortality is always higher for the most underprivileged. Generally, there is little difference between the first three per capita income fifths, but this disparity is increased in the last two fifths, independent of which special unit is being analyzed.

\section{Review of the Literature on Mother and Child Health}

A review of scientific literature on the disparities in the health of mothers of under-fives from different social and economic groups between 1990 and 2007 was carried out.

The results cast no doubt on the existence of marked social inequalities in terms of child health and nutrition throughout the country, which is evidenced in the mortality, morbidity, nutrition and service use indexes. In all studied indicators, the poor always showed a less favorable situation in terms of prenatal care, birth weight (both by a restriction in intrauterine growth and preterm delivery), exclusive breastfeeding, immunizations, preventive medical care, morbidity, malnutrition, micronutrient deficiencies, cognitive development and, consequently, mortality.

The few indicators that are worse among richer mothers and children include higher caesarian birth rates, overweight/obesity rates and the use of oral re-hydration therapy for diarrhea. Recent surveys on breastfeeding show that the practice, which was more common among poor families, is now more frequent among those of a higher social and economic level, at least during the baby's first six months of life.

\subsection{Indigenous health}

The most recent Demographic Census (2000) shows that the educational level of the indigenous people remains very low and that there are important differences between fertility rates of urban (2.7) and in rural (5.7) indigenous women.. Census data also show an infant mortality rate in 2000 of 51.4 per thousand, significantly higher than the national rate (30.1 for thousand) and the rate for "black" and "brown" infants (34.9 and 33.0 for thousand, respectively).

Acute respiratory infections and diarrheas are the main causes of disease and death in children of less than five years. More than $25 \%$ of them are malnourished. Precarious sanitation and housing conditions, as well as low coverage and quality of health services combine to further undermine the nutritional level of indigenous children.

\section{RECOMMENDATIONS}

This section includes a series of recommendations for SDH-related interventions intended to address the problems listed in the report, especially those concerning health inequity. 


\subsection{Ongoing policies and programs}

SDH-related actions comprised in social policies carried out by several federal government institutions, as executed in the 2004-2006 budget, have been listed.

The resources involved and the amount of actions carried out indicate that the universe studied here is a prominent theme in the federal government's political agenda. The increases recorded show that, as a whole, investments in the sector did not decline.

As to the articulation of policies, programs and actions, data suggests that there is little communication between theme areas, little participation of the Ministry of Health in the actions studied, high fragmentation of actions, redundancy, competitiveness between federal agencies and little coordination among them.

Despite the descriptive character of this review, a few implications in terms of public policies might be inferred: to broaden the scope of investments in the actions studied; to rationalize investments, focusing on the actions showing the highest levels of consistency over time; to articulate these actions; and to integrate the various federal agencies involved in carrying out these programs and actions (including the Ministry of Health) in a common agenda based on SDH needs.

\subsection{Institutionalizing processes}

SDH interventions to promote health equality should encompass the various levels referred to by Dahlgreen and Whitehead, that is, they should address proximal (individual behavior), intermediary (life and work conditions) and distal (social, economic and cultural macrostructure) determinants. In order for interventions in the various levels of Dahlgren and Whitehead's model to be feasible, effective and sustainable, they must be based on three basic principles: intersectoriality; social participation and scientific evidence.

In order for the coordination of SDH actions to be sustainably institutionalized (which would allow the aforementioned problems with the low levels of articulation to be overcome), the CNDSS recommends the establishment of a instance of Intersectorial Actions for Health Promotion and the Quality of Life within the Civil Cabinet. This instance should be responsible for managing and evaluating SDH-related projects, programs, interventions or policies developed by represented institutions.

The instance should be coordinated by the Civil Cabinet of the Presidency of the Republic, and the Ministry of Health should work as a Technical/Executive Secretariat.

It would be advisable, at least at first, to prioritize intersectorial actions related to health promotion of children and adolescents and strengthen the already existing network of healthy municipalities. Moreover, the buttressing of two other strategies for promoting health, which have been tried in different contexts, is also advised: health-promoting schools and a healthy working environment.

In order to produce scientific evidence on the SDHs on a regular basis, the creation of a joint MCT/MS program is suggested. This program should provide support to SDH- related 
research projects and to the establishment of networks for researchers and administrators to interchange and collaborate in order for projects to be continued and for the results to be applied. The creation of a monitoring system of health inequities and of evaluation of the impact of intersectorial action on health is also recommended.

Participative management mechanisms, especially the Municipal Health Councils, should be strenghtened to promote social participation in SDH actions. This participation is pivotal to give the necessary political support to SDH interventions and to empower vulnerable population groups.

\section{ANNEX}

CNDSS activities have been organized in five lines of action. In each of these lines of action, several activities were carried out through the participation of specialists, professionals and other members of the collaborator institutions, in addition to the members of the Commission.

The first line of action refers to the Generation and Dissemination of Knowledge and Information. This entails producing knowledge and data about the relationship between social determinants and health conditions, especially concerning health inequalities, to serve as a basis for policies and programs.

The second line of action refers to Policies and Programs. Its goal is to promote and evaluate governmental and non-governmental policies, programs and interventions concerning SDHs carried out on the local, regional or national level.

The third line of action refers to the Mobilization of the Civil Society and its objective is to call the attention of various sectors in the society to the importance of the SDHs and the possibilities of addressing them.

The fourth line of action concerns the Development and of a Website on SDHs (www. determinantes.fiocruz.br). The goal is to collect and register information and knowledge on SDHs that are already available in information systems and in the national and international scientific literatures. The final objective is for the website to become a reference for those interested in the issue.

The fifth line of action refers to International Cooperation, which includes cooperation with the Commission on Determinants of Health of the WHO and with Latin American countries to promote a greater focus on the SDHs in their health policies and/or the creation of the countries' specific national commissions.

The fifth line of action refers to International Cooperation, which includes cooperation with the Commission on Determinants of Health of the WHO and with Latin American countries to promote a greater focus on the SDHs in their health policies and/or the creation of the countries' specific national commissions. 
Formato: $21 \times 26 \mathrm{~cm}$

Tipologia: Caxton Lt Bt e Calibri

Papel: Cartão Supremo $250 \mathrm{~g} / \mathrm{m}^{2}$ (capa)

e Print Max $90 \mathrm{~g} / \mathrm{m}^{2}$ (miolo)

CTP, impressão e acabamento: Imprinta Express Gráfica e Editora Ltda.

Rio de Janeiro, setembro de 2008

Não encontrando nossos títulos em livrarias contactar a EDITORA FIOCRUZ:

Av. Brasil, $4036-1^{\circ}$ andar - sala 112 - Manguinhos

21040-361 - Rio de Janeiro - RJ

Tels: (21) 3882-9039 e 3882-9041

Fax: (21) 3882-9007

http://www.fiocruz.br

e-mail: editora@fiocruz.br 